Faculdade de Filosofia, Ciências e Letras de Ribeirão Preto

Departamento de Química

Programa de Pós-Graduação em Química

Edilene Delphino Rodrigues

\title{
'Estratégias de aumento de eficiência da análise de Produtos Naturais por Espectroscopia de Ressonância Magnética Nuclear’
}

\author{
RIBEIRÃO PRETO - SP
}




\section{Edilene Delphino Rodrigues}

\section{"Estratégias de aumento de eficiência da análise de Produtos Naturais por Espectroscopia de Ressonância Magnética Nuclear"}

Tese apresentada à Faculdade de Filosofia, Ciências e Letras de Ribeirão Preto da Universidade de São Paulo, como parte das exigências para a obtenção do título de Doutor em Ciências.

Área: Química

Orientador: Prof. Dr. Gil Valdo José Da Silva

RIBEIRÃO PRETO - SP

2010 


\section{FICHA CATALOGRÁFICA}

Rodrigues, Edilene Delphino

Estratégias de aumento de eficiência da análise de Produtos

Naturais por Espectroscopia de Ressonância Magnética Nuclear.

Ribeirão Preto, 2010.

215p.: il.; $30 \mathrm{~cm}$

Tese de Doutorado, apresentada à Faculdade de Filosofia, Ciências e Letras de Ribeirão Preto/USP. Área de concentração: Química.

Orientador: Silva, Gil Valdo José da

1 RMN. 2. DOSY. 3. SVD. 4. Acoplamento heteronuclear 5. Duguetia furfuracea. 6. Bidens sulphurea. 7.Bidens gardneri. 8. Poliacetilenos. 9. Alcalóides 10. Flavonóides. 
RODRIGUES, EDILENE DELPHINO. Estratégias de aumento de eficiência da análise de Produtos Naturais por Espectroscopia de Ressonância Magnética Nuclear. Tese apresentada à Faculdade de Filosofia, Ciências e Letras de Ribeirão Preto da Universidade de São Paulo, como parte das exigências para a obtenção do título de Doutor em Ciências, Área: Química.

Aprovada em:

BANCA EXAMINADORA

Prof. Dr

Julgamento:

Prof. Dr.

Julgamento:

Prof. Dr.

Julgamento:

Prof. Dr.

Julgamento:

Prof. Dr.

Julgamento:
Instituição:

Assinatura:

Instituição:

Assinatura:

Instituição:

Assinatura:

Instituição:

Assinatura:

Instituição:

Assinatura: 
"Posso ter defeitos, viver ansioso e ficar irritado algumas vezes, mas não esqueço de que minha vida é a maior empresa do mundo, e posso evitar que ela vá à falência. / Ser feliz é reconhecer que vale a pena viver apesar de todos os desafios, incompreensões e períodos de crise.

Ser feliz é deixar de ser vítima dos problemas e se tornar um autor da própria história. É atravessar desertos fora de si, mas ser capaz de encontrar um oásis no recôndito da sua alma. / É agradecer a Deus a cada manhã pelo milagre da vida.

Ser feliz é não ter medo dos próprios sentimentos. / É saber falar de si mesmo. / É ter coragem para ouvir um "não". / É ter segurança para receber uma crítica, mesmo que injusta. / Pedras no caminho? / Guardo todas, um dia vou construir um castelo..."

\section{Fernando Pessoa}

"Há duas formas para viver a sua vida: / Uma é acreditar que não existe milagre. / A outra é acreditar que todas as coisas são um milagre."

\section{Fernando Pessoa}

"Para ser grande, sê inteiro. / Nada teu exagera ou exclui. / Põe quanto és no mínimo que fazes Assim, a lua inteira brilha, porque alta vive."

\section{Fernando Pessoa}

"O estudo em geral, a busca da verdade e da beleza são domínios em que nos é consentido ficar crianças toda a vida."

Albert Einstein 
Dedico este trabalho a:

Meu esposo, Marcos, colaborador incansável e incondicional, força propulsora de minha caminhada acadêmica: algumas de suas loucuras me fazem crescer!

Minhas filhas por se constituírem diferentemente enquanto pessoas:

Júlia, conselheira que me impede de cometer gafes. ("Há duas espécies de chatos: os chatos propriamente ditos e os amigos, que são os nossos chatos prediletos.” - Mário Quintana),

Lúcia, mediadora, que me acalma os impulsos, sua sensatez faz com que, por muitas vezes, nossos papéis se invertam!

Ana, belo sorriso que me ilumina e me motiva a prosseguir. ("Ser feliz sem motivo é a mais autêntica forma de felicidade." Carlos Drummond de Andrade).

Vocês são igualmente belas e admiráveis em essência, estímulos que me impulsionaram a buscar vida nova a cada dia, meus agradecimentos por terem aceitado se privar de minha companhia pelos estudos, concedendo a mim a oportunidade de me realizar ainda mais. Amo muito vocês!

Meus pais: Oswaldo e Antonia (in memorian), e minha sogra Ana Maria pelo carinho, dedicação, aceitação, apoio e estímulo de sempre! 


\section{AGRADECIMENTOS}

Agradeço especialmente a $\boldsymbol{D E} \boldsymbol{U} \boldsymbol{S}$ pela dádiva da vida e por, em muitos momentos aflitivos, proporcionar-me a sua paz e a serenidade para enfrentar os obstáculos que me atravessavam e superar os desafios.

À minha FAMÍLIA pela cumplicidade, compreensão e estímulo.

Ao Prof. Dr. Gil Valdo José da Silva, pela amizade, enorme paciência, confiança, estímulos e preciosos ensinamentos durante a realização deste trabalho. Por me ensinar a vivenciar a frase de Mário Quintana: “A resposta certa, não importa nada: o essencial é que as perguntas estejam certas".

À minha amiga Denise Brentan da Silva, pela enorme, preciosa e fundamental colaboração, sem a qual não seria possível a realização deste sonho. Enfim, sua vinda para Ribeirão Preto foi essencial para a realização deste sonho, científica e afetivamente falando: Que a nossa parceria perdure!

À Profa. Dra. Dionéia $\boldsymbol{C}$. $R$. de Oliveira, pelas valiosas sugestões durante o exame de qualificação e por ter permitido a colaboração da Denise.

Aos amigos: meu chefe Prof. Dr. Walmir S. Garcez, Prof ${ }^{a}$. Fernanda. R. Garcez, Prof $^{a}$. Célia M. Silva e Prof ${ }^{a}$. Márcia H. R. da Matta e Prof. Adilson Beatriz pela amizade, estímulo e confiança a mim dispensados para que eu pudesse realizar este trabalho.

Aos professores e amigos: Profa. Dra. Carmen L. Cardoso e Prof. Dr. Luiz Alberto. B. de Moraes, pelos ensinamentos, amizade e momentos de desabafo e descontração na antessala do RMN, ou LSO e/ou corredores do DQ/FFCLRP/USP.

Aos amigos químicos: Mércia V. Carlos, Rodrigo F. Silva, Ademir G. C. Costalonga, Cristina Amaro, Ivy Calandreli e Renata F. Martins, pela amizade e ensinamentos, sobretudo à Mércia pela paciência em ouvir minhas lamúrias.

Aos amigos do LSO: Mirela I. Sairre, Daiane C. Sass, Viviane Nardini, Shirley M. Muniz, Rodrigo Rotta, Juliana Araújo, por me apresentarem o lado apaixonante da Síntese Orgânica e por às vezes me permitirem ser mãe e ao mesmo tempo irmã mais "nova": Sentirei Saudades! Aos demais amigos do LSO e apêndices, Murilo, Daniel, Thiago (“Chaves”), Pedro, Oswaldo Galo, André, Marcelo, Ana Carolina, Ana Paula, Mirian, Vinícius Vicente, 
Camila, Aline e Jader, por suportarem ouvir e se permitirem rir de minhas piadas sem graça. Sobretudo, à Camila, por suportar meu mal-humor.

Aos professores Dr. Paulo Marcos Donate e Dr. Mauricio Gomes Constantino, pelos ensinamentos, aconselhamentos e/ou críticas que promoveram meu crescimento científico e humano.

Ao amigo Jader Barbosa, apoio imensurável durante atos de "rebeldia" de meu computador: lidar com hardwares não é duro só no nome.

A Mônica Campitelli, Rodrigo Rotta, Ademir G. C. Costalonga e Prof. Luiz O. Murta Jr. pelas dicas de programação.

Às amigas Mirela I. Sairre, Daiane C. Sass e Aline S. Lázaro por me permitirem participar da "diretoria da descontração do LSO" com "happy hour" e "baladas" divertidíssimos: vocês com certeza me ajudaram a suportar os momentos de saudades!

Aos amigos de Campo Grande-MS (Maria Otávia, Aloizio, Luzinátia, Adilson, Ronaldo Amaral, Joana, Sr. Luiz, Marilene, Maria José, Lourdes e Cida) por serem meu 'refúgio emocional' durante estes quatro anos.

Aos casais 'Josimara e André', 'Silvana e Marcos', 'João e Ana (in memorian)', 'Merlin e Marcos', 'Luzinátia (Luzi) e Aloizio', 'Lucinéia e José Manoel', pelos sinais de eterna amizade. 'Merlin e Marcos': obrigada por me fazer sentir em casa no RJ! 'Luzi e Aloizio': meus assessores de assuntos campo-grandenses! 'João e Ana': provas de fé!

Ao amigo Químico Vinícius Palaretti, por ser tão bom profissional e boa pessoa, me devolvendo o prazer de entrar no Laboratório de RMN: Que pena que você não chegou antes!

Aos professores e funcionários do Departamento de Química da FFCLRP-USP pelo acolhimento, amizade e auxílio durante a execução e conclusão deste trabalho, sobretudo, Profa. Laura T. Okano, Prof. José R. Romero, Profa. Glaucia M. da Silva, Profa. Márcia A. M. S. da Veiga, Prof. Pietro Ciancaglini, Vera Lúcia (Verinha), André L. P. Barnabé, Edson Ricardo de Oliveira, Isabel A. de Oliveira, Ivana A. Borin, Lâmia M. A. e Silva, Losane R. da S. Mazzucato, Lourivaldo dos S. Pereira, Maria D. da Silva, Olímpia P. Martins, Sônia R. de Oliveira e Vinicius F. Banhos. 
A todos que direta e indiretamente contribuíram para amenizar a caminhada até aqui, e, por que não? Àqueles que, intencionalmente ou não, inseriram dificuldades, dando ao presente momento o sabor de vitória e ainda mais prazeroso: MUITO OBRIGADA!

Ao $\boldsymbol{C N P q}$, pela bolsa de estudos concedida, à $\boldsymbol{U F M S}$ pelo afastamento remunerado, à CAPES e à $\boldsymbol{F A P E S P}$, pelo apoio financeiro. 


\section{ÍNDICE}

$\begin{array}{lll}\text { RESUMO vii } & \text { vii }\end{array}$

$\begin{array}{lc}\text { ABSTRACT } & \text { viii }\end{array}$

ABREVIATURAS, SIGLAS E SÍMBOLOS ix

LISTA DE FIGURAS xii

LISTA DE TABELAS $\quad$ xiv

1 Introdução 1

I.1 Importância da Química de Produtos Naturais (QPN) 2

Elucidação de Produtos Naturais (PN) 6

1.3 Métodos espectroscópicos e espectrométricos aplicados à elucidação estrutural de Produtos $\begin{array}{ll}\text { Naturais (PN) } & 7\end{array}$

$1.4 \quad$ Espectroscopia de ressonância magnética nuclear (RMN) 11

1.4.1 Espectroscopia ordenada por difusão (RMN DOSY 1D e 2D) 14

1.4.1.1 Definição do Fenômeno da Difusão Molecular $\quad 14$

$\begin{array}{ll}\text { 1.4.1.2 Medidas de Difusão Molecular } & 15\end{array}$

1.4.1.2.1 Medidas de Difusão por RMN-DOSY (1D e 2D) 16

1.4.1.2.1.1 Eco de spin com pulsos de gradientes de campo magnético (PFG) 17

1.4.1.2.1.2 Eco de spin estimulados (PFGSTE) 20

$\begin{array}{lll}\text { 1.4.1.3 Vantagens da Técnica DOSY } & 20\end{array}$

1.4.1.4 Limitações da Técnica DOSY $\quad 21$

1.4.1.5 Processos Envolvidos em um Experimento de DOSY 21

1.4.1.6 Estratégias para o aumento da qualidade de um espectro de DOSY 23

1.4.1.7 Aplicações da técnica RMN DOSY-1D e 2D 27

1.4.2 Estratégias de aumento de sensibilidade de RMN de ${ }^{13} \mathrm{C}$ via processamento 28

$\begin{array}{lll}\text { 1.4.2.1 Evolução do Processamento dos dados de RMN } & 28\end{array}$

1.4.2.2 Processamento de dados de RMN (tratamento do sinal) 28

1.4.2.3 A importância do processamento dos dados no aumento de sensibilidade da espectroscopia de $\begin{array}{ll}\text { RMN } & 31\end{array}$

1.4.3 Estudo de constantes de acoplamento de longa distância heteronuclear JCH em sistemas poliinsaturados 36

1.4.3.1 Importância e métodos de determinação de constantes de acoplamento de spin-spin heteronuclear 36

2 Objetivos 43

3 Materiais e Métodos 45

$3.1 \quad$ Análises por RMN 46

3.1.1 Equipamentos utilizados para análise por RMN 46

3.1.1.1 Espectrômetro BRUKER® -Modelo DRX500 - Ultra Shield® 
3.1.1.2 Espectrômetro BRUKER® -Modelo DRX400 46

3.1.1.3 Espectrômetro BRUKER® -Modelo DPX300

3.2 Origem dos Materiais Vegetais $\quad 47$

3.3 A RMN DOSY-2D na análise de frações do extrato etanólico de Bidens sulphurea 48

3.3.1 Obtenção e identificação dos componentes da fração acetato de etila do extrato etanólico de Bidens sulphurea

3.3.2 Obtenção de espectros DOSY (1D e 2D)

3.3.3 Processos cromatográficos e espectroscópicos usados para a verificação qualitativa da confiabilidade da análise por DOSY (1D e 2D)

3.3.3.1 Análise Cromatográfica de BSAcOEt

3.3.3.2 Análise espectroscópica dos componentes majoritários de BSAcOEt 49

3.4 O tratamento de sinal de RMN por SVD 50

3.4.1 Condições dos espectros de RMN de ${ }^{13} \mathrm{C}\left\{{ }^{1} \mathrm{H}\right\}$ para aplicação do método de seccionamento. 50

3.4.2 Programas computacionais utilizados para a filtragem do sinal de $\mathrm{RMN}$ de ${ }^{13} \mathrm{C}\left\{{ }^{1} \mathrm{H}\right\}$ por SVD. 50

3.4.3 Obtenção das amostras analisadas por RMN de ${ }^{13} \mathrm{C}\left\{{ }^{1} \mathrm{H}\right\}$ tratado por SVD 50

3.4.3.1 Obtenção da Fração DF, a partir do extrato alcaloídico das cascas do caule subterrâneo de Duguetia furfuracea

3.4.3.2 Obtenção das substâncias 7 - 9 a partir da fração acetato de etila do extrato hidroalcoólico das partes aéreas de B. gardneri

3.5 Constantes de acoplamento heteronuclear a longa distância, ${ }^{\mathrm{n}} J_{\mathrm{CH}}$

$4 \quad$ RESULTADOS E DISCUSSÃO

4.1 Análise da fração Acetato de etila do extrato etanólico das partes aéreas de B. sulphurea por RMN: DOSY-2D

4.1.1 Obtenção e análise do espectro DOSY-2D da fração BSAcOEt 56

4.1.2 Verificação qualitativa da confiabilidade da aplicação da técnica DOSY-2D na identificação dos componentes majoritários da fração BSAcOEt

4.2 Melhoramento de espectros de RMN de ${ }^{13} \mathrm{C}\left\{{ }^{1} \mathrm{H}\right\}$ por SVD

4.2.1 Tratamento integral do espectro e RMN de ${ }^{13} \mathrm{C}\left\{{ }^{1} \mathrm{H}\right\}$ da Fração DF com o método de seccionamento e SVD.

4.2.2 Tratamento integral do espectro e $\mathrm{RMN}$ de ${ }^{13} \mathrm{C}\left\{{ }^{1} \mathrm{H}\right\}$ do composto 7 com o método de seccionamento e filtragem de sinal.

4.2.3 Tratamento parcial do espectro e $\mathrm{RMN}$ de ${ }^{13} \mathrm{C}\left\{{ }^{1} \mathrm{H}\right\}$ do composto 8 com o método de seccionamento e filtragem de sinal.

4.2.4 Tratamento do espectro e RMN de $13 \mathrm{C}\left\{{ }^{1} \mathrm{H}\right\}$ do composto 9.

4.3 Elucidação estrutural de poliacetilenos baseadas nas constantes de acoplamento de longa distância heteronuclear $\mathrm{J}_{\mathrm{CH}}$

4.3.1 Identificação dos poliacetilenos 10 e 11, presentes na fração Acetato de etila de Bidens gardneri

4.3.1.1 Elucidação da estrutura do composto 10

4.3.1.2 Experimento G-BIRDR-X-CPMG-HSQMBC 80

4.3.1.3 Elucidação da estrutura do composto 11

5 Conclusões $\quad 85$

$6 \quad$ Referências Bibliográficas $\quad 88$ 
7.1 Compostos 1-4 : aplicação de DOSY-2D

7.1.1 Dados de EM-ESI:

$\begin{array}{llr}\text { 7.1.1.1 } & \text { Espectro de EM-ESI do composto } 1 & 100\end{array}$

7.1.1.2 Espectro de EM-ESI do composto 2

7.1.1.3 Espectro de EM-ESI do composto $3 \quad 102$

7.1.1.4 Espectro de EM-ESI do composto 4

$\begin{array}{ll}\text { 7.1.2 Dados de UV: } & 104\end{array}$

$\begin{array}{lll}\text { 7.1.2.1 } & \text { Espectro de UV do composto } 1 & 104\end{array}$

$\begin{array}{llr}\text { 7.1.2.2 } & \text { Espectro de UV do composto } 2 & 104\end{array}$

$\begin{array}{lll}\text { 7.1.2.3 Espectro de UV do composto } 3 & 104\end{array}$

$\begin{array}{lll}\text { 7.1.2.4 } & \text { Espectro de UV do composto } 4 & 104\end{array}$

7.1.3 Dados de RMN do composto 1: 105

7.1.3.1 Espectro de RMN de ${ }^{1} \mathrm{H}(500 \mathrm{MHz})$ do composto 1 em DMSO-d ${ }_{6}$.

7.1.3.2 Ampliações do Espectro de RMN de ${ }^{1} \mathrm{H}(500 \mathrm{MHz})$ do composto 1 em DMSO-d ${ }_{6}$. 106

7.1.3.3 Ampliação do Espectro de RMN de ${ }^{1} \mathrm{H}(500 \mathrm{MHz})$ do composto 1 em DMSO-d 6107

7.1.3.4 Espectro de RMN de ${ }^{13} \mathrm{C}\left\{{ }^{1} \mathrm{H}\right\}(125 \mathrm{MHz})$ do composto 1 em DMSO-d 6 .

7.1.3.5 Espectro de RMN de ${ }^{13} \mathrm{C}$ (DEPT 135, $125 \mathrm{MHz}$ ) do composto 1 em DMSO-d 6

7.1.3.6 Mapa de contorno gerado a partir do experimento HMQC $\left({ }^{13} \mathrm{C}: 125 \mathrm{MHz},{ }^{1} \mathrm{H}: 500 \mathrm{MHz}\right) \mathrm{do}$ composto 1 em DMSO-d 6

7.1.3.7 Mapa de contorno gerado a partir do experimento COSY $90^{\circ}\left({ }^{1} \mathrm{H},{ }^{1} \mathrm{H}\right.$ : $\left.500 \mathrm{MHz}\right)$ do composto 1 em DMSO-d 6 .

7.1.3.8 Mapa de contorno gerado a partir do experimento $\mathrm{HMBC}\left({ }^{13} \mathrm{C}: 125 \mathrm{MHz},{ }^{1} \mathrm{H}: 500 \mathrm{MHz}\right)$, modulado para ${ }^{2} \mathrm{~J}_{\mathrm{CH}}=8 \mathrm{~Hz}$, do composto 1 em DMSO- $\mathrm{d}_{6}$.

7.1.3.9 Mapa de contorno gerado a partir do experimento $\mathrm{HMBC}\left({ }^{13} \mathrm{C}: 125 \mathrm{MHz},{ }^{1} \mathrm{H}: 500 \mathrm{MHz}\right)$, modulado para ${ }^{2} \mathrm{~J}_{\mathrm{CH}}=4 \mathrm{~Hz}$, do composto 1 em DMSO- $\mathrm{d}_{6}$.

$\begin{array}{lll}\text { 7.1.4 Dados de RMN do composto } 2 & 114\end{array}$

7.1.4.1 Espectro de RMN de ${ }^{1} \mathrm{H}(500 \mathrm{MHz})$ do composto 2 em DMSO-d . $_{6}$

7.1.4.2 Ampliações do Espectro de RMN de ${ }^{1} \mathrm{H}(500 \mathrm{MHz})$ do composto 2 em DMSO-d 6

7.1.4.3 Espectro de RMN de ${ }^{13} \mathrm{C}\left\{{ }^{1} \mathrm{H}\right\}(125 \mathrm{MHz})$ do composto 2 em DMSO-d 6 .

7.1.4.4 Espectro de RMN de ${ }^{13} \mathrm{C}$ (DEPT 135, $125 \mathrm{MHz}$ ) do composto 2 em DMSO-d 6 . 117

7.1.4.5 Mapa de contorno gerado a partir do experimento HMQC $\left({ }^{13} \mathrm{C}: 125 \mathrm{MHz},{ }^{1} \mathrm{H}: 500 \mathrm{MHz}\right) \mathrm{do}$ composto 2 em DMSO-d $\mathrm{d}_{6}$.

7.1.4.6 Mapa de contorno gerado a partir do experimento $\operatorname{COSY} 90^{\circ}\left[{ }^{1} \mathrm{H},{ }^{1} \mathrm{H}: 500 \mathrm{MHz}\right]$ do composto 2 em DMSO-d

7.1.4.7 Mapa de contorno gerado a partir do experimento $\mathrm{HMBC}\left({ }^{13} \mathrm{C}: 125 \mathrm{MHz},{ }^{1} \mathrm{H}: 500 \mathrm{MHz}\right)$, modulado para ${ }^{2} \mathrm{~J}_{\mathrm{CH}}=8 \mathrm{~Hz}$, do composto 2 em DMSO- $\mathrm{d}_{6}$.

7.1.4.8 Mapa de contorno gerado a partir do experimento $\mathrm{HMBC}\left({ }^{13} \mathrm{C}: 125 \mathrm{MHz},{ }^{1} \mathrm{H}: 500 \mathrm{MHz}\right)$, modulado para ${ }^{2} \mathrm{~J}_{\mathrm{CH}}=4 \mathrm{~Hz}$, do composto 2 em DMSO- $\mathrm{d}_{6}$

7.1.5 Dados de RMN do composto 3:

7.1.5.1 Espectro de RMN de ${ }^{1} \mathrm{H}(500 \mathrm{MHz})$ do composto 3 em DMSO-d $\mathrm{d}_{6}$.

7.1.5.2 Ampliações do Espectro de RMN de ${ }^{1} \mathrm{H}(500 \mathrm{MHz})$ do composto 3 em DMSO-d $\mathrm{d}_{6}$. 
7.1.5.3 Ampliação do Espectro de RMN de ${ }^{1} \mathrm{H}(500 \mathrm{MHz})$ do composto 3 em DMSO-d 6 .

7.1.5.4 Espectro de RMN de ${ }^{13} \mathrm{C}\left\{{ }^{1} \mathrm{H}\right\}(125 \mathrm{MHz})$ do composto 3 em DMSO-d $\mathrm{d}_{6}$.

7.1.5.5 Espectro de RMN de ${ }^{13} \mathrm{C}$ (DEPT $135^{\circ}, 125 \mathrm{MHz}$ ) do composto 3 em DMSO-d ${ }_{6}$.

7.1.5.6 Mapa de contorno gerado a partir do experimento HMQC $\left({ }^{13} \mathrm{C}: 125 \mathrm{MHz},{ }^{1} \mathrm{H}: 500 \mathrm{MHz}\right) \mathrm{do}$ composto 3 em DMSO-d $\mathrm{d}_{6}$.

7.1.5.7 Mapa de contorno gerado a partir do experimento $\operatorname{COSY} 90^{\circ}\left({ }^{1} \mathrm{H},{ }^{1} \mathrm{H}: 500 \mathrm{MHz}\right)$ do composto 3 em DMSO-d 6 .

7.1.5.8 Mapa de contorno gerado a partir do experimento $\mathrm{HMBC}\left({ }^{13} \mathrm{C}: 125 \mathrm{MHz},{ }^{1} \mathrm{H}: 500 \mathrm{MHz}\right)$, modulado para ${ }^{2} \mathrm{~J}_{\mathrm{CH}}=8 \mathrm{~Hz}$, do composto 3 em DMSO- $\mathrm{d}_{6}$.

7.1.5.9 Mapa de contorno gerado a partir do experimento HMBC $\left({ }^{13} \mathrm{C}: 125 \mathrm{MHz},{ }^{1} \mathrm{H}: 500 \mathrm{MHz}\right)$, modulado para ${ }^{2} \mathrm{~J}_{\mathrm{CH}}=4 \mathrm{~Hz}$, do composto 3 em DMSO- $\mathrm{d}_{6}$.

7.1.6 Dados de RMN do composto 4:

7.1.6.1 Espectro de RMN de ${ }^{1} \mathrm{H}(500 \mathrm{MHz})$ do composto 4 em DMSO-d $\mathrm{d}_{6}$.

7.1.6.2 Ampliações do Espectro de RMN de ${ }^{1} \mathrm{H}(500 \mathrm{MHz})$ do composto 4 em DMSO-d $\mathrm{d}_{6}$.

7.1.6.3 Espectro de RMN de ${ }^{13} \mathrm{C}\left\{{ }^{1} \mathrm{H}\right\}(125 \mathrm{MHz})$ do composto 4 em DMSO-d $\mathrm{d}_{6}$.

7.1.6.4 Espectro de RMN de ${ }^{13} \mathrm{C}\left(\mathrm{DEPT} 135^{\circ}, 125 \mathrm{MHz}\right)$ do composto 4 em DMSO-d $\mathrm{d}_{6}$.

7.1.6.5 Mapa de contorno gerado a partir do experimento HMQC $\left({ }^{13} \mathrm{C}: 125 \mathrm{MHz},{ }^{1} \mathrm{H}: 500 \mathrm{MHz}\right)$ do composto 4 em DMSO-d $\mathrm{d}_{6}$.

7.1.6.6 Mapa de contorno gerado a partir do experimento $\operatorname{COSY} 90^{\circ}\left({ }^{1} \mathrm{H},{ }^{1} \mathrm{H}: 500 \mathrm{MHz}\right)$ do composto 4 em DMSO-d 6 .

7.1.6.7 Mapa de contorno gerado a partir do experimento $\mathrm{HMBC}\left({ }^{13} \mathrm{C}: 125 \mathrm{MHz},{ }^{1} \mathrm{H}: 500 \mathrm{MHz}\right)$, modulado para ${ }^{2} \mathrm{~J}_{\mathrm{CH}}=8 \mathrm{~Hz}$, do composto 3 em DMSO-d 6 .

7.2 Dados dos compostos 5-9: aplicação do método de seccionamento e limpeza do sinal por processamento

7.2.1 Dados de RMN dos componentes da Fração DF:

7.2.1.1 Espectro de RMN de ${ }^{1} \mathrm{H}(500 \mathrm{MHz})$ da Fração DF em $\mathrm{CDCl}_{3}$.

7.2.1.2 Espectros de RMN de ${ }^{13} \mathrm{C}\left\{{ }^{1} \mathrm{H}\right\}(125 \mathrm{MHz})$ da Fração DF em $\mathrm{CDCl}_{3}$.

7.2.1.2.1 Espectro original

7.2.1.2.2 Espectro tratado pelo método de seccionamento e limpeza de sinal

7.2.1.3 Espectro de RMN de ${ }^{13} \mathrm{C}\left(\mathrm{DEPT} 135^{\circ}, 125 \mathrm{MHz}\right)$ da Fração DF em $\mathrm{CDCl}_{3}$.

7.2.2 Dados de RMN do composto 7

7.2.2.1 Espectro de RMN de ${ }^{1} \mathrm{H}(300 \mathrm{MHz})$ do composto 7 em Metanol- $\mathrm{d}_{4}$.

7.2.2.2 Ampliações do Espectro de RMN de ${ }^{1} \mathrm{H}(300 \mathrm{MHz})$ do composto 7 em Metanol- $\mathrm{d}_{4}$.

7.2.2.3 Espectros de RMN de ${ }^{13} \mathrm{C}\left\{{ }^{1} \mathrm{H}\right\}(75 \mathrm{MHz})$ do composto 7 em Metanol- $\mathrm{d}_{4}$.

7.2.2.3.1 Espectro original $\quad 144$

7.2.2.3.2 Espectro tratado pelo método de seccionamento e limpeza de sinal 145

7.2.2.4 Espectro de RMN de 13C(DEPT 135 ${ }^{\circ}, 75 \mathrm{MHz}$ ) do composto 7 Metanol-d4,. 146

7.2.2.5 Mapa de contorno gerado a partir do experimento HMQC (13C: $125 \mathrm{MHz}$ e 1H: $500 \mathrm{MHz}$ ) do composto 7 em DMSO-d6,

7.2.2.6 Mapa de contorno gerado a partir do experimento $\operatorname{COSY} 90^{\circ}[1 \mathrm{H}, 1 \mathrm{H}]$ do composto 7 em DMSO-d6, (500 MHz)

7.2.2.7 Ampliações do Mapa de contorno gerado a partir do experimento COSY $90^{\circ}[1 \mathrm{H}, 1 \mathrm{H}]$ do composto 7 em DMSO-d6, (500 MHz) 
7.2.2.8 Mapa de contorno gerado a partir do experimento HMBC [13C,1H], modulado para 2JCH=8Hz, do composto 7 em DMSO-d6, (13C: $125 \mathrm{MHz}$ e 1H: $500 \mathrm{MHz}$ )

7.2.2.9 Mapa de contorno gerado a partir do experimento g-NOESY [1H, 1H] do composto $7 \mathrm{em}$ DMSO-d6, (1H: $500 \mathrm{MHz}$ )

7.2.3 Dados de RMN do composto 8:

7.2.3.1 Espectro de RMN de $1 \mathrm{H}$ do composto 8 em DMSO-d6, $500 \mathrm{MHz}$.

7.2.3.2 Ampliações do Espectro de RMN de ${ }^{1} \mathrm{H}$ do composto 8 em DMSO-d6, $500 \mathrm{MHz}$

7.2.3.3 Espectro de RMN de ${ }^{13} \mathrm{C}\left\{{ }^{1} \mathrm{H}\right\}(125 \mathrm{MHz})$ do composto 8 em DMSO-d 6 .

7.2.3.4 Espectro de RMN de ${ }^{13} \mathrm{C}\left(\mathrm{DEPT} 135^{\circ}, 125 \mathrm{MHz}\right)$ do composto 8 em DMSO-d6,.

7.2.3.5 Espectro de RMN de ${ }^{13} \mathrm{C}\left(\mathrm{DEPT} 90^{\circ}, 125 \mathrm{MHz}\right)$ do composto 8 em DMSO-d6,.

7.2.3.6 Mapas de contorno gerado a partir do experimento HMQC $\left({ }^{13} \mathrm{C}: 125 \mathrm{MHz}\right.$ e $\left.{ }^{1} \mathrm{H}: 500 \mathrm{MHz}\right)$ do composto 8 em DMSO-d $\mathrm{d}_{6}$.

7.2.3.7 Mapas de contorno gerado a partir do experimento COSY $90^{\circ}\left({ }^{1} \mathrm{H},{ }^{1} \mathrm{H}: 500 \mathrm{MHz}\right)$ do composto 8 em DMSO-d 6 .

7.2.3.8 Mapa de contorno gerado a partir do experimento $\mathrm{HMBC}\left({ }^{13} \mathrm{C}: 125 \mathrm{MHz}\right.$ e $\left.{ }^{1} \mathrm{H}: 500 \mathrm{MHz}\right)$, modulado para ${ }^{2} \mathrm{~J}_{\mathrm{CH}}=8 \mathrm{~Hz}$, do composto 8 em DMSO- $\mathrm{d}_{6}$.

7.2.3.9 Mapa de contorno gerado a partir do experimento $\mathrm{HMBC}\left({ }^{13} \mathrm{C}: 125 \mathrm{MHz}\right.$ e ${ }^{1} \mathrm{H}$ : $\left.500 \mathrm{MHz}\right)$, modulado para ${ }^{2} \mathrm{~J}_{\mathrm{CH}}=4 \mathrm{~Hz}$, do composto 8 em DMSO- $\mathrm{d}_{6}$.

7.2.3.10 Mapa de contorno gerado a partir do experimento g-NOESY $\left({ }^{1} \mathrm{H}: 500 \mathrm{MHz}\right)$ do composto $8 \mathrm{em}$ DMSO-d 6 .

7.2.3.11 Ampliação do mapa de contorno gerado a partir do experimento g-NOESY $\left({ }^{1} \mathrm{H}: 500 \mathrm{MHz}\right)$ do composto 8 em DMSO- $\mathrm{d}_{6}$.

7.2.3.12 Mapa de contorno gerado a partir do experimento ROESY $\left[{ }^{1} \mathrm{H},{ }^{1} \mathrm{H}\right]$ do composto 8 em DMSOd6, $\left({ }^{1} \mathrm{H}: 500 \mathrm{MHz}\right)$

7.2.3.13 Ampliação do mapa de contorno gerado a partir do experimento $\operatorname{ROESY}\left[{ }^{1} \mathrm{H},{ }^{1} \mathrm{H}\right]$ do composto 8 em DMSO-d6, $\left({ }^{1} \mathrm{H}: 500 \mathrm{MHz}\right)$

7.2.4 Dados de RMN do composto 9: 165

7.2.4.1 Espectro de RMN de ${ }^{1} \mathrm{H}$ do composto 9 em DMSO-d6, $500 \mathrm{MHz}$.

7.2.4.2 Ampliações do Espectro de RMN de ${ }^{1} \mathrm{H}$ do composto 9 em DMSO-d6, $500 \mathrm{MHz}$.

7.2.4.3 Espectro de RMN de ${ }^{13} \mathrm{C}\left\{{ }^{1} \mathrm{H}\right\}(125 \mathrm{MHz})$ do composto 9 em DMSO-d 6

7.2.4.4 Espectro de RMN de ${ }^{13} \mathrm{C}\left(\mathrm{DEPT} 135^{\circ}, 125 \mathrm{MHz}\right)$ do composto 9 em DMSO-d $\mathrm{d}_{6}$. 168

7.2.4.5 Mapa de contorno gerado a partir do experimento HMQC $\left({ }^{13} \mathrm{C}: 125 \mathrm{MHz}\right.$ e $\left.{ }^{1} \mathrm{H}: 500 \mathrm{MHz}\right) \mathrm{do}$ composto 9 em DMSO-d 6 .

7.2.4.6 Mapa de contorno gerado a partir do experimento COSY $90^{\circ}\left({ }^{1} \mathrm{H},{ }^{1} \mathrm{H}, 500 \mathrm{MHz}\right)$ do composto 9 em DMSO-d 6 .

7.2.4.7 Mapa de contorno gerado a partir do experimento $\mathrm{HMBC}\left({ }^{13} \mathrm{C}: 125 \mathrm{MHz}\right.$ e ${ }^{1} \mathrm{H}$ : $\left.500 \mathrm{MHz}\right)$, modulado para ${ }^{2} \mathrm{~J}_{\mathrm{CH}}=8 \mathrm{~Hz}$, do composto 9 em DMSO- $\mathrm{d}_{6}$.

7.2.5 Dados de RMN do composto 10: 172

7.2.5.1 Espectro de RMN de ${ }^{1} \mathrm{H}(500 \mathrm{MHz})$ do composto 10 em DMSO-d $\mathrm{d}_{6}$.

7.2.5.2 Ampliações do Espectro de RMN de ${ }^{1} \mathrm{H}(500 \mathrm{MHz})$ do composto 10 em DMSO-d . $\quad 173$

7.2.5.3 Ampliações do Espectro de RMN de ${ }^{1} \mathrm{H}(500 \mathrm{MHz})$ do composto 10 em DMSO-d 6

7.2.5.4 Ampliações do Espectro de RMN de ${ }^{1} \mathrm{H}(500 \mathrm{MHz})$ do composto 10 em DMSO-d 6

7.2.5.5 Espectro de RMN de ${ }^{13} \mathrm{C}\left\{{ }^{1} \mathrm{H}\right\}(125 \mathrm{MHz})$ do composto 10 em DMSO-d $\mathrm{d}_{6}$.

7.2.5.6 Espectro de RMN de ${ }^{13} \mathrm{C}$ (DEPT 135, $125 \mathrm{MHz}$ ) do composto 10 em DMSO-d 6 . 177 
7.2.5.7 Mapa de contorno gerado a partir do experimento HSQC $\left({ }^{13} \mathrm{C}: 125 \mathrm{MHz}\right.$ e $\left.{ }^{1} \mathrm{H}: 500 \mathrm{MHz}\right)$ do composto 10 em DMSO-d . $_{\text {. }}$

7.2.5.8 Mapa de contorno gerado a partir do experimento TOCSY $\left({ }^{1} \mathrm{H},{ }^{1} \mathrm{H}, 500 \mathrm{MHz}\right)$ do composto 10 em DMSO-d . $_{6}$.

7.2.5.9 Mapa de contorno gerado a partir do experimento $\mathrm{HMBC}\left({ }^{13} \mathrm{C}: 125 \mathrm{MHz}\right.$ e $\left.{ }^{1} \mathrm{H}: 500 \mathrm{MHz}\right)$, modulado para ${ }^{2} \mathrm{~J}_{\mathrm{CH}}=8 \mathrm{~Hz}$, do composto $10 \mathrm{em}$ DMSO- $\mathrm{d}_{6}$.

7.2.5.10 Mapa de contorno gerado a partir do experimento NOESY $\left({ }^{1} \mathrm{H},{ }^{1} \mathrm{H}, 500 \mathrm{MHz}\right)$ do composto 10 em DMSO-d 6 .

7.2.5.11 Mapa de contorno gerado a partir do experimento J-resolved $\left({ }^{1} \mathrm{H},{ }^{1} \mathrm{H}, 500 \mathrm{MHz}\right)$ do composto 10 em DMSO-d 6 .

7.2.6 Dados de RMN do composto 11:

7.2.6.1 Espectro de RMN de ${ }^{1} \mathrm{H}(500 \mathrm{MHz})$ do composto 11 em DMSO- $\mathrm{d}_{6}$.

7.2.6.2 Ampliações do Espectro de RMN de ${ }^{1} \mathrm{H}(500 \mathrm{MHz})$ do composto 11 em DMSO-d ${ }_{6}$.

7.2.6.3 Ampliações do Espectro de RMN de ${ }^{1} \mathrm{H}(500 \mathrm{MHz})$ do composto 11 em DMSO-d ${ }_{6}$.

7.2.6.4 Espectro de RMN de ${ }^{13} \mathrm{C}\left\{{ }^{1} \mathrm{H}\right\}(125 \mathrm{MHz})$ do composto 11 em DMSO-d 6 .

7.2.6.5 Espectro de RMN de ${ }^{13} \mathrm{C}\left(\mathrm{DEPT} 135^{\circ}, 125 \mathrm{MHz}\right)$ do composto 11 em DMSO-d $\mathrm{d}_{6}$.

7.2.6.6 Mapa de contorno gerado a partir do experimento HSQC $\left({ }^{13} \mathrm{C}: 125 \mathrm{MHz}\right.$ e $\left.{ }^{1} \mathrm{H}: 500 \mathrm{MHz}\right) \mathrm{do}$ composto 11 em DMSO-d $\mathrm{d}_{6}$.

7.2.6.7 Mapa de contorno gerado a partir do experimento $\mathrm{HMBC}\left({ }^{13} \mathrm{C}: 125 \mathrm{MHz}\right.$ e ${ }^{1} \mathrm{H}: 500 \mathrm{MHz}$, modulado para ${ }^{2} \mathrm{~J}_{\mathrm{CH}}=4 \mathrm{~Hz}$, do composto 11 em DMSO- $\mathrm{d}_{6}$.

7.2.6.8 Mapa de contorno gerado a partir do experimento J-resolved $\left({ }^{1} \mathrm{H},{ }^{1} \mathrm{H}, 500 \mathrm{MHz}\right)$ do composto 10 em DMSO-d $\mathrm{d}_{6}$.

7.2.6.9 Mapa de contorno do G-BIRD ${ }_{\mathrm{R}-\mathrm{X}}$ CPMG-HSQMBC para o composto 10.

8 Apêndice B: Descrição das Fontes dos Produtos Naturais Analisados 192

8.1 Plantas da Família Asteraceae 193

8.1.1 Tribo Heliantheae 193

8.1.1.1 Subtribo Coreopsidinae 194

8.1.1.1.1 Gênero Bidens $\quad 195$

8.1.1.1.1.1 Bidens gardneri Bak. 196

8.1.1.1.1.2 Bidens sulphurea (Cav.) Sch. Bip. 199

8.2 Plantas da Família Annonaceae 202

8.2.1 Gênero Duguetia 202

8.2.1.1 Espécie Duguetia furfuracea 204

$9 \quad$ Apêndice C: Obtenção da Fração DF de D. furfuracea 207 


\section{RESUMO}

RODRIGUES, E. D. Estratégias de aumento de eficiência da análise de Produtos Naturais por Espectroscopia de Ressonância Magnética Nuclear. 2010. 215p. Tese (Doutorado) Faculdade de Filosofia, Ciências e Letras de Ribeirão Preto, Universidade de São Paulo, Ribeirão Preto - SP, 2010.

Dois dos principais aspectos da Química de Produtos Naturais são a identificação e a determinação estrutural dos compostos orgânicos presentes em materiais de origem vegetal ou animal. Para realizar esta tarefa são empregados diversos métodos de separação e espectroscópicos. Dentre os métodos espectroscópicos, destaca-se a espectroscopia de ressonância magnética nuclear pela riqueza dos dados fornecidos. Entretanto, o desenvolvimento da área exige métodos cada vez mais eficientes e sensíveis, para permitir o estudo de amostras em quantidades cada vez menores. Neste trabalho, empregamos três estratégias distintas para aumentar a eficiência da análise de amostras de produtos naturais por RMN. A primeira estratégia busca acelerar o processo de identificação dos componentes de frações de extratos vegetais através da separação virtual dos componentes da mistura, baseada nas diferenças de seus coeficientes de difusão. Esta estratégia permitiu identificar os quatro componentes majoritários da fração em acetato de etila do extrato etanólico das partes aéreas de Bidens sulphurea (Asteraceae) através de um estudo de RMN DOSY-2D. A segunda estratégia é dedicada ao problema da baixa sensibilidade da $\mathrm{RMN}{ }^{13} \mathrm{C}$, o que torna difícil, e em alguns casos, proibitiva em termos do tempo necessário, a análise de amostras muito pequenas. Dada a dificuldade de se obter diretamente um espectro com uma relação sinal/ruído adequada, uma abordagem possível se baseia em estratégias de pós-processamento de um espectro de RMN em que predomina o ruído. A estratégia utilizada neste trabalho fornece um espectro reconstruído de secções que foram previamente processadas para a eliminação do ruído pela decomposição do valor singular (SVD). Os espectros assim processados nos auxiliaram na identificação e/ou elucidação estrutural de dois alcalóides obtidos de Duguetia furfuraceae (Annonaceae) e um poliacetileno e dois flavonóides de $B$. sulphurea (Asteraceae). A terceira estratégia utilizada neste trabalho se baseia na ampliação dos parâmetros rotineiramente obtidos numa análise por RMN, com a finalidade de fornecer novos subsídios para a determinação da estrutura de produtos naturais. Neste sentido, a determinação das constantes de acoplamento heteronuclear $\left({ }^{\mathrm{n}} \mathrm{J}_{\mathrm{CH}}\right)$ forneceu dados valiosos para a identificação de dois poliacetilenos obtidos de B. gardneri.

Palavras-chave: RMN. DOSY. SVD. Acoplamento heteronuclear. Bidens sulphurea. Bidens gardneri. Duguetia furfuracea. Flavonóides. Poliacetilenos. Alcalóides 


\section{ABSTRACT}

RODRIGUES, E. D. Strategies to improve efficiency Natural Products analys by Nuclear Magnetic Resonance Spectroscopy. 2010. 215p. Tese (Doutorado) - Faculdade de Filosofia, Ciências e Letras de Ribeirão Preto, Universidade de São Paulo, Ribeirão Preto - SP, 2010.

Two major aspects of Natural Products Chemistry are the identification and structure determination of organic compounds in materials of vegetable or animal. To accomplish this task are used various methods of separation and spectroscopic. Among spectroscopic methods, we highlight the spectroscopy of nuclear magnetic resonance by the wealth of data provided. However, the development of the area requires methods increasingly efficient and sensitive to allow the study of small or diluted samples. In this work, we employ three different strategies to increase the efficiency of analysis of samples of natural products by NMR. The first strategy seeks to accelerate the process of identifying the components of fractions of plant extracts through the virtual separation of the components of the mixture based on differences in their diffusion coefficients. With this strategy we have identified four major components of the in ethyl acetate fraction of ethanol extract of aerial parts of Bidens sulphurea (Asteraceae) by 2D DOSY NMR. The second strategy is devoted to the problem of low sensitivity of 13C NMR, which makes it difficult, and in some cases prohibitive in terms of time, the analysis of very small samples. Due to the difficulty of obtaining directly a spectrum with a signal-to-noise ratio adequate, a possible approach is based on strategies for post-processing of an NMR spectrum in which noise predominates. This strategy used here provides a spectrum of reconstructed sections were first processed to remove noise by singular value decomposition (SVD). Spectra processed of this way helped us in identifying and / or structural elucidation of two alkaloids derived from Duguetia furfuraceae (Annonaceae) and a polyacetylene and two flavonoids from Bidens gardneri (Asteraceae). The third strategy used in this work is based on expansion of the parameters routinely obtained in an analysis by NMR in order to provide new subsidies for the structure determination of natural products. In this sense, the determination of heteronuclear coupling constants $\left({ }^{\mathrm{n}} J_{\mathrm{CH}}\right)$ provided valuable data for the identification of two polyacetylenes obtained from B. gardneri.

Keywords: $\quad$ NMR. DOSY. SVD. Heteronuclear coupling. Bidens sulphurea. Bidens gardneri. Duguetia furfuracea. Flavonoids. Polyacetylenes. Alkaloids 


\section{ABREVIATURAS, SIGLAS E SÍMBOLOS}

$\mathrm{ACN} \rightarrow$ acetonitrila

AcOEt $\rightarrow$ acetato de etila

$\mathrm{AIF} \rightarrow$ análise por injeção de fluxo

$\mathrm{B}_{0} \rightarrow$ campo magnético estático

$\mathrm{B}_{\mathrm{L}} \rightarrow$ campo magnético local

BPPLED $\rightarrow$ "bipolar pulse pairs longitudinal eddy currents delay"

BPPSTE $\rightarrow$ "bipolar pulse pairs stimulated echo"

BSAcOEt $\rightarrow$ fração de $B$. sulphurea em acetato de etila

$\mathrm{BSDCM} \rightarrow$ fração diclorometânica de B. sulphurea

$\mathrm{CCDC} \rightarrow$ cromatografia de camada delgada comparativa

$\mathrm{CDB} \rightarrow$ Convenção da Diversidade Biológica

$\mathrm{CDCl}_{3} \rightarrow$ clorofórmio deuterado

$\mathrm{CG} \rightarrow$ cromatografia gasosa

$\mathrm{CL} \rightarrow$ cromatografia líquida

$\mathrm{CLAE} \rightarrow$ cromatografia líquida de alta eficiência

$\mathrm{COSY} \rightarrow$ "correlation spectroscopy"

CPMG $\rightarrow$ sequência de eco de spin de Carr-Purcell-Meiboom-Gill

$1 \mathrm{D}$ ou $2 \mathrm{D}$ ou $3 \mathrm{D} \rightarrow$ unidimensional ou bidimensional ou tridimensional

$\mathrm{D} \rightarrow$ coeficiente de difusão molecular, dado por $\mathrm{m}^{2} . \mathrm{s}^{-1}$

$d \rightarrow$ dubleto

$\mathrm{DAD} \rightarrow$ detector com arranjo de diodos

$\mathrm{DC} \rightarrow$ Espectroscopia de dicroísmo circular

$\mathrm{DCM} \rightarrow$ diclorometano

$d d \rightarrow$ duplo-dubleto ou dubleto de dubleto

$d d d \rightarrow$ dubleto de duplo-dubleto

$d d d d \rightarrow$ duplo-dubleto de duplo-dubleto

DEPT $\rightarrow$ "Distortionless Enhancement by Polarization Transfer"

DFT ou TFD $\rightarrow$ a transformada de Fourier discreta

$d l \rightarrow$ dubleto largo

DMSO-d $\mathrm{d}_{6} \rightarrow$ Dimetilsulfóxido hexadeuterado

DOSY $\rightarrow$ "diffusion ordenated spectroscopy" = Espectroscopia ordenada por difusão

$d t \rightarrow$ duplo tripleto ou dubleto de tripleto

$d t d \rightarrow$ dubleto de tripleto de dubleto

$d t t \rightarrow$ dubleto de tripleto de tripleto

$\mathrm{EC} \rightarrow$ Eletroforese capilar (EC)

$\mathrm{EF} \rightarrow$ emissão de fluorescência

$\mathrm{EM} \rightarrow$ espectrometria de massas

EMBRAPA $\rightarrow$ Empresa Brasileira de Pesquisa Agropecuária

$\mathrm{ESI} \rightarrow$ "electrospray ionization"

EUA $\rightarrow$ Estados Unidos da América

FDA $\rightarrow$ "U.S. Food and Drug Administration"

FFT $\rightarrow$ Transformada de Fourier rápida ("Fast Fourier Transform").

FID $\rightarrow$ "free induction decay" = decaimento livre da indução 
FT ou TF $\rightarrow$ transformada de Fourier (FT)

$\mathrm{g} \rightarrow$ amplitude do gradiente $(\mathrm{g})$

$\mathrm{g}_{0} \rightarrow$ gradiente estático proveniente da não-homogeneidade do campo magnético

gap $\rightarrow$ degrau

G-BIRD $\rightarrow$ desacoplamento por rotação bilinear com gradiente ("biliniear rotation decoupling with gradient")

GCSTE $\rightarrow$ "gradient compensated stimulated echo spin"

GCSTEL $\rightarrow$ "gradient compensated stimulated echo spin lock"

$\mathrm{HAc} \rightarrow$ ácido acético

Hertz $\rightarrow$ hertz $\left(1 \mathrm{~s}^{-1}\right)$

Hex $\rightarrow$ hexano

HINR $\rightarrow$ redução de ruído por inversão harmônica

$\mathrm{HMBC} \rightarrow$ correlação heteronuclear a múltiplas ligações ("Heteronuclear multiple-bond correlation")

HMQC $\rightarrow$ correlação heteronuclear de quantum múltiplo ("Heteronuclear multiple-quantum correlation")

HSQC $\rightarrow$ correlação heteronuclear de quantum único ("Heteronuclear single-quantum correlation")

HSQMBC $\rightarrow$ correlação heteronuclear de quantum único a múltiplas ligações ("heteronuclear single quantum multiple bond correlation")

$i \rightarrow$ índice de um ponto de uma matriz

$\mathrm{I} \rightarrow$ intensidade do sinal

IFT ou TFI $\rightarrow$ Transformada de Fourier inversa ("Inverse Fourier Transform");

IH ou HI $\rightarrow$ Inversão Harmônica ("harmonic inversion”)

IV $\rightarrow$ Espectroscopia de absorção no infravermelho

IV-TF $\rightarrow$ Infravermelho com Transformada de Fourier (IV-TF)

$J \rightarrow$ constantes de acoplamento.

$J$-resolved $\rightarrow$ técnica de separação de acoplamentos ("J-resolved spectroscopy")

$\overrightarrow{\mathrm{J}} \rightarrow$ fluxo de matéria $\rightarrow \mathrm{n}^{\mathrm{o}}$ de moléculas que atravessa uma superfície de controle por $\mathrm{m}^{2} \cdot \mathrm{s}^{-1}$

$\mathrm{k} \rightarrow$ constante de Boltzmann $\left(\mathrm{J} . \mathrm{K}^{-1}\right)$

$m \rightarrow$ multipleto

$\mathrm{MeOH} \rightarrow$ metanol

$\mathrm{MHz} \rightarrow$ megahertz $\left(10^{6}\right.$ hertz $)$

multi. $\rightarrow$ multiplicidade

${ }^{\mathrm{n}} J_{\mathrm{C}, \mathrm{H}} \rightarrow$ constantes de acoplamento heteronuclear carbono-hidrogênio, onde $\mathrm{n}$ é número de ligações entre o núcleos participante

${ }^{\mathrm{n}} J_{\mathrm{H}, \mathrm{H}} \rightarrow$ constantes de acoplamento homonuclear, onde $\mathrm{n}$ é número de ligações entre o

${ }^{\mathrm{n}} J_{\mathrm{X}, \mathrm{H}} \rightarrow$ constantes de acoplamento heteronuclear, onde $\mathrm{n}$ é número de ligações entre o núcleos participante e $\mathrm{X}$ pode ser qualquer núcleo diferente de $\mathrm{H}$.

NOESY $\rightarrow$ Spectroscopia do efeito nuclear de Overhauser ("Nuclear Overhauser Effect Spectroscopy")

NP/PEG $\rightarrow$ "Natural Products"(aminoetiléster difenilborínico) / Polietilenoglicol

$n s \rightarrow$ número de medidas ou varreduras

$\mathrm{o} 1 \mathrm{p} \rightarrow$ frequência em que a metade de sw está fixada

OMS $\rightarrow$ Organização Mundial de Saúde

p.a. $\rightarrow$ padrão de acoplamento

$\mathrm{PFG} \rightarrow$ pulse Field gradient $=\mathrm{PGC} \rightarrow$ pulso de gradiente de campo 
PFGLED $\rightarrow$ Pulso de gradiente com intervalo de tempo para eliminar correntes parasitas ("pulsed field gradient longitudinal eddy current delay")

PFGSE $\rightarrow$ "pulse field gradient spin echo" = eco de spin com pulso de gradiente de campo.

PFGSTE $\rightarrow$ "pulse field gradient stimulated echo" = eco de spin com pulso de gradiente de campo.

$\mathrm{PN} \rightarrow$ Produtos Naturais

ppm $\rightarrow$ partes por milhão

QPN $\rightarrow$ Química de Produtos Naturais

$\mathrm{rf} \rightarrow$ radiofrequência

$\mathrm{R}_{\mathrm{H}} \rightarrow$ raio hidrodinâmico

$\mathrm{RMN} \rightarrow$ Espectroscopia de ressonância magnética nuclear

RMN de ${ }^{13} \mathrm{C}\left\{{ }^{1} \mathrm{H}\right\} \rightarrow$ ressonância magnética de carbono 13 desacoplado do hidrogênio

$\mathrm{RMN}$ de ${ }^{13} \mathrm{C} \rightarrow$ ressonância magnética de carbono 13

RMN de ${ }^{1} \mathrm{H} \rightarrow$ ressonância magnética nuclear de hidrogênio 1

$s \rightarrow$ singleto

$\mathrm{S} / \mathrm{R} \rightarrow$ relação sinal ruído

$\mathrm{SI} \rightarrow$ número de pontos no domínio da frequência

$\mathrm{s}_{\mathrm{i}} \rightarrow$ valor singular de uma matriz

$s l \rightarrow$ singleto largo

$\mathrm{SPME} \rightarrow$

SVD $\rightarrow$ decomposição do valor singular ("singular value decomposition")

$\mathrm{sW} \rightarrow$ largura espectral)

swp $\rightarrow$ largura espectral em ppm

$\mathrm{T} \rightarrow$ temperatura $(\mathrm{K})$,

$t \rightarrow$ tripleto

$\mathrm{T}_{1} \rightarrow$ relaxação longitudinal

$\mathrm{T}_{2} \rightarrow$ relaxação transversal

$\mathrm{T}_{2}^{*} \rightarrow$ relaxação transversal efetiva

$\mathrm{TD} \rightarrow$ número de pontos no domínio do tempo

$t d d \rightarrow$ tripleto de dubleto de dubleto

TFA $\rightarrow$ ácido trifluoracético 


\section{LISTA DE FIGURAS}

Figura 1. Fármacos aprovados pelo FDA (U.S. Food and Drug Administration) no período de 1981 a $2007^{[9,10]}$.

Figura 2. Exemplos de alguns produtos naturais de grande relevância ${ }^{[14,15]}$.

Figura 3. Estruturas do colesterol propostas em 1927 e 1932 e estrutura do ergosterol ${ }^{[23,24]}$. 6

Figura 4. Espectro eletromagnético ${ }^{[32,34,36,37,38,39]}$.

Figura 5. Diagrama do sistema de bobinas anti-Helmholtz e bobina de radiofrequência (rf) de uma sonda com gradiente.

Figura 6. Sequência de pulsos para o experimento de ecos de spins com gradientes de campo pulsados (PFGSE) ${ }^{[65,69,87]}$.

Figura 7. Sequência de pulsos para o experimento de 'ecos de spins' estimulados ${ }^{[69,87]}$.

Figura 8. Processos ocorridos e um experimento de PFGSE de acordo com Antalek e Cohen e colaboradores ${ }^{[68,86]}$.

Figura 9. Posição relativa entre $\mathrm{rf}\left(\mathrm{B}_{1}\right)$ e campo magnético estático $\left(\mathrm{B}_{0}\right)$

Figura 10. Sinal de excitação típico para RMN pulsada. (A) sequência de pulsos; (B) vista expandida do pulso de rf.

Figura 11. Efeito do processo de promediação de conjunto para um espectro.

Figura 12. Demonstração da verificação de estabilidade de "gap".

Figura 13. Método de redução de ruído por SVD.

Figura 14. Exemplo de acoplamento tipo ${ }^{3} J_{C H}$ sem anologia com acoplamento homonuclear $\mathrm{H}, \mathrm{H}^{[43,156]}$

Figura 15. Diferença de valores de constante de acoplamento em função da geometria molecular

Figura 16. Experimento G-BIRD ${ }_{\mathrm{R}, \mathrm{X}}-\mathrm{CPMG}-\mathrm{HSQMBC}{ }^{[158]}$.

Figura 17. Sequência de pulso ledbpgp2s usada nos experimentos DOSY-2D.

Figura 18. Espectro de RMN de ${ }^{1} \mathrm{H}(500 \mathrm{MHz})$ da fração Acetato (BSAcOEt) do extrato etanólico das partes aéreas de $B$. sulphurea.

Figura 19. DOSY-2D de BSAcOEt em DMSO-d6: $\Delta=50 \mathrm{~ms} ; \delta=3250 \mu \mathrm{s}$.

Figura 20. Ampliações do espectro de RMN DOSY-2D de BSAcOEt em DMSO- $d_{6}$ : $\Delta=50 \mathrm{~ms} ; \delta=3250 \mu \mathrm{s}$.

Figura 21. Estruturas propostas e coeficientes de difusão dos componentes majoritários (1a - 4a) da fração $B S A c O E t$ obtidos a partir das correlações dos sinais dos prótons anoméricos das unidades de açúcar observadas no espectro de DOSY-2D.

Figura 22. Cromatograma da fração BSAcOEt obtido após análise por CLAE-UV analítica

Figura 23. Estruturas dos compostos majoritários de BSAcOEt.

Figura 24. Espectro original de $R M N$ de ${ }^{13} \mathrm{C}\left\{{ }^{1} \mathrm{H}\right\}(125 \mathrm{MHz})$ da Fração DF em $\mathrm{CDCl}_{3}$ obtido com 8192 pontos no domínio da frequência após 16384 varreduras (11h e 46min).

Figura 25. Verificação da estabilidade de gap nas secções escolhidas do espectro de $R M N$ de ${ }^{13} \mathrm{C}\left\{{ }^{1} \mathrm{H}\right\}$ (125 MHz) da Fração DF em $\mathrm{CDCl}_{3}$ obtido com 8192 pontos no domínio da frequência após 16384 varreduras (11h e 46min).

Figura 26. Espectro de RMN de ${ }^{13} \mathrm{C}\left\{{ }^{1} \mathrm{H}\right\}$ da Fração DF tratado pelo método de seccionamento e filtragem de sinal.

Figura 27. Estruturas dos alcalóides: dicentrinona (5) e (-)-duguetina $\beta$-N-óxido (6), componentes da fração A.

Figura 28. Espectro original de $\mathrm{RMN}$ de ${ }^{13} \mathrm{C}\left\{{ }^{1} \mathrm{H}\right\}(75 \mathrm{MHz})$ do composto 7 em Metanol- $\mathrm{d}_{4}$.

Figura 29. Espectro de RMN de ${ }^{13} \mathrm{C}\left\{{ }^{1} \mathrm{H}\right\}$ do composto 7 tratado pelo método de seccionamento e limpeza de sinal.

Figura 30. Estrutura do composto 7. 
Figura 32. Degraus ou "gaps" observados nas secções selecionadas espectro de RMN de ${ }^{13} \mathrm{C}\left\{{ }^{1} \mathrm{H}\right\}$ do composto 8 em DMSO-d6 em função do número de varreduras.

Figura 33. Aumento da relação S/R das secções 1 e 2 do espectro de $\mathrm{RMN}$ de ${ }^{13} \mathrm{C}\left\{{ }^{1} \mathrm{H}\right\}$ do composto 8 com o tratamento com SVD.

Figura 34. Estruturas do composto 8.

Figura 35. Espectro de RMN de ${ }^{13} \mathrm{C}\left\{{ }^{1} \mathrm{H}\right\}$ (125 MHz) original do composto 9 em DMSO-d 6 adquirido com 12888 varreduras.

Figura 36. Evolução dos degraus em função de varreduras, observados nas secção selecionada do espectro de RMN de ${ }^{13} \mathrm{C}\left\{{ }^{1} \mathrm{H}\right\}$ do composto 9 em DMSO-d 6 .

Figura 37. Evolução dos "gaps" em função dos transientes, observados nas secções selecionadas do espectro de RMN de ${ }^{13} \mathrm{C}\left\{{ }^{1} \mathrm{H}\right\}$ do composto 9 em DMSO-d 6 .

Figura 38. Estruturas do composto 9.

Figura 39. Estruturas possíveis do cromóforo eno-diino-eno.

Figura 40. Estrutura do composto 10.

Figura 41. Mapa de contorno do G-BIRD ${ }_{R-X} C P M G-H S Q M B C$ para o composto 10.

Figura 42. Ampliações de secções do espectro 1D gerado a partir das correlações para o carbono em 79,8 ppm observadas no mapa de contorno do experimento G-BIRD ${ }_{\mathrm{R}-\mathrm{X}} \mathrm{CPMG}-\mathrm{HSQMBC}$ para o composto 10.

Figura 43. Ampliações de secções do espectro 1D gerado a partir das correlações para o carbono em 81,3 ppm observadas no mapa de contorno do experimento G-BIRD ${ }_{\mathrm{R}-\mathrm{X}} \mathrm{CPMG}-\mathrm{HSQMBC}$ para o composto 10.

Figura 44. Estrutura do composto 11.

Figura 45. Esqueleto básico dos flavonóides (A), chalconas (B) e auronas (C)

Figura 46. Acetileno típico de Bidens

Figura 47. Ocorrência de metabólitos no gênero Bidens ${ }^{[163]}$

Figura 48. Aspectos morfológicos da Bidens gardneri Bak. ${ }^{[163]}$

Figura 49. Substâncias majoritárias da fração volátil das partes aéreas de Bidens gardneri Bak. [163]

Figura 50. Componentes majoritários da fração hexânica do extrato etanólico das partes aéreas de $B$. gardneri Bak. ${ }^{[163]}$

Figura 51. Substâncias isoladas a partir de Bidens gardneri Bak. ${ }^{[163]} \quad 198$

Figura 52. Bidens sulphurea (Cav.) Sch. Bip. ${ }^{[163]}$

Figura 53. Substâncias majoritárias da fração hexânica do extrato etanólico das partes aéreas de Bidens sulphurea (Cav.) Sch. Bip. ${ }^{[163]}$.

Figura 54. Componentes majoritários da fração hexânica do extrato etanólico das partes aéreas de $B$. gardneri Bak. ${ }^{[163]}$.

Figura 55. Substâncias isoladas a partir da fração hexânica do extrato etanólico das flores de Bidens sulphurea (Cav.) Sch. Bip. ${ }^{[163]}$.

Figura 56. Estrutura do caempferol, do caempferol glicosilado, da isorramnetina e da duguetina ${ }^{[210,211,212]}$. 203

Figura 57. Tipos de alcalóides obtidos de espécies do gênero Duguetia ${ }^{[210,211,212]}$. 203

Figura 58. Metabólitos isolados de espécies de Duguetia ${ }^{[210,211,212,213,214,215,216,217,218,219,220,221]}$ [222] 204

Figura 59. Partes aéreas de Duguetia furfuracea St. Hil 205

Figura 60. Substâncias obtidas de espécimes da espécie Duguetia furfuracea (A. St.-Hil.) Benth. \& Hook f. $[164,178,210,211,212,213,214,215,216,217,219,220,221,222]$ 


\section{LISTA DE TABELAS}

Tabela 1. História do uso de produtos naturais na Medicina ${ }^{[5]}$.

Tabela 2. Origem dos 277 fármacos classificados como essenciais pela Organização Mundial da Saúde $(\mathrm{OMS})^{[10]}$.

Tabela 3. Sequências de pulsos usadas em experimentos DOSY e os recursos usados para aumentar da qualidade do espectro DOSY. ${ }^{[68,126,134,135,136]}$.

Tabela 4. Efeito da orientação dos substituintes eletronegativos sobre o valor da constante de acoplamento heteronuclear a duas ligações $\left({ }^{2} J_{\mathrm{CH}}\right){ }^{[156]}$.

Tabela 5. Padrões de acoplamento heteronuclear a duas ligações $\left({ }^{2} \mathrm{~J}_{\mathrm{CH}}\right)$ e efeito de substituintes ${ }^{[43,156]}$

Tabela 6. Padrões de acoplamento heteronuclear a três ligações $\left({ }^{3} J_{\mathrm{CH}}\right)$ análogos a acoplamentos homonuclear ${ }^{1} \mathrm{H},{ }^{1} \mathrm{H}^{[43,156]}$.

Tabela 7. Padrões de acoplamento heteronuclear a três ligações $\left({ }^{3} \mathbf{J}_{\mathrm{CH}}\right)$ sem analogia com acoplamentos homonuclear $\mathrm{H}, \mathrm{H}^{[43,156]}$

Tabela 8. Parâmetros de aquisição dos espectros de DOSY-1D da Fração BSAcOEt realizados para ajuste do valor de tempo de aplicação do pulso de gradiente de campo $(\delta)$

Tabela 9. Dados espectroscópicos dos compostos 1 a 4.

Tabela 10. Dados de RMN de ${ }^{1} \mathrm{H}(500 \mathrm{MHz})$ e ${ }^{13} \mathrm{C}\left\{{ }^{1} \mathrm{H}\right\}(125 \mathrm{MHz})$ de 5 e 6 em CDCl3

Tabela 11. Dados de RMN de ${ }^{1} \mathrm{H}(300 \mathrm{MHz})$ e ${ }^{13} \mathrm{C}\{1 \mathrm{H}\}(75 \mathrm{MHz})$ do composto 7 em Metanol-d4, incluindo dados de padrão de acoplamento (p.a.) e J obtidos do experimento J-resolved, multiplicidade de $\mathrm{C}$ (multi.) obtida do experimento DEPT $135^{\circ}$ e dados da literatura de RMN de ${ }^{1} \mathrm{H}(400 \mathrm{MHz})$ e ${ }^{13} \mathrm{C}\left\{{ }^{1} \mathrm{H}\right\}(100 \mathrm{MHz})$ em DMSO-d6 ${ }^{[179]}$.

Tabela 12. Dados de $R M N$ de ${ }^{1} \mathrm{H}(500 \mathrm{MHz})$ e ${ }^{13} \mathrm{C}\left\{{ }^{1} \mathrm{H}\right\}(125 \mathrm{MHz})$ do compostos 8 em DMSO-d $\mathrm{d}_{6}$.

Tabela 13. Dados de RMN de ${ }^{1} \mathrm{H}(500 \mathrm{MHz}) \mathrm{e}^{13} \mathrm{C}\left\{{ }^{1} \mathrm{H}\right\}(125 \mathrm{MHz})$ do composto 9 em DMSO-d 6

Tabela 14. Dados de RMN de ${ }^{1} \mathrm{H}(300 \mathrm{MHz})$ e ${ }^{13 \mathrm{C}}\left\{{ }^{1} \mathrm{H}\right\}(75 \mathrm{MHz})$ do composto 10 em Metanol-d4, incluindo dados de padrão de acoplamento (p.a.) e J obtidos do experimento J-resolved, COSY e/ou TOCSY, multiplicidade de C (multi.) obtida do experimento DEPT 135 ${ }^{\circ}$, HSQC, HMBC e/ou G-BIRD ${ }_{\mathrm{R}-\mathrm{X}} \mathrm{CPMG}-\mathrm{HSQMBC}$ e dados da literatura de RMN de ${ }^{1} \mathrm{H}$ do composto 7 (400 $\mathrm{MHz}) \mathrm{e}^{13} \mathrm{C}\left\{{ }^{1} \mathrm{H}\right\}(100 \mathrm{MHz})$ em DMSO-d ${ }_{6}{ }^{[179]}$.

Tabela 15. Dados de RMN de ${ }^{l} \mathrm{H}(300 \mathrm{MHz})$ e ${ }^{13} \mathrm{C}\{l \mathrm{H}\}$ (75 MHz) do composto 11 em Metanol-d4, incluindo dados de padrão de acoplamento (p.a.) e J obtidos dos experimento J-resolved, COSY e/ou TOCSY, multiplicidade de C (multi.) obtida do experimentos DEPT $135^{\circ}$, HMQC e ou HMBC e a comparação com dados para o composto $\mathbf{1 0}$. 


\subsection{Importância da Química de Produtos Naturais (QPN)}

Os produtos naturais têm servido como fonte de fármacos desde a antiguidade e, atualmente, cerca de metade dos medicamentos existentes é derivada de fontes naturais. A quimiodiversidade da natureza, ou seja, variedade de plantas, microorganismos e organismos marinhos, etc., ainda oferece uma fonte valiosa para a descoberta de novos fármacos ${ }^{[1,2,3,4]}$. Tabela 1. História do uso de produtos naturais na Medicina ${ }^{[5]}$.

\begin{tabular}{|c|c|}
\hline PERÍODO & DESCRIÇÃO \\
\hline Antes de 3000 a. C. & $\begin{array}{l}\text { Medicina aiuvédica (conhecimento da vida) e Medicina tradicional chinesa: } \\
\text { Introduziu propriedades medicinais de plantas e outros produtos naturais }\end{array}$ \\
\hline 1500 a. C. & $\begin{array}{l}\text { Ebers Papyrus: } \\
\text { Apresentou um grande número de fármacos de fontes naturais (exemplo, goma arábica) }\end{array}$ \\
\hline 460-377 a. C. & $\begin{array}{l}\text { Hiprócrates ("pai da medicina"): } \\
\text { Descreveu várias plantas e animais que poderiam ser fontes de medicamentos }\end{array}$ \\
\hline 370-287 a. C. & $\begin{array}{l}\text { Teofrato (médico grego): } \\
\text { Descreveu várias plantas e animais que poderiam ser fontes de medicamentos }\end{array}$ \\
\hline 23-79 d. C. & $\begin{array}{l}\text { Pliny The Elder: } \\
\text { Descreveu várias plantas e animais que poderiam ser fontes de medicamentos }\end{array}$ \\
\hline 60-80 d. C. & $\begin{array}{l}\text { Pedáneo Dioscórides: } \\
\text { Escreveu De Materia Medica que descrevia mais de } 600 \text { plantas medicinais }\end{array}$ \\
\hline 131-200 d. C. & $\begin{array}{l}\text { Galeno: } \\
\text { Medicina botânica (Galênica) e a difundiu no ocidente }\end{array}$ \\
\hline Século XV d. C. & $\begin{array}{l}\text { Kraüterbuch (Herbais): } \\
\text { Apresentou informação e pinturas de plantas medicinais }\end{array}$ \\
\hline
\end{tabular}

A importância da Química de Produtos Naturais (QPN) no descobrimento de novos fármacos é incontestável, estima-se que $40 \%$ dos novos fármacos aprovados nos últimos vinte anos sejam provenientes de produtos naturais. Uma análise da origem dos medicamentos desenvolvidos entre 1981 e 2002 mostrou que 28\% das novas entidades químicas lançadas no mercado eram produtos naturais ou derivados destes. Outros $24 \%$ dessas novas entidades químicas eram resultante de sínteses de produtos naturais ou análogos sintetizados com base em estudos de farmacóforos relacionados aos produtos naturais ${ }^{[6]}$. A combinação destas porcentagens (52\% das novas entidades) sugere que os produtos naturais são importantes fontes de novos fármacos e também alvos adequados para futuras modificações durante o desenvolvimento de fármacos.

A utilização de produtos naturais na busca por novos fármacos é proveniente de sua riqueza estrutural e da complexidade de seus esqueletos carbônicos. Além disso, como os 
produtos naturais são metabólitos naturais de seres vivos, podem ser mais amigáveis aos sistemas biológicos do que moléculas sintéticas ${ }^{[7,8]}$.

A importância dos produtos naturais também é evidenciada na relação de fármacos essenciais da Organização Mundial de Saúde (OMS), como pode ser verificado na Tabela 1, dos duzentos e setenta e sete fármacos classificados como essenciais: 33,2\% são de origem natural (animal, vegetal, mineral, microbiana), sem contar alguns dos fármacos semisintéticos obtidos por modificações de produtos naturais. Grande parte das vacinas e soros considerados essenciais também é de origem natural ${ }^{[9]}$.

Tabela 2. Origem dos 277 fármacos classificados como essenciais pela Organização Mundial da Saúde (OMS) ${ }^{[10]}$.

\begin{tabular}{lc}
\hline FÁRMACOS OBTIDOS POR: & PORCENTAGEM (\%) \\
\hline Síntese & 51,6 \\
Fontes vegetais & 10,1 \\
Semi-síntese & 7,2 \\
Fontes minerais & 8,1 \\
Fontes animais & 7,9 \\
Cultivo de microorganismos & 7,2 \\
Vacinas e soros & 7,9 \\
\hline
\end{tabular}

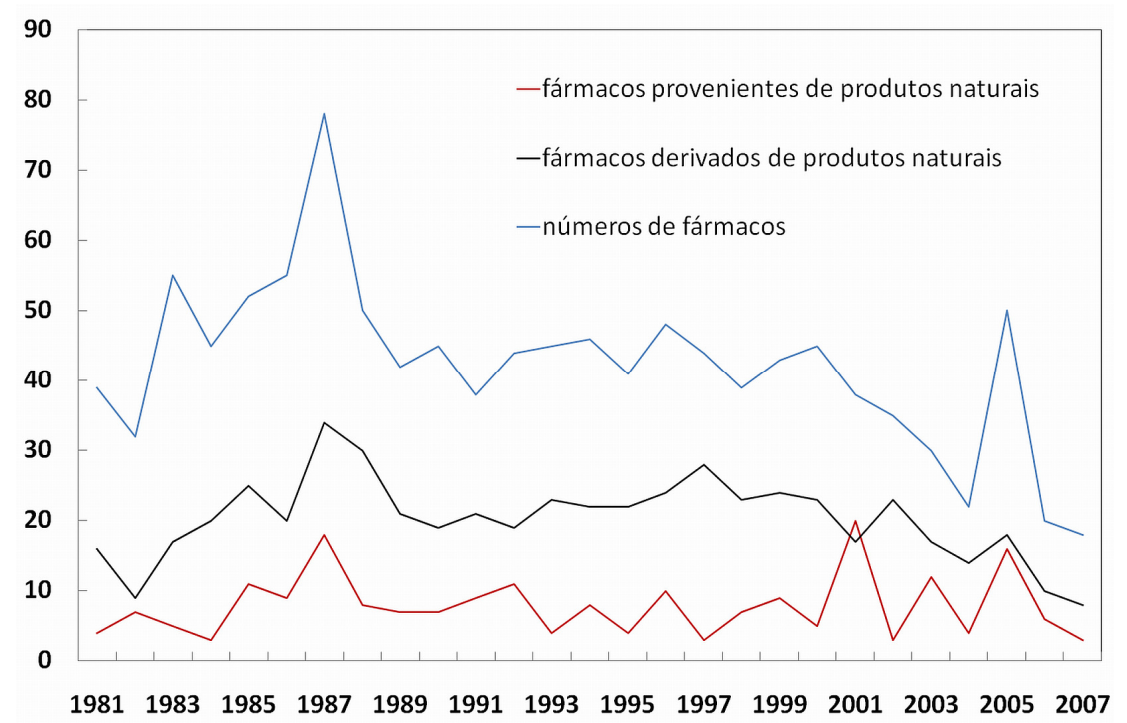

Figura 1. Fármacos aprovados pelo FDA (U.S. Food and Drug Administration) no período de 1981 a $2007^{[9,10]}$.

No período de 1981-2006 houve um grande desenvolvimento de novos fármacos, no qual os produtos naturais desempenharam um papel fundamental, principalmente nas áreas relacionadas ao tratamento de câncer e doenças infecciosas, representando aproximadamente 
$63 \%$ e $70 \%$ de origem natural, respectivamente ${ }^{[9,11]}$. No período de $2005-2007$, foram aprovados treze fármacos de origem natural e derivados, sendo dois de origem de organismos marinhos. Até março de 2008, 37 candidatos que estavam em fase de desenvolvimento (6 em fase de registro e 31 na fase III), eram de origem natural ${ }^{[6,12]}$.

Os fármacos recentemente aprovados e em desenvolvimento incluem compostos oriundos de plantas, bactérias, fungos e animais. Entre as drogas obtidas a partir de plantas e bactérias há predominância de indicações terapêuticas como anticâncer, anti-infecciosa e antidiabética $^{[13]}$. Muitas substâncias naturais são consideradas como protótipos, alvos ou são bases para as modificações estruturais na busca de drogas com melhor atividade farmacológica e possibilidades terapêuticas ${ }^{[2,14]}$.

Dessa forma, muitos fármacos foram descobertos e ainda são utilizados na terapêutica atual, como a morfina isolada de Papaver somniferum, a artemisinina, um poderoso agente antimalárico, isolada de Artemisia annua e agentes anticancerígenos como a vimblastina, vincristina, taxol e a camptotecina ${ }^{[14]}$ (Figura 2).

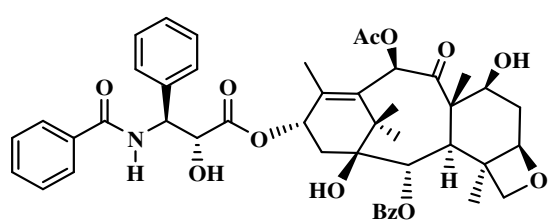

Taxol

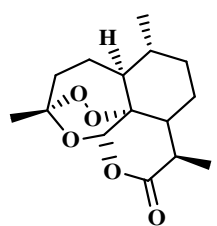

Artemisinina

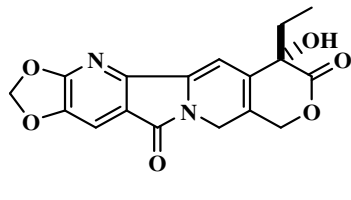

Camptotecina<smiles>COc1ccc([C@@H]2c3cc4c(cc3[C@@H](O)[C@@H]3COC(=O)[C@H]32)OCO4)cc1OC</smiles>

Podofilotoxina

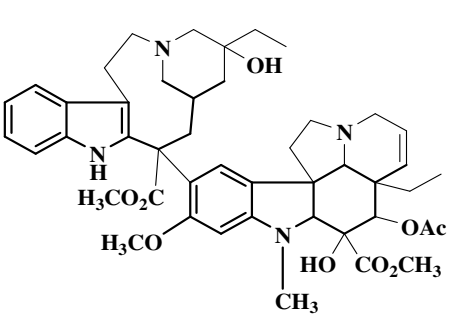

Vimblastina

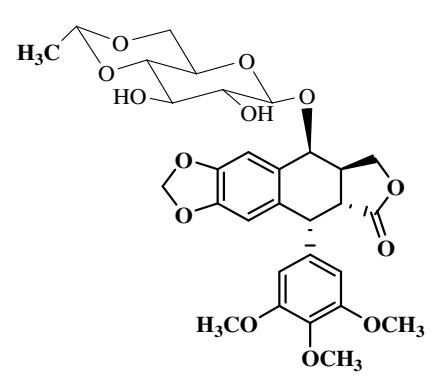

Etoposídeo

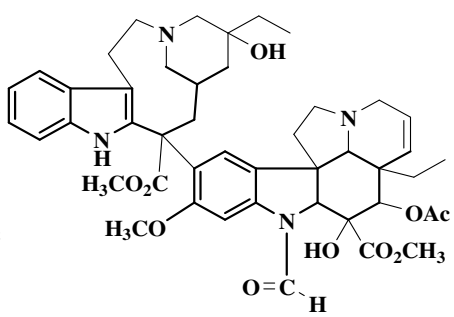

Vincristina

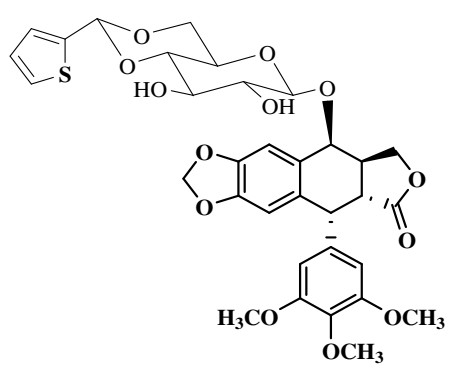

Teniposídeo

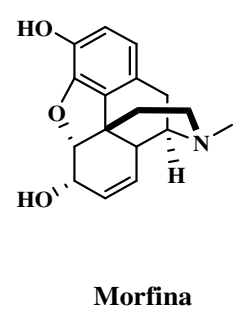

Morfina

Figura 2. Exemplos de alguns produtos naturais de grande relevância ${ }^{[14,15]}$. 
Além destas, a podofilotoxina, uma ciclolignana com propriedades antivirais e antitumorais, foi modificada quimicamente para originar as drogas etoposídeo e teniposídeo (Figura 2) ${ }^{[15]}$.

Os exemplos citados estimulam e justificam a busca por produtos naturais, já que estes mostram uma grande diversidade estrutural, complexidade e muitas vezes propriedades farmacológicas eminentes, além do fato da enorme biodiversidade existente e ainda inexplorada (plantas, oceanos e microorganismos) ${ }^{[1,16]}$.

Adicionalmente, há um crescente interesse no desenvolvimento de produtos contendo misturas de compostos naturais, como os obtidos a partir da medicina popular e extratos com composições químicas definidas ${ }^{[13]}$.

Segundo Singh e Levine ${ }^{[17]}$, dados de pesquisa realizada em 2004 nos Estados Unidos da América (EUA) revelaram que 12 a $14 \%$ da população norte-americana usam medicamentos de origem em produtos naturais. Ainda, segundo Singh e Levine, 9,6\% dos canadenses usam pelo menos um medicamento de origem natural.

No Brasil, a QPN tem sua importância ainda mais destacada. Segundo estimativas da Convenção da Diversidade Biológica (CDB) ${ }^{[18]}$, o Brasil hospeda entre 15 e $20 \%$ de toda a biodiversidade mundial, sendo considerado o maior do planeta em número de espécies endêmicas e detem a maior floresta equatorial e tropical úmida do planeta.

Dados estatísticos indicam ainda que existem 55 mil espécies de plantas, 517 de anfíbios (294 endêmicas), 1.622 de aves (192 endêmicas), 524 de mamíferos (cerca de 130 endêmicas), 468 de répteis (172 endêmicas), 3.000 espécies de peixes de água doce e cerca de 15 milhões de insetos, muitos completamente desconhecidos ${ }^{[18]}$. Por tudo isto, o Brasil não pode abdicar de sua vocação para os produtos naturais. Neste contexto, a área de QPN é, dentro da Química brasileira, a mais antiga e a que, talvez ainda hoje, congregue o maior número de pesquisadores.

Desde antes do descobrimento do Brasil a QPN já era praticada pelos indígenas através da utilização de corantes e remédios obtidos de árvores e ervas ${ }^{[19]}$. Durante o período colonial, os médicos portugueses que aqui vieram foram obrigados a utilizar tais remédios, pois os medicamentos mais tradicionais eram escassos. Além disto, os portugueses, por motivos econômicos, também buscavam no Brasil as especiarias do sertão, como, canela, 
baunilha, cravo, anil, raízes aromáticas, urucum, puxurí, salsa, sementes oleaginosas, madeiras etc..

Os produtos naturais não são apenas fontes de fármacos, eles desempenham uma multiplicidade de papéis no ambiente, como a fertilidade do solo, o destino de poluentes e de transportes, incluindo biodisponibilidade, ciclo de nutrientes, especiação de metais, e ciclos de carbono e nitrogênio ${ }^{[20]}$.

Neste sentido, os produtos naturais representam uma parte importante da cultura científica e tem um enorme impacto sobre a química, a biologia e a medicina ${ }^{[21,22]}$. Contudo, devido à sua natureza complexa, os produtos naturais são verdadeiros desafios para os químicos analíticos.

\subsection{Elucidação de Produtos Naturais (PN)}

Até a metade do século XX a elucidação estrutural de produtos naturais dependia quase que exclusivamente do poder da síntese orgânica ou, mais especificamente, das formas de degradação ou, até mesmo de reações de derivatização para testar hipóteses estruturais das substâncias em estudo. Para tanto era necessária disponibilidade de grandes quantidades das substâncias estudadas. Assim, elucidar as estruturas era uma tarefa que consumia anos de esforços e, na maioria dos casos, o estabelecimento da configuração absoluta ou relativa estava fora de questão ${ }^{[23]}$.

A arte de elucidar estruturas era muito tediosa e com muitas limitações e muitas das propostas desta época foram posteriormente consideradas equivocadas. Como exemplo clássico disto é a estrutura proposta por Wieland e Windaus para o colesterol em 1927 que foi corrigida em 1932 após a obtenção da elucidação estrutural do ergosterol por Bernal a partir da análise por raio $\mathrm{X}$ de um cristal deste esteróide ${ }^{[24]}$.

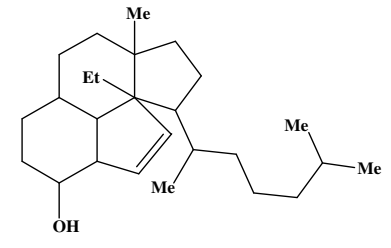

(a) Estrutura de colesterol segundo Wieland / Windaus (1927)

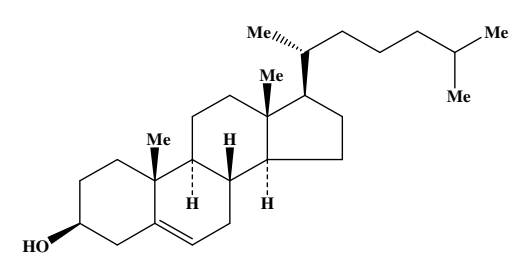

(b) Estrutura correta do colesterol (1932)

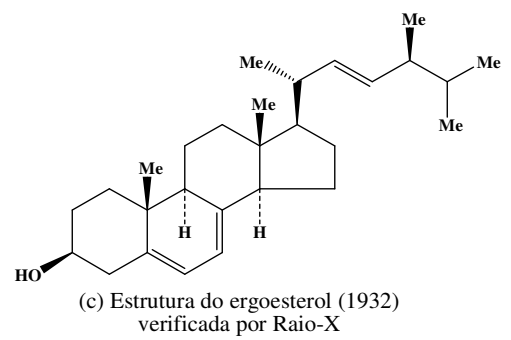
(c) Estrutura do ergoesterol (1932)
verificada por Raio-X

Figura 3. Estruturas do colesterol propostas em 1927 e 1932 e estrutura do ergosterol ${ }^{[23,24]}$. 
Os grandes desafios associados aos produtos naturais, tais como isolamento, purificação, elucidação estrutural, síntese ou estudos de mecanismos de ação têm estimulado o desenvolvimento de várias áreas ou técnicas como espectroscopia, cromatografia, entre outras, além de permitir um maior desenvolvimento de várias disciplinas ${ }^{[25]}$.

Principalmente, a partir do final da década de 60 do século XX a abordagem clássica do estudo de química de produtos naturais foi gradualmente substituída por medidas mais precisas: métodos espectroscópicos ou espectrométricos, cuja vantagem principal é o fato de necessitarem de quantidade menor das substâncias em estudo e/ou não serem destrutivos ${ }^{[23]}$.

\subsection{Métodos espectroscópicos e espectrométricos aplicados à elucidação estrutural de Produtos Naturais (PN)}

Métodos como espectroscopia de ressonância magnética nuclear (RMN), espectroscopia no ultravioleta (UV) e infravermelho (IV), espectrometria de dicroísmo circular $(\mathrm{CD})$ e de massa $(\mathrm{EM})$ têm crescido tanto em número quanto em precisão, possibilitando ao pesquisador caracterizar um produto natural desconhecido, em pouco tempo, tendo com apenas alguns miligramas de amostra.

Vale salientar que o desenvolvimento destes métodos ainda não eliminou por inteiro a necessidade da realização da síntese de produtos naturais para a confirmação de estruturas. A síntese desempenha agora um papel diferente no processo de elucidação estrutural, voltandose mais ao entendimento de mecanismos de reações e à maior disponibilização de produtos naturais para ensaios biológicos e farmacológicos, além de modificações estruturais para otimização das atividades biológicas e, consequentemente, à produção industrial de novos produtos ativos ${ }^{[26]}$.

Outro fator de desenvolvimento e crescente uso dos métodos espectroscópicos é a possibilidade da combinação destas técnicas com métodos de separação, aumentando a precisão e velocidade dos estudos da QPN ${ }^{[5]}$. Neste sentido, a comunidade científica tem investido muito no desenvolvimento de bioensaios que permitam monitorar um ou vários efeitos de um produto natural, ao mesmo tempo, que métodos analíticos têm sido refinados para se alcançar níveis mais elevado de resolução e sensibilidade.

Para obter informações estruturais que levem à identificação dos componentes de extratos brutos, a cromatografia líquida (CL), geralmente a cromatografia líquida de alta 
eficiência (CLAE), a cromatografia gasosa (CG) ou a eletroforese capilar (EC) são ligadas às técnicas espectroscópicas como infravermelho com transformada de Fourier (IV-TF), absorbância no UV-visível ou emissão de fluorescência com detector com arranjo de diodos (UV-DAD ou EF-DAD), espectrometria de massas (EM) e ressonância magnética nuclear (RMN), resultando em várias técnicas combinadas ("hifenadas", acopladas): EC-EM; CGEM; CLAE-EM; CLAE-RMN; CLAE-DAD-EM, CLAE-EM-EM, CLAE-RMN-EM, CLAEDAD-RMN-EM. Entre estas combinações a combinação da CLAE com EM e/ou RMN tem aumentado a capacidade de resolver problemas estruturais de produtos naturais complexos. Como a sensibilidade da técnica CLAE-EM é maior e seu custo é menor, ela é mais usada que a CLAE-RMN ${ }^{[27,28,29,30]}$.

Cada uma das técnicas espectroscópicas ou espectrométricas fornece características estruturais específicas, por exemplo, os espectros de UV de produtos naturais proporcionam informação sobre o tipo de constituintes e, no caso de polifenóis, o padrão de oxidação ${ }^{[27]}$.

A espectrometria IV fornece informações sobre os grupos funcionais presentes (ligações carbono-carbono duplas ou triplas, funções nitrogenadas como amina, amida, nitrila, etc., ou oxigenadas, como álcool, cetonas, ácido carboxílico, aldeídos e a presença de enxofre, halogênios, entre outros). Já a espectrometria de massas fornece informações sobre o peso molecular e estruturas dos analitos ${ }^{[31]}$. E a espectroscopia de RMN é a técnica espectroscópica mais poderosa para a obtenção de informações estruturais detalhadas sobre compostos orgânicos em solução e no estado sólido, incluindo informações sobre a disposição dos grupos funcionais na molécula, a estereoquímica, etc.. Entretanto, o potencial de cada técnica, medido pelo número de informações úteis fornecidas, depende também do grau de dificuldade de extrair e interpretar as informações e varia de problema a problema.

Apesar do alto potencial da técnica de RMN, ela apresenta uma baixa sensibilidade que tem sido compensada com os recentes progressos em gradientes de campo pulsado (PFG) supressão de solvente, tecnologia de construção de sondas e magnetos com campo alto $[32,33,34]$

Em termos de sensibilidade, vale ressaltar que a comparação entre as técnicas depende não só do fenômeno observado e medido, como também das particularidades das amostras e equipamentos (disponibilidade e facilidade de manuseio), número de informações estruturais fornecidas e grau de facilidade de interpretar estas informações. 
Em geral a sensibilidade de um método ou instrumento é a sua capacidade de discriminar entre pequenas diferenças de concentração de um analito ${ }^{[35]}$. Em espectroscopia muitas vezes a sensibilidade é considerada como sendo o limite de detecção de um cromóforo que pode corresponder a um grupo funcional ou a um único átomo ou grupo de átomos não relacionado com uma funcionalidade química. A detecção de um cromóforo permite deduzir a presença de um fragmento ou elemento estrutural na molécula.

Alguns métodos como, por exemplo, a $\mathrm{RMN}-{ }^{1} \mathrm{H}$, detectam todos os cromóforos acessíveis de uma molécula com igual sensibilidade. Outros como UV e $\mathrm{RMN}-{ }^{13} \mathrm{C}$ apresentam diferenças de sensibilidade de acordo com o cromóforo ou grupo de átomos.

Assim uma maneira simples de comparar a sensibilidade entre as quatro principais técnicas espectroscópicas utilizadas em QPN seria em termos da quantidade de amostra necessária para a análise, desta forma a ordem decrescente de sensibilidade seria: EM $>U V \geq$ IR $>\mathrm{RMN}-{ }^{1} \mathrm{H}>\mathrm{RMN}-{ }^{13} \mathrm{C}$. Entretanto, as considerações da sensibilidade relativa aos cromóforos poderiam ser importantes.

Outro ponto a ser levado em conta é o custo da instrumentação e manutenção de cada técnica. Os instrumentos e acessórios para EM e RMN custam bem mais do que os espectrômetros de UV e IV. Quanto mais caro é o instrumento, mais cara é a sua manutenção.

Quanto ao grau de facilidade operacional de cada técnica, os espectrômetros de UV e IV são mais acessíveis. E, finalmente, quanto ao grau de conhecimento teórico que o operador e/ou usuário da técnica necessita ter para melhor manusear o equipamento e interpretar resultados, a ordem seria $\mathrm{RMN}>\mathrm{EM}>\mathrm{UV} \approx \mathrm{IV}$.

A Figura 4 mostra as frequências e comprimentos de ondas envolvidos em cada técnica espectroscópica. Mostra também a distribuição de Bolztman à temperatura ambiente em cada técnica. Pode-se observar que na espectroscopia de RMN ocorre a menor diferença populacional entre os níveis de energia envolvidos. Isto significa que o número de spins no estado excitado é bem próximo ao número de spins no estado fundamental. Logo, pode-se dizer que a RMN é menos sensível que as demais técnicas espectroscópicas, entretanto, desenvolvimentos recentes, como o uso de criossondas e a utilização de campos magnéticos cada vez mais elevados tornam a sensibilidade, principalmente nos casos de núcleos mais sensíveis como hidrogênio, fósforo e flúor, comparáveis com as demais técnicas. 

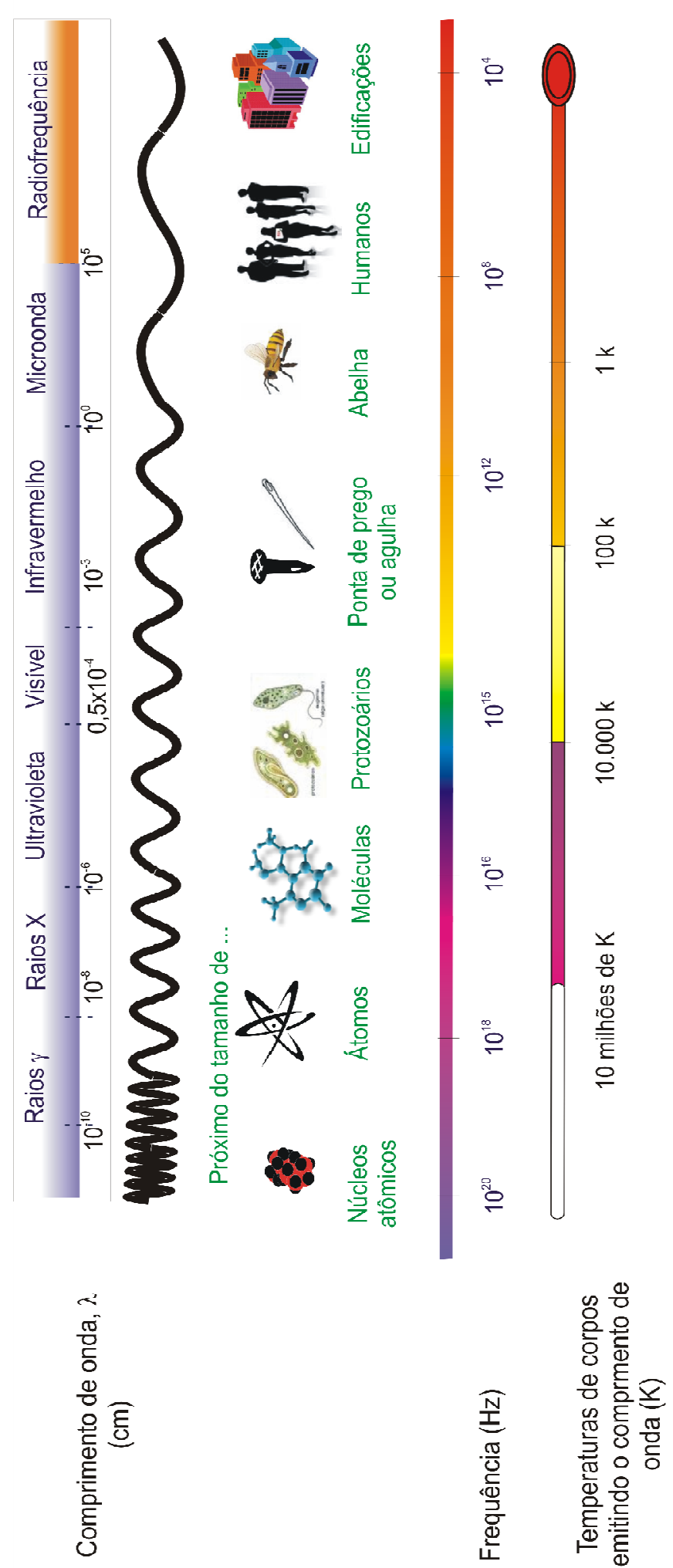

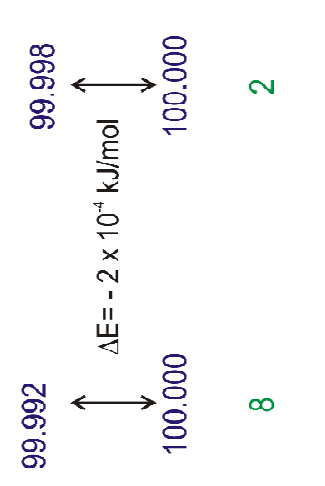

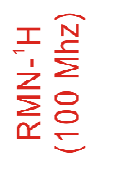

竞

믐 $\frac{\mathscr{L}}{\frac{1}{5}}$

迹

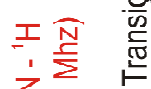

这员

荧

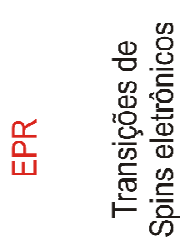

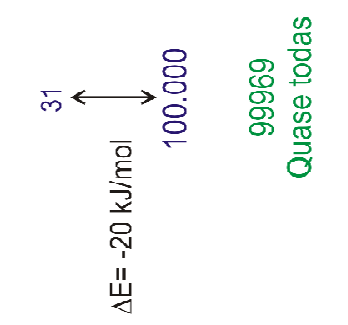

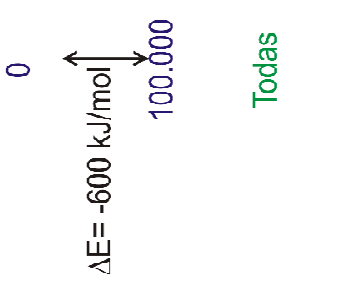

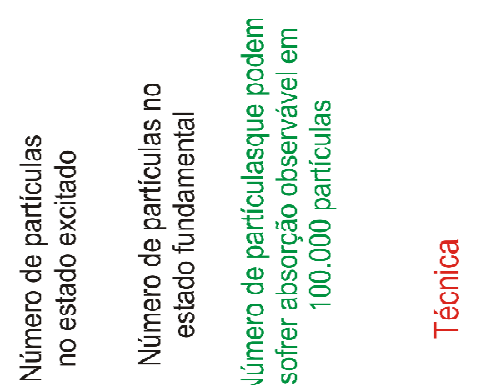

Figura 4. Espectro eletromagnético ${ }^{[32,34,36,37,38,39]}$. 


\subsection{Espectroscopia de ressonância magnética nuclear (RMN)}

A espectroscopia de ressonância magnética nuclear é uma técnica que permite determinar propriedades de uma substância através da medida da interação de um campo eletromagnético (radiofrequência) com uma coleção de núcleos na presença de um campo magnético forte ${ }^{[40,41]}$.

A energia da absorvida está na faixa de megahertz $(\mathrm{MHz})$ do espectro eletromagnético e está relacionada às transições entre níveis de energia rotacionais (spin) dos núcleos componentes das espécies (átomos ou íons) contidas na amostra. Isso se dá necessariamente sob a influência de um campo magnético e sob a concomitante irradiação de ondas de rádio na faixa de frequências acima citada ${ }^{[33,42,43]}$.

O conceito de spin surgiu da necessidade de se explicar os resultados inesperados da experiência de Stern-Gerlach em $1927^{[44]}$. Nessa experiência, um feixe colimado de átomos de prata, oriundos de um forno a alta temperatura, atravessavam um campo magnético altamente não-homogêneo. Tal experimento era destinado a medir a distribuição dos momentos magnéticos, devidos principalmente aos elétrons.

Como os átomos saiam do forno no seu estado fundamental $1 s^{0}$, não deveriam sofrer desvios na presença do campo magnético não-homogêneo. Logo, a distribuição esperada era a da perda da coerência espacial do feixe durante o seu tempo de vôo, do forno de origem até o alvo, o que não aconteceu.

O resultado obtido foram duas manchas de depósito de prata sobre o alvo, indicando que o feixe se dividira em dois durante o percurso. Isso indicou que os átomos de prata do feixe ainda tinham um grau de liberdade de momento angular, mas que não era o momento angular orbital dos elétrons no átomo, mas sim um momento angular intrínseco destas partículas ${ }^{[44]}$. A esse "momento angular intrínseco" deu-se o nome de "spin".

Em 1924, Wolfgang Pauli havia postulado que os núcleos se comportariam como minúsculos ímãs. Posteriormente, em 1939, Rabi e colaboradores submeteram um feixe molecular de hidrogênio $\left(\mathrm{H}_{2}\right)$, em alto vácuo, a um campo magnético não-homogêneo em conjunto com uma radiação na faixa de radiofrequência $(r f)$. Para certo valor de frequência o feixe absorvia energia e sofria um pequeno desvio. Isso era constatado como uma queda da intensidade observada do feixe na região do detector. Este experimento marca, historicamente, a primeira observação do efeito da ressonância magnética nuclear. 
Em meados da década de 1940 duas equipes, uma de Bloch ${ }^{[45]}$ e seus colaboradores na Universidade de Stanford, e outra de Purcell ${ }^{[46,47]}$ e colaboradores na Universidade de Harvard, procurando aprimorar a medida de momentos magnéticos nucleares, observaram sinais de absorção de radiofrequência dos núcleos de ${ }^{1} \mathrm{H}$ na água e na parafina, respectivamente. Tal observação conferiu aos dois pesquisadores o prêmio Nobel de Física em $1952^{[48]}$.

Quando Packard e outros assistentes de Bloch substituíram a água por etanol, em 1950 e 1951, e notaram que havia três sinais e não somente um sinal ${ }^{[49]}$, ficaram decepcionados. Entretanto, esse aparente fracasso indicou alguns dos aspectos mais poderosos da técnica: o deslocamento químico, ou seja, a múltipla capacidade de identificar a estrutura pela análise de parâmetros originados de acoplamentos mútuos de grupos de núcleos interagentes.

Pouco tempo depois, em 1953, já eram produzidos os primeiros espectrômetros de RMN no mercado, já com uma elevada resolução e grande sensibilidade ${ }^{[41]}$.

Nestas seis décadas desde a inovação proposta por Bloch e Purcell, a RMN desenvolveu-se de forma espantosa, sendo útil não só na física e química, mas também na medicina, biologia, agricultura e, mais recentemente, na chamada computação quântica. Devido a essas contribuições, vários pesquisadores receberam outros prêmios Nobel: os suíços Richard Ernst (Química, 1991) e Kurt Wüthrich (Química, 2002), bem como o inglês Peter Mansfield e o norte-americano Paul Lauterbur (Medicina, 2003) ${ }^{[48]}$.

Cabe destacar que a RMN é um fenômeno físico baseado na propriedade dos núcleos de produzirem campos magnéticos relacionados com seus momentos angulares e sua carga ${ }^{[32,34,36,37,39,40,42,50]}$. O momento angular do núcleo é descrito em termos do número de spin I que pode assumir valores $0,1 / 2,1,3 / 2$, etc.

Os núcleos de maior interesse à análise química por RMN são os que possuem número de spin I igual a $1 / 2$, com distribuição de carga esférica e uniforme: ${ }_{1}^{1} \mathrm{H},{ }_{1}^{3} \mathrm{H},{ }_{6}^{13} \mathrm{C},{ }_{7}^{15} \mathrm{~N},{ }_{9}^{19} \mathrm{~F},{ }_{15}^{31} \mathrm{P}$, porém a técnica pode ser aplicada a núcleos de spin igual a $1\left(\right.$ ex.: $\left.{ }_{1}^{2} \mathrm{H},{ }_{3}^{6} \mathrm{Li}\right)$, ou igual a $5 / 2$ (ex.: ${ }_{13}^{27} \mathrm{Al},{ }_{8}^{16} \mathrm{O}$ ), etc.. Deste modo, a espectroscopia de RMN pode fornecer detalhes de informações estruturais, químicas e eletrônicas de praticamente qualquer molécula (orgânica ou inorgânica) ${ }^{[51]}$. Isto aliado ao fato de não ser um método destrutivo fez com que esta técnica tornasse um instrumento fundamental da química analítica moderna. 
A interação entre os núcleos e o campo magnético externo não depende apenas do tipo de núcleo, mas, também, do ambiente químico em que se encontra tal núcleo. Os núcleos em uma molécula são blindados fracamente pelas nuvens eletrônicas que os cercam, cuja densidade varia com o ambiente químico, ou seja, a vizinhança deste núcleo interfere na frequência de transições do núcleo. Esta variação dá origem à absorção em posições diferentes no espectro de RMN. Assim, uma análise cuidadosa dos espectros obtidos pode fornecer informações precisas da dinâmica e estrutura molecular da amostra, bem como interações inter- e intramoleculares ${ }^{[52]}$

Desde a sua descoberta em 1946, a espectroscopia de RMN tem tido um rápido crescimento, fruto dos contínuos avanços da tecnologia e da utilidade deste método em Química ${ }^{[53]}$.

Como outras técnicas espectroscópicas, RMN depende das variações de energia quantificáveis que podem ser induzidas em pequenas moléculas quando estas são irradiadas por radiação eletromagnética. Os requisitos energéticos da $\mathrm{RMN}\left(10^{-6} \mathrm{~kJ} / \mathrm{mol}\right)$ são relativamente pequenos quando comparados com outras técnicas espectrofotométricas (a radiação de infravermelho situa-se nos $10^{-4} \mathrm{~kJ} / \mathrm{mol}$; e a ultravioleta no intervalo $160-1300$ $\mathrm{kJ} / \mathrm{mol})^{[54]}$.

A espectroscopia de RMN é uma das técnicas mais ricas em termos de fornecimento de informações estruturais de compostos orgânicos, como os produtos naturais. Entretanto, tal técnica é a menos sensível, o que torna seu tempo de análise maior do que o das demais técnicas. Isto somado ao alto custo do equipamento e acessórios de RMN faz com que seja imprescindível a busca de estratégias de aumento da sensibilidade e da eficiência da técnica e redução de tempo e custo de análise, com a finalidade de agilizar a elucidação estrutural, identificação e ou quantificação de produtos naturais.

A espectroscopia de RMN pode ser aplicada não só à identificação e elucidação estrutural de compostos químicos, mas também na quantificação de componentes da amostra, estudos de dinâmica de sistemas, incluindo equilíbrio químico, movimento molecular e interações intermoleculares (incluindo difusão, troca química, ligação de hidrogênio). É utilizada pela síntese orgânica e inorgânica, química de produtos naturais, bioquímica e físicoquímica, na determinação de estereoquímica, na análise conformacional e no acompanhamento do curso de uma reação química. 


\subsubsection{Espectroscopia ordenada por difusão (RMN DOSY 1D e 2D)}

\subsubsection{Definição do Fenômeno da Difusão Molecular}

A identificação de substâncias antes da separação dos constituintes de extratos vegetais aumenta a eficiência da Química de Produtos Naturais, especialmente quando alguns dos compostos são sensíveis aos métodos de purificação ou propensos a gerarem artefatos (produtos de degradação). Neste contexto, a Espectroscopia Ordenada por Difusão (DOSY) revelou-se uma ferramenta útil e muito poderosa ${ }^{[55,56,57,58,59,60,61,62,63,64,65]}$. Esta técnica baseiase na difusão molecular, que consiste no movimento aleatório de partículas (moléculas) em um gás ou líquido impulsionado pela energia térmica do sistema ${ }^{[66,67,68,69]}$

Pelo processo de difusão a matéria é transportada de uma parte do sistema para outra. A velocidade de migração de uma partícula é medida pelo seu fluxo $\vec{J}$, ou seja, pela quantidade de partículas que atravessa uma unidade de área por unidade de tempo.

A difusão molecular ocorre em direções aleatórias, produzindo um fluxo de matéria $(\vec{J})$ em todas as direções. No Sistema Internacional de Unidades o fluxo $\vec{J}$ é o número de moléculas que atravessa uma superfície de controle por metro quadrado por segundo ${ }^{[66]}$. Para o estudo da difusão molecular por RMN devem ser consideradas apenas as moléculas que se movem na direção $\mathrm{z}$, paralela ao campo magnético do espectrômetro, ou seja, o fluxo de matéria em z $\left(\vec{J}_{z}\right)$. Segundo a lei de Fick, o fluxo de matéria na direção z é proporcional ao número de moléculas que migram ao longo dessa direção ${ }^{[66,67,68,69]}$.

$\vec{J}_{z}=-\mathrm{D}(\mathrm{dN} / \mathrm{dz})$

A constante de proporcionalidade D na Equação 1 é o coeficiente de difusão molecular na direção escolhida e depende da temperatura, da viscosidade, bem como de qualquer interação intermolecular (soluto-solvente ou soluto-soluto).

O coeficiente $\mathbf{D}$ depende do peso molecular efetivo, do tamanho e da forma, fornecendo informações sobre a dinâmica molecular (interações moleculares, estado de agregação e mudanças conformacionais) ${ }^{[55,57,67,68,69,70,71,72,73,74,75,76,77,78]}$.

O valor de $\mathbf{D}$ é dado em $\mathrm{m}^{2} \cdot \mathrm{s}^{-1}$ e é característico de cada substância e pode ser usado para estimar o tamanho molecular em solução ${ }^{[55,68,69]}$. Este coeficiente pode ser calculado 
através da equação Stokes-Einstein, considerando uma molécula em formato esférico:

$\mathrm{D}=\mathrm{kT} / 6 \pi \eta \mathrm{R}_{\mathrm{H}}$

onde $\mathrm{k}\left(\mathrm{J} . \mathrm{K}^{-1}\right)$ é a constante Boltzmann, T é a temperatura $(\mathrm{K}), \eta(\mathrm{P})$ é a viscosidade do solvente, e $\mathrm{R}_{\mathrm{H}}(\mathrm{m})$ é o raio hidrodinâmico ${ }^{[68,69]}$.

Neste caso, a distância média percorrida pelas moléculas será $\mathrm{z}=\sqrt{2 D t}$ e a probabilidade de uma molécula percorrer uma distância $d z$ após o tempo $t$ pode ser representada pela seguinte equação:

$\mathrm{P}(\mathrm{z}, \mathrm{t})=(4 \pi \mathrm{Dt})^{-1 / 2} \exp \left[-\left(\mathrm{z}^{2} / 4 \mathrm{Dt}\right)\right]$

Valores típicos de coeficientes de difusão em líquidos, a temperaturas moderadas $\left(25-30{ }^{\circ} \mathrm{C}\right)$ variam de $10^{-12} \mathrm{~m}^{2} \mathrm{~s}^{-1}$ (para polímeros de alta massa molar em solução) até $10^{-9} \mathrm{~m}^{2} \mathrm{~s}^{-1}$ (para moléculas pequenas em soluções pouco viscosas ${ }^{[79]}$.

Se uma molécula em solução for considerada como uma partícula esférica, seu raio hidrodinâmico sofrerá influências de fatores como solvatação, interações inter e intramoleculares, estado de agregação. Logo o valor de seu coeficiente de difusão $(D)$ fornecerá informações sobre propriedades relacionadas a seu volume molecular ${ }^{[60,78,80,81,82,83]}$.

\subsubsection{Medidas de Difusão Molecular}

Entre várias técnicas de medida do coeficiente de difusão em líquidos destacam-se: espalhamento de luz; cela de diafragma; interferômetro de Gouy; análise por injeção de fluxo (FIA); dispersão de Taylor-Aris e Ressonância Magnética Nuclear (RMN). Esta última tem se mostrado uma ferramenta útil e poderosa para a análise de misturas complexas, sobretudo por não requerer uma separação prévia.

Neste sentido, a técnica de RMN DOSY ("Diffusion Ordenated Spectroscopy") ou espectroscopia ordenada por difusão destaca-se por ser capaz de fornecer informações facilmente analisáveis e possibilitar uma visão global dos tamanhos de partículas em uma amostra e a detecção de impurezas ${ }^{[80,84,85]}$.

Uma das principais vantagens da técnica DOSY é o fato de ser um método não destrutivo, separando os componentes moleculares da mistura apenas "virtualmente", sendo capaz de identificá-los em misturas e caracterizá-los simultaneamente quanto ao tamanho de 
agregados e outras estruturas presentes ${ }^{[69,83,86,87]}$. Portanto, ela tem sido aplicada na análise de uma ampla extensão de misturas complexas, tais como extratos de tecidos ${ }^{[88]}$; polímeros ${ }^{[89] \text {; }}$

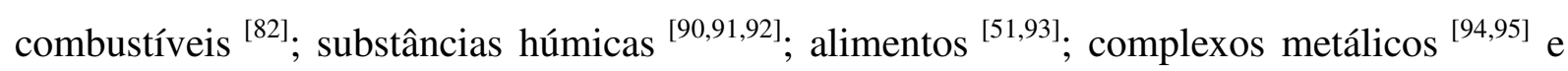
produtos naturais ${ }^{[96,97,98]}$.

Além disto, tem sido usada em estudos de: formação de complexos ${ }^{[72,99,100]}$; de determinação da distribuição do tamanho de partículas ${ }^{[101,102,103]}$; de massa molecular de compostos poliméricos ${ }^{[78,80,104,105]}$; de equilíbrio ${ }^{[102,106,107]}$ e de troca química ${ }^{[61,108,109,110]}$, bem como análise de interações moleculares ${ }^{[61,87,108,111]}$, além do próprio fenômeno da difusão $[112,113,114,115]$.

No caso da análise de misturas de produtos naturais, como frações pré-purificadas de extratos de plantas, a técnica DOSY é uma ferramenta em potencial, sendo uma alternativa para análise de misturas cujos componentes sejam instáveis aos métodos de purificação ${ }^{[98]}$ ou de difícil separação como, por exemplo, misturas de polissacarídeos ${ }^{[116]}$.

\subsection{Medidas de Difusão por RMN-DOSY (1D e 2D)}

Medidas de difusão por RMN são feitas desde 1950 quando Hahn desenvolveu a sequência de pulsos de 'eco de spin'. Hahn observou e elucidou o efeito da difusão molecular sobre as amplitudes dos 'ecos de spin'. Assim, é possível medir a difusão molecular monitorando as amplitudes dos ecos na presença de um gradiente linear de campo magnético $[68,69,87]$

Na sequência de 'eco de spin' tipo Hahn, $\left[90^{\circ}-\tau-180^{\circ}-\tau-(\text { eco)- }]_{\mathrm{n}}\right.$, elaborada por CarrPurcell, a perfeita refocalização do vetor magnetização só ocorre se cada spin nuclear (de constante magnetogírica $\gamma$ ) se mantiver sob a ação de um campo magnético homogêneo, durante o tempo $2 \tau$. Como as moléculas em solução estão em constante difusão, a refocalização não será perfeita e a amplitude ou intensidade do sinal I ( $2 \tau)$ do 'eco de spin' será reduzida (atenuada), de acordo com a equação:

$$
\frac{\mathrm{I}(2 \tau)}{\mathrm{I}(0)}=\exp \left[-\left(\frac{2 \tau}{\mathrm{T}_{2}}\right)-\frac{2}{3} \gamma^{2} \mathrm{~g}^{2} \mathrm{D} \tau^{3}\right]
$$

Embora seja possível medir a difusão molecular com a sequência de Hahn, é difícil separar as contribuições da relaxação transversal $\left(\mathbf{T}_{2}\right)$ e da difusão molecular $(D)$. Para tanto é 
possível usar a sequência $90^{\circ}-\tau-\left[180^{\circ}-\tau-(\text { eco })-\tau-180^{\circ}-\tau-(\text { eco })-\tau\right]_{n}$, derivada da sequência de Hahn ${ }^{[117]}$. Neste caso, o efeito de atenuação do eco, devido à difusão molecular, pode ser separado do efeito devido à $\mathrm{T}_{2}$, de acordo com a equação 5 , válida para ímãs de alta resolução:

$$
\frac{\mathrm{I}(\mathrm{t})}{\mathrm{I}(0)}=\exp \left[-\frac{\mathrm{t}}{\mathrm{T}_{2}}\right] \exp \left[-\frac{1}{3}(\gamma \mathrm{g} \tau)^{2} \mathrm{Dt}\right]
$$

\subsection{Eco de spin com pulsos de gradientes de campo magnético (PFG)}

O uso de gradientes de campo magnético estáticos limita a faixa de valores de coeficientes de difusão que podem ser medidos ${ }^{[68,69,87]}$. Para medir coeficientes de difusão pequenos é necessário utilizar valores elevados de gradiente, produzindo um grande alargamento do eco obtido, com consequente diminuição da sua amplitude e da relação sinalruído, aumentando a dificuldade de detecção. Contudo, Stejskal e Tanner, encontraram uma maneira de contornar este problema com o uso de pulsos de gradientes de campo (PFG) [118,119]

A sequência PFGSE (pulso de gradiente de campo - PFG com 'eco de spin' - SE) é derivada do conceito de 'eco de spin' de Hahn (1950) e de Carr e Purcell (1954) e utiliza dois pulsos de gradiente de campo magnético, essenciais nos estudos dos efeitos do movimento translacional na intensidade do sinal ${ }^{[68,69,87]}$.

Embora uma descrição completa do experimento seja dada por Price ${ }^{[120]}$, uma breve discussão qualitativa do efeito do gradiente de campo magnético é apropriada. Supondo-se que seja utilizado um instrumento com magneto de corpo vertical, o gradiente de campo magnético é produzido por um sistema de bobinas anti-Helmholtz (par de Maxwell) que consiste em duas bobinas conectadas em série e posicionadas coaxialmente fora da bobina de radiofrequência (rf), (Figura 5) ${ }^{[68]}$.

Uma das bobinas de gradiente está posicionada acima da bobina de $r f$ e conduz a corrente em um sentido, enquanto a outra bobina de gradiente, posicionada abaixo da bobina de $r f$, conduz a corrente no sentido oposto. O campo magnético produzido pelas bobinas de gradiente cria uma situação em que a intensidade do campo magnético diminui do topo para o fundo da amostra, ou vice-versa, isto é, o gradiente de campo é formado na direção vertical, 
paralela ao campo magnético externo $\left(B_{0}\right)$. Entre as várias características designadas às bobinas de gradiente as duas mais importantes são: a blindagem e a linearidade do campo ${ }^{[68]}$.
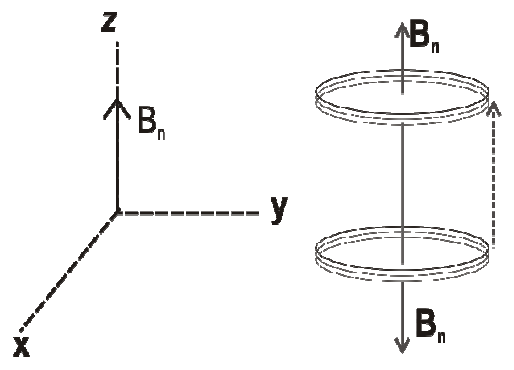

$\mathbf{G}_{\mathbf{2}}$

(a) sistema de bobina

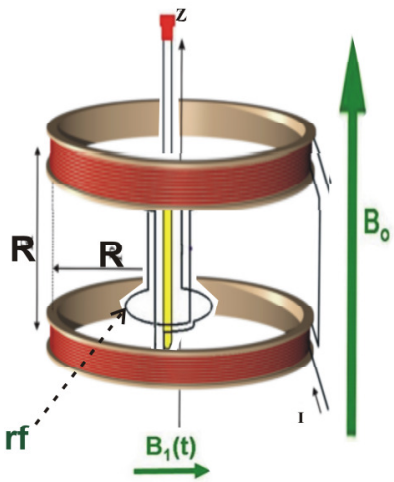

I = corrente elétrica

$\mathrm{BO}=$ campo magnético estático

If = bobina de radiofrequência

B1 = campo magnético gerado por if

$\mathrm{R}=$ raio das bobinas de anti-Helmholtz

e distância entre elas

Dimensões não estão em escala anti-Helmholtz
Figura 5 .
Diagrama do sistema de bobinas anti-Helmholtz e bobina de radiofrequência (rf) de uma sonda com gradiente.

A "intensidade" do gradiente é definida experimentalmente em termos da amplitude de gradiente $(\boldsymbol{g})$, duração $(\boldsymbol{\delta})$ e constante giromagnética $(\gamma)$ que, quando multiplicados definem a área do gradiente aplicado ${ }^{[83]}$. Assim, os gradientes são usados para impor ângulos de fase espacialmente dependentes $(\boldsymbol{\Phi})$ na magnetização líquida dos núcleos na amostra. Embora a frequência de precessão ( $\boldsymbol{\omega})$ do núcleo dependa do campo magnético estático local $\left(\mathbf{B}_{\mathbf{L}}\right)$, a fase da magnetização $(\boldsymbol{\Phi})$ em uma determinada posição definida pelas coordenadas $x y z$ depende da intensidade do gradiente de campo aplicado. De fato, os pulsos de gradiente permitem que as posições dos núcleos sejam identificadas antes e depois do tempo de difusão experimental (período $\Delta)^{[68,83]}$.

Um campo magnético não é produzido somente dentro da bobina de gradiente, mas fora dela também. Sempre que um material condutor elétrico (neste caso o corpo da sonda) experimenta um campo magnético variável, como no início ou no fim de um pulso de gradiente, uma corrente elétrica, chamada de corrente parasita ("eddy"), é formada próxima da superfície condutora (isto é, o corpo da sonda, criando um campo secundário oposto ao sentido do gradiente, que interfere na detecção do FID ("free induction decay"), resultando em distorções na forma das linhas e na linha de base do espectro de $\mathrm{RMN}^{[68,83]}$.

Para minimizar esta interferência as bobinas modernas são protegidas (blindadas) por várias bobinas colocadas ao seu redor e em série com as duas bobinas principais, criando um 
campo igual, mas oposto fora das bobinas principais. O campo criado pela blindagem das bobinas de gradiente cancela, portanto, o produzido pelas bobinas principais no corpo da sonda ${ }^{[68]}$. Muitas vezes o sistema de bobinas de blindagem não é suficiente para cancelar os efeitos das correntes parasitas, assim, o ideal é inserir na sequência de pulsos um intervalo de tempo TR, durante o qual as correntes parasitas são dissipadas (ou, pelo menos, minimizadas) antes da detecção do sinal de $\mathrm{RMN}^{[83]}$.

O outro aspecto a ser considerado é a linearidade do campo. O campo magnético varia linearmente ao longo do eixo z (isto é, ao longo da altura do tubo de RMN) desde que o gradiente aplicado seja constante (uniforme). Qualquer variação no gradiente de campo afeta os resultados obtidos pelos experimentos PFGSE, prejudicando a obtenção de um decaimento exponencial puro dos sinais.

A técnica de PFGSE consiste em uma sequência do tipo $\mathbf{9 0}^{\circ}-\tau-\mathbf{1 8 0}^{\circ}{ }^{[65,69,87]}$, onde se aplicam dois pulsos de gradiente, um antes e outro após o pulso $r f$ de $180^{\circ}$ (Figura 7).

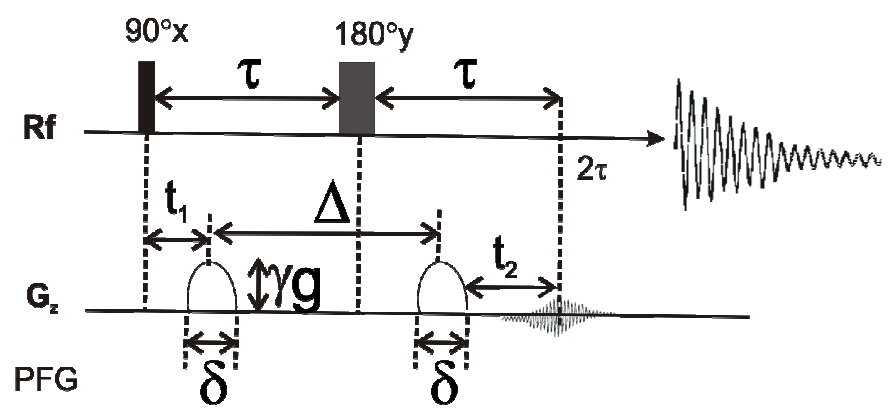

Figura 6. Sequência de pulsos para o experimento de ecos de spins com gradientes de campo pulsados (PFGSE) ${ }^{[65,69,87]}$.

A intensidade $\boldsymbol{g}$ do pulso de gradiente deve ser muito superior ao gradiente estático $\boldsymbol{g}_{\boldsymbol{o}}$, proveniente da não-homogeneidade do campo magnético $\left(\boldsymbol{g}>>\boldsymbol{g}_{\boldsymbol{o}}\right)$. A duração $\boldsymbol{\delta}$ do pulso de gradiente deve ser curta quando comparada com o tempo $\tau$ entre os pulsos $\boldsymbol{r} \boldsymbol{f}(\boldsymbol{\delta}<<\tau)$. Assim, a amplitude do eco será dada pela equação:

$$
\frac{\mathrm{I}(2 \tau)}{\mathrm{I}(0)}=\exp \left[-\frac{2 \tau}{\mathrm{T}_{2}}\right] \exp \left[-\mathrm{D}(\gamma \mathrm{g} \delta)^{2}\left(\Delta-\frac{\delta}{3}\right)\right]
$$

onde $\Delta$ é o intervalo de tempo entre os inícios dos dois pulsos de gradiente consecutivos (Figura 7). O termo de correção - $\delta / 3$ é uma consequência da forma retangular dos pulsos de gradiente. Esta técnica tem duas vantagens sobre as que usam gradientes estáticos:

a) torna possível separar o efeito de atenuação do eco devido à difusão, do produzido pela relaxação transversal efetiva $\left(\mathrm{T}_{2}^{*}\right)$, conduzindo o 
experimento em um intervalo $\tau$ fixo, entre os pulsos rf e variando a chamada área do pulso de gradiente: $\mathrm{q}=\gamma \mathrm{g} \delta$; e,

b) detecta o eco de spin sob um campo magnético homogêneo ${ }^{[121]}$..

\subsection{Eco de spin estimulados (PFGSTE)}

A técnica PFGSE pode ser melhorada com o uso de sequência de ecos de spins estimulados, que consiste em uma sequência de três pulsos de rf de $90^{\circ}$ (Figura 8), onde é aplicado um pulso de gradiente entre os dois primeiros pulsos de rf e um segundo pulso de gradiente após o terceiro pulso rf.

Uma sequência de três pulsos de $\mathrm{rf}$ de $90^{\circ}$ pode resultar em até cinco ecos de spin. $\mathrm{O}$ primeiro eco é chamado de eco estimulado e a sua atenuação pela difusão (dada pela equação 8) compete tanto com a relaxação transversal $T_{2}$, quanto com a relaxação longitudinal $T_{1}$. Quando ocorre troca química, por exemplo, $\mathrm{T}_{2}$ pode ser bem menor que $\mathrm{T}_{1}$ e pode ser mais vantajoso usar a técnica baseada em ecos estimulados.

$$
\frac{\mathrm{I}(\mathrm{T}+2 \tau)}{\mathrm{I}(0)}=\frac{1}{2} \exp \left[-\left(\frac{2 \tau}{\mathrm{T}_{2}}\right)-\frac{\mathrm{T}}{\mathrm{T}_{1}}\right] \exp \left[-\mathrm{D}(\gamma \mathrm{g} \delta)^{2}\left(\Delta-\frac{\delta}{3}\right)\right]
$$

onde: T é o intervalo de tempo entre o segundo e o terceiro pulso rf de $90^{\circ}$. Se $\tau$ e $\mathrm{T}$ forem mantidos constantes os efeitos de $\mathrm{T}_{1}$ e $\mathrm{T}_{2}$ podem ser separados do efeito da difusão, na atenuação do eco.

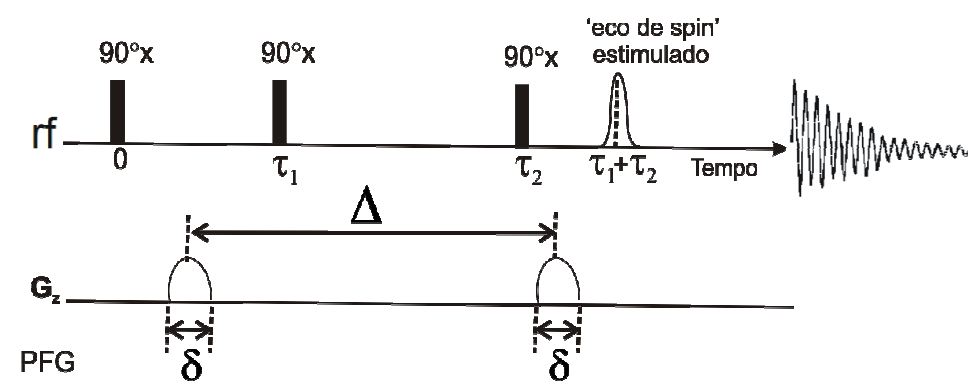

Figura 7. Sequência de pulsos para o experimento de 'ecos de spins' estimulados ${ }^{[69,87]}$.

\subsubsection{Vantagens da Técnica DOSY}

A técnica DOSY apresenta duas características importantes: a simplicidade e a flexibilidade. Um experimento de DOSY pode medir a difusão de qualquer substância que tenha núcleos ativos em RMN ${ }^{[122]}$, podendo ser aplicada para moléculas orgânicas e inorgânicas ${ }^{[61,92,108]}$. Para as moléculas orgânicas, na maioria das vezes monitora-se o núcleo 
de ${ }^{1} \mathrm{H}^{[69,87]}$, mas trabalhos envolvendo o núcleo de ${ }^{13} \mathrm{C},{ }^{15} \mathrm{~N},{ }^{29} \mathrm{Si}$ e ${ }^{31} \mathrm{P}$ também podem ser encontrados na literatura ${ }^{[81,82,86,106,114,123,124]}$.

Apka e colaboradores afirmam que monitorar o núcleo de ${ }^{13} \mathrm{C}$ pode ser mais vantajoso que o núcleo de ${ }^{1} \mathrm{H}^{[56,106,125]}$. A relaxação longitudinal $\left(\mathrm{T}_{1}\right)$ do ${ }^{13} \mathrm{C}$ é mais demorada e permite o estudo das heterogeneidades estruturais, pois ocorrem em escala maior do que as normalmente acessíveis por RMN de ${ }^{1} \mathrm{H}$. O núcleo de ${ }^{13} \mathrm{C}$ é menos sensível à falta de homogeneidade de campo, uma vez que sua constante giromagnética é menor ${ }^{[56,106,125]}$. Além disso, a maior resolução de frequência do espectro de ${ }^{13} \mathrm{C}$ torna possível identificar ressonâncias individuais, sendo, pois, praticável a aquisição de medidas de dispersão específica de espécies em sistemas com multicomponentes, onde a observação de ${ }^{1} \mathrm{H}$ produz um espectro de baixa resolução.

\subsubsection{Limitações da Técnica DOSY}

As limitações da técnica DOSY são as inerentes à RMN, por exemplo:

a) Necessidade de se dispor de um espectrômetro de RMN equipado com gradientes de campo pulsado; e,

b) Baixa sensibilidade

c) A sobreposição de sinais de $\mathrm{RMN}$ de ${ }^{1} \mathrm{H}$ diminui a resolução na dimensão da difusão, principalmente se existir interações intermoleculares (como ligação de hidrogênio) entres os componentes da mistura analisada. Uma solução para isto seria o uso de técnicas de DOSY-3D, combinando a técnica DOSY com outras técnicas de RMN 2D, como NOESY, COSY, HMQC, TOCSY, etc.

A abordagem mais simples de DOSY utiliza a sequência de pulso de Stejskal e Tanner, PFGSE (Figura 9(b)). Se os pulsos de gradiente não fossem aplicados o pulso de $180^{\circ}$ iria refocar a evolução dos deslocamentos químicos e o sinal detectado seria atenuado somente pela relaxação transversal $\left(\mathrm{T}_{2}\right)$ durante o período $2 \tau$.

\subsubsection{Processos Envolvidos em um Experimento de DOSY}

A aplicação do pulso de gradiente provocará a refocalização completa do sinal, desconsiderando as perdas por $\mathrm{T}_{2}$ se o campo magnético local experimentado pelo núcleo for 
idêntico durante o período de difusão $\Delta$, ou seja, se o núcleo estiver na mesma posição do sistema nos momentos da aplicação do primeiro e do segundo pulso ${ }^{[68,86]}$.

a) Processos da PFGSE

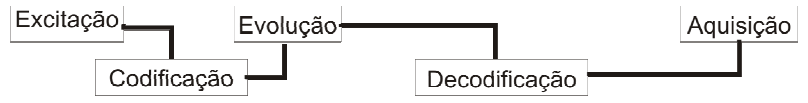

b) PFGSE
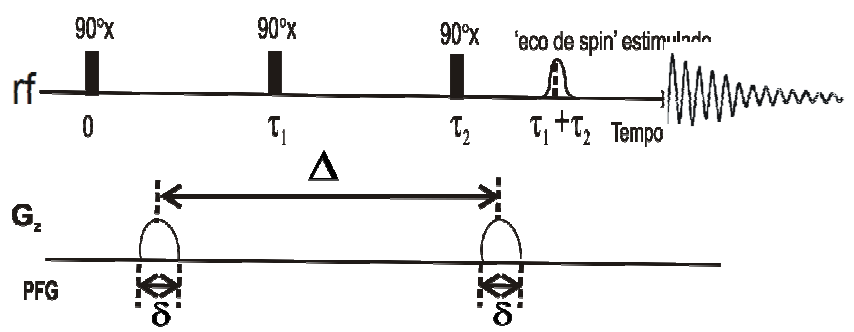

c) Ausência de difusão
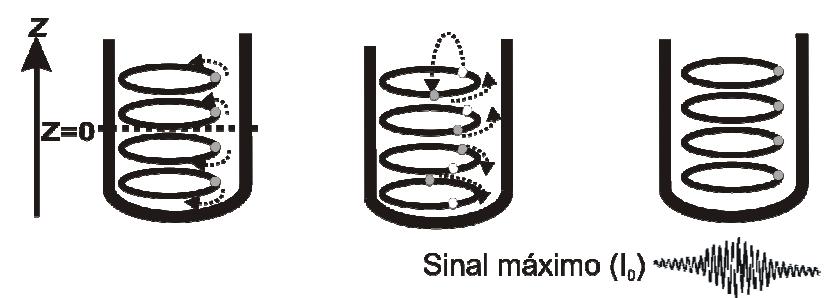

d) Presença de difusão

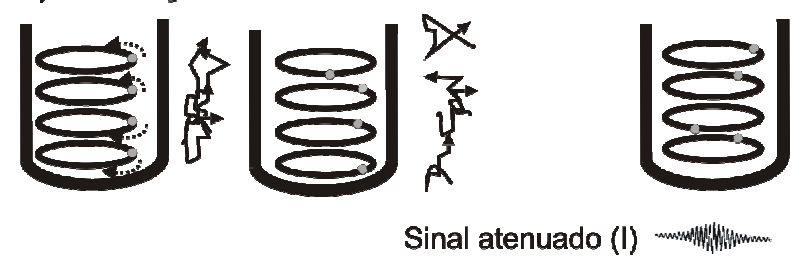

Figura 8. Processos ocorridos e um experimento de PFGSE de acordo com Antalek e Cohen e colaboradores ${ }^{[68,86]}$.

Segundo Antalek ${ }^{[68]}$ o experimento de PFGSE é dividido em cinco componentes (Figura 9(a)):

1. Processo de excitação - quando a magnetização líquida é instantaneamente colocada no plano e a fase dos spins é coerente;

2. Codificação ou perda de fase - quando as posições dos spins são marcadas pela produção de ângulo de fase espacialmente dependente, ou seja, a frequência de Larmor $(\omega)$ varia uniformemente ao longo do eixo $z$ durante o pulso gradiente

3. Evolução - durante o período $\Delta$ os spins mudam de posição devido ao constante movimento translacional (difusão) e sua magnetização gira $180^{\circ}$ devido ao pulso de rf;

4. Decodificação ou recuperação da fase - o segundo pulso de gradiente localiza o spin, que devido ao pulso de $180^{\circ}$ tem sua fase invertida e a contribuição de fase adicionada pelo primeiro pulso gradiente é agora subtraída. Não ocorrendo a 
difusão é obtido um sinal máximo, mas se a difusão ocorrer, alguns spins não estarão na mesma posição e, portanto, sua fase não será cancelada (a refocalização será apenas parcial) e o sinal obtido será atenuado, por isso a importância da uniformidade do gradiente por toda a amostra ao longo de $z$, evitando criação de artefatos ou ocultando sinais reais da amostra.

5. Aquisição do sinal - Ao final do experimento, o sinal detectado será atenuado pela distância percorrida pela molécula ao longo do eixo $z$ (eixo do magneto e do gradiente) durante o período $\Delta$. A distância percorrida, como mostrado anteriormente pela Equação $4\left(\mathrm{z}=(2 \mathrm{Dt})^{1 / 2}\right)$, depende do coeficiente de difusão (D) da molécula.

A intensidade observada do sinal (I) para um experimento PFGSE pode ser obtida com uma modificação da Equação 8, por substituição dos termos $\mathrm{I}(2 \tau)$ por $I$, resultando na Equação 9, onde $\mathrm{I}_{0}$ é a intensidade do sinal quando a intensidade do gradiente é zero, ou seja, logo após o pulso de $90^{\circ}$, $\tau$ é o intervalo entre os pulsos de rf e $\mathrm{T}_{2}$ é o tempo de relaxação transversal ${ }^{[68]}$.

$\mathrm{I}=\mathrm{I}_{0} \exp \left[-\frac{2 \tau}{\mathrm{T}_{2}}\right] \exp \left[-\mathrm{D}(\gamma g \delta)^{2}\left(\Delta-\frac{\delta}{3}\right)\right]$

Assim, o valor de $\boldsymbol{D}$ pode ser obtido através da determinação do coeficiente angular da reta gerada pelo gráfico de $\ln \left(\mathrm{I} / \mathrm{I}_{0}\right)$ vs $(\gamma \mathrm{g} \delta)^{2}$. Logo, realizando-se vários experimentos de PFGSE com $\Delta$ e $\delta$ constantes e porcentagem da intensidade do gradiente variável, é possível obter o valor de $D$.

\subsubsection{Estratégias para o aumento da qualidade de um espectro de DOSY}

Como já mencionado para minimizar as perdas de magnetização devido à relaxação transversal $\mathrm{T}_{2}$, o que leva a degradações significativas da relação sinal-ruído em moléculas com $\mathrm{T}_{2}$ curto, pode-se usar a sequência de pulso de eco de spin estimulado (PFGSTE), substituindo o pulso de $180^{\circ}$ por dois pulsos de $90^{\circ}$ como mostrado na Tabela 4 .

Segundo Antalek ${ }^{[68]}$, o sucesso de um experimento PFGSE com finalidade analítica depende da eliminação de alguns artefatos experimentais que podem aparecer nos espectros gerados. Para ele, um bom conjunto de dados de RMN de PFGSE deve possuir um bom registro das frequências de ressonâncias; deve ser capaz de produzir uma boa diferenciação 
dos componentes do FID; não deve apresentar espalhamento ou distorção de fase dependente do gradiente, nem artefatos de linha base; e, finalmente, deve apresentar um decaimento exponencial puro.

Os principais fatores de geração de artefatos são: correntes parasitas; correntes de convecção térmica geradas pela diferença de temperatura entre regiões do sistema e falta de homogeneidade do campo e do gradiente de campo (desajustes entre os pulsos de gradientes seqüenciais, pelos ruídos de fundo e pelo amortecimento da radiação). Existem, também, artefatos gerados por troca química que, embora sejam menos comuns, podem afetar a eficiência do experimento.

As correntes parasitas provocam deformações de linha base e reduzem a resolução dos sinais de DOSY. Estes problemas podem ser solucionados com utilização de bobinas ativamente blindadas e/ou uso de sequências pulsos modificadas como as PFGLED e BPPLED (Tabela 3) que possuem um intervalo de tempo para dissipação dessas correntes $[33,68,126]$.

Os artefatos gerados pelas correntes de convecção térmica dependem da velocidade destas correntes. São eles: o aumento do valor de D e origem de sinais com intensidades negativas ${ }^{[68,127,128,129,130,131]}$. Para eliminá-los ou minimizá-los é necessário:

- ajustar e controlar a temperatura da amostra, lembrando que temperaturas diferentes da temperatura ambiente são mais fáceis de controlar;

- $\quad$ usar solventes viscosos e tubos de RMN com diâmetro o menor possível;

- minimizar a altura da amostra;

- ajustar o fluxo de gás afim de promover uma troca de calor eficaz; e,

- realizar o experimento sem girar a amostra.

A falta de homogeneidade do gradiente de campo (desajustes entre os pulsos de gradientes sequenciais) pode produzir distorção residual de fase, causando perda de intensidades do sinal de eco. Dependendo da intensidade do gradiente, estes distúrbios podem ser confundidos com os efeitos das correntes parasitas. Por isso é importante que a área efetiva do primeiro e do segundo pulso de gradiente sejam exatamente idênticas. Em geral, o uso de pulsos de gradientes não-retangulares, como senoidais, facilita a reprodutibilidade $[120,132]$. 
Os ruídos de fundo são frutos de imperfeições do campo $\mathrm{B}_{0}$ e são gerados pela bobina principal, pela bobina de gradiente, pela falta de ajuste da homogeneidade de campo, por materiais em suspensão, etc. Estes ruídos podem diminuir a relaxação transversal $T_{2}{ }^{*}$ ou alterar as curvas de decaimento dos sinais, afetando a sensibilidade. Neste caso o uso de pulsos de rf de $180^{\circ}$ para refocalizar o efeito da defasagem (sequências de pulsos de BPPSTE e BPPLED), e/ou de pulsos de gradientes bipolares, como, nas sequências de pulsos de GCSTE, GCSTEL, BPPSTE e BPPLED (Tabela 4) podem reduzir os efeitos dos ruídos, desde que eles sejam constantes durante todo o experimento ${ }^{[132]}$.

O amortecimento da radiação pode ocorrer quando a magnetização nuclear de espécies presentes for suficientemente forte para que a corrente induzida na bobina seja grande o bastante para perturbar sua própria movimentação no sistema de medida. Isto promove alargamento excessivo dos sinais mais intensos, anomalias nas fases dos sinais e erros sistemáticos na amplitude do sinal. O problema causado pelo amortecimento da radiação pode ser solucionado com a calibração do sistema de gradiente de campo pulsado com experimentos PFGSE envolvendo substâncias com coeficiente de difusão determinado por outra técnica ${ }^{[133]}$; a manutenção da magnetização transversal defasada e redução da longitudinal com uso de sequências de pulsos próprias para este fim. Trabalhar sempre que possível com misturas equimolares também contribui na resolução deste problema.

A ocorrência de troca química entre duas espécies presentes na solução pode produzir distorções de sinais e perdas severas de sensibilidade, bem como, interpretações errôneas. Se a troca de hidrogênio, entre duas espécies da solução, ocorrer muitas vezes durante o período de difusão $(\Delta)$ uma única correlação será observada para os dois sinais e o valor de $\boldsymbol{D}$ será a média entre os coeficientes das duas espécies. As sequências com pulsos de gradientes bipolares como BPPSTE, BPPLED, GCSTE, GCSTEL são úteis na prevenção destes problemas (Tabela 4) ${ }^{[61,108,109,121]}$. 
Tabela 3. Sequências de pulsos usadas em experimentos DOSY e os recursos usados para aumentar da qualidade do espectro DOSY. ${ }^{[68,126,134,135,136]}$.
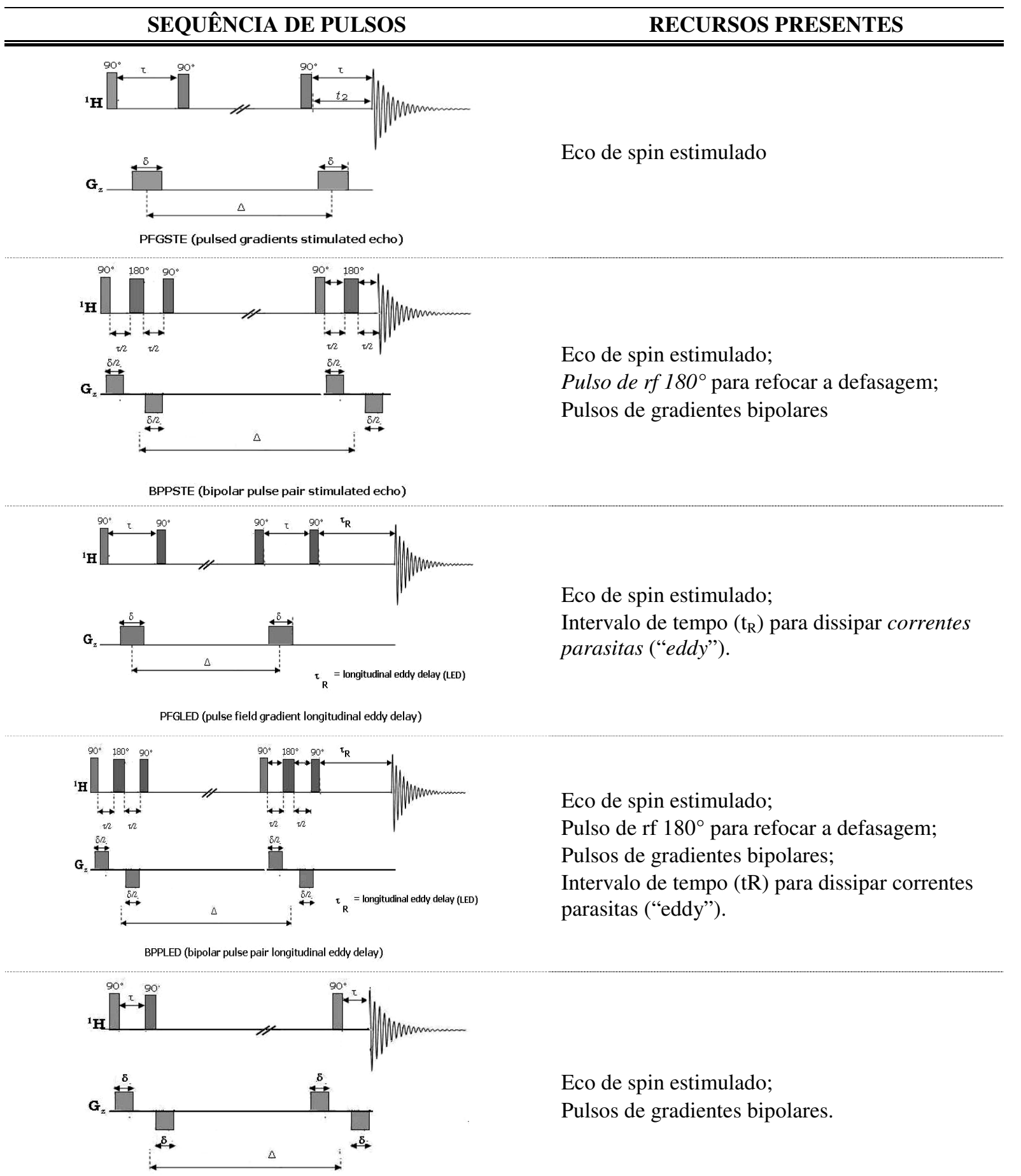

Eco de spin estimulado;

Pulsos de gradientes bipolares.

GCSTE (gradient compensated stimulated echo)

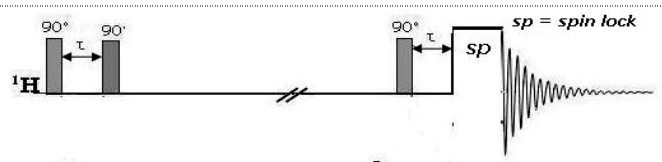

Eco de spin estimulado;

Pulsos de gradientes bipolares;

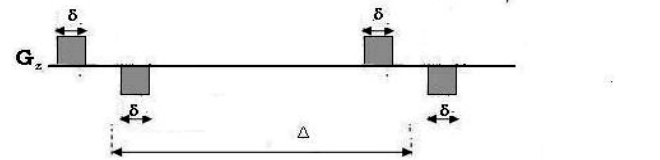

Trava de spin ("Spin lock") para eliminar defeitos de fase e anomalias geradas por sistemas de spin fortemente acoplados.

GCSTEL (gradient compensated stimulated echo spin lock) 


\subsubsection{Aplicações da técnica RMN DOSY-1D e 2D}

A técnica DOSY tem sido aplicada em várias áreas, tais como química ambiental ${ }^{[57,116]}$, farmacêutica ${ }^{[84,132]}$, combinatória ${ }^{[59,86]}$, química dos materiais ${ }^{[70,71,72,137,138]}$, analítica ${ }^{[59,75]}$, intermediários de reações ${ }^{[139,140]}$ e alimentos ${ }^{[51,141]}$, entre outros. Em virtude da sua finalidade ser a separação virtual dos componentes de uma mistura, da sua habilidade de resolver misturas complexas e permitir a identificação simultânea dos compostos, a técnica DOSY é chamada por muitos pesquisadores da área como a "cromatografia de spin" ou “cromatografia de RMN" [56,59,69,86,87].

Alguns pesquisadores relacionam a técnica DOSY com cromatografia de exclusão por tamanho, porque em ambas as técnicas, a forma e o tamanho molecular são importantes e, sem dúvida, a técnica DOSY pode ser utilizada para estimar os tamanhos e pesos moleculares dos compostos desconhecidos, quando realizada uma curva de calibração com compostos conhecidos ${ }^{[56,86,97]}$. Outros pesquisadores sugerem o uso de espectroscopia ordenada por difusão como um complemento para cromatografia de exclusão por tamanho ${ }^{[142]}$. 


\subsubsection{Estratégias de aumento de sensibilidade de $\mathrm{RMN}$ de ${ }^{13} \mathrm{C}$ via processamento}

\subsubsection{Evolução do Processamento dos dados de RMN}

Atualmente, existem dois tipos de espectrômetros em uso: de onda contínua e de ondas pulsadas com transformada de Fourier (RMN-TF).

Nas primeiras décadas da espectroscopia de RMN, a maioria dos espectrômetros usados para fins químicos era de onda contínua. O processo envolvido neste tipo de espectrômetro é parecido ao processo da espectroscopia de absorção: é usada uma fonte de frequência fixa (radiação de rádio frequência, rf) e varia a corrente elétrica de uma bobina de eletroímã, variando, portanto, o campo magnético $\left(\mathrm{B}_{0}\right)$, para observar os sinais de absorção ressonante de onda contínua ${ }^{[33,35,41]}$. O uso deste tipo de equipamento atualmente está limitado a análises de rotina na indústria petroquímica, de produtos alimentícios e materiais agrícolas.

A introdução do espectrômetro de RMN-TF começou em 1965-1966 pela "Varian Associates" depois dos trabalhos de Richard Ernst e Weston Anderson ${ }^{[143,144,145]}$. A partir deste trabalho pioneiro, vários avanços como a introdução de experimentos multidimensionais e, mais recentemente, os protocolos otimizados de aquisição, têm confirmado o papel fundamental do processamento de dados na RMN de alta resolução ${ }^{[144]}$.

O ano de 1965 foi marcado não só pela proposta de RMN pulsada de Ernst como também pela publicação por James Cooley e John Tukey ${ }^{[146]}$ de um algoritmo chamado DFT de ordem $\mathrm{N} \log (\mathrm{N})$, que juntamente com subsequentes modificações são conhecidos como FFT ('Fast Fourier Transform'). O uso dos algoritmos FFT foi mais pronunciado a partir do desenvolvimento do computador digital, enquanto Ernst e Anderson, usando um PDP-8 (12 bits), levavam segundos para obter uma FFT, hoje, usando um único circuito integrado com 32 ou 64 bits, demora cerca de $10^{-3}$ segundos para se obter a mesma FFT.

\subsubsection{Processamento de dados de RMN (tratamento do sinal)}

Nos instrumentos com ondas pulsadas, a amostra é irradiada com pulsos periódicos de rf, direcionados para a amostra, perpendicularmente ao campo magnético estático Figura 9. 
Esses pulsos de excitação originam um sinal no domínio do tempo que decai durante o intervalo $\mathrm{T}$ entre os pulsos, Figura 10 (a). Este sinal é chamado de decaimento livre da indução ou FID ("free induction decay"). Este sinal é convertido para um sinal no domínio de frequência aplicando-se uma transformada de Fourier, resultando no espectro de RMN da amostra.

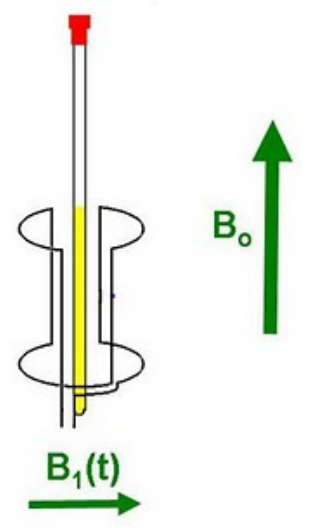

Figura 9. Posição relativa entre $\operatorname{rf}\left(\mathrm{B}_{1}\right)$ e campo magnético estático $\left(\mathrm{B}_{0}\right)$

Os pulsos de rf aplicados são bem curtos, de 1 a $10^{-6} \mathrm{~s}$, como mostrado na Figura 10. A sua frequência está na ordem de $10^{1}$ a $10^{3} \mathrm{MHz}$. O intervalo T entre os pulsos é da ordem de alguns segundos. Durante o tempo T, um sinal de rf no domínio do tempo (FID) é emitido pelos núcleos excitados à medida que relaxam, ou seja, retornam ao estado fundamental. Logo o valor de $\mathrm{T}$ deve ser suficiente para dar tempo para todos os núcleos relaxarem antes da aplicação do próximo pulso.

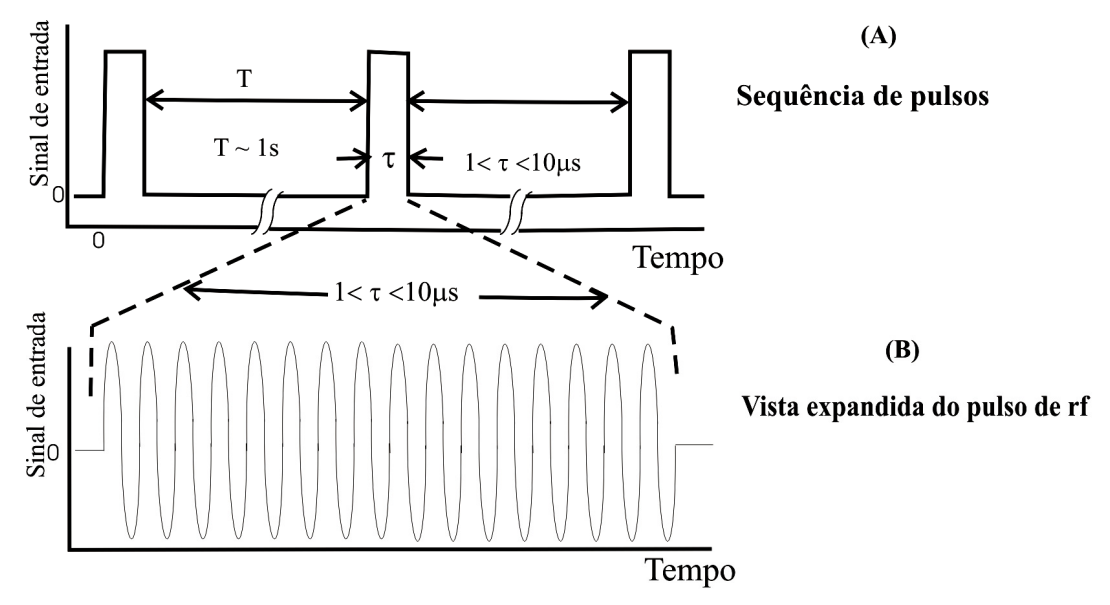

Eixo do tempo não está em escala

Figura 10. Sinal de excitação típico para RMN pulsada. (A) sequência de pulsos; (B) vista expandida do pulso de rf .

O FID é detectado por uma bobina receptora de rf localizada perpendicularmente ao campo magnético estático. Na verdade a mesma bobina usada para emitir o pulso de rf de 
excitação é usada para detectar o sinal emitido pela amostra. Assim, o FID de cada pulso é digitalizado e armazenado em um computador para ser processado.

Durante o processamento os FIDs de vários pulsos sucessivos são somados para melhorar a relação sinal ruído (S/R). Esse processo é chamado de promediação de conjunto ou coadição.

O sinal pode ser submetido a outros tratamentos matemáticos para melhorar a $\mathrm{S} / \mathrm{R}$, como filtragem digital, ajuste polinomial ou apodização através de sua multiplicação por uma função exponencial ou gaussiana, por exemplo, para eliminar o ruído. A própria transformada de Fourier é um filtro digital. Muitos destes procedimentos são aplicados em forma de ondas não periódicas e irregulares a sinais que não possuem onda síncrona e sinais periódicos.

Na promediação de conjunto séries sucessivas de dados armazenados são coletadas e somadas ponto a ponto, $\mathrm{S}_{\mathrm{x}}$. O resultado deste processo pode ser observado genericamente na Figura 11.

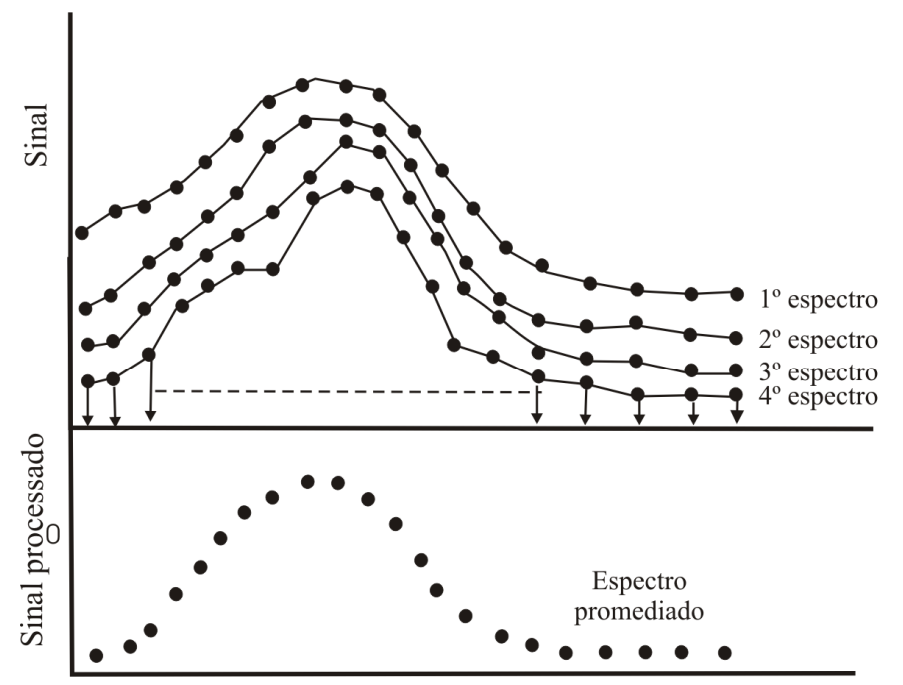

(C)

Dados digitais antes do processamento por promediação de conjunto

\section{(D)}

Dados digitais após processamento por promediação de conjunto

Deslocamento químico

Figura 11. Efeito do processo de promediação de conjunto para um espectro.

$$
\text { O valor médio do sinal } S_{x} \text { é dado pela equação: } \quad S_{x}=\frac{\sum_{i=1}^{n s} S_{i}}{n s}
$$

onde $\mathrm{S}_{\mathrm{i}}$ são as medidas individuais do sinal incluindo o ruído, com $\mathrm{i}=1,2,3, \ldots$, ns. O valor médio $S_{x}$ menos o valor de $S_{i}$ será o ruído $R_{i}$ ou simplesmente $R: \quad R=S_{x}-S_{i}$ ou: $\quad \mathrm{R}=\frac{\sum_{\mathrm{i}=1}^{\mathrm{ns}} \mathrm{S}_{\mathrm{i}}}{\mathrm{ns}}-\mathrm{S}_{\mathrm{i}}$

Ao elevar o ruído ao quadrado, somar ao desvio da média do sinal $S_{\mathrm{x}}$ e dividir pelo número de 
varreduras $n s$, obtém-se o ruído quadrático médio RQM ou variança do sinal, A equação neste

caso é: $\quad R Q M=\frac{\sum_{i=1}^{n s}\left(S_{x}-S_{i}\right)^{2}}{n s}$

O valor efetivo do ruído $\mathrm{R}$ é o seu desvio padrão $\mathrm{R}_{\mathrm{x}}$ :

$\mathrm{R}_{\mathrm{x}}=\sqrt{\frac{\sum_{\mathrm{i}=1}^{\mathrm{ns}}\left(\mathrm{S}_{\mathrm{x}}-\mathrm{S}_{\mathrm{i}}\right)^{2}}{\mathrm{~ns}}}$

A relação sinal ruído para a medida é o valor médio do sinal dividido pelo seu desvio padrão:

$$
\mathrm{S} / \mathrm{R}=\frac{\mathrm{S}_{\mathrm{x}}}{\sqrt{\frac{\sum_{\mathrm{i}=1}^{\mathrm{ns}}\left(\mathrm{S}_{\mathrm{x}}-\mathrm{S}_{\mathrm{i}}\right)^{2}}{\mathrm{~ns}}}}
$$

Multiplicando-se tanto o numerador como o denominador pelo número de varreduras $n s$, tem-

se que: $\quad S / R=\frac{n s . S_{x}}{\frac{n s}{\sqrt{n s}} \sqrt{\sum_{i=1}^{n s}\left(S_{x}-S_{i}\right)^{2}}}=\sqrt{n s} \cdot \frac{S_{x}}{\sqrt{\sum_{i=1}^{n s}\left(S_{x}-S_{i}\right)^{2}}}$

As flutuações aleatórias do ruído tendem a ser canceladas à medida que o número de varreduras aumenta, mas o sinal acumula. Assim, a relação $S / R$ é proporcional à raiz quadrada do número de varreduras $n s$, ou seja $\mathrm{S} / \mathrm{R} \propto \sqrt{\mathrm{ns}}$.

Para conseguir as vantagens da promediação de conjunto e ainda extrair toda a informação disponível em um sinal, a amostragem deve ser feita numa frequência de pelo menos duas vezes a do componente do sinal de maior frequência, conforme o teorema de Nyquist.

\subsubsection{A importância do processamento dos dados no aumento de sensibilidade da espectroscopia de RMN}

O processamento de sinal de RMN continua a ser um desafio ${ }^{[147]}$, devido à considerável complexidade dos sistemas computacionais necessários para modelar a dinâmica física adequadamente. Além disso, a baixa sensibilidade inerente ao fenômeno de RMN torna os ruídos produzidos pela própria instrumentação um dos mais importantes interferentes na medida do sinal. Além disso, muitas amostras analisadas por RMN são muito diluídas, sobretudo as provenientes de produtos naturais. A baixa concentração de uma amostra 
dificulta ou até mesmo inviabiliza a obtenção de um espectro de RMN de ${ }^{13} \mathrm{C}$ com uma boa relação S/R. Além do efeito da concentração do analito, a intensidade do sinal de RMN é afetada pela intensidade do campo magnético e temperatura.

A maneira mais usual para resolver o problema causado pela baixa concentração é o aumento do número de varreduras $n s$ durante a aquisição dos espectros, uma vez que o ruído cresce mais lentamente que o sinal da amostra, na razão de $\sqrt{n s}$.

Em muitos casos o número necessário de varreduras para obtenção de um espectro com boa relação $\mathrm{S} / \mathrm{R}$ é tão alto que pode ser considerado proibitivo, pois aumenta exageradamente o tempo necessário para análise. Deste modo, é imprescindível o estabelecimento de métodos de processamento de dados de RMN que possibilitem uma maximização de extração de informação relevante a partir de um sinal medido.

$\mathrm{Na}$ literatura encontram-se vários trabalhos neste sentido. A maioria envolve a utilização da decomposição do valor singular (SVD - "singular value decomposition") da matriz complexa formada pelas componentes: real e imaginária do sinal para separar o sinal do ruído. Os métodos existentes são: inversão harmônica, predição linear ('linear prediction'), aproximações de Pade, filtro de diagonalização ou derivação ${ }^{[148,149,150,151,152]}$.

Trabalhando com $\mathrm{N}_{\mathrm{d}}$ amostras decimadas de sinal $C_{n s}$ medido no domínio do tempo, o sinal medido poderão ser criados vetores linearmente independentes $\vec{C}_{n s}=\left(C_{n s}, C_{n s+1}, \ldots, C_{n s+M-1}\right)$ com $M \cong N_{d} / 2$, definindo um espaço vetor com dimensão M. Os vetores de sinal medido é a soma de um vetor de sinal real $\left(\vec{S}_{n}\right)$ com um vetor de ruídos (ou flutuações) aleatórios $\left(\vec{S}_{n s}\right)$, ou seja, $\vec{C}_{n s}=\vec{S}_{n s}+\vec{R}_{n s}$

O modelo harmônico estabelece que os elementos sinal real (sem ruído) $S_{n}$ no domínio do tempo, são criados a partir da soma de K harmônicas, ou seja, o espectro é a soma de K Lorentzianas, onde $\mathrm{K}$ pode ser relacionado ao número de picos observados na seção ou espectro. $\mathrm{K}$, na verdade, é o número de pontos que se destacam no sinal medido $\mathrm{C}_{\mathrm{n}}$.

O modelo é expresso vetorialmente, ponto por ponto, como:

$$
\vec{S}_{n s}=\sum_{k=1}^{K} d_{k} z_{k}^{n s} \vec{s}_{k} \quad \text { e } \quad S_{n s}=\sum_{k=1}^{K} d_{k} z_{k}^{n s}
$$

onde: $\left(\vec{s}_{k}\right)^{\mathrm{T}}=\left(1, z_{k}, z_{k}^{2}, \ldots, z_{k}^{M-1}\right), \quad z_{k}=\exp \left(-\mathrm{i} \varpi_{\mathrm{k}} \tau_{d}\right), \quad \mathrm{d}_{\mathrm{k}}$ é amplitude e $\omega_{\mathrm{k}}$ é a frequência complexa (com parte imaginária $<0$ ), $\mathrm{z}_{\mathrm{k}}$ é o decaimento exponencial no domínio 
do tempo. A parte real da frequência $\omega_{\mathrm{k}}$ e o módulo da parte imaginária é duas vezes a largura da Lorentziana com altura: $d_{k} /\left|\operatorname{Im}\left(\varpi_{k}\right)\right|$. Logo, para o sinal digitalizado ${ }_{n s}$ amostrado no período $T(t=N T, n=0 \ldots N-1)$, tem se:

$c_{n s}=\sum_{k=1}^{K} d_{k} e^{-i \omega_{k} n T} \quad \operatorname{Im}\left(\omega_{\mathrm{k}}\right)<0$

onde $\left\{\omega_{\mathrm{k}}, d_{\mathrm{k}}\right\} \in \mathbb{C}$ são: a frequência $\mathrm{e}$ amplitudes complexas de cada parcial k, respectivamente. A ordem dada por K corresponde à ordem do sinal. Seguindo a metodologia de Cadzow ${ }^{[153]}$, a partir do sinal no domínio do tempo ${ }_{n s}$, pode-se construir a matriz de correlação covariante Hermitiana $M \times M$ como $^{[148]}$ :

$R_{i j}=\frac{1}{N_{d}-M+1} \sum_{n=0}^{N d-M} C_{n s+i-1} C_{n s+j-1 *}$

onde $N_{d}$ é o número de pontos do sinal $C_{n s}$ decimado, $M \cong N_{d} / 2$.

A matriz $R_{i j}$ pode ser diagonalizada por SVD, obtendo-se os autovalores (ou valores singulares) $s_{i}$ e os autovetores $\vec{u}_{i}$ com $i=1, \ldots, M$ indexados de modo que $s_{i}>s_{i+1}$.

Segundo Kunikeev e colaboradores este método deve ser usado em seções do espectro do sinal medido. Neste caso o espectro obtido com a transformada de Fourier do sinal medido $C_{n s}$ é dividido em seções de 200 a 500 pontos, contendo, preferencialmente um único sinal para facilitar o desempenho computacional. Esta seção é, então, submetida à TF inversa, obtendo-se o FID da seção. Em seguida, constrói-se uma matriz hermitiana $R_{i j}$ para cada FID de seção de espectro, A matriz $R_{i j}$ de cada seção é submetida à SVD e os valores singulares das matriz resultantes são os sinais filtrados (com ruído reduzido) da seção.

A segmentação do espectro é realizada por três motivos:

$1^{\circ}$ motivo: A segmentação pode facilitar o processo de redução de ruído por SVD, pois sem a divisão em seções, o gráfico dos valores singulares derivado do SVD e discutido a seguir, fica tão cheio de pontos de valores singulares de sinais e ruído dificultando sua análise.

$2^{\circ}$ motivo: A segmentação permite que cada seção seja processada individualmente, conforme as necessidades e características específicas, pois nem todas as seções do espectro apresentam a mesma relação S/R. 
$3^{\circ}$ motivo: Sem a segmentação e dimensão $\mathrm{N}_{\mathrm{d}} / 2$ da matriz hermitiana resultante do método de Cadzow seria tão grande que o tempo necessário para a diagonalização seria muito longo.

Voltando-se a considerar a equação 19, o processo de SVD resulta na decomposição do sinal $C_{n s}$ em seus componentes $\left\{K, \omega_{\mathrm{k}}\right.$ e $\left.d_{\mathrm{k}}\right\}$. Se $\mathrm{N}>2 \mathrm{~K}$, o sinal pode ser totalmente reconstruído e se pode obter a posição $\left(\operatorname{Re}\left(\omega_{\mathrm{k}}\right)\right)$, a largura $\left(\operatorname{Im}\left(\omega_{\mathrm{k}}\right)\right)$, a altura $\left(\left|d_{\mathrm{k}}\right|\right)$ e a fase $\left(\operatorname{Arg}\left(d_{\mathrm{k}}\right)\right)$ de cada estrutura ressonante no espectro ${ }^{[147]}$.

A aplicabilidade da SVD em um sinal $C_{n s}$ pode ser verificada por um critério qualitativo. Os dados resultantes da SVD da matriz $R_{i j}$ são colocados na ordem decrescente e o gráfico $\ln s_{i}$ versus $i$, com $i=1, \ldots, N_{d}$ é $s_{i}$ é o valor singular no ponto é obtido. Tal gráfico deve apresentar um degrau (“gap”) (Figura 12), entre os valores singulares sem ruído e os valores singulares com ruído, indicando que o método foi capaz de discriminar o sinal em relação ao ruído, e / ou que o número de varreduras em que o espectro foi adquirido foi suficiente para permitir a obtenção de um aumento por SV da relação $S / R$ da seção ou espectro em questão. $\mathrm{O}$ número $\mathrm{K}$ de pontos antes do degrau é maior ou igual ao número de sinais na seção ou espectro analisado. Além disso, o número $\mathrm{K}$ pode ser acompanhado em função do número de varreduras $n s$. Quando K se mantiver constante diante do aumento de ns o "gap" é considerado estável e os dados de sinal medido são considerados aptos para ser decompostos por SVD.

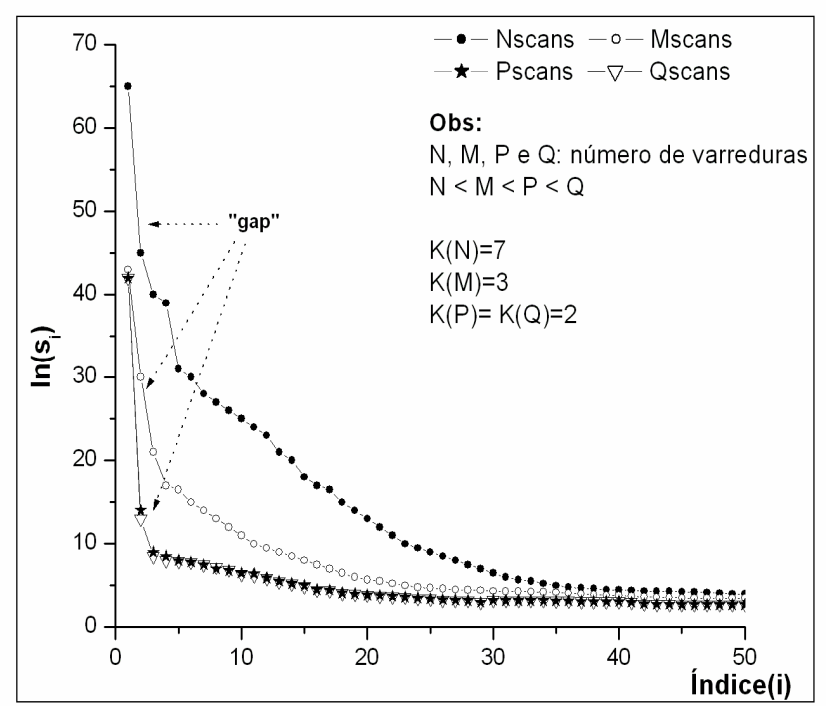

Figura 12. Demonstração da verificação de estabilidade de "gap". 
O tratamento descrito anteriormente pode ser esquematizado em 4 etapas, conforme a

\section{Figura 13:}

$1^{\text {a }}$ etapa: Aplicação da Transformada de Fourier e divisão do espectro em seções contendo preferencialmente um único sinal;

2a etapa: Obtenção do FID da seção selecionada através da Transformada de Fourier inversa (IFT);

$3^{\mathrm{a}}$ etapa: Redução de ruído por SVD e verificação da estabilidade do "gap";

$4^{\mathrm{a}}$ etapa: Combinação linear dos FIDs filtrados (ou limpo ou com menos ruído) e obtenção do espectro filtrado.

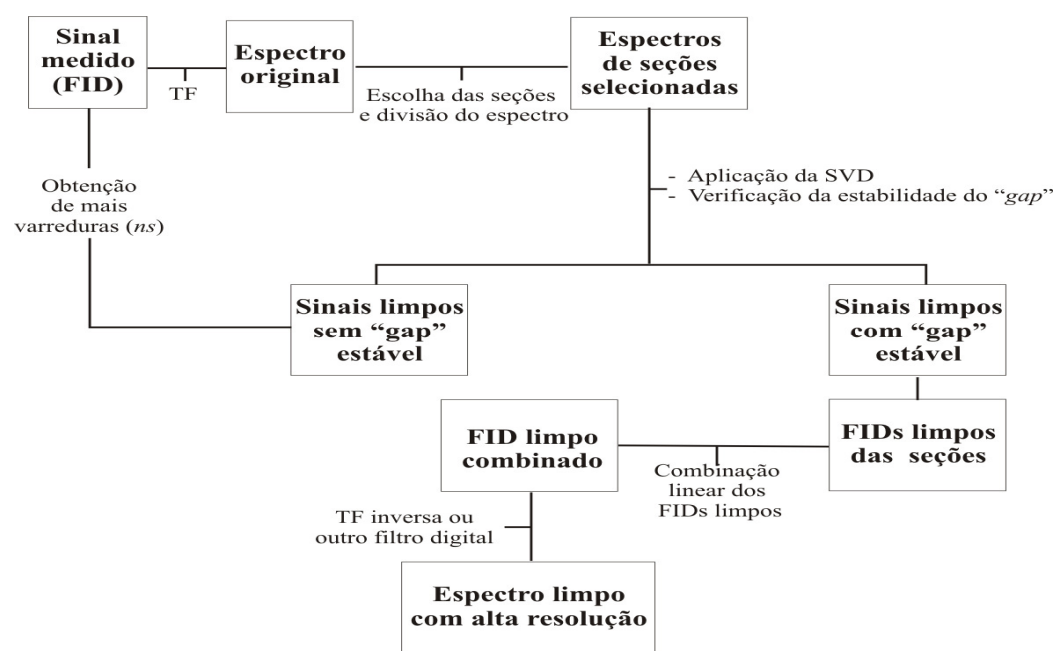

Figura 13. Método de redução de ruído por SVD.

A transformada de Fourier inversa aplicada na última etapa pode ser substituída por um algoritmo de inversão harmônica, que segundo Kunikeev e colaboradores, fornece um maior aumento da relação $S / R$ com uma resolução espectral mais elevada para um dado comprimento de sinal, pois a informação usada, a priori, é uma combinação linear de exponenciais com decaimento complexo, o que fornece um bom modelo para um sinal de FID [148,149,150,151,152,154]. Entretanto, a relação S/R do espectro obtido a partir da transformada de Fourier do FID submetido ao SVD é excelente e permite sua utilização como parte da estratégia de redução de ruído por SVD, aumentando a eficiência da análise por RMN.

A escolha criteriosa das seções e o respeito aos critérios de aplicabilidade impedem que o método insira alguma linha falsa, criando artefatos e/ou suprima linhas verdadeiras, eliminando picos reais de um sinal muito ruidoso. Logo, um limite da relação S/R do FID original é estabelecido. Segundo Kunikeev e colaboradores ${ }^{[151]}$, para que o redutor de ruído por SVD possa ser aplicado, a relação S/R do FID a ser tratado deve ser maior ou igual a 1,5. 


\subsubsection{Estudo de constantes de acoplamento de longa distância heteronuclear JCH em sistemas poliinsaturados}

\subsubsection{Importância e métodos de determinação de constantes de acoplamento de spin-spin heteronuclear}

As constantes de acoplamento spin-spin heteronuclear a longa distância $\left({ }^{2} J_{C H}\right.$ e ou ${ }^{3} J_{C H}$ ) são importantes nos estudos de elucidação estrutural de compostos orgânicos, fornecendo informações sobre a estereoquímica (conformação e configuração). Entretanto, o uso dos valores destas constantes não é tão frequente devido a problemas inerentes aos métodos de sua determinação. Tais problemas decorrem do fato de que as constantes de acoplamento heteronuclear a longa distância, em geral, são pequenas (1 a $10 \mathrm{~Hz})$ e da mesma magnitude da constante de acoplamento homonuclear a três ligações, ${ }^{3} J_{H H}$, além de serem associadas a núcleos de baixa sensibilidade como ${ }^{13} \mathrm{C}$ e ${ }^{15} \mathrm{~N}^{[155]}$.

$\mathrm{O}$ valor da constante de acoplamento heteronuclear ${ }^{3} J_{C H}$ depende do ângulo diedro $(\theta)$ formado entre os núcleos acoplados que apresenta um comportamento geral descrito pela equação de Karplus para acoplamento ${ }^{3} J_{H H}{ }^{[34,37,43]}$. A dependência angular do acoplamento ${ }^{2} J_{C H}$ se origina das interações intramoleculares que os núcleos envolvidos participam devido a interações hiperconjugativas dos orbitais $\sigma_{\mathrm{CX}}$ ligantes, onde $\mathrm{X}$ é um substituinte eletronegativo ou antiligantes $\sigma^{*} \mathrm{CX}$ contendo os núcleos acoplados (Tabela 5).

Tabela 4. Efeito da orientação dos substituintes eletronegativos sobre o valor da constante de acoplamento heteronuclear a duas ligações $\left({ }^{2} J_{\mathrm{CH}}\right)^{[156]}$.

\begin{tabular}{|c|c|c|c|c|}
\hline Orientação & Ângulo diedro $(\theta)$ & ${ }^{2} \mathrm{~J}_{\mathrm{CH}}$ & $\begin{array}{l}\text { Exemplos } \\
\text { Substância }\end{array}$ & ${ }^{2} \mathrm{~J}_{\mathrm{C}_{1}, \mathrm{H}_{2}}$ \\
\hline$\underset{\text { (antiperiplanar) }}{\mathrm{O}-\mathrm{C}_{\mathrm{H}}^{\mathrm{C}}}$ & $\begin{array}{l}180^{\circ} \\
\theta\end{array}$ & positiva & & $+1 \mathrm{~Hz}$ \\
\hline $\mathrm{O}_{\mathrm{c}-\mathrm{c}^{\prime}}^{\mathrm{H}}$ & $\begin{array}{l}0^{\circ} \\
\theta \\
0 \\
\end{array}$ & negativa & & $-5,7 \mathrm{~Hz}$ \\
\hline
\end{tabular}

Outra importante característica da constante ${ }^{2} J_{C H}$ é sua dependência pronunciada da eletronegatividade dos substituintes. Basicamente, pode-se distinguir quatro padrões de 
acoplamentos diferentes, que podem ser subdivididos de acordo a existência ou não de um padrão análogo ao acoplamento próton-próton. Esta classificação pode ser útil se puder ser feito um paralelo entre ${ }^{2} J_{C C H} \mathrm{e}^{3} J_{H C H}$. Em alguns casos podem existir o acoplamento geminal entre os núcleos -C-O-H ou -C-NH-, ${ }^{2} J_{\mathrm{COH}} \mathrm{e}^{2} J_{\mathrm{CNH}}$, respectivamente ${ }^{[43,156]}$.

Em sistemas saturados os efeitos da eletronegatividade e dos pares de elétrons não ligantes do substituinte sobre a constante ${ }^{2} J_{C H}$ são análogos aos efeitos sobre ${ }^{2} J_{H H}$. A presença de substituintes eletronegativos ligados no carbono central aumenta o valor de ${ }^{2} J_{C H}$. Entretanto, se o substituinte eletronegativo estiver ligado ao carbono terminal a constante ${ }^{2} J_{C H}$ dependerá da orientação do substituinte (Tabelas 5 e 6). Quando este substituinte for um oxigênio com orientação antiperiplanar (ângulo diedro $\theta=180^{\circ}$ ) o valor de ${ }^{2} J_{C H}$ será positivo, se $\theta$ for igual a $0^{\circ} \mathrm{o}$ valor de ${ }^{2} J_{C H}$ será negativo (Tabelas 5 e 6) ${ }^{[43,156]}$.

Enquanto a constante de acoplamento ${ }^{3} J_{C H}$ pode ser utilizada na determinação da estereoquímica, a constante ${ }^{2} J_{C H}$ exibe um comportamento mais complexo, podendo ser positiva ou negativa, abrangendo uma faixa maior $(-10 \mathrm{a}+20 \mathrm{~Hz})^{[33,43,156]}$.

Basicamente, quatro padrões de acoplamento ${ }^{13} \mathrm{C},{ }^{1} \mathrm{H}$ a duas ligações podem ser distinguidos: dois são análogos a acoplamento homonuclear ${ }^{1} \mathrm{H},{ }^{1} \mathrm{H}$ e dois não apresentam analogia alguma ao acoplamento ${ }^{1} \mathrm{H},{ }^{1} \mathrm{H}$. Estes padrões são apresentados na Tabela 5.

O valor da constante de acoplamento a duas ligações do "tipo B" (Tabela 5) recebe uma contribuição negativa de substituintes em beta e uma contribuição positiva de substituintes em alfa.

Em sistemas cíclicos conjugados tipo $\mathrm{O}=\mathrm{C}-\mathrm{CH}=\mathrm{C}-$ a constante ${ }^{2} J_{C H}$ torna-se mais positivas com o aumento do ângulo de ligações $\mathrm{C}-\mathrm{C}-\mathrm{H}$. Um substituinte eletronegativo no carbono envolvido no acoplamento provoca um aumento positivo significativo no valor de ${ }^{2} J_{C H}$.

Os valores da ${ }^{2} J_{C H}$ em sistemas insaturados do "tipo C" (Tabela 5) são calculados a partir do valor de ${ }^{2} J_{C H}$ para o etileno $(2,4 \mathrm{~Hz})$ somado aos incrementos provocados por substituintes geminais e vicinais (trans ou cis). Os valores destes incrementos encontram-se, geralmente, tabelados nos livros que abordam a ressonância magnética nuclear como ferramenta da elucidação estrutural. 
Tabela 5. Padrões de acoplamento heteronuclear a duas ligações $\left({ }^{2} \mathbf{J}_{\mathrm{CH}}\right)$ e efeito de substituintes ${ }^{[43,156]}$

I) Acoplamentos análogos a H,H

Tipo A Exemplos:<smiles>CC(C)(C)C</smiles>

Sem substituintes eletronegativos

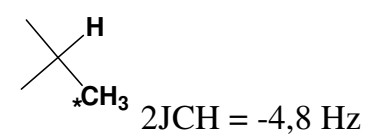

Com substituintes eletronegativos

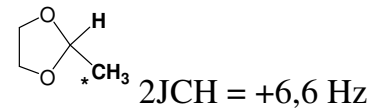

Tipo B

Em anéis: aumento do ângulo de ligação $\mathrm{C}-\mathrm{C}-\mathrm{H}$

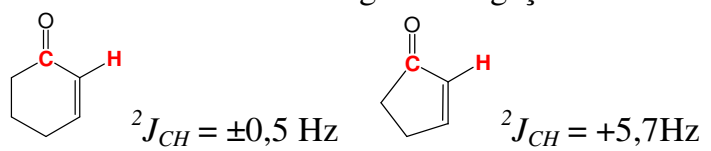

Contribuição positiva do substituinte no carbono participante do acoplamento trans-orientado

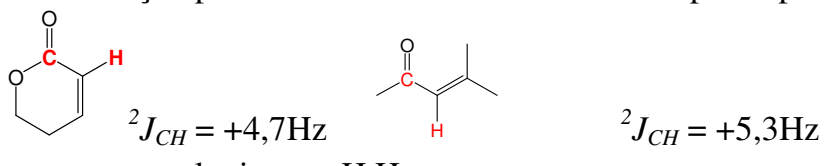

II) acoplamentos sem analogia com $\mathrm{H}, \mathrm{H}$

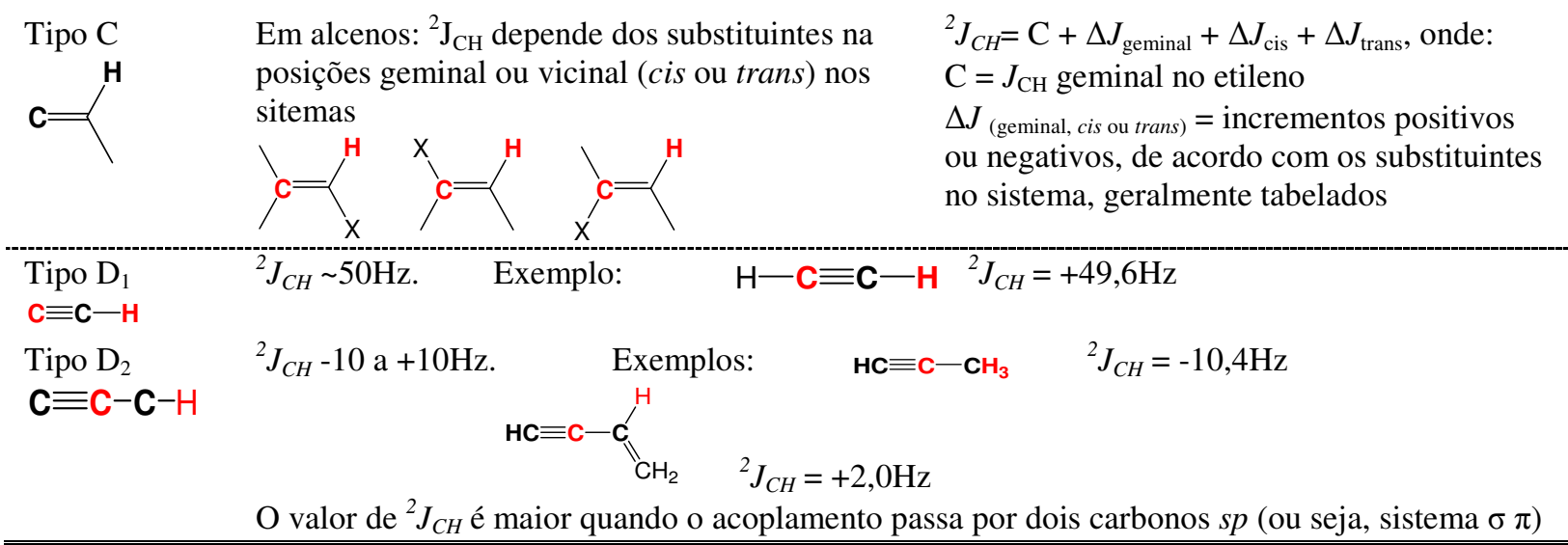

$\mathrm{O}$ sinal e a magnitude das constantes de acoplamento heteronuclear $\mathrm{CH}$ a três ligações $\left({ }^{3} J_{C H}\right)$ são funções do tipo de ligações entre os núcleos envolvidos. Portanto, este tipo de acoplamento é subdividido de acordo com os tipos de ligações e com a existência ou não de analogia com padrões de acoplamento homonuclear ${ }^{1} \mathrm{H},{ }^{1} \mathrm{H}$, conforme a Tabela 6. 
Tabela 6. Padrões de acoplamento heteronuclear a três ligações $\left({ }^{3} J_{\mathrm{CH}}\right)$ análogos a acoplamentos homonuclear ${ }^{1} \mathrm{H},{ }^{1} \mathrm{H}^{[43,156]}$.

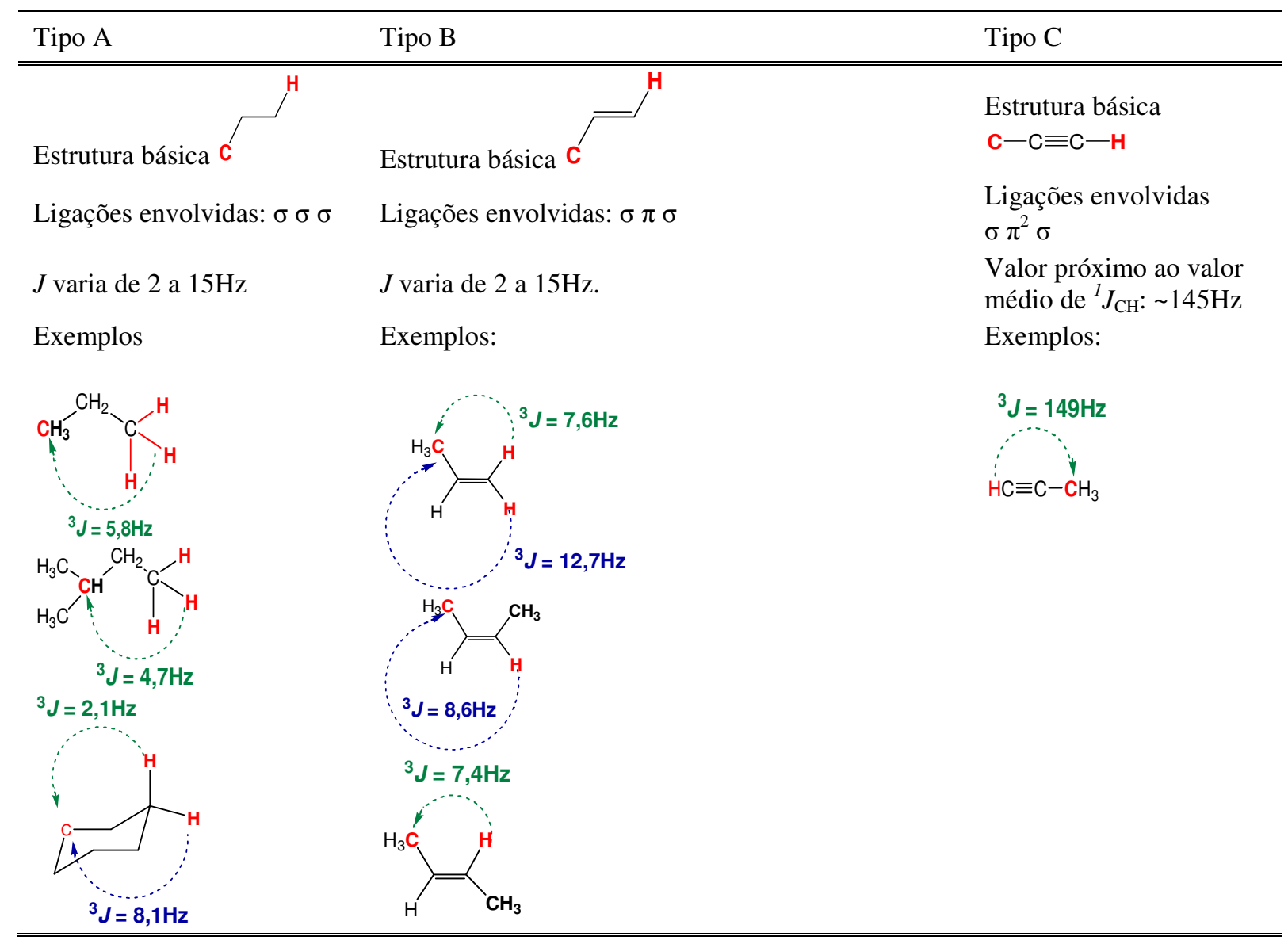

Novamente o valor ou magnitude da constante depende da proximidade de heteroátomos eletronegativos em relação aos átomos de carbonos centrais, estejam eles integrados à rede de acoplamento ou ao redor desta. Em contraste à ${ }^{2} J_{C H}$ a constante ${ }^{3} J_{C H}$ sempre será positiva, independente da natureza da ligação ou substituição.

O padrão de acoplamento mais estudado é o do tipo A (Tabela 7) que envolve três ligações simples contiguas $(\sigma \sigma \sigma)$.

Tabela 7. Padrões de acoplamento heteronuclear a três ligações $\left({ }^{3} \mathrm{~J}_{\mathrm{CH}}\right)$ sem analogia com acoplamentos homonuclear $\mathrm{H}, \mathrm{H}^{[43,156]}$

\begin{tabular}{lll}
\hline $\mathrm{D}$ & $\mathrm{E}$ & $\mathrm{F}$ \\
\hline \multicolumn{1}{c}{$\mathrm{C}-\mathrm{H}=\mathrm{C}^{\prime}$} & $\mathrm{C}^{\mathrm{H}}$ & $\mathrm{C}=\mathrm{C}=\mathrm{C}^{\prime}$ \\
$\sigma \sigma \pi$ & $\mathrm{C}=\mathrm{C}-\mathrm{C}^{\prime}$ & $\pi \pi \sigma$ \\
\hline \hline
\end{tabular}


Este tipo de acoplamento obedece à equação de Karplus e é evidenciado na Figura 15. A equação de Karplus, equação 21, relaciona o ângulo diedro $\theta$ formado entre os núcleos participantes do acoplamento com o valor da constante de acoplamento.

${ }^{3} J_{H, C}=A \cos ^{2}(\theta)+A \cos ^{2}(\theta)+C$

onde A, B, C são parâmetros derivados empiricamente a partir de valores dependentes dos átomos e substituintes envolvidos no acoplamento.

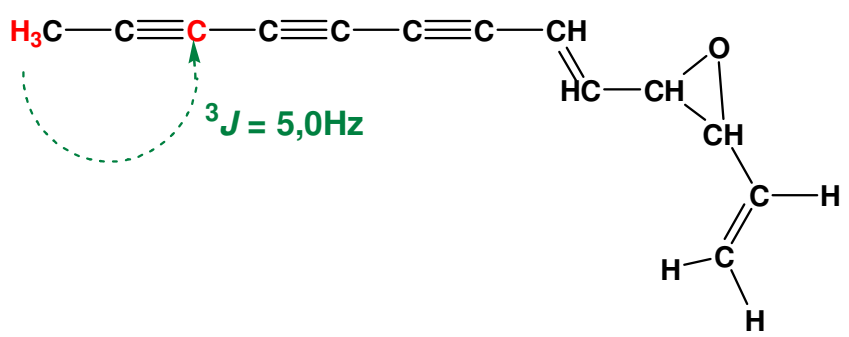

Figura 14. Exemplo de acoplamento tipo ${ }^{3} J_{C H}$ sem anologia com acoplamento homonuclear $\mathrm{H}, \mathrm{H}^{[43,156]}$

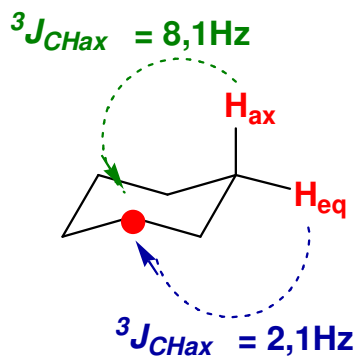

ciclo-hexano

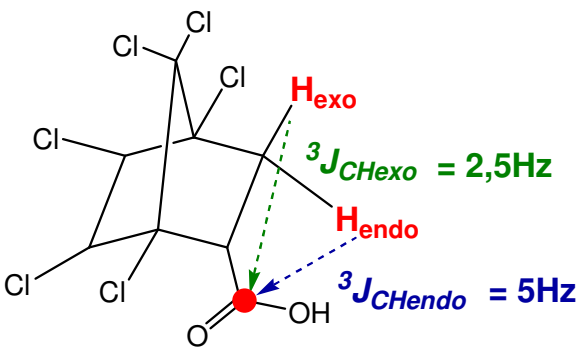

ácido

1,4,5,6,7,7-hexaclorobiciclo[2.2.1]heptano-2-carboxílico

Figura 15. Diferença de valores de constante de acoplamento em função da geometria molecular

Há vários métodos de determinação de constantes de acoplamento heteronuclear. Um método tradicionalmente usado é o HMBC (Heteronuclear multiple-bond correlation) que fornece informações apenas qualitativas, pois os acoplamentos homonucleares ${ }^{1} \mathrm{H},{ }^{1} \mathrm{H}$ podem distorcer a forma dos picos das correlações observada, este método não é usado para medida quantitativa de constantes de acoplamento heteronuclear ${ }^{[157,158]}$.

Outro método é uma versão HSQC (Heteronuclear single quantum correlation) adaptada, conhecida como HSQCMBC, que tem a vantagem de ser menos influenciada pela evolução do acoplamento homonuclear ${ }^{1} \mathrm{H},{ }^{1} \mathrm{H}$.

A sequência de pulsos CPMG (Carr-Purcell-Meiboom-Gill) ${ }^{[159]}$, comumente aplicada na determinação da constante de relaxação transversal $\mathrm{T}_{2}$, pode ser combinada com a HSQC, 
para a determinação de constante de acoplamento heteronuclear com a vantagem de suprimir a evolução do acoplamento homonuclear. As correlações observadas no espectro obtido a partir desta sequência de pulso apresentam boa intensidade sem problemas de fase ${ }^{[160]}$.

Uma dificuldade observada em alguns experimentos de determinação de constante de acoplamento heteronuclear a longa distância é a correlação incorreta de alguns picos causada pela evolução do acoplamento homonuclear de $J_{H H}{ }^{[157,158]}$.

Uma boa alternativa para eliminar este problema é uma adaptação da sequência CPMG, experimento G-BIRD ${ }_{\mathrm{R}, \mathrm{X}}-\mathrm{CPMG} \mathrm{HSQMBC}^{[158]}$ (Figura 14), que envolve além da sequência CPMG, uma sequência de HSQMBC, que permite a obtenção do valor numérico da constante de acoplamento e o filtro GBIRD que suprime o sinal referente aos ${ }^{1} \mathrm{H}$ ligados a ${ }^{12} \mathrm{C}$ $[33,157,158,160]$.

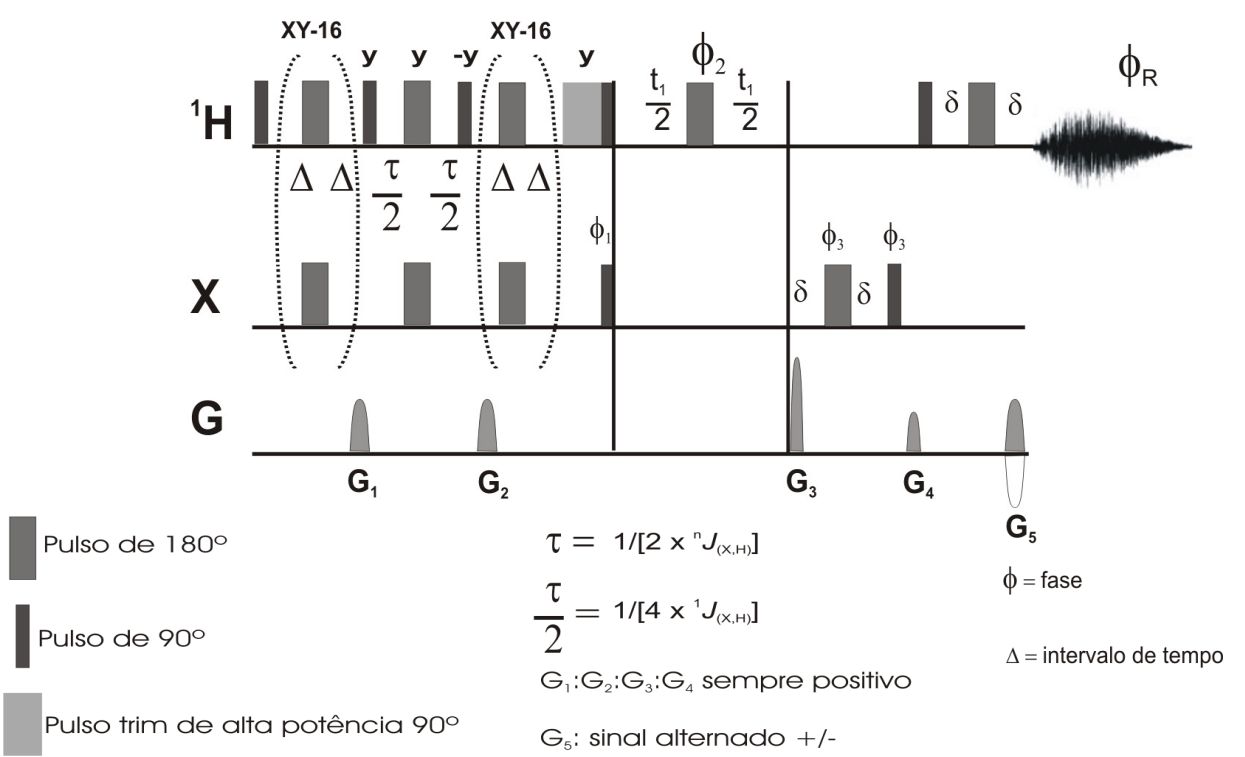

Figura 16. Experimento G-BIRD ${ }_{\mathrm{R}, \mathrm{X}}-\mathrm{CPMG}-\mathrm{HSQMBC}{ }^{[158]}$.

Por causa das linhas extremamente estreitas e comportamento de fase excelente fornecido pela sequência HSQMBC, as constantes de acoplamento heteronuclear entre singletos dos ${ }^{1} \mathrm{H}$ e ressonâncias de ${ }^{13} \mathrm{C}$ podem ser medidas diretamente a partir dos espectros de HSQMBC 1D ou 2D, a menos que a constante de acoplamento heteronuclear se aproxime da largura pico da correlação ${ }^{[161]}$.

Se a ressonância do próton de interesse for um multipleto, a interpretação do acoplamento heteronuclear fica dificultada. Uma maneira simplificada de simular o sinal observado consiste na adição de dois espectros de ${ }^{1} \mathrm{H}$, com fases invertidas um em relação ao outro e deslocados horizontalmente até que o espectro soma corresponda com o espectro a HSQMBC 1D ou uma fatia dos dados 2D HSQMBC. A magnitude do deslocamento 
horizontal é igual ao valor da constante de acoplamento heteronuclear. Devido às características de fase fornecida pelo experimento HSQMBC, o pico simulado deverá ser praticamente idêntico ao do experimento de correlação heteronuclear, resultando em um nível de confiança de pelo menos $\pm 0,5 \mathrm{~Hz}$ na medida da constante de acoplamento.

Ao contrário dos experimentos HMBC sensíveis à fase, o experimento HSQMBC requer apenas um multipleto de ${ }^{1} \mathrm{H}$ para a análise de ajuste de pico. Em regiões de sobreposição espectral na dimensão ${ }^{1} \mathrm{H}$, uma absorção pura de experimento TOCSY-2D ou HSQC pode ser usada para fornecer o multipleto de ${ }^{1} \mathrm{H}$ resolvido. ${ }^{[162]}$ 
O objetivo principal deste trabalho de doutorado foi buscar estratégias de aumento de eficiência da análise de produtos naturais por $\mathrm{RMN} \mathrm{de}{ }^{1} \mathrm{H} \mathrm{e}{ }^{13} \mathrm{C}$.

Neste sentido, um dos objetivos específicos é a avaliação da viabilidade de uma identificação sem separação prévia dos componentes de extratos vegetais, aproveitando as diferenças de seus coeficientes de difusão através da técnica de RMN de ${ }^{1} \mathrm{H}$ DOSY-2D.

O segundo objetivo específico foi avaliar o aumento da relação sinal/ruído de espectros de $\mathrm{RMN}$ de ${ }^{13} \mathrm{C}$ através do processamento do sinal por SVD ("singular value decomposition").

A terceira meta é ampliar os parâmetros rotineiramente obtidos numa análise por RMN, incluindo a determinação das constantes de acoplamento heteronuclear $\left({ }^{n} J_{\mathrm{CH}}\right)$, com a finalidade de fornecer novos subsídios para a determinação da estrutura de produtos naturais. 


\subsection{Análises por RMN}

\subsubsection{Equipamentos utilizados para análise por RMN}

Para as análises por RMN realizadas durante este trabalho foram utilizados os seguintes equipamentos:

\subsubsection{Espectrômetro BRUKER ${ }^{\circledR}$-Modelo DRX500 - Ultra Shield ${ }^{\circledR}$}

Com magneto de 11,74 Teslas e sonda multinuclear de detecção inversa $\left({ }^{1} \mathrm{H}: 500,13\right.$ $\mathrm{MHz},{ }^{13} \mathrm{C}: 125,77 \mathrm{MHz}$ ) para tubos de amostras de $5 \mathrm{~mm}$ de amostra, com sistema de "lock" de Deutério $\left({ }^{2} \mathrm{H}\right)$ e bobina geradora de gradiente de campo em z (campo máximo de 53,5 Gauss. $\mathrm{cm}^{-1}$ ). Para os experimentos realizados com controle de temperatura foi utilizada unidade de temperatura variável, modelo BVT-3200 (BRUKER®) e um sensor tipo termopar, modelo T, com fluxo de nitrogênio líquido para estabilizar a temperatura em 300K.

\subsubsection{Espectrômetro BRUKER ${ }^{\circledR}$-Modelo DRX400}

Com magneto de 9,40 Teslas e e sonda dual de detecção direta $\left({ }^{1} \mathrm{H}: 400,13 \mathrm{MHz},{ }^{13} \mathrm{C}\right.$ : 100,613 MHz) para tubos de amostras de $5 \mathrm{~mm}$ de amostra, com sistema de "lock" de Deutério $\left({ }^{2} \mathrm{H}\right)$.

\subsubsection{Espectrômetro BRUKER ${ }^{\circledR}$-Modelo DPX300}

Com magneto de 7,05 Teslas e e sonda multinuclear de detecção inversa $\left({ }^{1} \mathrm{H}: 300,13\right.$ $\mathrm{MHz},{ }^{13} \mathrm{C}: 75,468 \mathrm{MHz}$ ) para tubos de amostras de $5 \mathrm{~mm}$ de amostra, com sistema de "lock" de Deutério $\left({ }^{2} \mathrm{H}\right)$, bobina geradora de gradiente em z (campo máximo de 53,5 Gauss.cm-1). 


\subsection{Origem dos Materiais Vegetais}

No presente trabalho foram analisadas substâncias obtidas de três espécies de plantas: duas da família Asteraceae (Bidens sulphurea e Bidens gardneri) e uma da família Annonaceae (Duguetia furfuracea). No apêndice B, no final deste trabalho, são apresentadas as descrições das espécies e respectivas famílias.

A coleta das asteráceas, bem como a obtenção e fracionamento de seus extratos hidroalcoólicos foram realizados por Denise Brentan da Silva ${ }^{[163]}$, como parte de seu doutoramento em Ciências Farmacêuticas da Faculdade de Ciências Farmacêuticas de Ribeirão Preto (FCFRP/USP).

A coleta e fracionamento da $D$. furfuracea também foram realizadas por Denise Brentan da Silva ${ }^{[164]}$ durante seu mestrado em Química pela Universidade Federal de Mato Grosso do Sul (UFMS). A descrição deste processo encontra-se no Apêndice $\mathbf{C}$ no final deste trabalho. 


\subsection{A RMN DOSY-2D na análise de frações do extrato etanólico de Bidens sulphurea}

\subsubsection{Obtenção e identificação dos componentes da fração acetato de etila do extrato etanólico de Bidens sulphurea}

As partes aéreas (folhas e caules) da planta B. sulphurea (Cav.) Sch. Bip. (Asteraceae) foram coletadas em Julho de 2006 no município de Campo Grande/MS, identificadas pela Profa. Dra. Mara Angelina Galvão Magenta (Universidade Santa Cecília/SP). Uma exsicata foi depositada no Herbário CG/MS (UFMS, Campo Grande, MS). Cabe salientar que a coleta do material vegetal, bem como a obtenção e fracionamento do extrato hidroalcoólico de $B$. sulphurea foram realizados por Denise Brentan da Silva, como parte de seu doutoramento em Ciências Farmacêuticas da Faculdade de Ciências Farmacêuticas de Ribeirão Preto (FCFRP/USP).

O extrato etanólico-aquoso foi obtido após a extração com etanol 90\% por percolação das partes aéreas de $B$. sulphurea, secas e trituradas $(2,07 \mathrm{~kg})$. Posteriormente, foi submetido a um fracionamento por partição líquido-líquido com hexano (Hex), diclorometano (DCM) e acetato de etila (AcOEt), obtendo-se as frações: hexânica, diclorometânica, acetato e metanólica. As três frações bem como o extrato bruto foram submetidos à análise por RMNDOSY-2D.

\subsubsection{Obtenção de espectros DOSY (1D e 2D)}

Os experimentos DOSY-(1D e 2D) foram realizados como indicado por Kerssembaum ${ }^{[165]}$, utilizando as sequências de pulsos ledbpgp $2 s 1 d^{\mathrm{TM}}$ e ledbpgp $2 s^{\mathrm{TM}}$ (Figura 17), que envolvem: dois pulsos de gradiente em $z$ bipolares; um intervalo de tempo para dissipação de correntes parasitas ("eddy currents"); dois pulsos de "spoil" (purga) para eliminar magnetizações indesejadas oriundas de imperfeições experimentais. 


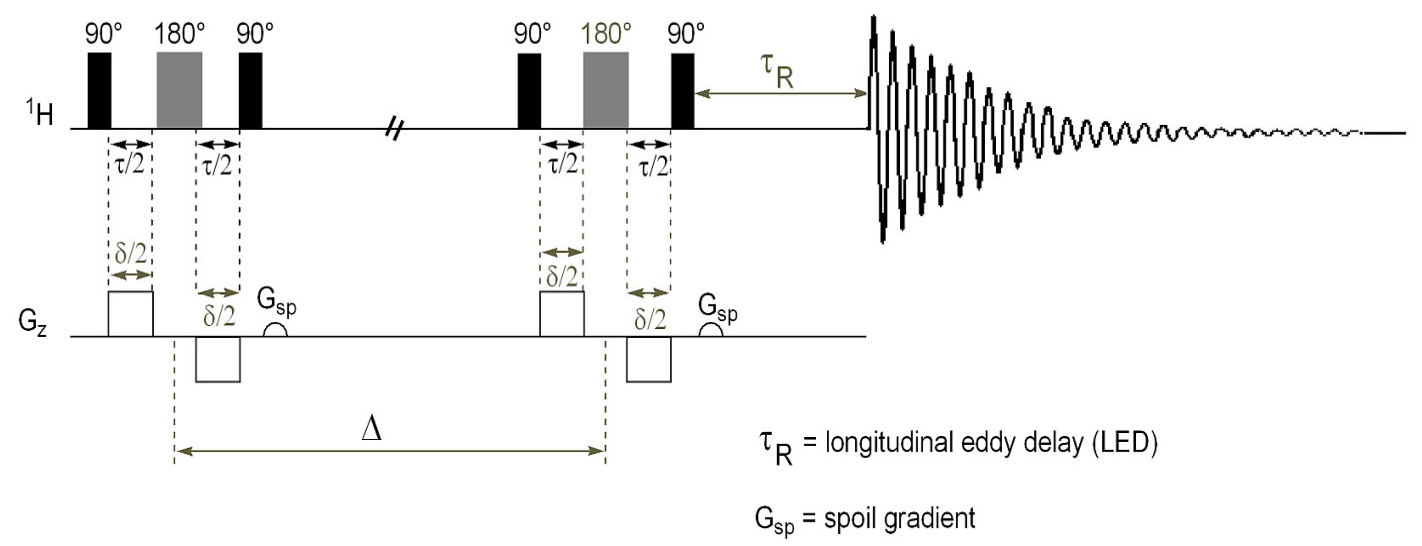

Figura 17. Sequência de pulso ledbpgp2s usada nos experimentos DOSY-2D.

\subsubsection{Processos cromatográficos e espectroscópicos usados para a verificação qualitativa da confiabilidade da análise por DOSY (1D e 2D)}

\subsubsection{Análise Cromatográfica de BSAcOEt}

Primeiramente, foi realizada uma coluna cromatográfica de Sephadex- LH20® de BSAcOEt, que resultou em 233 frações de $25 \mathrm{~mL}$ cada. As frações entre 69 e 89 foram reunidas por apresentarem alta semelhança na cromatografia de camada delgada comparativa (CCDC), utilizando como fase móvel AcOET:HAc:HForm:H2O (100:11:11:26) e NP/PEG como revelador. Após a evaporação do solvente esta mistura apresentou aspecto de sólido amorfo e foi, então, submetida à CLAE-UV a $270 \mathrm{~nm}$, utilizando como fase estacionária reversa uma coluna C-18 semipreparativa (Shim-pack Prep-ODS (Kit) - Shimadzu, 20 mm DI x $25 \mathrm{~cm}$ ). A fase móvel foi composta pelo sistema 'eluente A' (ACN com 0,01\% de TFA) e sistema 'eluente B' (H2O com $0,01 \%$ de TFA), com um gradiente linear de $15 \%$ a $100 \%$ do 'eluente A' por 64 minutos e um gradiente linear de 100\% a 15\% do 'eluente A' durante 70 a 85 min a uma a vazão de $9 \mathrm{~mL} \cdot \mathrm{min}^{-1}$. Este processo possibilitou a separação dos quatros componentes principais da fração acetato.

\subsubsection{Análise espectroscópica dos componentes majoritários de BSAcOEt}

Os componentes majoritários de BSAcOEt foram analisados por EM-ESI e por RMN$1 \mathrm{D}$ de ${ }^{1} \mathrm{H}$ e de ${ }^{13} \mathrm{C}\left({ }^{13} \mathrm{C}\left\{{ }^{1} \mathrm{H}\right\}\right.$ e DEPT $\left.135^{\circ}\right)$ e RMN-2D (HMQC e HMBC). 


\subsection{O tratamento de sinal de RMN por SVD}

\subsubsection{Condições dos espectros de RMN de ${ }^{13} \mathrm{C}\left\{{ }^{1} \mathrm{H}\right\}$ para aplicação do método de seccionamento.}

Os parâmetros de aquisição e processamento como: largura espectral (sw), posição da radiação na frequência da metade de sw (o1p); solvente, número de pontos no domínio do tempo (TD); número de pontos no domínio da frequência (SI); função de janela (Wdw); entre outros, foram ajustados conforme as características de cada amostra analisada, de modo a se obter espectros com a melhor resolução possível. Para simplificar e minimizar o tempo do processo optou-se por trabalhar preferencialmente com FID com TD=16384 pontos e espectros transformados com $\mathrm{SI}=8192$ pontos.

\subsubsection{Programas computacionais utilizados para a filtragem do sinal de RMN de ${ }^{13} C\left\{{ }^{1} \mathrm{H}\right\}$ por SVD.}

Para o processamento do FID e prepará-lo para o tratamento com SVD, foram utilizados os programas de processamento de espectros de RMN (MestreNova ${ }^{\circledR}$, Bruker XWinNMR®, TOPSPIN®, SpinWoks ${ }^{\circledR}$ e/ou ACDLabs®).

Para o seccionamento e aplicação de SVD foram elaboradas rotina na linguagem do programa Matlab® versão 7.04 da “The MathWorks, Inc".

Para o processamento dos espectros DOSY-2D foi utilizado a rotina de de processamento disponível no TOPSPIN®.

\subsubsection{Obtenção das amostras analisadas por $\mathrm{RMN}$ de ${ }^{13} \mathrm{C}\left\{{ }^{1} \mathrm{H}\right\}$ tratado por SVD}

\subsubsection{Obtenção da Fração DF, a partir do extrato alcaloídico das cascas do caule subterrâneo de Duguetia furfuracea}

A fração A foi gentilmente cedida por Denise Brentan da Silva. A obtenção desta fração, a partir das partes subterrâneas (casca do raiz e madeira) de Duguetia furfuracea (A. St .- Hil.) Benth. \& Hook f., foi realizada durante seu curso de mestrado na Universidade 
Federal de Mato Grosso do Sul. O procedimento detalhado desta obtenção é descrito ao final deste trabalho no Apêndice C.

\subsubsection{Obtenção das substâncias 7 - 9 a partir da fração acetato de etila do extrato hidroalcoólico das partes aéreas de $B$. gardneri}

As partes aéreas de Bidens gardneri Bak. foram coletadas em Outubro de 2005 e Fevereiro de 2006 nos municípios de Aquidauana/MS e Barão de Melgaço/MT, ambos encontram-se na região da região do Pantanal Sul-mato-grossense. Sua identificação foi feita pelo pesquisador Arnildo Pott (EMBRAPA de Campo Grande/MS) e exsicatas foram depositadas no herbário da EMBRAPA, Campo Grande/MS, sob os números A. Pott 13.680 e A. Pott 13.855 .

O extrato hidroalcoólico das partes aéreas (folhas e caules) de B. gardneri foi obtido a partir de 694,30 g do material seco e triturado, submetido à extração por percolação com etanol $90 \%$ e fluxo de 20 gotas/min e concentrado em rotaevaporador, resultando em 110,34 g de extrato hidroalcoólico bruto seco.

Parte deste extrato bruto seco (101,56 g) foi solubilizada em 1,5 L de solução $\mathrm{MeOH}: \mathrm{H}_{2} \mathrm{O}$ (9:1), obtendo-se uma solução hidrometanólica que foi submetida a partição líquido-líquido com Hex, DCM e AcOEt, obtendo-se quatro frações: Hexânica, Diclorometânica, Acetato e Hidrometanólica.

Uma alíquota de 2,98 g da fração acetato de etila do extrato hidroalcoólico das partes aéreas de B. gardneri foi analisada em CLAE-DAD, sendo constatada a presença de substâncias com espectros de UV compatíveis com poliacetilenos. Esta fração foi então submetida à cromatografia em coluna aberta de Sephadex LH-20, utilizando MeOH em sistema isocrático, sempre com a menor presença de luz possível, para preservar os poliacetilenos. Este procedimento resultou a obtenção de 53 frações de $90 \mathrm{~mL}$ que foram concentradas em rotaevaporador, na ausência de luz, e analisadas em CLAE-DAD e reunidas em 19 grupos de acordo com os seus perfis cromatográficos.

A oitava fração da Coluna de Sephadex LH-20, obtida da Fração Acetato, depois de seca, apresentou uma massa de 208,7 mg foi analisada por CLAE-DAD, que confirmou a presença de poliacetilenos. Assim, esta fração foi purificada por CLAE-UV utilizando uma 
coluna semi-preparativa de C18 (Shim-pack Prep-ODS, marca Shimadzu, sendo: a analítica com 4,6 mm de DI e $25 \mathrm{~cm}$ comprimento e a preparativa com $20 \mathrm{~mm}$ de DI e $25 \mathrm{~cm}$ de comprimento). O fluxo de eluição foi de $9 \mathrm{~mL} / \mathrm{mim}$, comprimento de onda foi selecionado em $280 \mathrm{~nm}$ e como fase móvel composta pelos eluentes: $\mathrm{ACN}$ (bomba B) e $\mathrm{H}_{2} \mathrm{O}$ (bomba A) variando linearmente de 10 a $100 \%$ de ACN até 47 min de experimento e de $100 \%$ a $10 \%$ de ACN de 50 a 52 min, mantendo-se em $10 \%$ até o final $\left(60^{\circ} \mathrm{min}\right)$.

Deste processo foram selecionadas para aplicação do método de processamento por seccionamento e SVD ${ }^{[148,150,151,166]}$ e/ou para estudo de determinação de constante de acoplamento heteronuclear a duas ou três ligações, as seguintes substâncias:

- A substância (10) com tempo de retenção igual a 25,7 min;

- A substância (11) com tempo de retenção igual a 28,0 min.

A décima fração da Coluna de Sephadex LH-20, obtida da Fração Acetato, apresentou depois de seca a massa de 113,4 mg. Sendo, também, composta por uma mistura de poliacetilenos foi submetida à purificação por CLAE-UV. Para tanto, utilizou-se uma coluna semi-preparativa de C18 (Shim-pack Prep-ODS, marca Shimadzu, sendo: a analítica com 4,6 $\mathrm{mm}$ de DI e $25 \mathrm{~cm}$ comprimento e a preparativa com $20 \mathrm{~mm}$ de DI e $25 \mathrm{~cm}$ de comprimento), com fluxo de $9 \mathrm{~mL} / \mathrm{mim}$, comprimento de onda $270 \mathrm{~nm}$ e fase móvel composta pelos eluentes: $\mathrm{ACN}$ (bomba B) e $\mathrm{H}_{2} \mathrm{O}$ (bomba A), variando linearmente de 20 a $46 \%$ de ACN até 35 min; de 46 a $100 \%$ de ACN até 38 min de experimento e de $100 \%$ a $20 \%$ de ACN até $43 \mathrm{~min}$, mantendo-se assim até o final do experimento $\left(48^{\circ} \mathrm{min}\right)$. Deste processo foi selecionado o composto com tempo de retenção igual a 15,6 min (11,1 mg).

A análise do perfil cromatográfico em CLAE-DAD da décima fração da Coluna de Sephadex LH-20 da Fração Acetato mostrou que se tratava de mistura de flavonóides, cujo o componente majoritário apresentava espetro de UV característico de uma flavona. Logo, esta fração foi submetida à recristalização com $\mathrm{MeOH}$ e acetona (precipitado = 46,9 mg), obtendose a 7-O- $\beta$-glicopiranosil-apigenina (8), que posteriormente foi submetida aos experimentos de RMN abordados no presente trabalho.

As frações de 30 e 31 da Coluna de Sephadex LH-20 da Fração Acetato foram reunidas e submetidas ao processo de purificação por recristalização com AcOEt e $\mathrm{MeOH}$, obtendo-se 9,7 mg da substância 9, também selecionada para o presente estudo. 


\subsection{Constantes de acoplamento heteronuclear a longa distância, ${ }^{\mathrm{n}} J_{\mathrm{CH}}$}

Para o estudo das constantes de acoplamento heteronuclear ${ }^{\mathrm{n}} J_{\mathrm{CH}}$ foi utilizado o experimento G-BIRD ${ }_{\mathrm{R}, \mathrm{X}}-\mathrm{CPMG}-\mathrm{HSQMBC}^{[158]}$. 


\section{RESULTADOS E DISCUSSÃO}


Uma vez que objetivo principal deste trabalho é a busca por estratégias de aumento de eficiência da análise de produtos naturais por RMN, visando a redução de tempo e custo de análise de produtos naturais, como mencionado anteriormente, aplicou-se três estratégias:

$\checkmark$ Técnica de RMN DOSY-2D: estratégia de análise de produtos naturais em mistura, ou seja, sem separação prévia;

$\checkmark$ Método seccionamento e filtragem de sinal, via processamento ${ }^{[148,150,151,166] \text { : }}$ estratégia de aumento da sensibilidade (ou aumento da relação sinal/ruído, S/R) de $\mathrm{RMN}$ de ${ }^{13} \mathrm{C}$ de amostras diluídas;

$\checkmark$ Experimento G-BIRD ${ }_{\mathrm{R}, \mathrm{X}}$-CPMG-HSQMBC ${ }^{[158]}$ para determinar constante de acoplamento heteronuclear a longa distância: estratégia de agilizar a identificação de poliacetilenos, incluindo informações sobre suas estereoquímicas.

Os resultados da aplicação destas estratégias são apresentados a seguir. 


\subsection{Análise da fração Acetato de etila do extrato etanólico das partes aéreas de B. sulphurea por RMN: DOSY-2D}

\subsubsection{Obtenção e análise do espectro DOSY-2D da fração BSAcOEt}

Para uma análise preliminar, o extrato etanólico bruto e suas três frações foram submetidos a experimentos de RMN DOSY-2D. O perfil do espectro de DOSY-2D da fração diclorometânica (BSDCM) foi bastante semelhante ao da fração acetato de etila (BSAcOEt). Como o espectro da fração BSAcOEt apresentou uma resolução um pouco melhor, optou-se por aprimorar o estudo desta fração.

A intensidade do sinal obtido depende do coeficiente da difusão, da intensidade do gradiente $(g)$ e do tempo de duração $(\delta)$ do pulso de gradiente de campo (PFG). Se não ocorrer a difusão, o sinal obtido terá intensidade máxima, mas caso ela ocorra, o sinal obtido será atenuado, conforme a seguinte equação ${ }^{[68]}$ :

$$
\mathrm{I}=\mathrm{I}_{0} \exp \left[(-\mathrm{D}) \cdot(\gamma \mathrm{g} \delta)^{2} \cdot(\Delta-\delta / 3)\right]
$$

onde, $I_{0}$ é a intensidade do sinal na ausência do PFG, $\Delta$ é $o$ tempo de difusão, D é o coeficiente de difusão $e \gamma$ é a razão giromagnética do núcleo sob investigação. Deste modo, dois experimentos DOSY-1D foram realizados com 5 e $95 \%$ de g, com valores iniciais de $\Delta$ e $\delta, 2000 \mu$ s e $50 \mathrm{~ms}$, respectivamente.

Considerando a intensidade do sinal obtido com $5 \%$ de g igual a $I_{0}$ e a intensidade do sinal com $95 \%$ de g igual a $\mathrm{I}$, determina-se a relação $I / I_{0}$. Se $I / I_{0}$ for igual a 0,05 significa que o experimento de $D O S Y-2 D$ um decaimento exponencial que obedecerá a Equação 1 e terá uma boa resolução na dimensão de Log D. Caso contrário, novos pares de experimentos $1 D$ devem ser realizados, variando-se o valor de $\Delta$ ou $\delta$ até obter a relação $I / I_{0}=0,05$. Nota-se que a variação de $\delta$ proporciona um maior efeito sobre I e, portanto, deve ser o parâmetro variável. Assim, o valor do tempo de aplicação do pulso de gradiente de campo, $\delta$ foi ajustado para as condições da análise (tipo da amostra, concentração relativa dos componentes da amostra, solvente, etc.).

Para ajustar o melhor valor de $\delta$ para a análise da fração BSAcOEt por DOSY-2D foram realizados vários experimentos de DOSY-1D, com os parâmetros de aquisição listados 
na Tabela 8 que foram sempre os mesmos, com exceção do valor de $\delta$ que inicialmente foi igual a $2000 \mu$ s e variou de 100 em $100 \mu$ s até o valor de $4000 \mu$ s.

Para cada valor de $\delta$, foram realizados dois experimentos, um com a magnitude do gradiente $(g)$ em seu valor máximo (95\% de $g$ ) e outro no seu valor mínimo $(5 \% g)$. Os espectros gerados com o processamento de cada par de experimentos com o mesmo valor de $\delta$ foram comparados quanto à intensidade dos sinais. Se a intensidade do sinal do espectro adquirido com $95 \%$ de $g$ fosse igual a cinco por cento da intensidade do espectro adquirido com 5\% de g, o valor de $\delta$ utilizado nesses experimentos seria considerado o valor adequado para a realização do experimento DOSY-2D para a amostra e condições de análise em questão.

Cabe salientar que estes valores não são nem 100\% de g nem 0\% de g para garantir que o sinal a ser adquirido não ultrapasse a capacidade do amplificador e do registrador de sinal do espectrômetro, nem seja tão pequeno que não possa ser detectado.

O valor de $\delta$ estabelecido neste processo foi de $3250 \mu$ s. Assim, realizou-se o experimento de RMN DOSY-2D com $\delta=3250 \mu$ s e uma variação linear de 5 a $95 \%$ de força de gradiente com 32 passos.

Tabela 8. Parâmetros de aquisição dos espectros de DOSY-1D da Fração BSAcOEt realizados para ajuste do valor de tempo de aplicação do pulso de gradiente de campo $(\delta)$

\begin{tabular}{llll}
\hline \hline Parâmetro (unidade) & Valor & Parâmetro (unidade) & Valor \\
\hline \hline Valor inicial de $\delta(\mu \mathrm{s})$ & 2000 & Largura espectral =sw (ppm) & 15,011 \\
Tempo de difusão $=\Delta(\mathrm{ms})$ & 50 & Metade de $\mathrm{sw}=\mathrm{sw} / 2(\mathrm{ppm})$ & 7,00 \\
Máximo da magnitude do gradiente $-g$ & $95 \% \mathrm{~g}$ & Número de varreduras $=n s$ & 32 \\
Mínimo da magnitude do gradiente $-g$ & $5 \% \mathrm{~g}$ & Temperatura $(\mathrm{K})$ & 300 \\
Tempo de espera para recuperar & 200 & Duração do pulso de purga = 'spoil & 1000 \\
gradiente =d16 $(\mu \mathrm{s})$ & & gradients' = p19 $(\mu \mathrm{s})$ & 32768 \\
Solvente & DMSO-d $_{6}$ & Número de pontos do FID =TD & 3 \\
\hline \hline
\end{tabular}

Uma rápida inspeção dos espectros de RMN 1H e DOSY (Figuras 18 e 19) mostra que a amostra é constituída por uma mistura de quatro substâncias majoritárias que apresentam um alto grau de similaridade estrutural, com $\log \mathrm{D}$ entre $-9,8$ e -10,0.

Agrupamentos de sinais podem fornecer pistas importantes sobre as estruturas destas substâncias: 
$\checkmark$ O primeiro grupo (Figura 18) é composto por sinais largos em 9,24; 9,73 e 10,88 ppm, típicos de hidroxilas fenólicas e um sinal maior e estreito 12,65 ppm, característico de hidroxila quelada a uma carbonila.

$\checkmark$ O segundo grupo compreende os sinais na região dos hidrogênios ligados a anel aromático, ou seja, em 6,21 ppm, 6,41 ppm, 6,82 ppm (dubleto, $J=8,5 \mathrm{~Hz}$ ), 7,48 ppm (dubleto, $J=2,0 \mathrm{~Hz}$ ) e 7,67 ppm (duplo-dubleto, $J=2,0$ e $8,5 \mathrm{~Hz}$ ), Figura 18.

Juntos, esses grupos de sinais apontam para uma estrutura de polifenóis, mais especificamente um flavonóide, já que o sinal em 12,65ppm é típico de um flavonóide com hidroxila no $\mathrm{C}-5^{[167]}$.

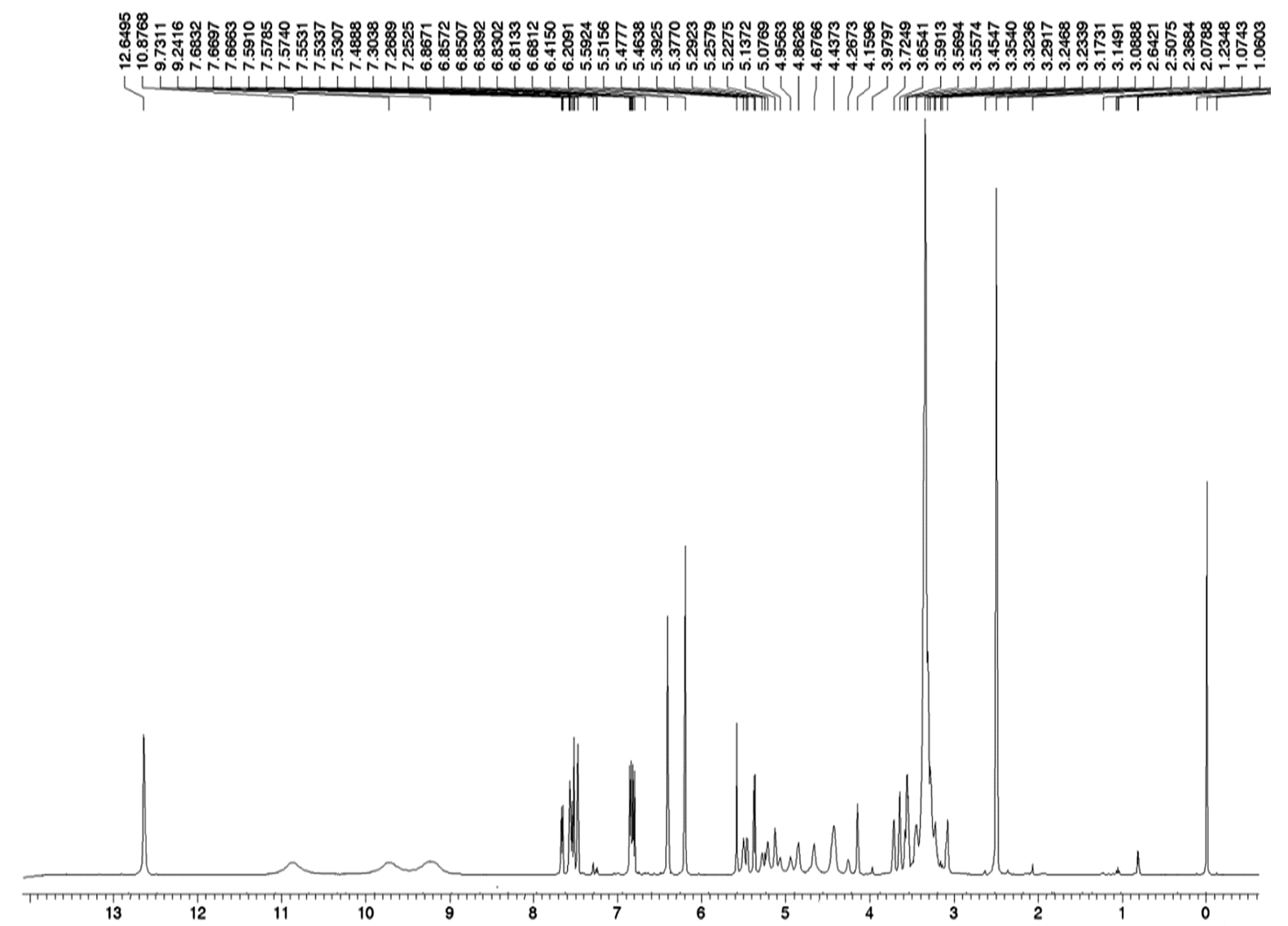

Figura 18. Espectro de RMN de ${ }^{1} \mathrm{H}(500 \mathrm{MHz})$ da fração Acetato (BSAcOEt) do extrato etanólico das partes aéreas de $B$. sulphurea. 


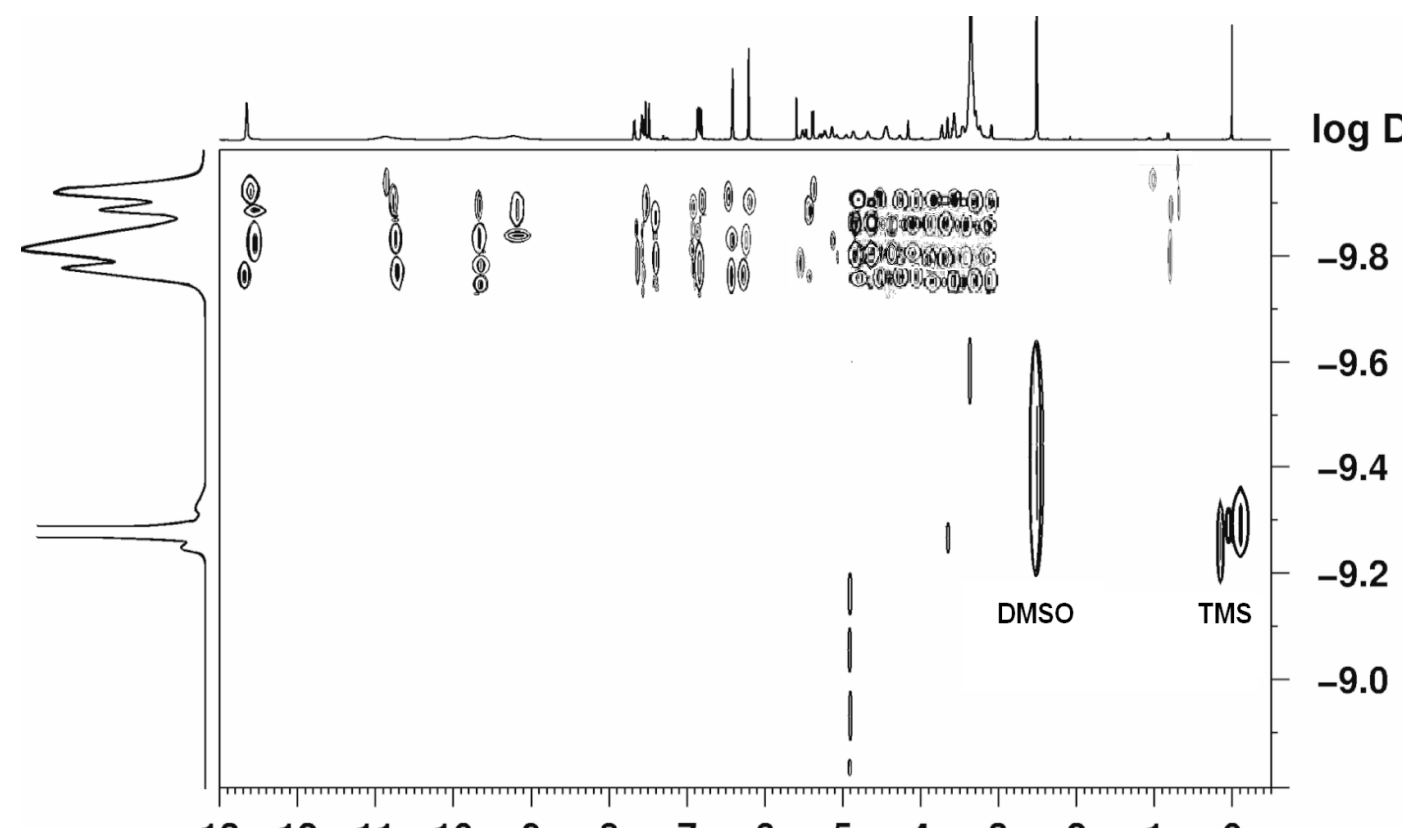

$\begin{array}{lllllllllllllll}13 & 12 & 11 & 10 & 9 & 8 & 7 & 6 & 5 & 4 & 3 & 2 & 1 & 0 & \mathrm{ppm}\end{array}$

Figura 19. DOSY-2D de BSAcOEt em DMSO-d6: $\Delta=50 \mathrm{~ms} ; \delta=3250 \mu \mathrm{s}$.

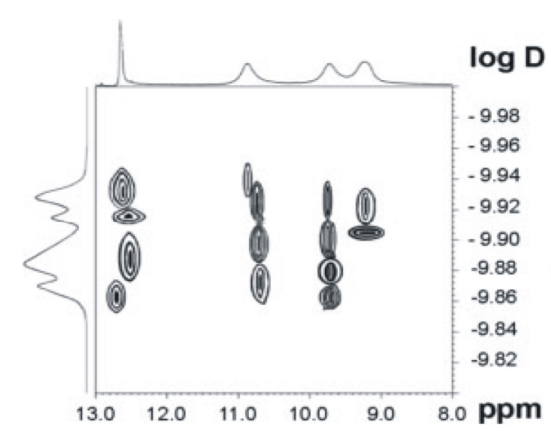

(a) Região de prótons de hidroxilas de polifenóis

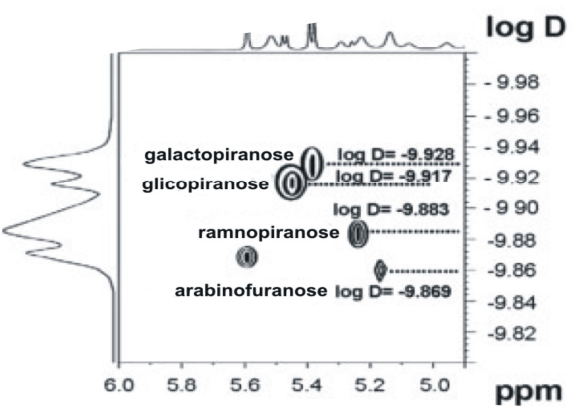

(b) Região de prótons ligados a carbonos anoméricos

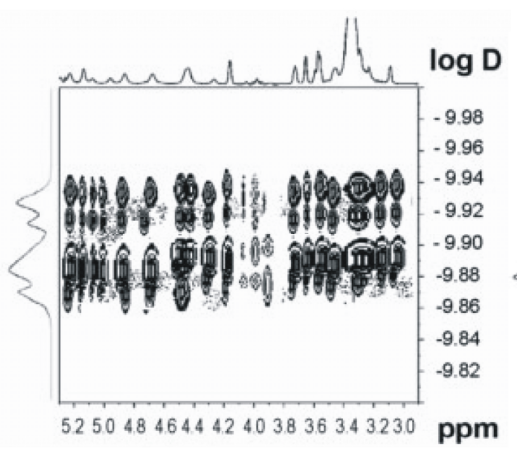

(c) Região de prótons ligados a prótons carbinólicos de açucar

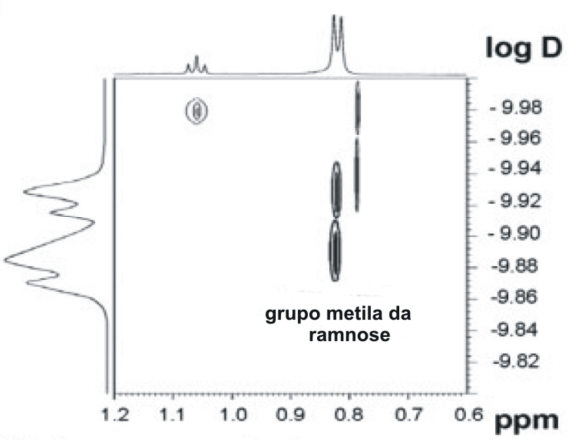

(d) Região de prótons típicos de metila da ramnose

Figura 20. Ampliações do espectro de RMN DOSY-2D de BSAcOEt em DMSO-d $d_{6}: \Delta=50 \mathrm{~ms}$; $\delta=3250 \mu$ s. 
Em um campo mais alto, na região entre 3,0 e 5,6 ppm, um outro grupo de sinais pode ser atribuído à presença de açúcar nas moléculas. Neste grupo, separado do conjunto principal, é possível identificar os prótons anoméricos entre 5,2 e 5,6 ppm (Figura 20b). De modo geral, estas observações apontam para flavonóides glicosilados. A atribuição de sinais e sua comparação com publicados na literatura levam a concluir que a aglicona (porção aromática) é uma unidade de quercetina ${ }^{[167]}$.

Os deslocamentos químicos de prótons anoméricos de açúcar de vários flavonóides glicosilados são bem conhecidos na literatura ${ }^{[4,167,168,169,170,171,172]}$. Com base nestes dados, os sinais em 5,38 ppm (dubleto, $J=7,7 \mathrm{~Hz}$ ), 5,47 ppm (dubleto , $J=7,2 \mathrm{~Hz}$ ) e 5,51 (singleto largo) sugerem que três dos açúcares presentes podem ser a glicopiranose, a galactopiranose e a arabinofuranose, respectivamente (Figuras 20b e 21).

O quarto componente majoritário da fração BSAcOEt apresenta uma correlação do log $\mathrm{D}=-9,88$ com o singleto largo em 5,23 ppm (referente a um próton anomérico) e com o dubleto $(\mathrm{J}=6,2 \mathrm{~Hz}$ ) em $0,82 \mathrm{ppm}$ referente a prótons metílicos (Figuras 20b e 21). Estas correlações sugerem que o açúcar presente no quarto componente da fração é uma ramnopiranose ${ }^{[168,173,174]}$.

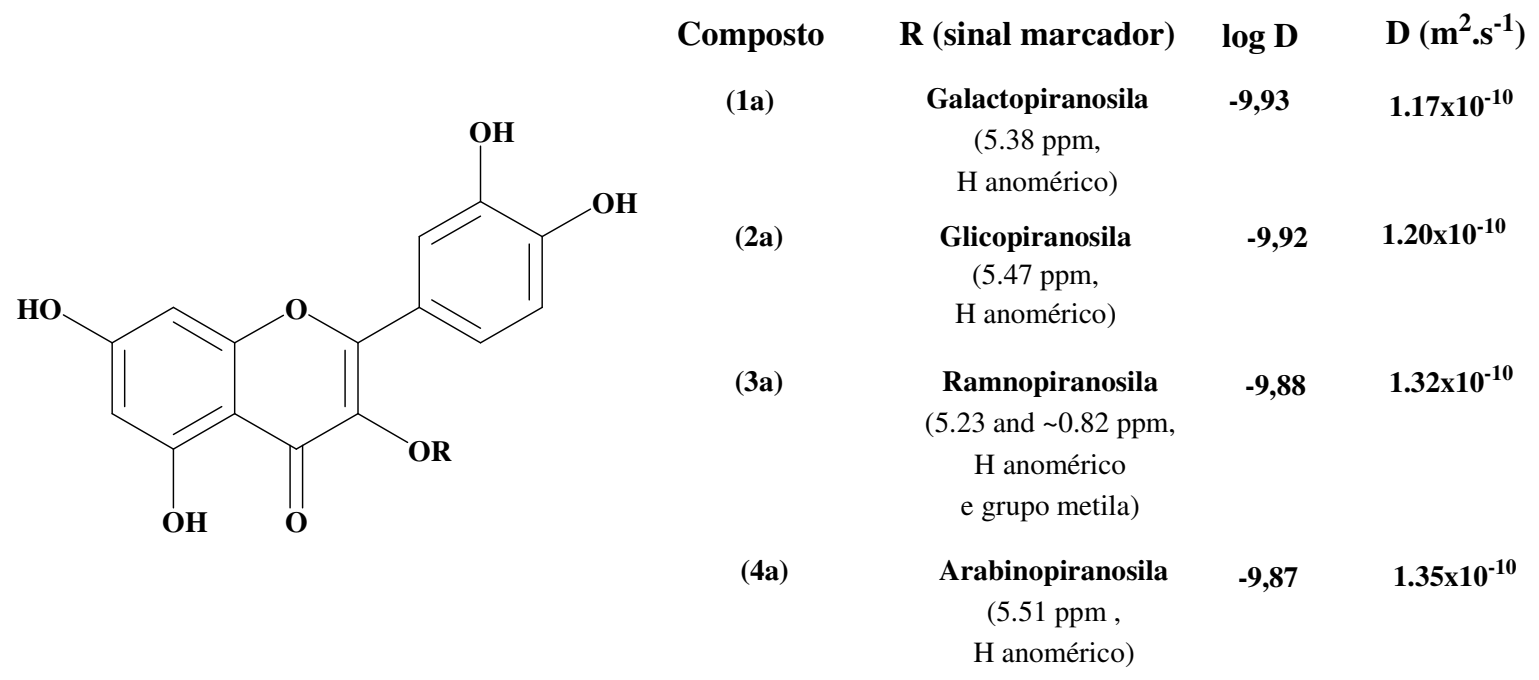

Figura 21. Estruturas propostas e coeficientes de difusão dos componentes majoritários (1a 4a) da fração BSAcOEt obtidos a partir das correlações dos sinais dos prótons anoméricos das unidades de açúcar observadas no espectro de DOSY-2D.

Os coeficientes de difusão foram medidos sobre os picos de correlação relacionados com o próton anomérico. A Figura 21 mostra a correspondência das estruturas propostas para os principais componentes da mistura com os dados de difusão destes. 
Neste ponto, é oportuno comparar a técnica DOSY-2D com a técnica de separação CLAE (Cromatografia Líquida de Alta Eficiência), já que esta última é muito eficiente e amplamente utilizada. Assim como os espectros de DOSY-2D, o cromatograma resultante da CLAE da fração (Figura 22) também revela a presença de quatro componentes principais da mistura em questão, além de outros três minoritários, que por estarem presentes em uma concentração bem menor que a dos principais não foram plenamente detectados ou identificados durante o experimento DOSY-2D.

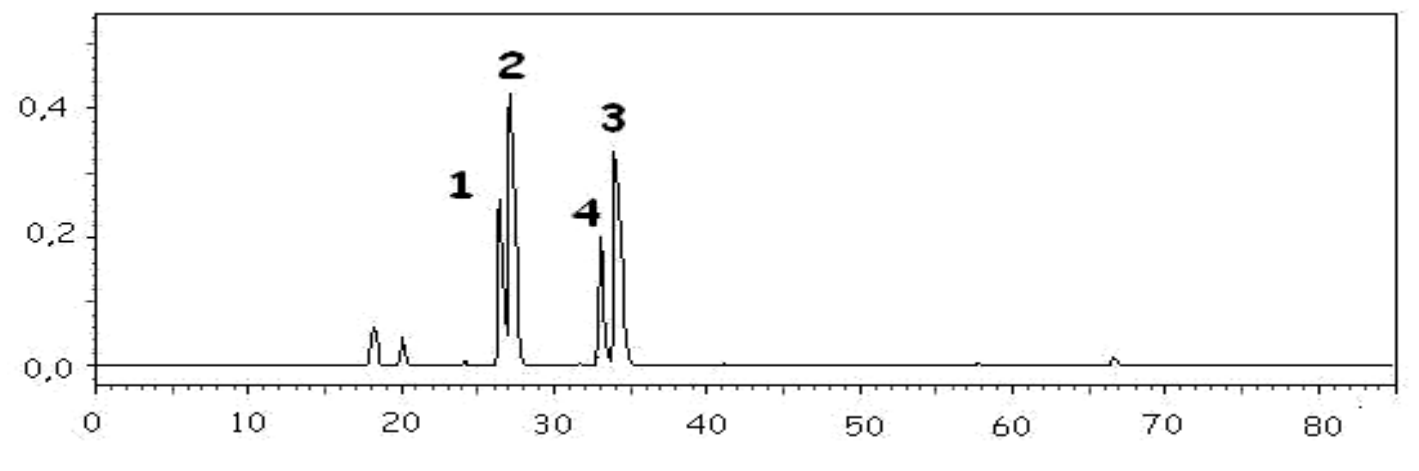

Minutes

Figura 22. Cromatograma da fração BSAcOEt obtido após análise por CLAE-UV analítica

Nota-se que o perfil cromatográfico da fração, apresentado na Figura 22, condiz com os dados fornecidos pelo experimento de RMN DOSY-2D. Observa-se, também, que apesar dos quatro compostos majoritários possuírem estruturas bastante semelhantes, eles apresentam uma diferença de polaridade suficiente para permitir sua separação por CLAE.

As características estruturais que produzem esta diferença de polaridade devem ser as responsáveis pela resolução obtida na direção da difusão nos espectros de DOSY-2D, permitindo que as moléculas pudessem ser diferenciadas por seus coeficientes de difusão, ou seja, possibilitando a sua separação virtual dos componentes da fração.

O fato de ser possível diferenciar as substâncias pelos seus coeficientes de difusão permite dizer que, embora as diferenças estruturais sejam sutis elas proporcionam às quatros substâncias majoritárias da fração possibilidade de diferentes interações moleculares e propriedades de agregação como consequências das diferenças de polaridade, preferências conformacionais, ligação de hidrogênio, etc.. Todos esses fatores contribuíram com o sucesso da análise por DOSY-2D. 


\subsubsection{Verificação qualitativa da confiabilidade da aplicação da técnica DOSY-2D na identificação dos componentes majoritários da fração BSAcOEt}

A fim de verificar qualitativamente a atribuição se sinais derivada do espectro DOSY2D para os componentes majoritários da fração foi realizada a separação da mistura, utilizando técnicas de separação (cromatografia em coluna de Sephadex LH-20®, cromatografia em camada delgada, CLAE-UV semipreparativa). Os principais componentes da fração (1 a 4), com tempos de retenção em CLAE-UV, respectivamente, iguais a 26,3; 26,9; 33,9 e 32,9 min, foram isolados e submetidos à análise por espectrometria de massa (EM-ESI) e por outras técnicas de RMN $\left({ }^{1} \mathrm{H},{ }^{13} \mathrm{C}, \mathrm{HMQC}, \mathrm{HMBC}\right.$, etc.).

Os espectros de massa obtidos mostraram que os componentes de 1-4 possuem íons moleculares $\mathrm{m} / \mathrm{z}$, respectivamente, iguais a 463,0871 $( \pm 1,2 \mathrm{ppm}), 463,0872( \pm 1,1 \mathrm{ppm})$, 447,0937 ( $\pm 2,2 \mathrm{ppm})$ e 433,0766 ( $\pm 1,1 \mathrm{ppm})$, respectivamente. Note que o penúltimo valor é a massa do composto 3 desprotonado. Os dados obtidos a partir das análises por RMN-1D de ${ }^{1} \mathrm{H}$, de ${ }^{13} \mathrm{C}\left\{{ }^{1} \mathrm{H}\right\}$ e de ${ }^{13} \mathrm{C}$ (DEPT $135^{\circ}$ ) e por RMN-2D (HMQC ${ }^{1} \mathrm{H}_{-}{ }^{13} \mathrm{C}$ e HMBC ${ }^{1} \mathrm{H}^{-13} \mathrm{C}$ ) são mostrados nas Tabela 9 e os espectros estão anexos no final do presente trabalho.

A comparação destes dados com os obtidos na literatura ${ }^{[175,176,177]}$ confirmou que os quatro principais componentes da fração acetato de etila do extrato etanólico das partes aéreas de B. sulphurea são os flavonóides glicosilados: quercetina-3-O- $\beta$-D-galactopiranosídeo (1), quercetina-3-O- $\beta$-D-glucopiranosídeo (2), quercetina-3-O- $\alpha$-L-ramnopiranosídeo (3) e quercetina-3-O- $\alpha$-L-arabinofuranosídeo (4), Figura $23{ }^{[175,176,177]}$.

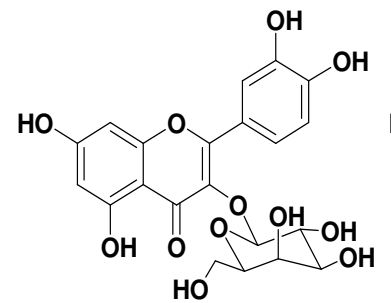

(1)

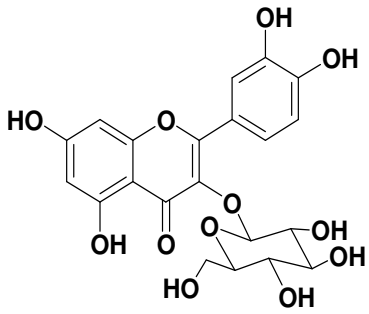

(2)

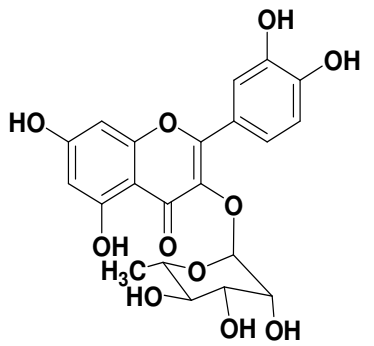

(3)

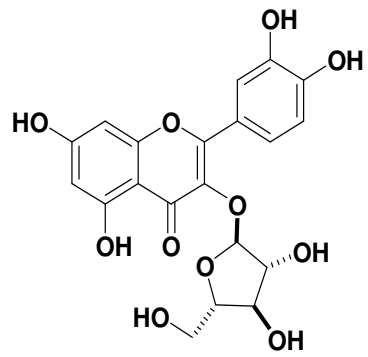

(4)

Figura 23. Estruturas dos compostos majoritários de BSAcOEt.

Tabela 9. Dados espectroscópicos dos compostos 1 a 4.

Composto Técnica $\quad$ Condições




\begin{tabular}{|c|c|c|c|}
\hline & & Experimentais & \\
\hline \multirow[t]{4}{*}{1} & $\begin{array}{l}\text { RMN de } \\
{ }^{13} \mathrm{C}\left\{{ }^{1} \mathrm{H}\right\} \\
\left(\delta_{\mathrm{C}}\right)\end{array}$ & $\begin{array}{l}125 \mathrm{MHz} \\
\text { DMSO-d }_{6}\end{array}$ & 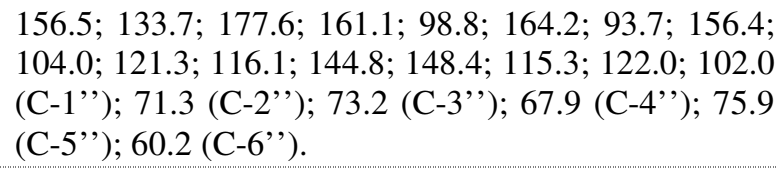 \\
\hline & $\begin{array}{l}\text { RMN de } \\
{ }^{1} \mathrm{H} \\
\left(\delta_{\mathrm{H}}\right)\end{array}$ & $\begin{array}{l}500 \mathrm{MHz} \\
\text { DMSO-d }_{6}\end{array}$ & 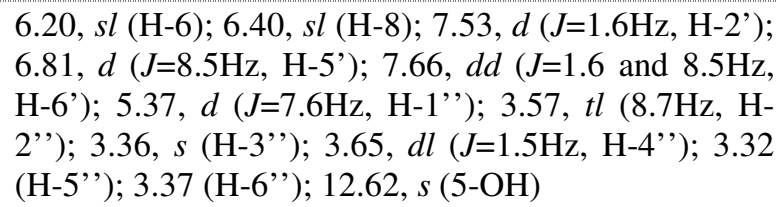 \\
\hline & DOSY-2D & $\begin{array}{l}500 \mathrm{MHz} \\
\text { DMSO-d }_{6}\end{array}$ & $\mathrm{D}=1,20 \times 10^{-10}, \mathrm{~m}^{2} \cdot \mathrm{s}^{-1}$ \\
\hline & EM-ESI & & $463.0871( \pm 1.2 \mathrm{ppm})$ \\
\hline \multirow[t]{4}{*}{2} & $\begin{array}{l}\text { RMN de } \\
{ }^{13} \mathrm{C}\left\{{ }^{1} \mathrm{H}\right\} \\
\left(\delta_{\mathrm{C}}\right)\end{array}$ & $\begin{array}{l}125 \mathrm{MHz} \\
\text { DMSO-d6 }\end{array}$ & 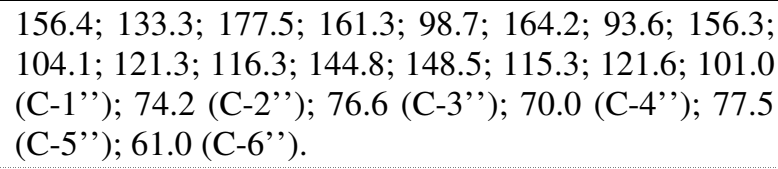 \\
\hline & $\begin{array}{l}{ }^{\mathrm{RMN}} \mathrm{He} \\
\left(\delta_{\mathrm{H}}\right)\end{array}$ & $\begin{array}{l}500 \mathrm{MHz}, \\
\text { DMSO-d6 }\end{array}$ & 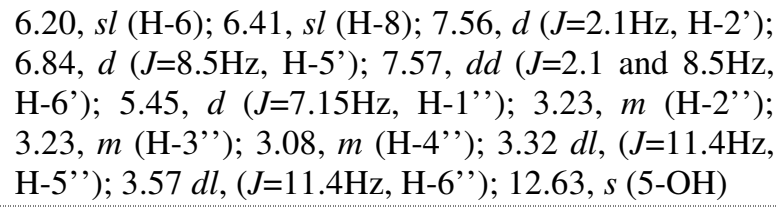 \\
\hline & DOSY-2D & $\begin{array}{l}500 \mathrm{MHz} \\
\text { DMSO-d6 }\end{array}$ & $\mathrm{D}=1,23 \times 10^{-10}, \mathrm{~m}^{2} \cdot \mathrm{s}^{-1}$ \\
\hline & EM-ESI & & $463.0872( \pm 1.1 \mathrm{ppm}$ \\
\hline \multirow[t]{4}{*}{3} & $\begin{array}{l}\text { RMN de } \\
{ }^{13} \mathrm{C}\left\{{ }^{1} \mathrm{H}\right\} \\
\left(\delta_{\mathrm{C}}\right)\end{array}$ & $\begin{array}{l}125 \mathrm{MHz} \\
\text { DMSO-d6 }\end{array}$ & $\begin{array}{l}\text { 157.0; 134.8; 178.2; 161.4; 99.2; 164.4; 94.3; 157.9; } \\
\text { 104.6; 121.3; 116.1; 145.4; 148.7; 116.2; 121.8; } 102.1 \\
(\mathrm{C}-1 \text { '”); } 70.7 \text { (C-2"); } 71.1 \text { (C-3'); } 71.5 \text { (C-4'”); } 70.4 \\
\text { (C-5'); } 17.9 \text { (C-6')). }\end{array}$ \\
\hline & $\begin{array}{l}\mathrm{RMN} \text { de } \\
{ }^{1} \mathrm{H} \\
\left(\delta_{\mathrm{H}}\right)\end{array}$ & $\begin{array}{l}500 \mathrm{MHz} \\
\text { DMSO-d6 }\end{array}$ & $\begin{array}{l}\text { 6.20, d (J=2.0Hz, H-6); 6.41,d (J=2.0Hz, H-8); } 7.48, \\
\text { sl (H-2'); 6.87, d }\left(\mathrm{J}=8.4 \mathrm{~Hz}, \mathrm{H}-5^{\prime}\right) ; 7.25, \mathrm{dl}(\mathrm{J}=8.4 \mathrm{~Hz}, \\
\text { H-6'); 5.24, sl (H-1'”);0.81, d (J=6.15Hz, H-6"); } \\
12.62, \mathrm{~s}(5-\mathrm{OH})\end{array}$ \\
\hline & DOSY-2D & $\begin{array}{l}500 \mathrm{MHz} \\
\text { DMSO-d6 }\end{array}$ & $\mathrm{D}=1,29 \mathrm{X} 10-10, \mathrm{~m} 2 . \mathrm{s}-1$ \\
\hline & EM-ESI & & $447.0937( \pm 2.2 \mathrm{ppm})$ \\
\hline \multirow[t]{4}{*}{4} & $\begin{array}{l}\text { RMN de } \\
{ }^{13} \mathrm{C}\left\{{ }^{1} \mathrm{H}\right\} \\
\left(\delta_{\mathrm{C}}\right)\end{array}$ & $\begin{array}{l}75 \mathrm{MHz} \\
\text { DMSO-d6 }\end{array}$ & 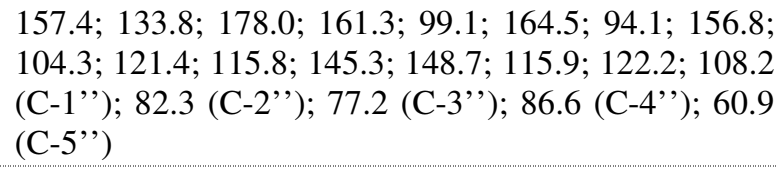 \\
\hline & $\begin{array}{c}\text { RMN de } \\
{ }^{1} \mathrm{H} \\
\left(\delta_{\mathrm{H}}\right)\end{array}$ & $\begin{array}{l}400 \mathrm{MHz} \\
\text { DMSO-d6 }\end{array}$ & 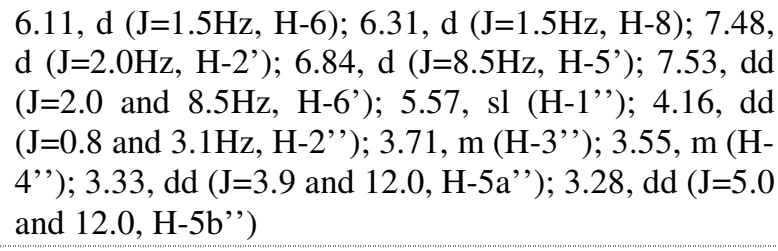 \\
\hline & DOSY-2D & $\begin{array}{l}500 \mathrm{MHz} \\
\text { DMSO-d6 }\end{array}$ & $\mathrm{D}=1,35 \times 10-10, \mathrm{~m} 2 . \mathrm{s}-1$ \\
\hline & EM-ESI & & $433.0766( \pm 1.1 \mathrm{ppm})$ \\
\hline
\end{tabular}




\subsection{Melhoramento de espectros de $\mathrm{RMN}$ de ${ }^{13} \mathrm{C}\left\{{ }^{1} \mathrm{H}\right\}$ por SVD}

\subsubsection{Tratamento integral do espectro e RMN de ${ }^{13} \mathrm{C}\left\{{ }^{1} \mathrm{H}\right\}$ da Fração DF com o método de seccionamento e SVD.}

O espectro de RMN de ${ }^{13} \mathrm{C}\left\{{ }^{1} \mathrm{H}\right\}$ da Fração DF (Figura 24) foi obtido com um experimento com 16384 varreduras (11h e $46 \mathrm{~min}$ ), largura espectral (sw) igual a 250.029 ppm, com a metade da largura (sw/2) fixada em 126ppm, FID com 32768 pontos e 8192 pontos no domínio da frequência. Observa-se neste espectro que a S/R da região entre 100 e 180 ppm é bastante baixa, o que dificulta a identificação dos sinais nesta região.

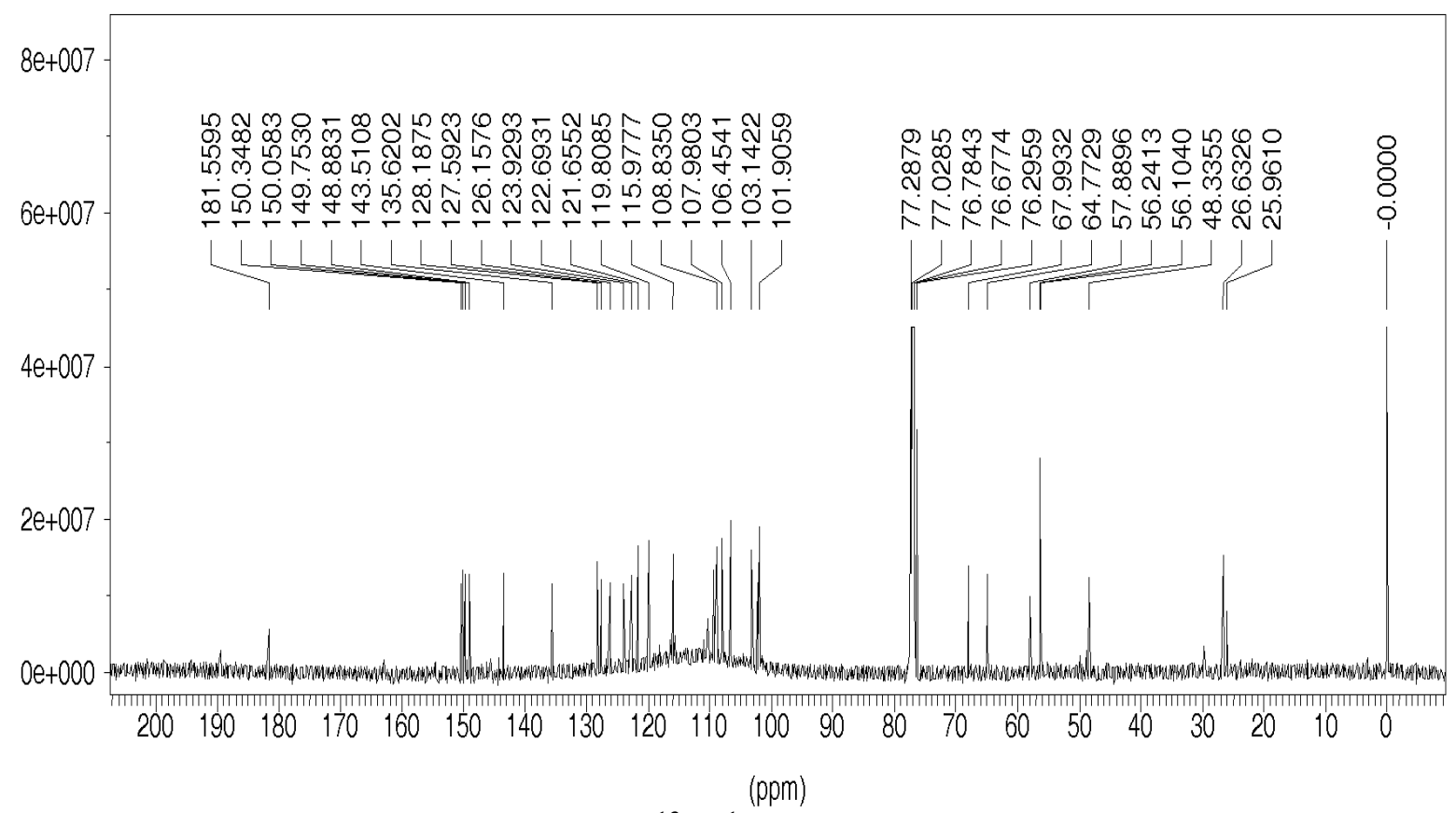

Figura 24. Espectro original de $R M N$ de ${ }^{13} \mathrm{C}\left\{{ }^{1} \mathrm{H}\right\}(125 \mathrm{MHz})$ da Fração DF em $\mathrm{CDCl}_{3}$ obtido com 8192 pontos no domínio da frequência após 16384 varreduras (11h e 46min).

Como o aumento de varreduras para aumentar a relação $S / R$ tornaria o experimento muito longo e, portanto, impraticável, optou-se por tratar integralmente este espectro com o método de seccionamento e filtragem de sinal por SVD, dividindo em trinta e duas secções, sendo vinte e oito secções com sinais das substâncias presentes, duas com sinais referentes ao solvente e TMS e duas apenas com ruído, que foram tratadas para minimizar os defeitos causados pela sobreposição de secções.

Verificou-se a aplicabilidade do método em cada uma delas, o qual teve em sua maioria valor de k=1. Por acreditar que, no momento, a apresentação dos "gaps" (degraus) 
obtidos em todas as secções não seja necessária, seis exemplos podem ser observados na Figura 25. Nota-se que algumas janelas não apresentaram "gap" visível e estável, como no caso da secção 24 , que após a análise dos números de sinais e o deslocamento do sinal nela contido, foi desconsiderada.

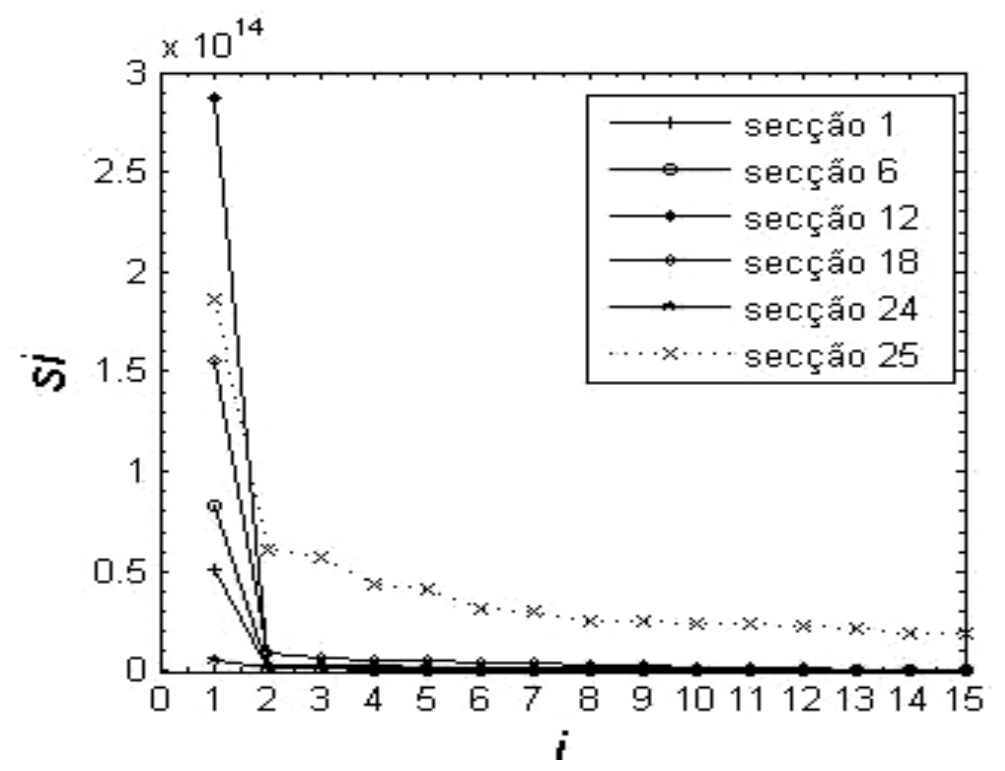

Figura 25. Verificação da estabilidade de gap nas secções escolhidas do espectro de $R M N$ de ${ }^{13} \mathrm{C}\left\{{ }^{1} \mathrm{H}\right\}(125 \mathrm{MHz})$ da Fração DF em $\mathrm{CDCl}_{3}$ obtido com 8192 pontos no domínio da frequência após 16384 varreduras (11h e 46min).

Para cada secção foi obtido o FID "Parcial" através da aplicação de transformada de Fourier inversa. Os dados correspondentes foram submetidos ao processo de redução de ruído por SVD com auxílio do programa Matlab 7/04®. Os FIDs filtrados foram submetidos a uma função de janela (exponencial ou gaussiana, de acordo com as características da secção tratada), seguida pela FFT e combinados linearmente, formando o espectro final filtrado (Figura 26). 


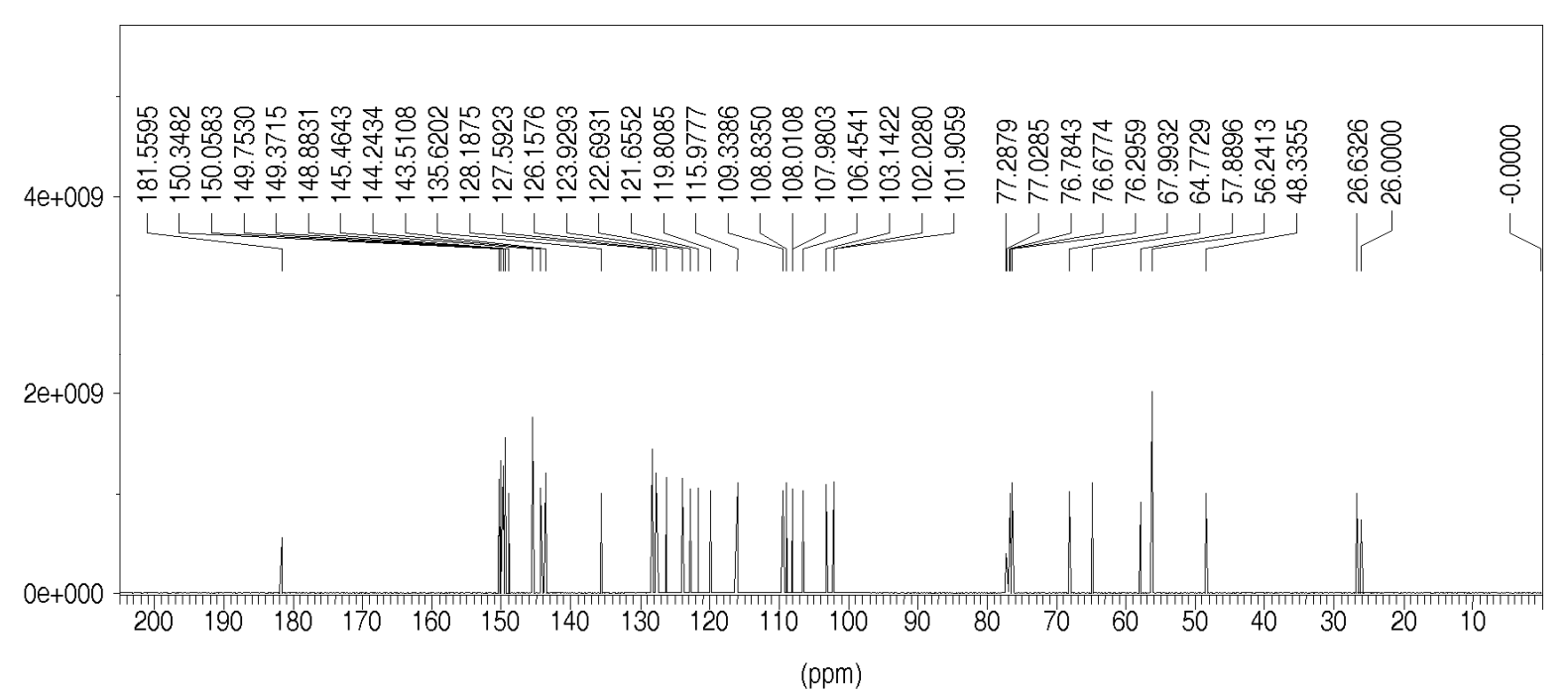

Figura 26. Espectro de $\mathrm{RMN}$ de ${ }^{13} \mathrm{C}\left\{{ }^{1} \mathrm{H}\right\}$ da Fração DF tratado pelo método de seccionamento e filtragem de sinal.

A comparação entre o espectro de RMN de ${ }^{13} \mathrm{C}$ da Fração DF tratado com o método de seccionamento e filtragem de sinal (Figuras 26), ou seja, 'espectro filtrado', e o espectro original (Figuras 24) mostra que o processo proporciona um aumento significativo da relação S/R de um espectro de RMN. Assim, o espectro filtrado foi analisado juntamente com os espectros de $\mathrm{RMN}$ de ${ }^{1} \mathrm{H}$ e de ${ }^{13} \mathrm{C}$ (DEPT $135^{\circ}$ ), conforme os dados listados na Tabela 10. A comparação destes dados com os da literatura ${ }^{[178]}$ possibilitou identificar duas das substâncias presentes na Fração DF, os alcalóides: dicentrinona (5) e (-)-duguetina $\beta$-N-óxido (6), Figura 27. 


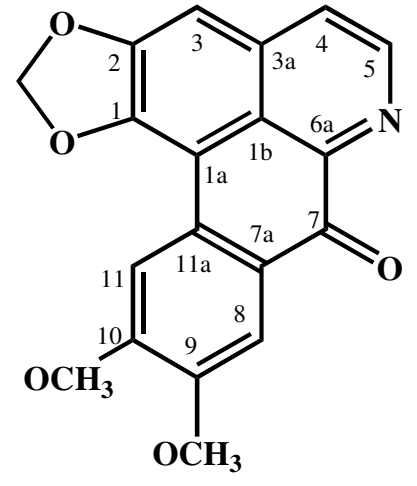

(5)<smiles>[2H][C@]12c3cc(OC)c(OC)cc3-c3cc4c(cc3[C@@H]1c1cc(OC)c(OC)cc1[C@@H]2O)OCO4</smiles>

(6)

Figura 27. Estruturas dos alcalóides: dicentrinona (5) e (-)-duguetina $\beta$-N-óxido (6), componentes da fração A.

Tabela 10. Dados de RMN de ${ }^{1} \mathrm{H}(500 \mathrm{MHz})$ e ${ }^{13} \mathrm{C}\left\{{ }^{1} \mathrm{H}\right\}(125 \mathrm{MHz})$ de 5 e 6 em CDCl3

\begin{tabular}{ccl}
\hline \hline Composto & $\mathrm{ppm}$ & \\
\hline \hline 5 & $\delta_{\mathrm{C}}$ & 152,$2 ; 107,5 ; 122,2 ; 147,6 ; 102,6 ; 136,2 ; 124,3 ; 142,9 ; 143,7 ; 180,4 ;$ \\
& & 125,$0 ; 109,1 ; 149,4 ; 154,1 ; 108,8 ; 127,755,6 ; 55,7 ; 102,7$ \\
\cline { 3 - 3 } & $\delta_{\mathrm{H}}$ & $6,14, \mathrm{~s} ; 7,54 d(J=5,2 \mathrm{~Hz}) ; 8,48 d(J=5,2 \mathrm{~Hz}) ; 7,58, s ; 7,59, s ; 3,74, s ;$ \\
& $3,81, s ; 6,14 s$ \\
\hline \multirow{2}{*}{6} & $\delta_{\mathrm{C}}$ & 149,$9 ; 149,0 ; 146,4 ; 143,6 ; 122,8 ; 119,9 ; 116,6 ; 116,1 ; 110,3 ; 108,0 ;$ \\
& & 106,$4 ; 101,9 ; 76,7 ; 68,0 ; 64,7 ; 56,2 ; 56.1 ; 48,7 ; 26,7$ \\
\cline { 3 - 3 } & $\delta_{\mathrm{H}}$ & $6,65, s ; 7,53, s ; 7.45, s ; 6,11, d(J=1,2 \mathrm{~Hz}) ; 6,28, d(J=1,2 \mathrm{~Hz}) ; 5,45, d$ \\
& & $(J=12,2 \mathrm{~Hz}) ; 3,84, s ; 3,90, s ; 4,83, d(J=12,2 \mathrm{~Hz}) ; 3,37 d d(J=12,0 \mathrm{e} 6,0 \mathrm{~Hz}) ;$ \\
& & $3,41 d d(J=12,0 \mathrm{e} 6,0 \mathrm{~Hz}) ; 3,56 d d(J=10,0 \mathrm{e} 6,0 \mathrm{~Hz}) ; 3,60 d d(J=10,0 \mathrm{e} 6,0$ \\
& $\mathrm{Hz})$ \\
\hline
\end{tabular}

O processo deste tratamento, no entanto, deve ser automatizado para viabilizar sua aplicação em análise de rotina, tornando-o menos trabalhoso. Apesar disto, ele pode ser bastante útil se aplicado de maneira parcial, ou seja, realizado em determinadas secções do espectro, onde a relação $S / R$ é bem inferior do que a apresentada na maioria das secções, e quando o número de varreduras realizados na aquisição de espectros for superior a 16k (12 horas de máquina, aproximadamente).

\subsubsection{Tratamento integral do espectro e $\mathrm{RMN}$ de ${ }^{13} \mathrm{C}\left\{{ }^{1} \mathrm{H}\right\}$ do composto 7 com o método de seccionamento e filtragem de sinal.}

Para identificar o composto 7 foram realizados experimentos de RMN-1D de ${ }^{1} \mathrm{H}$, ${ }^{13} \mathrm{C}\left\{{ }^{1} \mathrm{H}\right\}$ e ${ }^{13} \mathrm{C}$ (DEPT $135^{\circ}$ ). O espectro RMN-1D de ${ }^{13} \mathrm{C}\left\{{ }^{1} \mathrm{H}\right\}$, apresentado na Figura 28, foi 
obtido com 16384 varreduras e FID com 4096 pontos. Como todo o espectro apresentou uma baixa relação $\mathrm{S} / \mathrm{R}$, decidiu-se tratá-lo integralmente com o método de seccionamento e limpeza do sinal.

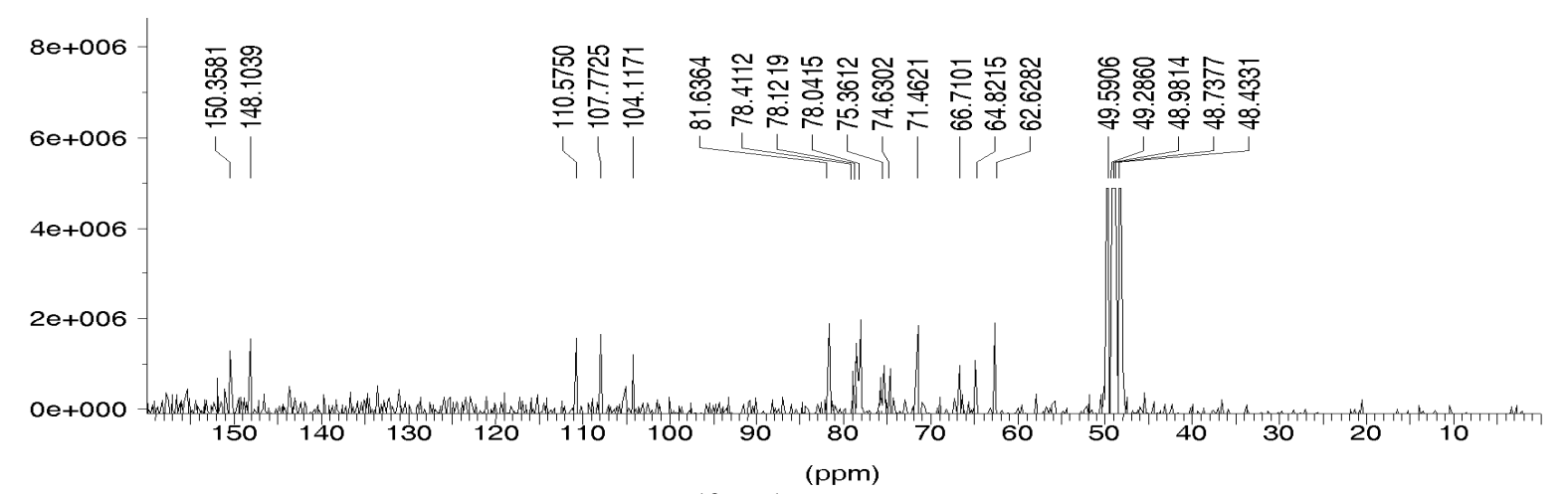

Figura 28. Espectro original de $\mathrm{RMN} \mathrm{de}{ }^{13} \mathrm{C}\left\{{ }^{1} \mathrm{H}\right\}(75 \mathrm{MHz})$ do composto 7 em Metanol- $\mathrm{d}_{4}$.

O referido espectro foi dividido em trinta secções. O tratamento de limpeza de sinal foi efetuado nas secções que apresentavam um singleto. A secção entre 48,5 a 50,5 ppm não foi tratada por apresentar apenas sinais referentes ao solvente. A Figura 29 apresenta o espectro resultante deste tratamento.

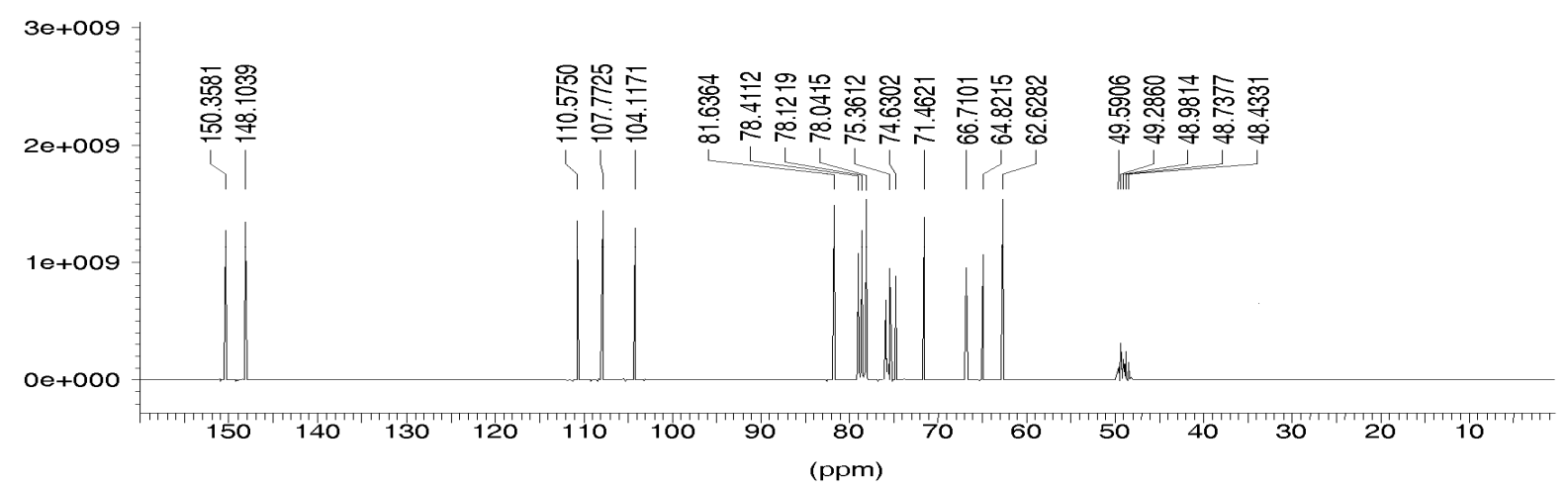

Figura 29. Espectro de $\mathrm{RMN}$ de ${ }^{13} \mathrm{C}\left\{{ }^{1} \mathrm{H}\right\}$ do composto 7 tratado pelo método de seccionamento e limpeza de sinal.

Assim, após a análise dos dados de $\mathrm{RMN}$ de ${ }^{13} \mathrm{C}\left\{{ }^{1} \mathrm{H}\right\}$ e DEPT $135^{\circ}$ e de ${ }^{1} \mathrm{H}$ apresentados na Tabela 11, os dados de J-resolved, HMQC e HMBC e a comparação destes com os da literatura ${ }^{[179,180]}$, o composto 7 pôde ser identificado como sendo o poliacetileno 2$O$ - $\beta$-glicopiranosil-trideca-3(E),11(E)-dien-5,7,9-triin-1,13-diol (Figura 30).

Vale salientar que este poliacetileno é do tipo eno-triino-eno, um tipo pouco comum no gênero Bidens, sendo os mais comuns os C13-acetilenos dos tipos eno-tetraino-eno, fenilacetileno, eno-diino-trieno e eno-diino-dieno ${ }^{[181]}$. Além disto, esta substância foi relatada três vezes na literatura, tendo sido encontrada nas espécies B. campylotheca e B. bipinnata, além da espécie B. gardneri ${ }^{[163,179,180]}$. 


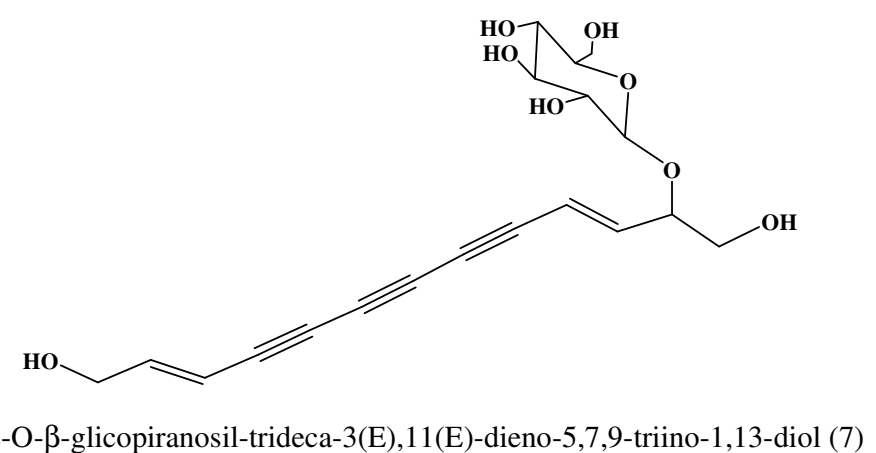

Figura 30. Estrutura do composto 7.

Tabela 11. Dados de RMN de ${ }^{1} \mathrm{H}(300 \mathrm{MHz})$ e ${ }^{13} \mathrm{C}\{1 \mathrm{H}\} \quad(75 \mathrm{MHz})$ do composto 7 em Metanol-d4, incluindo dados de padrão de acoplamento (p.a.) e $\mathrm{J}$ obtidos do experimento $J$ resolved, multiplicidade de $\mathrm{C}$ (multi.) obtida do experimento DEPT $135^{\circ}$ e dados da literatura de RMN de ${ }^{1} \mathrm{H}(400 \mathrm{MHz})$ e ${ }^{13} \mathrm{C}\left\{{ }^{1} \mathrm{H}\right\}(100 \mathrm{MHz})$ em DMSO-d6 ${ }^{[179]}$.

\begin{tabular}{|c|c|c|c|c|c|c|}
\hline \multirow[t]{2}{*}{$\mathrm{H} / \mathrm{C}$} & \multicolumn{3}{|c|}{ Composto 7} & \multicolumn{3}{|c|}{$\begin{array}{c}\text { 2-O-B-D-glicopiranosil-trideca-3 }(E), 11(E) \text {-dien- } \\
5,7,9 \text {-triin-1,2,13-triol }{ }^{[179]}\end{array}$} \\
\hline & $\delta_{\mathrm{H}}{ }^{\mathrm{a}}$ & p.a. $\left[J(\mathrm{~Hz})^{\#}\right]$ & $\begin{array}{c}\delta_{C^{b}} \\
\text { (multi.*) }\end{array}$ & $\delta_{\mathrm{H}}^{\mathrm{c}}$ & p.a. $\left[J(\mathrm{~Hz})^{\#}\right]$ & $\left(\delta_{C}\right)^{\mathrm{d}}$ \\
\hline 1 & 3,56 e 3,52 & 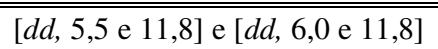 & $64,8(t)$ & 3,45 e 3,55 & {$[\mathrm{~m}] \mathrm{e}[\mathrm{m}]$} & 63,7 \\
\hline 2 & 4,30 & {$[d d d d, 1,8,5,2,5,5$ e 6,0$]$} & $81,6(d)$ & 4,37 & {$[m]$} & 78,7 \\
\hline 3 & 6,38 & {$[d d, 5,2$ e 16,1$]$} & $148,1(d)$ & 6,54 & {$[d d, 4,6$ e 15,8$]$} & 148,8 \\
\hline 4 & 5,91 & {$[d d d, 0,7,1,8$ e 16,1$]$} & $110,6(d)$ & 6,23 & {$[d d, 2,0$ e 15,8$]$} & 108,7 \\
\hline 5 & - & - & $78,1(s)$ & - & - & 76,8 \\
\hline 6 & - & - & $66,4(s)$ & - & - & 65,5 \\
\hline 7 & - & - & $75,1(s)$ & - & - & 74,5 \\
\hline 8 & - & - & $74,6(s)$ & - & - & 73,3 \\
\hline 9 & - & - & $66,7(s)$ & - & - & 65,7 \\
\hline 10 & - & - & $78,4(s)$ & - & - & 78,5 \\
\hline 11 & 5,80 & {$[d t d, 0,7,2,3$ e 16,0$]$} & $107,8(d)$ & 5,92 & {$[d d, J=2,5$ e 15,8$]$} & 105,1 \\
\hline 12 & 6,46 & {$[d t, 4,5$ e 16,0$]$} & $150,4(d)$ & 6,68 & {$[d d, J=3,5$ e 15,8$]$} & 152,1 \\
\hline 13 & 4,10 & {$[d d, 2,3$ e 4,5$]$} & $62,6(t)$ & 4,10 & {$[m]$} & 60,8 \\
\hline 1 ' & 4,35 & {$[d, 7,7]$} & $104,1(d)$ & 4,18 & {$[d, J=8,0]$} & 101,3 \\
\hline 2 ' & 3,16 & {$[d d, 7,7$ e 8,8$]$} & $75,3(d)$ & 3,07 & {$[t, J=8,0]$} & 73,4 \\
\hline 3 , & 3,30 & {$[t, 8,8]$} & $77,9(d)$ & 3,20 & {$[t, J=8,0]$} & 76,6 \\
\hline $4^{\prime}$ & 3,26 & {$[t, 8,8]$} & $71,5(d)$ & 3,10 & {$[m]$} & 70,5 \\
\hline 5 & 3,18 & {$[m]$} & $78,0(d)$ & 3,13 & {$[m]$} & 77,9 \\
\hline 6, & 3,60 e 3,75 & {$[d d, 5,4$ e 11,9$]$ e $[d d, 2,3$ e 11,9$]$} & $62,6(t)$ & 3,50 e 3,71 & {$[m]$ e $[m]$} & 61,0 \\
\hline
\end{tabular}




\subsubsection{Tratamento parcial do espectro e RMN de ${ }^{13} \mathrm{C}\left\{{ }^{1} \mathrm{H}\right\}$ do composto 8 com o método de seccionamento e filtragem de sinal.}

Os processos de seccionamento e filtragem do sinal de um espectro de RMN integralmente, dependendo do número de sinais presentes no espectro e das distâncias entre estes sinais, podem ser considerados como uma tarefa um tanto árdua. Entretanto, esta tarefa pode ser facilitada se o processo for realizado de modo parcial, ou seja, apenas sobre parte destes sinais.

Isto é possível, pois, devido a diferenças de constantes de relaxação dos diferentes tipos de carbonos da amostra, os espectros sempre apresentarão sinais bastante intensos que não precisam ser tratados e sinais passíveis de tratamento por apresentar baixa intensidade.

Para aplicar o método de seccionamento e limpeza do sinal parcialmente, é necessário que se tenha relativa certeza de que os sinais pouco intensos se referem a núcleos da mesma molécula que os sinais mais intensos, além de ter a certeza de que esses sinais não são ruídos, de modo a não criar "artefatos" de processamento o que conduziria a uma interpretação errônea dos dados. Para tanto, se faz necessário o acompanhamento da evolução da relação S/R em função do número de varreduras (ou tempo de experimento), observando, inclusive, o aumento ou não do número de sinais.

Se o número de supostos sinais se mantém constante com o aumento de varreduras o espectro poderá ser tratado parcialmente com o método de seccionamento e limpeza do sinal.

Logo, para o composto 8, foram realizados quatro experimentos de $\mathrm{RMN}$ de ${ }^{13} \mathrm{C}\left\{{ }^{1} \mathrm{H}\right\}$, com 128, 512, 2048 e 8192 varreduras, respectivamente, com $15 \mathrm{~min} ; 56 \mathrm{~min}$; 2h e 22 min e 9 $\mathrm{h}$ de duração. Todos eles com largura espectral (sw) igual a 250,069 ppm, com sw/2 fixada em 109,2 ppm, FID com 65536 pontos e 8192 pontos no domínio da frequência (SI). Observou-se, então, a evolução da relação S/R com o aumento de varreduras e o aumento ou não do número de sinais nos espectros. 


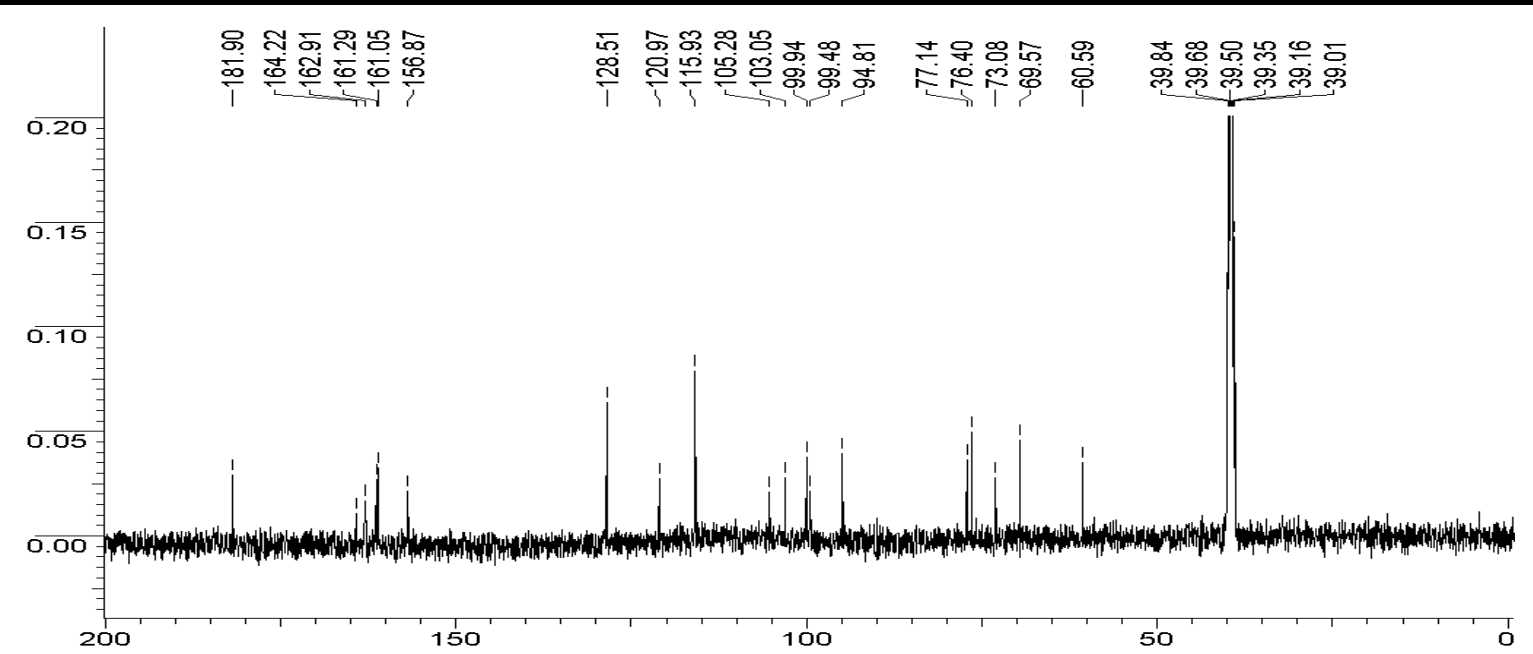

Figura 31. Espectro original de $R M N$ de ${ }^{13} \mathrm{C}\left\{{ }^{1} \mathrm{H}\right\}(125 \mathrm{MHz})$ do composto 8 em DMSO-d 6 .

Notou-se que o espectro obtido com 8192 varreduras (Figura 31) já apresentava todos os sinais da amostra apesar de sua baixa resolução. Entretanto, os sinais em 164,2 ppm e 162,9 ppm ainda não estavam bem definidos, sendo, portanto, escolhidos para a execução do seccionamento e limpeza parcial do espectro.

Após a separação das secções escolhidas, a construção de suas matrizes hermitianas e a diagonalização das mesmas, verificou-se a aplicabilidade do método através da estabilidade de "gap” observada no gráfico dos valores singulares (si) versus índices $(i)$.

A Figura 32 mostra a evolução dos "gaps" (degraus) para ambas as secções em função do número de varreduras. Observa-se que em ambas as secções o "gap"(k) foi igual a 1 apenas nos experimentos com 8192 varreduras, portanto, os dados destes experimentos foram os escolhidos para o tratamento por SVD. 


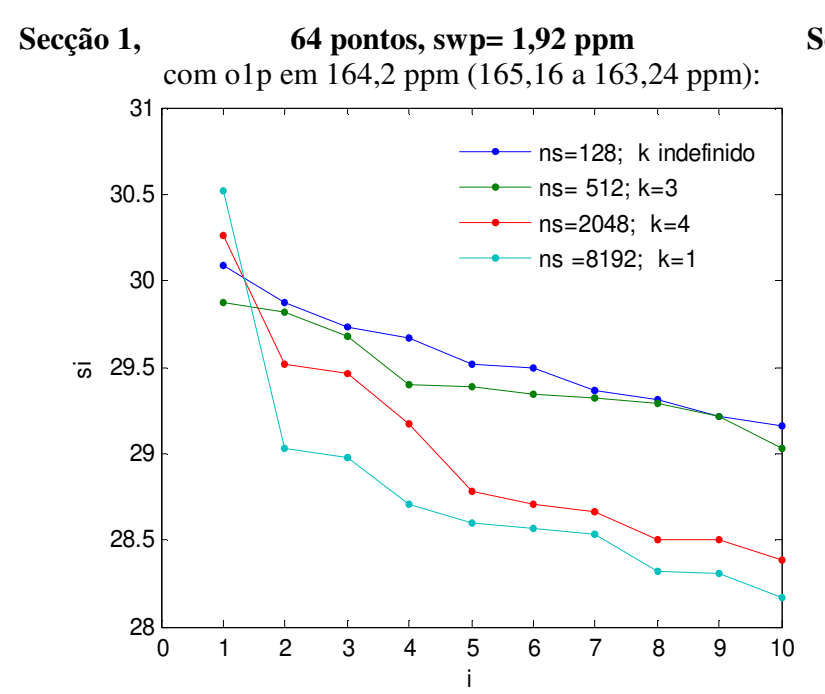

Secção 2, $\quad 64$ pontos, $\mathrm{swp}=1,92 \mathrm{ppm}$

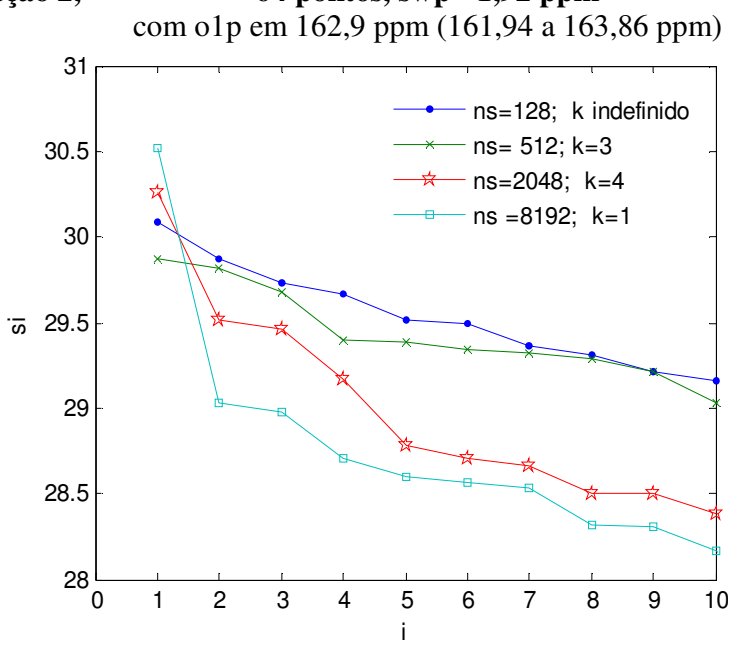

Figura 32. Degraus ou "gaps" observados nas secções selecionadas espectro de RMN de ${ }^{13} \mathrm{C}\left\{{ }^{1} \mathrm{H}\right\}$ do composto 8 em DMSO-d6 em função do número de varreduras.

O efeito do tratamento por SVD nas secções escolhidas pode ser observado na Figura 33. Nota-se que o tratamento aumentou consideravelmente a relação $S / R$ nas duas secções, confirmando a existência dos sinais em 164,22 e 162,88 ppm.

Secção 1:

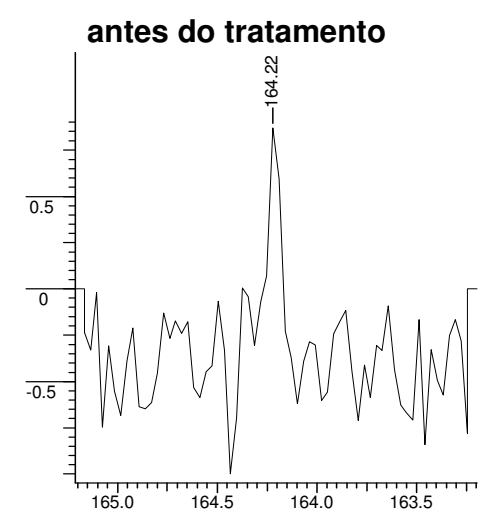

Secção 2:

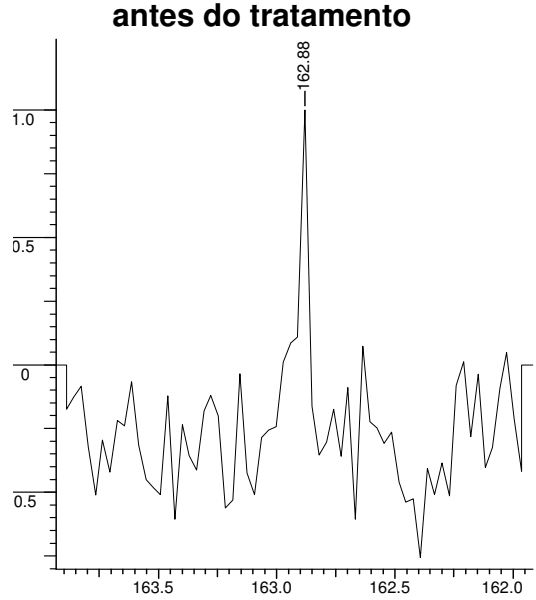

após tratamento
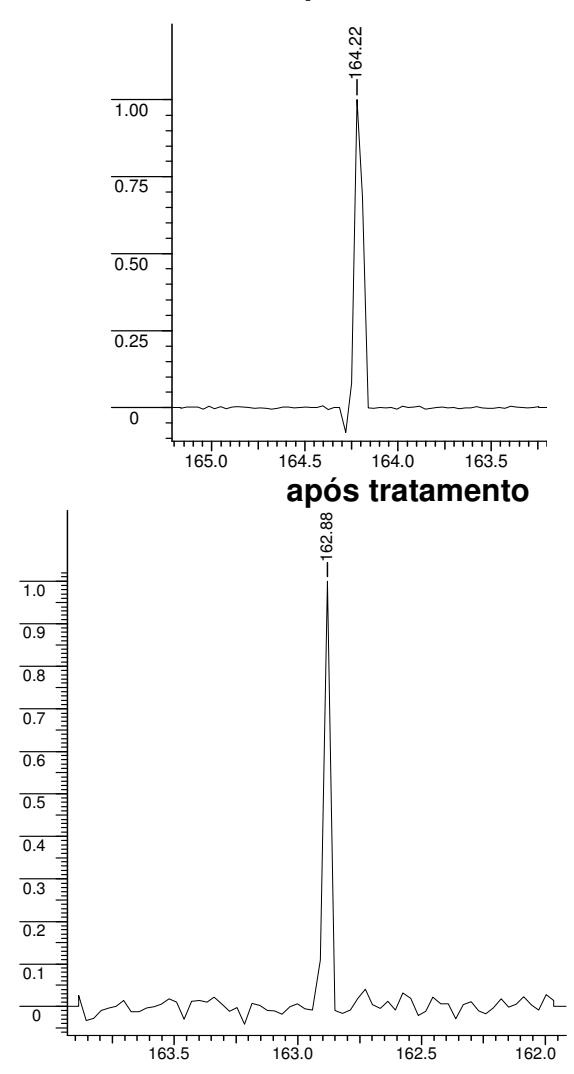

Figura 33. Aumento da relação $S / R$ das secções 1 e 2 do espectro de $R M N$ de ${ }^{13} \mathrm{C}\left\{{ }^{1} \mathrm{H}\right\}$ do composto 8 com o tratamento com SVD. 
Assim, após a análise dos dados de $\mathrm{RMN}$ de ${ }^{13} \mathrm{C}\left\{{ }^{1} \mathrm{H}\right\}$ e DEPT $135^{\circ}$ e de ${ }^{1} \mathrm{H}$ apresentados na Tabela 12, os dados de HMQC e HMBC e a comparação destes com os da literatura $^{[182]}$, o composto 8 pôde ser identificado como sendo o flavonóide glicosilado 7-O- $\beta$ glicopiranosilapigenina (Figura 34).

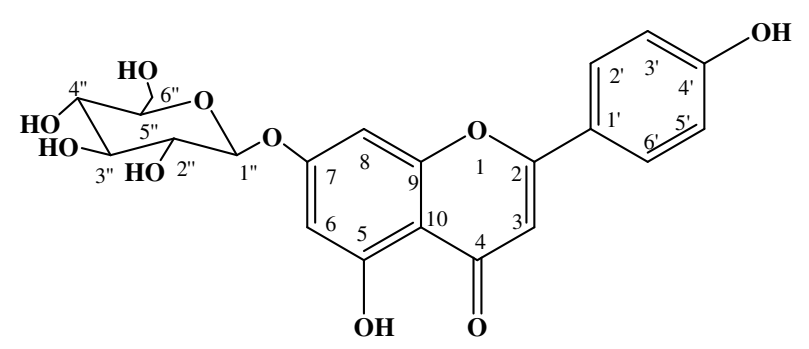

7-O- $\beta$-glicopiranosil-apigenina (8)

Figura 34. Estruturas do composto 8.

Tabela 12. Dados de $R M N$ de ${ }^{1} \mathrm{H}(500 \mathrm{MHz})$ e ${ }^{13} \mathrm{C}\left\{{ }^{1} \mathrm{H}\right\}(125 \mathrm{MHz})$ do compostos 8 em DMSO$\mathrm{d}_{6}$.

\begin{tabular}{cl}
\hline Dados & \multicolumn{1}{c}{ ppm } \\
\hline \hline \multirow{2}{*}{$\delta_{\mathrm{C}}$} & 181,$9 ; 164,2 ; 162.9 ; 161,3 ; 161,1 ; 156,9 ; 128,5 ; 121,0 ; 116,0 ; 105,3 ; 103,1 ; 99,9 ; 99,5 ; 94,8 ;$ \\
& 77,$1 ; 76,4 ; 73,1 ; 69,6 ; .60,6$ \\
& $7,95, d(J=8,4 \mathrm{~Hz}, 2 \mathrm{H}) ; 6,93, d(J=8,4 \mathrm{~Hz}, 2 \mathrm{H}) ; 6,44, s l(1 \mathrm{H}) ; 6,82, s l(1 \mathrm{H}) ; 6,86, s l(1 \mathrm{H}) ; 5,06, d$ \\
& $(J=7,2 \mathrm{~Hz}, 1 \mathrm{H})$ \\
$\delta_{\mathrm{H}}$ & $3,27, m \#, 3,45, d(J=8,4 \mathrm{~Hz}, 1 \mathrm{H}) ; 3,48, m \#, 3,18, d(J=7,6 \mathrm{~Hz}, 1 \mathrm{H}) ; 3 ., 29, m \#(1 \mathrm{H}) ; 3,71, d$ \\
& $(J=10,3 . \mathrm{Hz}, 1 \mathrm{H})$
\end{tabular}
\# sinais encobertos pelo sinal da água do DMSO, atribuídos pelo HMBC e HMQC. 


\subsubsection{Tratamento do espectro e RMN de $13 \mathrm{C}\left\{{ }^{1} \mathrm{H}\right\}$ do composto 9 .}

Para a análise do composto 9 foram realizados experimentos de $\mathrm{RMN}$ de ${ }^{1} \mathrm{H}$, de ${ }^{13} \mathrm{C}\left\{{ }^{1} \mathrm{H}\right\}$ e DEPT135 , além de experimentos de RMN-2D (COSY ${ }^{1} \mathrm{H},{ }^{1} \mathrm{H}, \mathrm{HMQC}$ e HMBC). $\mathrm{O}$ espectro de $\mathrm{RMN}$ de ${ }^{13} \mathrm{C}$ desacoplado foi obtido com diferentes números de varreduras (1024, 4092, 12888 e 16384). Nestes experimentos a largura espectral (sw), a sw/2, o número de pontos do FID, bem como o número de pontos no domínio da frequência (SI) foram iguais aos dos experimentos com o composto 8 e, a evolução da relação $S / R$ em função do número de varreduras foi observada.

A análise dos espectros de RMN de ${ }^{1} \mathrm{H}$ e de RMN-2D indicou que o composto 9, provavelmente seria uma chalcona glicosilada, com a unidade de açúcar acilada com ácido pcumárico. Para confirmar esta proposta seria necessário encontrar um sinal de carbono quaternário próximo à 190 ppm, típico de carbonila de chalconas.

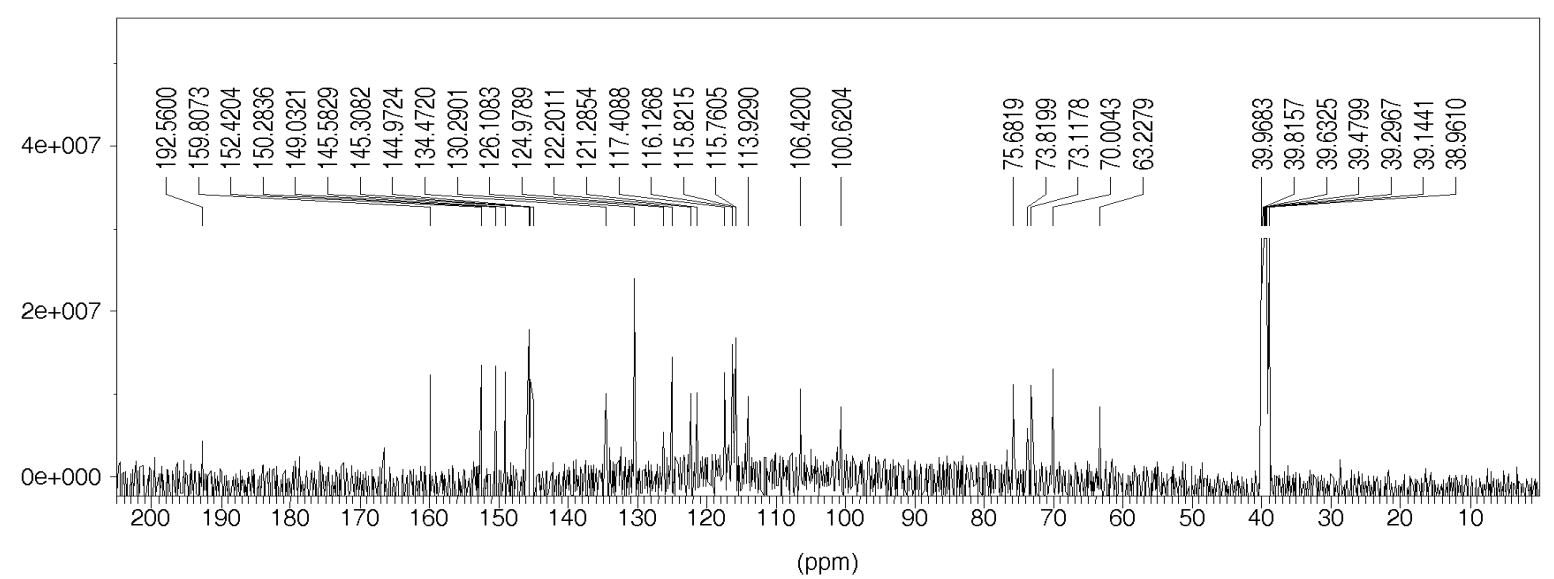

Figura 35. Espectro de RMN de ${ }^{13} \mathrm{C}\left\{{ }^{1} \mathrm{H}\right\}$ (125 MHz) original do composto 9 em DMSO-d 6 adquirido com 12888 varreduras.

Analisando esta região nos espectros de RMN de ${ }^{13} \mathrm{C}\left\{{ }^{1} \mathrm{H}\right\}$, observou-se nos espectros obtidos com 12888 (Figura 35) e 16384 varreduras a existência de um pico em, aproximadamente, 192,5 ppm, com intensidade baixa e insuficiente para considerá-lo como sinal. Assim, resolveu-se tratar a região entre 188,7 e 196,5 ppm por SVD, para melhorar a relação S/R desta região e confirmar ou não a existência deste sinal.

A aplicabilidade do tratamento foi analisada através do gráfico de si x $i$ mostrado na Figura 36. Observa-se que nos experimentos com 12888 e 16384 varreduras o "gap" apresentou $\mathrm{k}=1$, o que significa que os dados já eram estáveis com 12888 varreduras. Os dados deste experimento para cada secção escolhida foram tratados por SVD, resultando num 
ganho de S/R na ordem de 100, como mostrado na Figura 37. Deste modo, a existência do sinal em 192,6 ppm foi confirmada.

Cabe citar que as regiões próximas de 95 ppm e 30 ppm do espectro de RMN de ${ }^{13} \mathrm{C}\left\{{ }^{1} \mathrm{H}\right\}$, obtido com 12888 varreduras (Figura 37), também apresentaram supostos picos, que depois da análise de "gap", por não apresentar estabilidade no valor de k, foram descartados.

A comparação destes dados, juntamente com dados obtidos a partir dos demais experimentos de RMN (Tabela 13), com dados da literatura ${ }^{[183]}$ indicou que o composto 9 tratava-se do flavonóide 4'-O- $\beta$-(6”-trans-p-cumaroil)-glicopiranosilocamina (Figura 38).

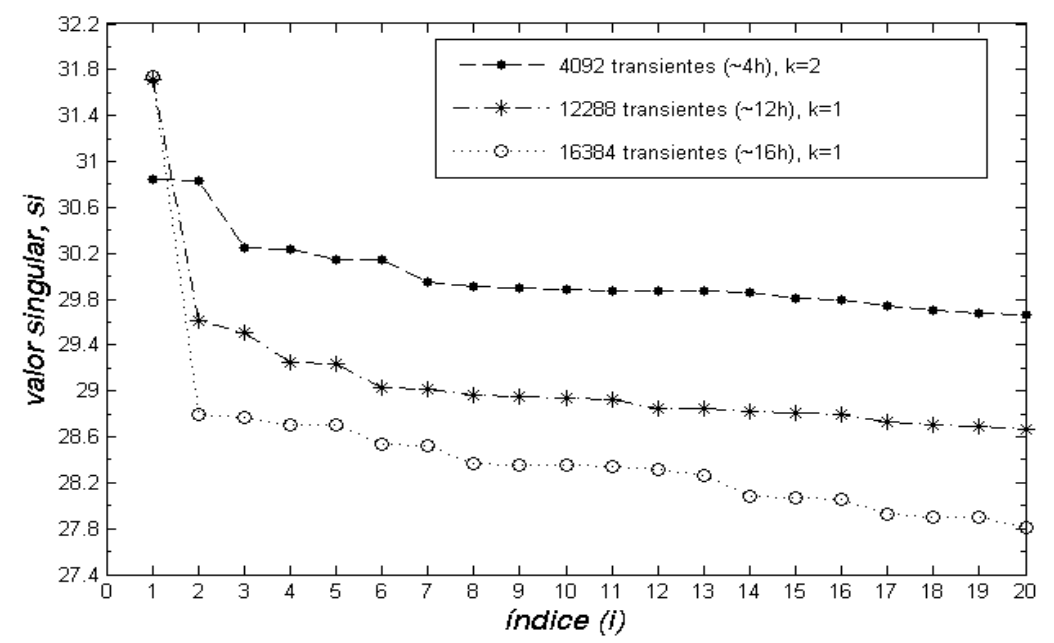

Figura 36. Evolução dos degraus em função de varreduras, observados nas secção selecionada do espectro de RMN de ${ }^{13} \mathrm{C}\left\{{ }^{1} \mathrm{H}\right\}$ do composto 9 em DMSO-d 6 .

Antes do Tratamento

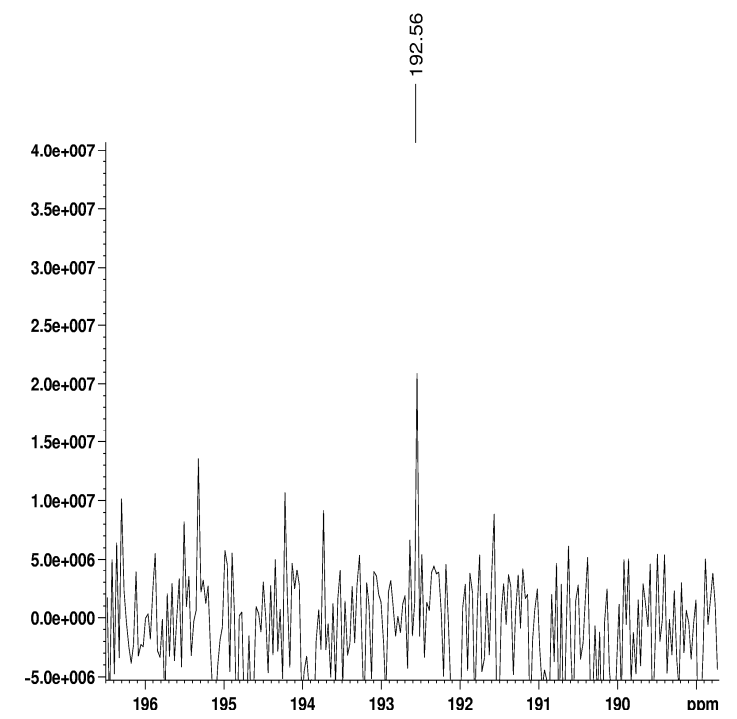

Após tratamento

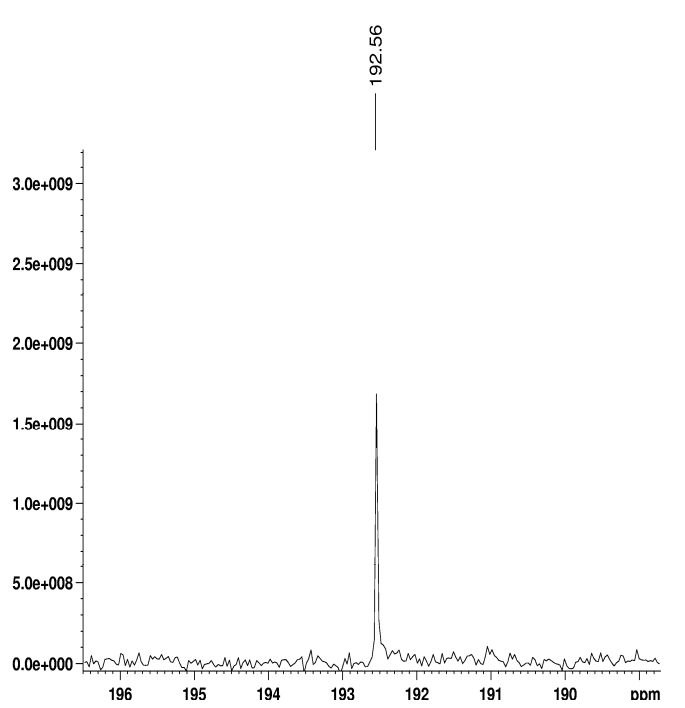

Figura 37. Evolução dos "gaps" em função dos transientes, observados nas secções selecionadas do espectro de RMN de ${ }^{13} \mathrm{C}\left\{{ }^{1} \mathrm{H}\right\}$ do composto 9 em DMSO-d 6 . 


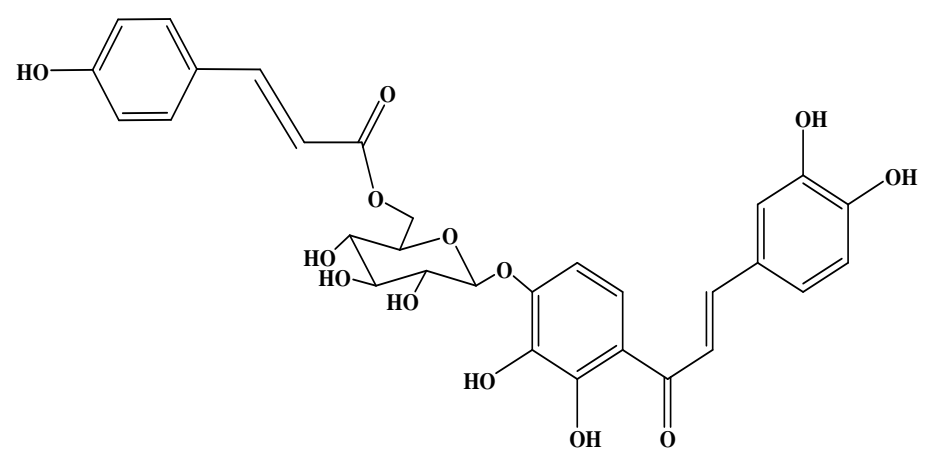

4'-O-ß3-(6"-trans-p-cumaroil)-glicopiranosil-ocanina (9)

Figura 38. Estruturas do composto 9.

Tabela 13. Dados de RMN de ${ }^{1} \mathrm{H}(500 \mathrm{MHz}) \mathrm{e}^{13} \mathrm{C}\left\{{ }^{1} \mathrm{H}\right\}(125 \mathrm{MHz})$ do composto 9 em DMSO$\mathrm{d}_{6}$

\begin{tabular}{ll}
\hline Dados & ppm \\
\hline \hline \multirow{2}{*}{$\delta_{\mathrm{C}}$} & 192,$6 ; 166,5 ; 159,8 ; 152,4 ; 150,3 ; 149,0 ; 145,6 \# ; 145,3 \# ; 145,5 ; 136,1 ; 130,4 * ; 126,1 ; 125,0 ;$ \\
& 123,$6 ; 121,3 ; 117,4 ; 116,2 * ; 115,9 ; 115,8 * ; 113,9 ; 106,5 ; 100,7 ; 75,7 ; 73,9 ; 73,1 ; 70,0 ; 63,3$ \\
& $7,81, d(J=9,2 \mathrm{~Hz}, 1 \mathrm{H}) ; 7,75, d(\mathrm{~J}=15,1 \mathrm{~Hz}, 1 \mathrm{H}) ; 7,70, d(\mathrm{~J}=15,7 \mathrm{~Hz}, 1 \mathrm{H}) ; 7,63, d(\mathrm{~J}=8,0 \mathrm{~Hz}, 2 \mathrm{H}) ;$ \\
& $7,60, d(\mathrm{~J}=15,1 \mathrm{~Hz}, 1 \mathrm{H}) ; 7,33, s(1 \mathrm{H}) ; 7,27, d(\mathrm{~J}=8,0 \mathrm{~Hz}, 1 \mathrm{H}) ; 6,89, d(\mathrm{~J}=8,0 \mathrm{~Hz}, 1 \mathrm{H}) ; 6,81, d$ \\
$\delta_{\mathrm{H}}$ & $(J=9,3 \mathrm{~Hz}, 1 \mathrm{H}) ; 6,79, d(\mathrm{~J}=8,0 \mathrm{~Hz}, 2 \mathrm{H}) ; 6,50, d(\mathrm{~J}=15,7 \mathrm{~Hz}, 1 \mathrm{H}) ; 5,09, d(\mathrm{~J}=6,4 \mathrm{~Hz}, 1 \mathrm{H}) ; 4,47, d d$ \\
& $(J=11,5 \mathrm{~Hz}, 1 \mathrm{H}) ; 4,29, d d(\mathrm{~J}=11,5 \mathrm{~Hz}, 1 \mathrm{H}) ; 3,82, d(\mathrm{~J}=7,9 \mathrm{~Hz}, 1 \mathrm{H}) ; 3,55, m \# ; 3,50, m \# ; 3,34, d$ \\
& $(J=8,9 \mathrm{~Hz}, 1 \mathrm{H}) ;$ \\
\hline \hline
\end{tabular}

\# sinais encobertos pelo sinal da água do $D M S O$, atribuídos pelo $H M B C$ e $H M Q C$. * referentes a dois carbonos 


\subsection{Elucidação estrutural de poliacetilenos baseadas nas constantes de acoplamento de longa distância heteronuclear $\mathbf{J}_{\mathbf{C H}}$}

A fração acetato de etila do extrato etanólico de B. gardneri mostrou-se rica em poliacetilenos. Apresentando além da substância 7, outros dois poliacetilenos (compostos $\mathbf{1 0}$ e 11).

Geralmente, a análise deste tipo de composto por RMN é dificultada pela baixa sensibilidade dos vários carbonos $s p$ não hidrogenados presentes, pois este tipo de carbonos possuem uma relaxação lenta, sendo necessário realizar experimentos com um tempo longo

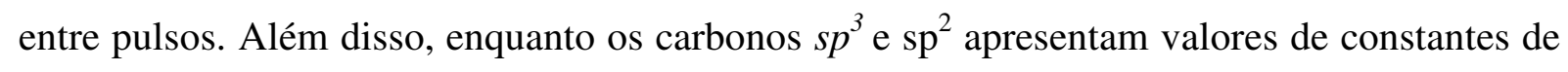
acoplamento heteronuclear $\left({ }^{1} J_{\mathrm{C}-\mathrm{H}}\right)$ respectivamente nas faixas: $115-125 \mathrm{~Hz}$ e $150-170 \mathrm{~Hz}$, os carbonos $s p$ apresentam valores bem diferentes $250-270 \mathrm{~Hz}^{[34]}$.

$\mathrm{O}$ acoplamento a duas ou três ligações $\left({ }^{2} J_{\mathrm{C}-\mathrm{H}}\right.$ ou $\left.{ }^{3} J_{\mathrm{C}-\mathrm{H}}\right)$ envolvendo carbono $s p^{3}$ também é diferenciado. $\mathrm{O}$ valor das constantes de acoplamento geminal $\left({ }^{2} J_{\mathrm{C}-\mathrm{H}}\right)$ através de ligações- $\sigma$ do sistema $\mathrm{R}-\mathrm{C} \equiv \mathrm{C}-\mathrm{H}\left(J_{\equiv \mathrm{CCH}}\right)$ é próximo de $10 \mathrm{~Hz}$ e através da ligação tripla $\left(J_{\mathrm{C} \equiv \mathrm{CH}}\right)$ pode variar de 40 a $65 \mathrm{~Hz}^{[43,184]}$.

No caso de acoplamento vicinal, ${ }^{3} J_{\mathrm{C}-\mathrm{H}}\left(J_{\mathrm{CC} \equiv \mathrm{CH}}\right.$ ou $\left.J_{\mathrm{C} \equiv \mathrm{CCH}}\right)$ os valores são de 2 a $6 \mathrm{~Hz}$. Estas diferenças de ${ }^{1} J_{\mathrm{C}-\mathrm{H}},{ }^{2} J_{\mathrm{C}-\mathrm{H}}$ ou ${ }^{3} J_{\mathrm{C}-\mathrm{H}}$ dificultam a análise destes compostos por RMN-2D, sobretudo experimentos modulados pelo valor destas constantes, como HMQC, HMBC, etc. ${ }^{[50]}$. Como na literatura são relatados poucos estudos de acoplamento de sistemas envolvendo carbonos $s p$, sobretudo em ligações triplas conjugadas com duplas ligações, há necessidade de estudar este sistema mais detalhadamente e determinar o valor destas constantes para poliacetilenos, possibilitando a identificação destes.

\subsubsection{Identificação dos poliacetilenos 10 e 11 , presentes na fração Acetato de etila de Bidens gardneri}

Os compostos $\mathbf{1 0}$ e 11 são substâncias sólidas e amorfas à temperatura ambiente, apresentam cor branca amarelada e são solúveis em $\mathrm{MeOH}$. Seu espectro de UV revelou diversas bandas com $\lambda_{\max }$ e intensidades típicas de um cromóforo tipo eno-diino-eno ${ }^{[185]}$. Existem quatro possibilidades estruturais para este tipo de cromóforo de acordo com a 
geometria das ligações duplas carbono-carbono, podendo ser: (cis)-eno-diino-(cis)-eno; (cis)eno-diino-(trans)-eno; (trans)-eno-diino-(cis)-eno e (trans)-eno-diino-(trans)-eno. As estruturas dessas possibilidades estão apresentadas na Figura 39.

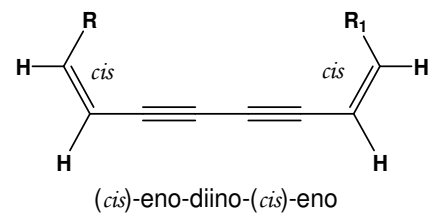

(a)

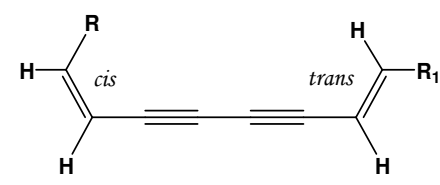

(cis)-eno-diino-(trans)-eno

(b)

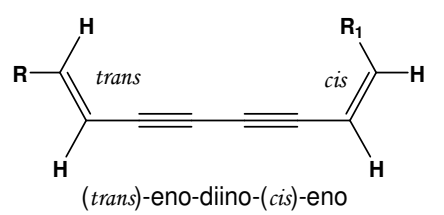

(c)

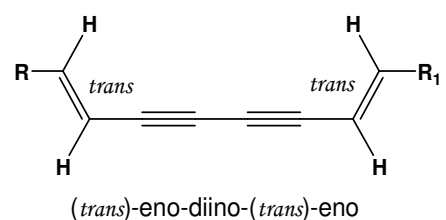

(d)

Figura 39. Estruturas possíveis do cromóforo eno-diino-eno.

Os experimentos de RMN ( ${ }^{1} \mathrm{H}, J$-resolved, HMBC, HSQC e/ou HMQC e G-BIRD $\mathrm{R}-\mathrm{X}^{-}$ CPMG-HSQMBC) podem auxiliar na determinação da configuração assumida pelos compostos $\mathbf{1 0}$ e 11.

\subsubsection{Elucidação da estrutura do composto 10}

$\mathrm{O}$ espectro de $\mathrm{RMN}{ }^{1} \mathrm{H}$ de $\mathbf{1 0}$ apresentou quatro sinais na região de hidrogênios olefínicos em: 6,39; 6,37; 5,83 e 5,66 ppm, com multiplicidades determinadas a partir do experimento $J$-resolved, respectivamente, iguais a $d t d,{ }^{1}(J=5,1 ; 5,1$ e $15,9 \mathrm{~Hz}) ; d t t,(J=0,7$; $0,7 ; 4,9 ; 4,9$; e $16,1 \mathrm{~Hz}) ; d t d^{*},(J=2,3 ; 2,3$ e $15,8 \mathrm{~Hz})$ e $d t^{*},(J=2,3 ; 2,3$ e $16,1 \mathrm{~Hz})$ (Tabela 14). Estes sinais apresentaram correlações no experimento de HSQC com os sinais de ${ }^{13} \mathrm{C}$ em 147,4; 150,0; 109,1 e 109,8 ppm, respectivamente, indicando a presença de duas ligações duplas carbono-carbono do tipo trans.

O espectro de RMN de ${ }^{13} \mathrm{C}$ apresentou outros dezesseis sinais, sendo quatro carbonos quaternários $(\delta 73,1 ; 75,0 ; 79,8$ e 81,3), indicativos de duas ligações triplas carbono-carbono conjugadas; nove carbonos carbinólicos $(\delta 59,6 ; 62,7 ; 62,8 ; 71,7 ; 75,4 ; 77,8 ; 77,9 ; 78,2$ e $104,0)$; e três carbonos alifáticos $(\delta 30,1 ; 35,4$; e 38,2$)$. Os espectros obtidos com os

$1 d=$ dubleto; $d d=$ duplo dubleto; $d t$, = duplo tripleto; $d t d=$ dubleto de triplo dubleto; $d t t=$ dubleto de triplo tripleto; $s=$ singleto; $t=$ tripleto; $t t=$ triplo tripleto 
experimentos $\mathrm{DEPT} 135^{\circ}$ e $\mathrm{HSQC}^{2}$ mostraram que o composto 10 possui em sua estrutura: um

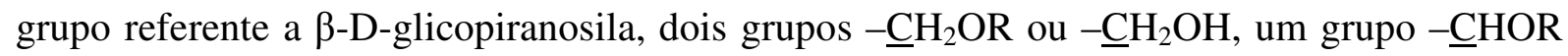
ou $-\underline{\mathrm{C}} \mathrm{HOH}-$, e três grupos $-\underline{\mathrm{CH}_{2}-}$.

Os experimentos de $\mathrm{HMBC}^{3}$ realizados foram modulados pelo valor de $145 \mathrm{~Hz}$ para const1 $\left({ }^{1} J_{\mathrm{CH}}\right)$ e 8 e $4 \mathrm{~Hz}$ para const $2\left({ }^{2} J_{\mathrm{CH}}\right.$ ou $\left.{ }^{3} J_{\mathrm{CH}}\right)$. Os espectros gerados a partir destes experimentos mostraram poucas correlações, sendo elas:

$$
\begin{array}{ll}
\checkmark & \delta_{\mathrm{H}} 4,15\left(-\underline{\mathrm{CH}}_{2} \mathrm{OH}\right) \rightarrow \delta_{\mathrm{C}} 147,4(=\underline{\mathrm{C}} \mathrm{H}-) ; \\
\checkmark & \delta_{\mathrm{H}} 3,83(-\mathrm{C} \underline{\mathrm{HOR}}) \rightarrow \delta_{\mathrm{C}} 150,0(=\underline{\mathrm{C}} \mathrm{H}-) ; \\
\checkmark & \delta_{\mathrm{H}} 4,35(-\mathrm{C} \underline{\mathrm{HOH}}, \text { anomérico }) \rightarrow \delta_{\mathrm{C}} 75,4(-\underline{\mathrm{C}} \mathrm{HOH}, \mathrm{C}-2 \text { ' do açúcar}) ; \text { e } \\
\checkmark & \delta_{\mathrm{H}} 3,42(-\underline{\mathrm{CHOH}}, \mathrm{C}-5 \text { ' do açúcar }) \rightarrow \delta_{\mathrm{C}} 62,7\left(-\underline{\mathrm{CH}}_{2} \mathrm{OH}, \mathrm{C}-6 \text { ' do açúcar }\right) .
\end{array}
$$

A presença de uma correlação no Mapa de contorno gerado a partir do experimento NOESY $\left({ }^{1} \mathrm{H}^{-1} \mathrm{H}\right)$ entre o $\mathrm{H}$-anomérico do grupo glicopiranosila $\left(\delta_{\mathrm{H}} 4,35\right)$ e o sinal em $\delta_{\mathrm{H}} 3,83$ e da correlação no espectro de HSQC deste com o carbono em $\delta_{\mathrm{C}} 78,2$ indicaram que o açúcar se liga à aglicona no $-\mathrm{CH}$ carbinólico. Estas afirmações juntamente com as correlações observadas no experimento TOCSY-2D e $J$-resolved indicam que o composto 10 é o 3-O- $\beta$ D-glicopiranosil-tetradeca-6(E),12(E)-dien-8,10-diin-1,14-diol (Figura 40).

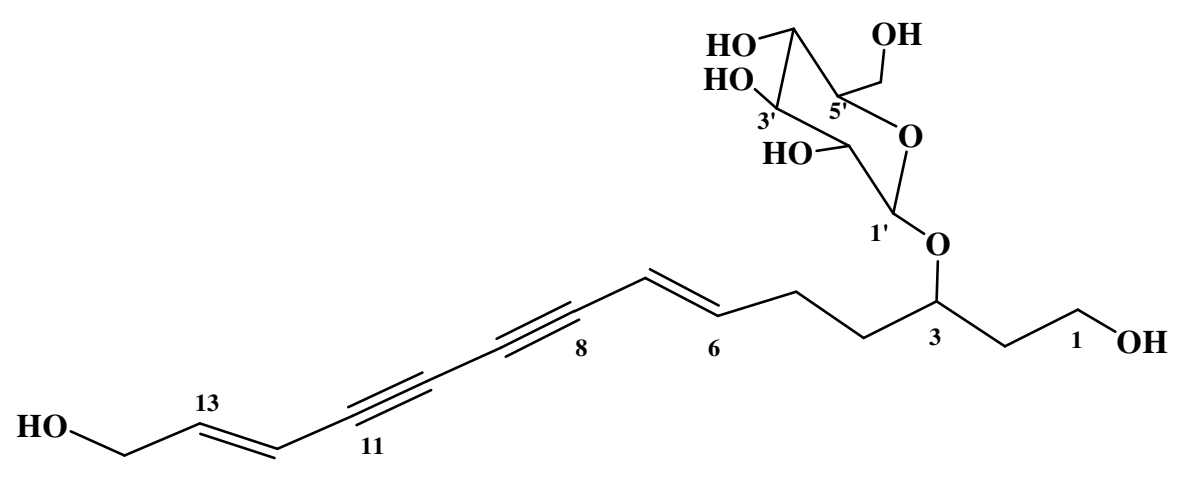

3-O- $\beta$-glicopiranosil-tetradeca-6(E),12(E)-dieno-8,10-diino-1,14-diol (10)

Figura 40. Estrutura do composto 10.

\footnotetext{
${ }^{2}$ DEPT135 $^{\circ}=$ 'Distortionless Enhancement by Polarisation Transfer'; HSQC = 'Heteronuclear Single-Quantum Correlation'

${ }^{3} \mathrm{HMBC}=$ 'Heteronuclear Multiple-Bond Correlation'
} 


\subsubsection{Experimento G-BIRDR-X-CPMG-HSQMBC}

O experimento G-BIRD ${ }_{\mathrm{R}, \mathrm{X}}-\mathrm{CPMG}-\mathrm{HSQMBC}{ }^{[158]}$ foi realizado para o composto 10 , se FID foi adquirido com 4096 pontos de dados em F2, 1024 incrementos para F1 com 32 varreduras por incremento e largura espectral (sw) F2 x F1 de 4496 x 22638 Hz, com rf fixado em 1850,5 (3,7 ppm em F2) e 12 450,02 Hz (99,0 ppm em F1), respectivamente.

Após processamento foi obtido o espectro mostrado Figura 41, com 16384 pontos em F2 e 1024 pontos em F1. Em ambas as dimensões o FID foi preenchido com zeros. O decaimento em F2 não foi submetido a nenhum método de apodização enquanto o decaimento em F1 foi apodizado por multiplicação de uma função cosseno com LB=0,30 Hz.

A razão de gradiente para G-BIRD ${ }_{\mathrm{R}, \mathrm{X}}-\mathrm{CPMG}-\mathrm{HSQMBC}^{[158]}$ foram $\mathrm{G} 1: \mathrm{G} 2$ : G3 : G4 foi $5: 3: 4: 1$. O intervalo de tempo para a transferência de polarização à longa distância foi definida a $\sim 31 \mathrm{~ms}$.

Os intervalos de tempos $\Delta$ foram ajustados para $200 \mu$ s. O pulso trim foi ajustado em $1.2 \mathrm{~ms}$ de duração.

Os valores de ${ }^{2,3} \mathrm{~J}_{\mathrm{CH}}$ foram determinados a partir de medidas diretas e posterior análise de montagem manual de picos.

Os experimentos de RMN 1D e os experimentos de correlação heteronuclear (HSQC e HMBC) foram suficientes para atribuir os sinais referentes aos carbonos $s p^{2}$ e $s p^{3}$ presentes na estrutura do composto 10. Os sinais dos carbonos $s p$, no entanto, não apresentaram nenhuma correlação a longa distância nos experimentos HMBC e, obviamente, nenhuma correlação a uma ligação no experimento HSQC. Deste modo, a atribuição dos valores de deslocamentos dos carbonos de C-8 a C-11 do composto 10 foi realizada com base na comparação com os dados da literatura do composto 7 e nas correlações observadas no mapa de contorno do experimento G-BIRD ${ }_{R-X} C P M G-H S Q M B C$ (Figura 41). 


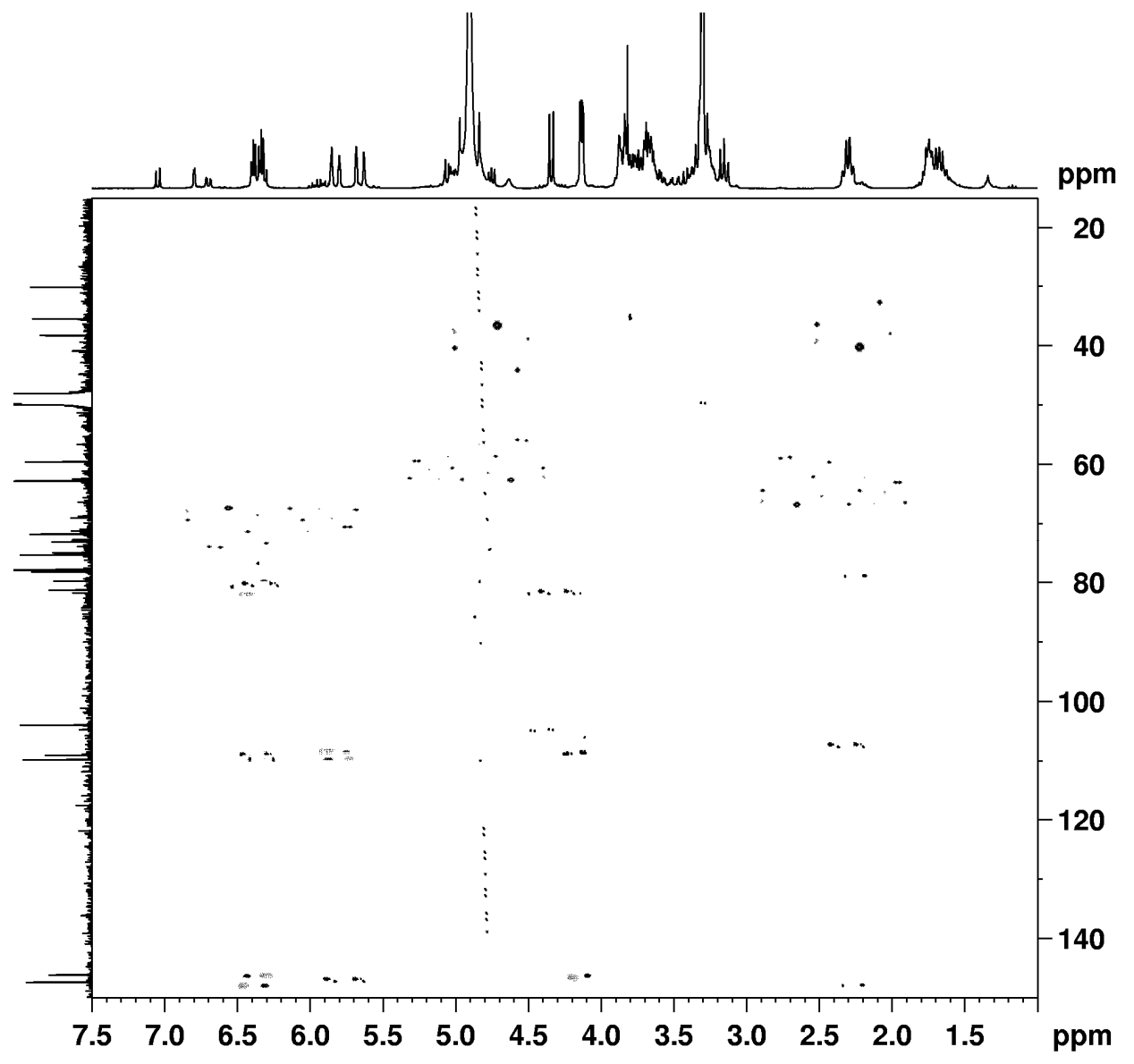

Figura 41. Mapa de contorno do G-BIRD $\mathrm{R}_{\mathrm{X}} \mathrm{CPMG-HSQMBC}$ para o composto $\mathbf{1 0 .}$

As correlações de interesse seriam as referentes aos carbonos em 79,8; 73,1; 75,0 e 81,3 ppm (C-8 a C-11). No entanto no mapa de contorno apresentado na Figura 41 não observadas correlações com os carbonos em 73,1 e 75,0 ppm, mas são observadas para os carbonos em 79,8 e 81,3 ppm. Assim, foram extraídos espectros 1D deste mapa, nas linhas referentes aos sinais em questão (Figuras 42 e 43). 


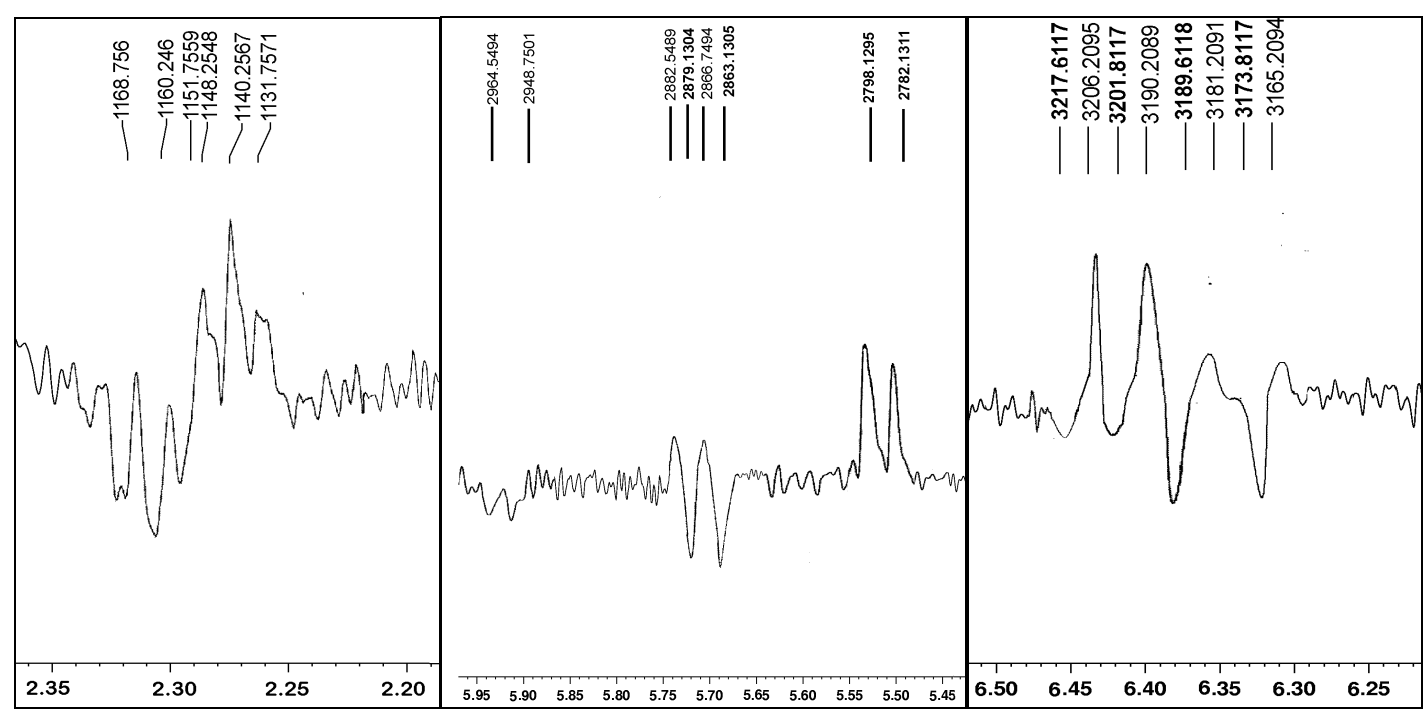

Figura 42. Ampliações de secções do espectro 1D gerado a partir das correlações para o carbono em 79,8 ppm observadas no mapa de contorno do experimento G-BIRD $\mathrm{R}_{\text {- }}$ xCPMG-HSQMBC para o composto 10.

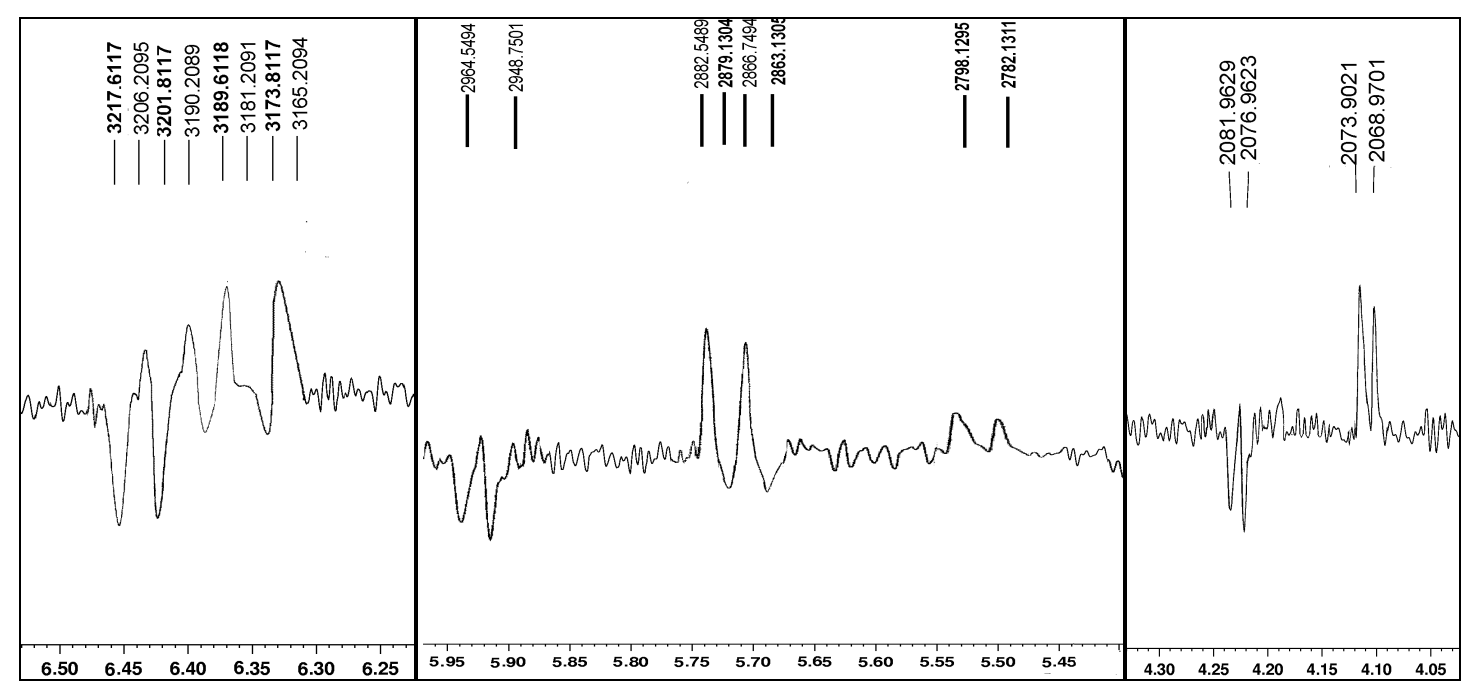

Figura 43. Ampliações de secções do espectro 1D gerado a partir das correlações para o carbono em 81,3 ppm observadas no mapa de contorno do experimento G-BIRD $\mathrm{R}_{\text {- }}$ xCPMG-HSQMBC para o composto 10.

A existência das correlações do $\delta_{\mathrm{C}}$ em 79,8 ppm com H-5 (2,33 ppm), H-6 (6,37 ppm) e H-7 (5,66 ppm) e das correlações do $\delta_{\mathrm{C}}$ em 81,3 ppm) com H-14 (4,15 ppm), H-13 (6,39 ppm) e H-12 (5,66 ppm), permitem afirmar que os valores dos deslocamento químicos de C-8 e C-11 são 79,8 ppm e 81,3 ppm, respectivamente.

A baixa resolução do mapa de contorno não permitiu a determinação precisa dos valores das constantes de acoplamento heteronuclear. Os valores aproximados determinados de ${ }^{3} \mathrm{~J}_{\mathrm{C}-8, \mathrm{H}-6}$ e ${ }^{3} \mathrm{~J}_{\mathrm{C}-11, \mathrm{H}-14}$ foram por volta de $80 \mathrm{~Hz}$, o que corrobora com a atribuição feita 
anteriormente para os carbonos C-8 e C-11. Logo a tabela de atribuição de sinais de RMN do composto 10 pode ser elaborada (Tabela 14).

Tabela 14. Dados de RMN de ${ }^{1} \mathrm{H}(300 \mathrm{MHz})$ e ${ }^{13 \mathrm{C}}\left\{{ }^{1} \mathrm{H}\right\}$ (75 MHz) do composto 10 em Metanol-d4, incluindo dados de padrão de acoplamento (p.a.) e $J$ obtidos do experimento $J$ resolved, COSY e/ou TOCSY, multiplicidade de C (multi.) obtida do experimento DEPT $135^{\circ}$, HSQC, HMBC e/ou G-BIRD ${ }_{\mathrm{R}-\mathrm{X}}$ CPMG-HSQMBC e dados da literatura de RMN de ${ }^{1} \mathrm{H}$ do composto $7(400 \mathrm{MHz})$ e ${ }^{13} \mathrm{C}\left\{{ }^{1} \mathrm{H}\right\}(100 \mathrm{MHz})$ em DMSO-d $\mathrm{d}_{6}{ }^{[179]}$.

\begin{tabular}{|c|c|c|c|c|}
\hline \multirow[t]{2}{*}{$\mathrm{H} / \mathrm{C}$} & \multicolumn{2}{|l|}{ Composto 10} & \multicolumn{2}{|c|}{ 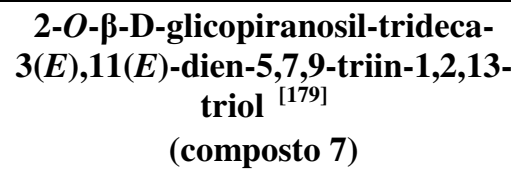 } \\
\hline & $\delta_{\mathrm{H}}[\mathrm{p} . \mathrm{a} ., J(\mathrm{~Hz})]$ & $\begin{array}{c}\delta_{\mathrm{C}} \\
\text { (multi.*) }\end{array}$ & $\delta_{\mathrm{H}}[$ p.a., $J(\mathrm{~Hz})]$ & $\left(\delta_{C}\right)^{\mathrm{d}}$ \\
\hline 1 & $3,63[d t, 16,0 ; 8,7$ e 8,7$] ; 3,75[d t, 16,0 ; 8,7$ e 8,7$]$ & $59,6(t)$ & $3,45[\mathrm{~m}] ; 3,55[\mathrm{~m}]$ & 63,7 \\
\hline 2 & $1,76[d t, 10,7 ; 8,7$ e 8,7$]$ & $38,2(t)$ & $4,37[m]$ & 78,7 \\
\hline 3 & $3,83[t t, 10,7 ; 10,7 ; 6,8$ e 6,8$]$ & $78,2(d)$ & $6,54[d d, 4,6$ e 15,8$]$ & 148,8 \\
\hline 4 & $1,66[t d d, 8,5 ; 8,5 ; 6,8$ e 0,7$]$ & $35,4(t)$ & $6,23[d d, 2,0$ e 15,8$]$ & 108,7 \\
\hline 5 & $2,30[t d d, 8,5 ; 8,5 ; 4,9$ e 2,3$]$ & $30,1(t)$ & - & 76,8 \\
\hline 6 & $6,37[d t t, 16,1 ; 4,9 ; 4,9 ; 0,7$ e 0,7$]$ & $150,0(d)$ & - & 65,5 \\
\hline 7 & $5,66[d t, 16,1 ; 2,3$ e 2,3$]$ & $109,8(d)$ & - & 74,5 \\
\hline 8 & - & $79,8(s)$ & - & 73,3 \\
\hline 9 & - & $73,1(s)$ & - & 65,7 \\
\hline 10 & - & $75,0(s)$ & - & 78,5 \\
\hline 11 & - & $81,3(s)$ & $5,92[d d, J=2,5$ e 15,8$]$ & 105,1 \\
\hline 12 & $5,83[d t, 15,8 ; 2,3$ e 2,3$]$ & $109,1(d)$ & $6,68[d d, J=3,5$ e 15,8$]$ & 152,1 \\
\hline 13 & $6,39[d t d, 15,8 ; 5,1$ e 5,1$]$ & $147,4(d)$ & $4,10[m]$ & 60,8 \\
\hline 14 & $4,15[d d, 2,3$ e 5,1$]$ & $62,8(t)$ & & \\
\hline 1 ' & $4,35[d, 8.4]$ & $104,0(d)$ & $4,18[d, J=8,0]$ & 101,3 \\
\hline 2 ' & $3,16[d d, 8,4$ e 8,9$]$ & $75,4(d)$ & $3,07[t, J=8,0]$ & 73,4 \\
\hline $3^{\prime}$ & $3,33[d d, 8,8$ e 8,9$]$ & $77,8(d)$ & $3,20[t, J=8,0]$ & 76,6 \\
\hline 4' & $3,27[d d, 8,8$ e 9.0$]$ & $71,7(d)$ & $3,10[\mathrm{~m}]$ & 70,5 \\
\hline 5 & $3,42[d d d, 2,3 ; 5,5$ e 9.0$]$ & $77,9(d)$ & $3,13[m]$ & 77,9 \\
\hline 6 & $3,60[d d, 5,5$ e 11,9$] ; 3,75[d d, 2,3$ e 11,9$]$ & $62,7(t)$ & $3,50[\mathrm{~m}] 3,71[\mathrm{~m}]$ & 61,0 \\
\hline
\end{tabular}

\subsubsection{Elucidação da estrutura do composto 11}

Para o composto 11 foram feitos os mesmos experimentos de RMN realizados para o composto 10, exceto o experimento G-BIRD ${ }_{\mathrm{R}-\mathrm{X}} \mathrm{CPMG}-\mathrm{HSQMBC}$. A análise destes experimentos gerou os dados constantes na Tabela 15, onde se pode observar que os compostos 10 e 11 apresentam o mesmo esqueleto carbônico: o tetradeca-6(E),12(E)-dien8,10-diino, diferenciando pela presença de uma carbonila em $\delta_{\mathrm{C}} 210,5$, ausência do sinais em $\delta_{\mathrm{H}} 3,83 / \delta_{\mathrm{C}} 78,2$ referentes a um grupo -CHOR, aumento dos deslocamentos químicos dos 
carbonos C-1, C-2 e C-4 e dos respectivos hidrogênios, bem como a mudança do padrão de acoplamento de H-2, H-4, H-5, H-6 e H-7. Estas diferenças indicam que o composto 11 é o 1O- $\beta$-D-glicopiranosil- 1,14-di-hidroxi-tetradeca - 6(E),12(E)-dien-8,10-diin-3-ona (Figura 44).

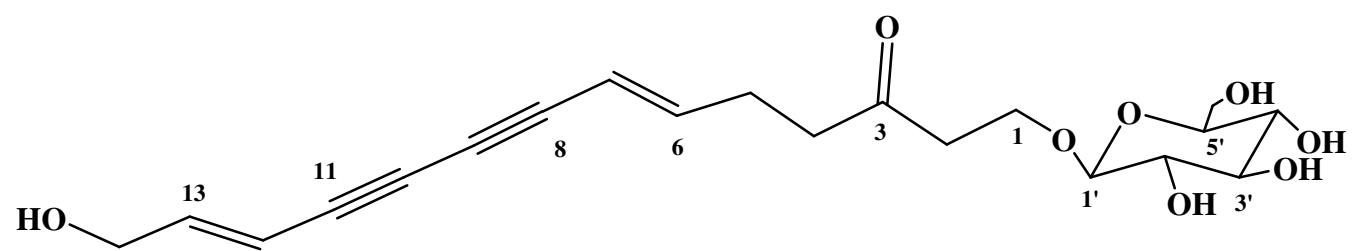

1-O-b-glicopiranosil-14-hidróxi-tetradeca-6(E),12(E)-dieno-8,10-diino-3-ona (11)

Figura 44. Estrutura do composto 11.

Tabela 15. Dados de RMN de ${ }^{1} \mathrm{H}(300 \mathrm{MHz})$ e ${ }^{13} \mathrm{C}\{1 \mathrm{H}\}$ (75 MHz) do composto 11 em Metanol-d4, incluindo dados de padrão de acoplamento (p.a.) e J obtidos dos experimento $J$ resolved, COSY e/ou TOCSY, multiplicidade de C (multi.) obtida do experimentos DEPT $135^{\circ}$, HMQC e ou HMBC e a comparação com dados para o composto $\mathbf{1 0 .}$

\begin{tabular}{|c|c|c|c|c|}
\hline \multirow[t]{2}{*}{$\mathbf{H} / \mathbf{C}$} & \multicolumn{2}{|l|}{ Composto 10} & \multicolumn{2}{|c|}{ Composto 11} \\
\hline & $\delta_{\mathrm{H}}{ }^{\mathrm{a}}\left[\mathrm{p} . \mathrm{a} ., J(\mathrm{~Hz})^{\#}\right]$ & $\delta_{\mathrm{C}}^{\mathrm{b}}$ (multi.*) & $\delta_{\mathrm{H}}{ }^{\mathrm{a}}\left[\mathrm{p} . \mathrm{a} ., J(\mathrm{~Hz})^{\#}\right]$ & $\delta_{\mathrm{C}}^{\mathrm{b}}$ (multi.*) \\
\hline 1 & $3,63[d t, 16,0 ; 8,7$ e 8,7$]$ & $59,6(t)$ & $4,12[d t, 6,3 ; 6,3$ e 10,8$]$ & $65,9(t)$ \\
\hline 2 & $\begin{array}{l}3.75[d t .16 .0: 8.7 \text { e } 8.71 \\
1,76[d t, 10,7 ; 8,7 \text { e } 8,7]\end{array}$ & $38,2(t)$ & $\begin{array}{l}3.83[d t .6 .3: 6.3 \text { e } 10.81 \\
2,75[t, 6.3]\end{array}$ & $43,8(t)$ \\
\hline 3 & $3,83[t t, 10,7 ; 10,7 ; 6,8$ e 6,8$]$ & $78,2(d)$ & - & $210,5(s)$ \\
\hline 4 & $1,66[t d d, 8,5 ; 8,5 ; 6,8$ e 0,7$]$ & $35,4(t)$ & $2,67[\mathrm{t} d, 2,1 ; 6,9$ e 6,9$]$ & $42,3(t)$ \\
\hline 5 & $2,30[t d d, 8,5 ; 8,5 ; 4,9$ e 2,3$]$ & $30,1(t)$ & $2,39[q d, 2,0 ; 6,9 ; 6,9$ e 6,9$]$ & $27,9(t)$ \\
\hline 6 & $6,37[d t t, 16,1 ; 4,9 ; 4,9 ; 0,7 \mathrm{e}$ & $150,0(d)$ & $6,29[d t d, 2,1 ; 6,9$ e 15,5$]$ & $148,2(d)$ \\
\hline 7 & $5,66[d t, 16,1 ; 2,3$ e 2,3$]$ & $109,8(d)$ & $5,64[d d, 2,0, \mathrm{e} 15,5]$ & $110,4(d)$ \\
\hline 8 & - & $79,8(s)$ & - & $80,0(s)$ \\
\hline 9 & - & $73,1(s)$ & - & $73,5(s)$ \\
\hline 10 & - & $75,0(s)$ & - & $74,8(s)$ \\
\hline 11 & - & $81,3(s)$ & - & $80,8(s)$ \\
\hline 12 & $5,83[d t, 15,8 ; 2,3$ e 2,3$]$ & $109,1(d)$ & $5,83[d t, 1,8 ; 1,8$ e 15,2$]$ & $109,0(d)$ \\
\hline 13 & $6,39[d t d, 15,8 ; 5,1$ e 5,1$]$ & $147,4(d)$ & $6,37[d t d, 4,7 ; 4,7$ e 15,2$]$ & $147,6(d)$ \\
\hline 14 & $4,15[d d, 2,3$ e 5,1$]$ & $62,8(t)$ & $4,13[d d, 1,8$ e 4,7$]$ & $62,87(t)$ \\
\hline 1 ' & $4,35[d, 8.4]$ & $104,0(d)$ & $4,25[d, 8,0]$ & $104,6(d)$ \\
\hline 2 ' & $3,16[d d, 8,4$ e 8,9$]$ & $75,4(d)$ & $3,13[d d, 8,0$ e 8,8$]$ & $75,0(d)$ \\
\hline 3 ' & $3,33[d d, 8,8$ e 8,9$]$ & $77,8(d)$ & $3,32[t, 8,8$ e 8,8$]$ & $78,0(d)$ \\
\hline $4^{\prime}$ & $3,27[d d, 8,8$ e 9.0$]$ & $71,7(d)$ & $3,24[d d, 7,8$ e 8,8$]$ & $71,7(d)$ \\
\hline 5 & $3,42[d d d, 2,3 ; 5,5$ e 9.0$]$ & $77,9(d)$ & $3,26[d d, 2,0 ; 5,8$ e 7,8$]$ & $78,1(d)$ \\
\hline $6^{\prime}$ & $\begin{array}{l}3,60[d d, 5,5 \text { e } 11,9] \\
3.75[d d, 2.3 \text { e } 11.9]\end{array}$ & $62,7(t)$ & $\begin{array}{l}3,65[d d, 5,8 \text { e } 11,8] \\
3.86[d d, 2.0 \text { e } 11.8]\end{array}$ & $62,8(t)$ \\
\hline
\end{tabular}


Com a finalidade de buscar estratégias de aumento da eficiência da análise de produtos naturais por RMN, visando a redução de tempo e custo de análise. Para tanto, foram feitas três abordagens distintas. Na primeira abordagem estudou-se a viabilidade da aplicação de DOSY2D na análise de extatos vegetais. Na segunda abordagem, foi avaliado o efeito do tratamento por SVD do sinal de RMN de ${ }^{13} \mathrm{C}$ de amostras diluídas, com o intuito de aumentar a sensibilidade da técnica. Finalmente, na terceira abordagem foi estudado o papel da constante de acoplamento hetero nuclear nJCH na elucidação de poliacetilenos com vários carbonos não hidrogenados.

A técnica de RMN DOSY-2D teve um papel importante na identificação dos componentes da fração acetato de etila do extrato etanólico das partes aéreas de Bidens sulphurea.

Geralmente, um espectro DOSY não apresenta uma resolução na dimensão dos deslocamentos químicos, suficiente para permitir a atribuição da multiplicidade e constante de acoplamento dos sinais dos prótons dos carbonos anoméricos, impossibilitando a determinação da configuração das unidades de açúcar. Assim, foi necessária a separação física dos componentes.

Apesar disso, pode-se dizer que a técnica DOSY-2D mostrou-se como uma importante ferramenta na análise preliminar da fração estudada, pois além de fornecer o número de componentes presentes em concentrações detectáveis, como a técnica de cromatografia, forneceu, também, informações estruturais, como o tipo dos esqueletos carbônicos. Isso permite dizer que esta técnica pode ser utilizada na análise rápida de produtos naturais, extratos, pois é capaz de identificar as substâncias em mistura com relativa rapidez e precisão, mesmo quando as substâncias são muito semelhantes, como os quatro compostos apresentados neste trabalho.

Com o uso da técnica DOSY, o químico de produtos naturais pode identificar compostos em mistura, usando dos métodos de separação somente quando for estritamente necessário ou conveniente.

O tratamento por SVD foi realizado no sinal secionado, através do procedimento proposto por Kunikeev e Taylor e foi seguido por uma transformada de Fourier inversa. O método mostrou ser bastante promissor como meio de racionalização do tempo de máquina gasto na análise de amostras diluídas, pois promove um ganho de sensibilidade de RMN de 
${ }^{13} \mathrm{C}$ bastante expressivo, ou seja, os espectros tratados com o método apresentam uma relação S/R bem superior aos espectros processados apenas com os recursos disponíveis nos programas de processamento de sinal de RMN.

Além disso, para se obter um ganho de S/R equivalente ao promovido pela aplicação do SVD através do aumento de transientes seria necessário um tempo muito longo, o que tornaria o experimento impraticável.

O fato de existir um critério de aplicabilidade do método (existência de "gap" estável) permite dizer que o método não gera nenhum artefato. Entretanto, deve-se tomar cuidado na escolha das secções tratadas de modo que contenham apenas um sinal para que nenhum seja suprimido. A aplicação sistemática do método requer maior automatização permitindo maior agilidade do operador na escolha e o tratamento dos sinais.

Nos experimentos em que os espectros foram parcialmente tratados, o método contribuiu com a identificação dos compostos analisados de modo preciso, demonstrando que pode ser uma ferramenta muito útil na análise de dados de RMN. Portanto, embora seja necessária sua automatização, o método de seccionamento e limpeza de sinal por SVD pode ser considerado uma boa estratégia para aumentar a sensibilidade de $\mathrm{RMN}$ de ${ }^{13} \mathrm{C}$, reduzindo o tempo de experimentos (e/ou otimizando o tempo de máquina), reduzindo custos e aumentando a qualidade das análises, mesmo de amostras muito diluídas.

A terceira técnica aqui destacada trata-se do experimento G-BIRD $D_{R, X}-C P M G-$ HSQMBC, usada como maneira de agilizar a identificação do poliacetileno 3-O- $\beta$-Dglicopiranosil-tetradeca-6(E),12(E)-dien-8,10-diin-1,14-diol. A sequência de pulso usada neste experimento, permitiu a observação de correlações a duas e três ligações de carbonos $s p$ da substância em questão, as quais não foram observadas nos experimentos HMBC modulado “tradicionalmente" pelo valor de ${ }^{2,3} J_{C, H}$ iguais a 4 e $8 \mathrm{~Hz} \mathrm{e}^{1} J_{C, H}$ igual ao valor médio típico 145Hz. Cabe salientar que em sistemas do tipo dos poliacetilenos os valores destas constantes de acoplamento heteronuclear assumem valores bem diferentes da média estabelecida para a maioria dos compostos orgânicos e usada para modular experimentos de RMN, como HSQC, HMQC e HMBC. Portanto, é necessário um estudo mais aprofundado sobre tais constantes nestes sistemas, de modo a facilitar a análise dos poliacetilenos por RMN. 
6

\section{Referências Bibliográficas}


1. Clardy, J.; Walsh, C. Nature, 432, 829-837. 2004.

2. Paterson, I.; Anderson, E. A. Science, 310, 451-453. 2005.

3. Li, J. W. H.; Vederas, J. C. Science, 325, 161-165. 2009.

4. Alvarez, L.; Marquina, S.; Villarreal, M. L.; Alonso, D.; Aranda, E.; Delgado, G. Planta Medica, 62, 355-357. 1996.

5. $\quad$ Sarker, S. D.; Latif, Z.; Gray, A. I. Natural Product Isolation. In Natural Products Isolation, 2005; pp. 1-25. 2005.

6. Cragg, G. M.; Newman, D. J. Pure Appl.Chem., 77, 7-24. 2005.

7. $\quad$ Chin, Y. W.; Balunas, M. J.; Chai, H. B.; Kinghorn, A. D. Aaps Journal, 8, E239E253. 2006.

8. Rapaka, R. S.; Sadee, W. Aaps Journal, 7, -. 2005.

9. $\quad$ Newman, D. J.; Cragg, G. M. Journal of Natural Products, 70, 461-477. 2007.

10. Colegate, S. M.; Molyneux., R. J., Eds. Bioactive Natural Products. Detection, Isolation, and Structural Determination, 2nd ed.; CRC Press, Taylor and Francis Group: Boca Raton. 2008.

11. Newman, D. J.; Cragg, G. M.; Snader, K. M. Journal of Natural Products, 66, 10221037. 2003.

12. Butler, M. S. Natural Product Reports, 25, 475-516. 2008.

13. Harvey, A. L. Drug Discovery Today, 13, 894-901. 2008.

14. Viegas Jr, C.; Bolzani, V. d. S.; Barreiro, E. J. Quimica Nova, 29, 326-337. 2006.

15. Gordaliza, M. Clinical and Translational Oncology, 9, 767-776. 2007.

16. Ojima, I. Journal of Medicinal Chemistry, 51, 2587-2588. 2008.

17. Singh, S. R.; Levine, M. Clin Pharmacol Ther, 75, P28-P28. 2004.

18. Barreiro, E. J.; Bolzani, V. D. Quimica Nova, 32, 679-688. 2009.

19. Pinto, A. C.; Silva, D. H. S.; Bolzani, V. d. S.; Lopes, N. P.; Epifanio, R. d. A. Quimica Nova, 25, 45-61. 2002.

20. Cook, R. Analytical and Bioanalytical Chemistry, 378, 1484-1503. 2004.

21. Nicolaou, K. C.; Montagnon, T. Molecules that changed the world : a brief history of the art and science of synthesis and its impact on society, Vol.; Wiley-VCH: Weinheim. 2008.

22. Demain, A. L. Medicinal Research Reviews, 29, 821-842. 2009.

23. Nicolaou, K. C.; Snyder, S. A. Angewandte Chemie-International Edition, 44, 20502050. 2005.

24. Bernal, J. D. Nature, 129, 721. 1932.

25. Maier, M. E. Natural Product Reports, 26, 1105-1124. 2009.

26. Pilli, R. A. Síntese Orgânica e a Química de Produtos Naturais, Divisão de Produtos Naturais da Sociedade Brasileira de Química: São Paulo. 
http://www.sbq.org.br/filiais/adm/Upload/subconteudo/pdf/Texto2.pdf; Acessada em: 04/02/2010; 2010.

27. Hostettmann, K.; Domon, B.; Schaufelberger, D.; Hostettmann, M. Journal of Chromatography, 283, 137-147. 1984.

28. Hostettmann, K.; Marston, A. Bioactive constituents of plants used in African traditional medicine. In Studies in natural products chemistry. Structure and chemistry (part A; Atta-ur-Rahman Ed.; Elsevier Science Publishers B.V., 1990; pp. 405-437. 1990.

29. Hostettmann, K.; Wolfender, J.-L.; Rodriguez, S. Planta Medica, 63, 2-10. 1997.

30. Hostettmann, K. Planta Medica, 74, L15. 2008.

31. Wolfender, J.-L.; Hostettmann, K. Applications of liquid chromatography-mass espectrometry to the investigation In Phytochemistry of medicinal plants Arnason, J. T.; Mata, R.; Romeo, J. T. Eds.; Plenum Press: New York, 1995. 1995.

32. Settle, F. A., Ed. Handbook of Instrumental Techniques for Analytical Chemistry; Prentice-Hall: Upper Saddler River. 1997.

33. Claridge, T. D. W. High-resolution NMR techniques in organic chemistry, Vol.; Elsevier: Amsterdam; London. 2009.

34. Pavia, D. L.; Lampman, G. M.; Kriz, G. S.; Vyvyan, J. R. Introduction to Spectroscopy, Vol., 4th ed.; Saunders-Golden-Sunburst: Belmont. 2001.

35. Skoog, D. A.; Holler, F. J.; Nieman, T. Princípios de análise instrumental, Vol., $5^{\text {a }}$ ed.; Bookman: Porto Alegre. 2002.

36. Lindon, J. C.; Tranter, G. E.; Holmes, J. L. Encyclopedia of spectroscopy and spectrometry, Vol. 1, 1 ed.; Elsevier / Academic Press: Ontario. 2000.

37. Constantino, M. G. Química Orgânica - Curso Básico Universitário, Vol. 3; LTCLivros Técnicos e Científicos Editora S. A.: Rio de Janeiro. 2008.

38. LBNL. http://www.lbl.gov/images/MicroWorlds/EMSpec.gif Ed.; Lawrence Berkeley National Laboratory: Berkeley CA; 2009.

39. Silverstein, R. M.; Webster, F. X.; David, K. Identificação Espectrométrica de Compostos Orgânicos Vol., 7th ed.; LTC. 2004.

40. Macomber, R. S. A Complete Introduction to Modern NMR Spectroscopy Vol.; John Wiley \& Sons: John Wiley \& Sons: New York. 1998.

41. Hoch, J. C.; Stern, A. S. NMR Data Processing, Vol., 1 ed.; John Wiley \& Sons: Hoboken. 1996.

42. Field, L. D.; Sternhell, S.; Kalman, J. R. Organic Strutuctures from Spectra, Vol. Único, 1 ed.; John Wiley \& Sons: Chichester. 1995.

43. Wehrli, F. W.; Marchand, A. P.; Wehrli, S. Interpretation of carbon-13 NMR spectra, Vol., 2nd ed.; John Wiley \& Sons: New Delhi. 1983.

44. Friedrich, B.; Herschbach, D. Physics Today, 56, 53-59. 2003.

45. Bloch, F.; Hansen, W. W.; Packard, M. Physical Review, 70, 474. 1946. 
46. Purcell, E. M.; Bloembergen, N.; Pound, R. V. Physical Review, 70, 988. 1946.

47. Purcell, E. M.; Torrey, H. C.; Pound, R. V. Physical Review, 69, 37. 1946.

48. Nobel-Foundation. The Nobel Prize, Nobel.org: Stockholm. http://nobelprize.org/nobel_prizes/; Acessada em: 05.01.2009; 2009.

49. Gil, V. M. S.; Geraldes, C. F. G. C. Ressonância Magnética Nuclear - Fundamentos Métodos e Aplicações, Vol. , 2002 ed.; Fundação Calouste Gulbekian. 2002.

50. Sanders, J. K. M.; Hunter, B. K. Modern NMR spectroscopy: a guide for chemists, Vol., 2nd ed.; Oxford University Press Inc: New york. 1993.

51. Gil, A. M.; Duarte, I.; Cabrita, E.; Goodfellow, B. J.; Spraul, M.; Kerssebaum, R. Analytica Chimica Acta, 506, 215-223. 2004.

52. Sowerby, A. Chemistry and Industry, 21-23. 2005.

53. Willard, H.; Merrit Jr, L. L.; Dean, J. Instrumental Methods of Analysis Vol., 6th ed.; Wadsworth Publishing Company: New york. 1981.

54. Skoog, D. A.; West, D. M.; Holler, F. J., Eds. Fundamentals of analytical chemistry, 8th ed.; Thomson-Brooks/Cole: Belmont CA. 2004.

55. Barjat, H.; Morris, G. A.; Swanson, A. G. J Magn Reson, 131, 131-138. 1998.

56. Gounarides, J. S.; Chen, A. D.; Shapiro, M. J. Journal of Chromatography BAnalytical Technologies in the Biomedical and Life Sciences, 725, 79-90. 1999.

57. Smejkalova, D.; Piccolo, A. Environmental Science \& Technology, 42, 699-706. 2008.

58. Tsuda, M.; Yasuda, T.; Fukushi, E.; Kawabata, J.; Sekiguchi, M.; Fromont, J.; Kobayashi, J. Organic Letters, 8, 4235-4238. 2006.

59. Viel, S.; Caldarelli, S. Chemical Communications, 2013-2015. 2008.

60. Williamson, R. T.; Chapin, E. L.; Carr, A. W.; Gilbert, J. R.; Graupner, P. R.; Lewer, P.; McKamey, P.; Carney, J. R.; Gerwick, W. H. Organic Letters, 2, 289-292. 2000.

61. Cabrita, E. J.; Berger, S.; Brauer, P.; Karger, J. J Magn Reson, 157, 124-131. 2002.

62. Park, K. D.; Lee, Y. J. Magnetic Resonance in Chemistry, 44, 887-891. 2006.

63. Caldarelli, S. Magnetic Resonance in Chemistry, 45, S48-S55. 2007.

64. Zielinski, M. E.; Morris, K. F. Magnetic Resonance in Chemistry, 47, 53-56. 2009.

65. Marsaioli, A. J.; Laverde Jr., A.; Fujiwara, F. Y.; Figueiredo, I. M.; A., S.; Fernandes, S. A.; Ferreira, A. G.; Vizzotto, L.; de Souza, A. A. Difusão Molecular por RMN, Vol.; AUREMN: Rio de Janeiro. 2009.

66. Atkins, P. W. Concept in Physical Chemistry, Vol. 1; Oxford University: Oxford 1995.

67. Weingärtner, H.; Holz, M. Annual Reports Section "C" (Physical Chemistry), 98, 121155. 2002.

68. Antalek, B. Concepts in Magnetic Resonance, 14, 225-258. 2002.

69. de Souza, A. A.; Laverde, A. Quimica Nova, 25, 1022-1026. 2002. 
70. Uccello-Barretta, G.; Balzano, F.; Pertici, F.; Jicsinszky, L.; Sicoli, G.; Schurig, V. European Journal of Organic Chemistry, 1855-1863. 2008.

71. Uccello-Barretta, G.; Balzano, F.; Evangelisti, C.; Raffa, P.; Mandoli, A.; Nazzi, S.; Vitulli, G. Journal of Organometallic Chemistry, 693, 1276-1282. 2008.

72. Viel, S.; Mannina, L.; Segre, A. Tetrahedron Letters, 43, 2515-2519. 2002.

73. Nilsson, M.; Morris, G. A. Chemical Communications, 933-935. 2007.

74. Huo, R.; Wehrens, R.; van Duynhoven, J.; Buydens, L. M. C. Analytica Chimica Acta, 490, 231-251. 2003.

75. Lin, M. F.; Shapiro, M. J. Journal of Organic Chemistry, 61, 7617-7619. 1996.

76. Fracaroli, A. M.; Granados, A. M.; de Rossi, R. H. Journal of Organic Chemistry, 74, 2114-2119. 2009.

77. Brand, T.; Cabrita, E. J.; Berger, S. Progress in Nuclear Magnetic Resonance Spectroscopy, 46, 159-196. 2005.

78. Crutchfield, C. A.; Harris, D. J. Magnetic Resonance in Chemistry, 45, 463-468. 2007.

79. Stilbs, P. Progress in Nuclear Magnetic Resonance Spectroscopy, 19, 1-45. 1987.

80. Crutchfield, C. A.; Harris, D. J. Journal of Magnetic Resonance, 185, 179-182. 2007.

81. Kapur, G. S.; Cabrita, E. J.; Berger, S. Tetrahedron Letters, 41, 7181-7185. 2000.

82. Kapur, G. S.; Findeisen, M.; Berger, S. Fuel, 79, 1347-1351. 2000.

83. Lucas, L. H.; Larive, C. K. Concepts in Magnetic Resonance Part A, 20A, 24-41. 2004.

84. Trefi, S.; Gilard, V.; Balayssac, S.; Malet-Martino, M.; Martino, R. Journal of Pharmaceutical and Biomedical Analysis, 46, 707-722. 2008.

85. Trefi, S.; Routaboul, C.; Hamieh, S.; Gilard, V.; Malet-Martino, M.; Martino, R. Journal of Pharmaceutical and Biomedical Analysis, 47, 103-113. 2008.

86. Cohen, Y.; Avram, L.; Frish, L. Angewandte Chemie-International Edition, 44, 520554. 2005.

87. Laverde, A.; da Conceicao, G. J. A.; Queiroz, S. C. N.; Fujiwara, F. Y.; Marsaioli, A. J. Magnetic Resonance in Chemistry, 40, 433-442. 2002.

88. Barjat, H.; Morris, G. A.; Smart, S.; Swanson, A. G.; Williams, S. C. R. Journal of Magnetic Resonance, Series B, 108, 170-172. 1995.

89. Thurecht, K. J.; Howdle, S. M.; Davis, A. L.; Hyde, J. R. Macromolecules, 40, 976982. 2007.

90. Dixon, A. M.; Larive, C. K. Analytical Chemistry, 69, 2122-2128. 1997.

91. Morris, K. F.; Cutak, B. J.; Dixon, A. M.; Larive, C. K. Analytical Chemistry, 71, 5315-5321. 1999.

92. Simpson, A. J. Magnetic Resonance in Chemistry, 40, S72-S82. 2002.

93. Gostan, T.; Brun, E.; Tramesel, D.; Prigent, Y.; Delsuc, M.-A.; Guigas, B. Bruker Report () 18-25. 2004. 
94. Lemonnier, J.-F.; Floquet, S.; Marrot, J.; Cadot, E. European Journal of Inorganic Chemistry, 2009, 5233-5239. 2009.

95. Pescitelli, G.; Di Bari, L.; Salvadori, P. Organometallics, 23, 4223-4229. 2004.

96. Politi, M.; Peschel, W.; Wilson, N.; Zloh, M.; Prieto, J. M.; Heinrich, M. Phytochemistry, 69, 562-570. 2008.

97. Politi, M.; Groves, P.; Chavez, M. I.; Canada, F. J.; Jimenez-Barbero, J. Carbohydrate Research, 341, 84-89. 2006.

98. Vizzotto, L. Estudo e Aplicações das Técnicas de RMN HR-MAS e DOSY em Plantas e Extratos de Planta da Ordem RUTALES, Doutorado, Departamento de Química, Universidade Federal de São Carlos, 200 p., orientador: Ferreira, A. G. 2004.

99. Díaz, M. D.; Berger, S. Carbohydrate Research, 329, 1-5. 2000.

100. Lin, M.; Jayawickrama, D. A.; Rose, R. A.; DelViscio, J. A.; Larive, C. K. Analytica Chimica Acta, 307, 449-457. 1995.

101. Chen, A. D.; Wu, D. H.; Johnson, C. S. Journal of Physical Chemistry, 99, 828-834. 1995.

102. Hinton, D. P.; Johnson, C. S. The Journal of Physical Chemistry, 97, 9064-9072. 1993.

103. Jian, X.; Ganzuo, L.; Zhiqiang, Z.; Guowei, Z.; Kejian, J. Colloids and Surfaces A: Physicochemical and Engineering Aspects, 191, 269-278. 2001.

104. Chen, A.; Wu, D. H.; Johnson, C. S. Journal of the American Chemical Society, 117, 7965-7970. 1995.

105. Viel, S.; Capitani, D.; Mannina, L.; Segre, A. Biomacromolecules, 4, 1843-1847. 2003.

106. Akpa, B. S.; Holland, D. J.; Sederman, A. J.; Johns, M. L.; Gladden, L. F. Journal of Magnetic Resonance, 186, 160-165. 2007.

107. Kimmich, R. Chemical Physics, 284, 253-285. 2002.

108. Cabrita, E. J.; Berger, S. Magnetic Resonance in Chemistry, 40, S122-S127. 2002.

109. Chen, A.; Johnson, C. S.; Lin, M.; Shapiro, M. J. Journal of the American Chemical Society, 120, 9094-9095. 1998.

110. Plummer, R.; Hill, D. J. T.; Whittaker, A. K. Macromolecules, 39, 3878-3889. 2006.

111. Bagno, A.; Rastrelli, F.; Saielli, G. Progress in Nuclear Magnetic Resonance Spectroscopy, 47, 41-93. 2005.

112. Kärger, J.; Vasenkov, S. Microporous and Mesoporous Materials, 85, 195-206. 2005.

113. Rondeau-Mouro, C.; Zykwinska, A.; Durand, S.; Doublier, J.-L.; Buléon, A. Carbohydrate Polymers, 57, 459-468. 2004.

114. Umecky, T.; Kanakubo, M.; Ikushima, Y. Fluid Phase Equilibria, 228-229, 329-333. 2005.

115. Zhao, T.; Beckham, H. W. Macromolecules, 36, 9859-9865. 2003. 
116. Tomati, U.; Belardinelli, M.; Galli, E.; Iori, V.; Capitani, D.; Mannina, L.; Viel, S.; Segre, A. Carbohydrate Research, 339, 1129-1134. 2004.

117. Carr, H. Y.; Purcell, E. M. Physical Review, 94, 630. 1954.

118. Stejskal, E. O.; Tanner, J. E. The Journal of Chemical Physics, 42, 288-292. 1965.

119. Stejskal, E. O. The Journal of Chemical Physics, 43. 1965.

120. Price, W. S. Concepts in Magnetic Resonance, 9, 299-336. 1997.

121. Johnson, C. S. Progress in Nuclear Magnetic Resonance Spectroscopy, 34, 203-256. 1999.

122. Hinton, D. P.; Johnson, C. S. Chemistry and Physics of Lipids, 69, 175-178. 1994.

123. Brand, T.; Cabrita, E. J.; Morris, G. A.; Gunther, R.; Hofmann, H. J.; Berger, S. Journal of Magnetic Resonance, 188, 387-387. 2007.

124. Brand, T.; Cabrita, E. J.; Morris, G. A.; Gunther, R.; Hofmann, H. J.; Berger, S. Journal of Magnetic Resonance, 187, 97-104. 2007.

125. Shapiro, Y. E.; Meirovitch, E. Journal of Physical Chemistry B, 113, 7003-7011. 2009.

126. Pelta, M. D.; Barjat, H.; Morris, G. A.; Davis, A. L.; Hammond, S. J. Magnetic Resonance in Chemistry, 36, 706-714. 1998.

127. Jerschow, A.; Muller, N. Macromolecules, 31, 6573-6578. 1998.

128. Jerschow, A.; Muller, N. Journal of Magnetic Resonance, 134, 17-29. 1998.

129. Jerschow, A.; Muller, N. Journal of Magnetic Resonance, 132, 13-18. 1998.

130. Loening, N. M.; Keeler, J. Journal of Magnetic Resonance, 139, 334-341. 1999.

131. Loening, N. M.; Keeler, J.; Morris, G. A. Journal of Magnetic Resonance, 153, 103112. 2001.

132. Price, K. E.; Lucas, L. H.; Larive, C. K. Analytical and Bioanalytical Chemistry, 378, 1405-1407. 2004.

133. Nilsson, M.; Connell, M. A.; Davis, A. L.; Morris, G. A. Analytical Chemistry, 78, 3040-3045. 2006.

134. Parella, T. Magnetic Resonance in Chemistry, 36, 467-495. 1998.

135. Parella, T.; Adell, P.; Sanchez-Ferrando, F.; Virgili, A. Magnetic Resonance in Chemistry, 36, 245-249. 1998.

136. Parella, T.; Belloc, J.; Sanchez-Ferrando, F.; Virgili, A. Magnetic Resonance in Chemistry, 36, 715-719. 1998.

137. Stoll, I.; Mix, A.; Rozhenko, A. B.; Neumann, B.; Stammler, H. G.; Mattay, J. Tetrahedron, 64, 3813-3825. 2008.

138. Schlorer, N. E.; Cabrita, E. J.; Berger, S. Angewandte Chemie-International Edition, 41, 107-109. 2002.

139. Li, D. Y.; Keresztes, I.; Hopson, R.; Williard, P. G. Accounts of Chemical Research, 42, 270-280. 2009. 
140. Kavakka, J. S.; Kilpelainen, I.; Heikkinen, S. Organic Letters, 11, 1349-1352. 2009.

141. Nilsson, M.; Morris, G. A. Analytical Chemistry, 80, 3777-3782. 2008.

142. Groves, P.; Rasmussen, M. O.; Molero, M. D.; Samain, E.; Canada, F. J.; Driguez, H.; Jimenez-Barbero, J. Glycobiology, 14, 451-456. 2004.

143. Ernst, R. R.; Anderson, W. A. Review of Scientific Instruments, 37, 93-102. 1966.

144. Tramesel, D.; Catherinot, V.; Delsuc, M.-A. Journal of Magnetic Resonance, 188, 5667. 2007.

145. Hoffmann, E. G.; Stempile, W.; Schroth, G.; Weimann, B.; Ziegler, E.; Brandt, J., pp. $375-386 ; 1972$.

146. Cooley, J. W.; Tukey, J. W. Mathematics of Computation, 19, 297-301. 1965.

147. O'Sullivan, E. A.; Cowan, C. F. N. Signal Processing, IET, 2, 49-58. 2008.

148. Kunikeev, S. D.; Taylor, H. S. Journal of Physical Chemistry A, 108, 743-753. 2004.

149. Mandelshtam, V. A.; Taylor, N. D.; Hu, H. T.; Smith, M.; Shaka, A. J. Chemical Physics Letters, 305, 209-216. 1999.

150. Kunikeev, S. D.; Taylor, H. S.; Schroer, T.; Haiges, R.; Jones, C. J. B.; Christe, K. O. Inorganic Chemistry, 45, 437-442. 2006.

151. Kunikeev, S. D.; Taylor, H. S.; Pan, J. J.; Kershaw, A.; McKenna, C. E. Journal of Organometallic Chemistry, 690, 2644-2650. 2005.

152. Mandelshtam, V. A.; Taylor, H. S.; Shaka, A. J. Journal of Magnetic Resonance, 133, 304-312. 1998.

153. Cadzow, J. A. Ieee Transactions on Acoustics Speech and Signal Processing, 36, 4962. 1988.

154. Mandelshtam, V. A.; Taylor, H. S. Journal of Chemical Physics, 108, 9970-9977. 1998.

155. Marquez, B. L.; Gerwick, W. H.; Williamson, R. T. Magnetic Resonance in Chemistry, 39, 499-530. 2001.

156. Kalinowski, H. O.; Berger, S.; Braun, S. Carbon-13 NMR spectroscopy, Vol., 4th ed.; John Wiley and Sons: New York, NY. 1988.

157. Lacerda, V.; da Silva, G. V. J.; Tormena, C. F.; Williamson, R. T.; Marquez, B. L. Magnetic Resonance in Chemistry, 45, 82-86. 2007.

158. Lacerda, V.; da Silva, G. V. J.; Constantino, M. G.; Tormena, C. F.; Williamson, R. T.; Marquez, B. L. Magnetic Resonance in Chemistry, 44, 95-98. 2006.

159. Pell, G. S.; Briellmann, R. S.; Waites, A. B.; Abbott, D. F.; Lewis, D. P.; Jackson, G. D. Journal of Magnetic Resonance Imaging, 23, 248-252. 2006.

160. Koskela, H.; Kilpelainen, I.; Heikkinen, S. Journal of Magnetic Resonance, 164, 228232. 2003.

161. Williamson, R. T.; Marquez, B. L.; Gerwick, W. H.; Kover, K. E. Magnetic Resonance in Chemistry, 38, 265-273. 2000. 
162. Simova, S. Magnetic Resonance in Chemistry, 36, 505-510. 1998.

163. Brentan da Silva, D. Faculdade de Ciências Farmacêuticas de Ribeirão Preto, Doutorado, 425. 2009.

164. Brentan da Silva, D. Departamento de Química do Centro de Ciências Exatas e Tecnologia, Mestre, 193. 2006.

165. Kerssebaum, R. DOSY and diffusion by NMR - Use Guide for XWinNMR 3.1/3.5, Vol. Version 1.03; Bruker BioSpin: Rheinstetten, Germany. 2002.

166. Kunikeev, S. D.; Taylor, H. S. Abstracts of Papers of the American Chemical Society, 227, U264-U265. 2004.

167. Wang, N. L.; Yao, X. S.; Ishii, R.; Kitanaka, S. Phytochemistry, 62, 741-746. 2003.

168. Kviecinski, M. R.; Felipe, K. B.; Schoenfelder, T.; Wiese, L. P. D.; Rossi, M. H.; Goncalez, E.; Felicio, J. D.; Wilhelm, D.; Pedrosa, R. C. Journal of Ethnopharmacology, 117, 69-75. 2008.

169. Chang, J. S.; Chiang, L. C.; Chen, C. C.; Liu, L. T.; Wang, K. C.; Lin, C. C. American Journal of Chinese Medicine, 29, 303-312. 2001.

170. Wu, L. W.; Chiang, Y. M.; Chuang, H. C.; Lo, C. P.; Yang, K. Y.; Wang, S. Y.; Shyur, L. F. Planta Medica, 73, 655-661. 2007.

171. Wang, N. L.; Yao, X. S.; Ishii, R.; Kitanaka, S. Chemical \& Pharmaceutical Bulletin, 49, 938-942. 2001.

172. Dimo, T.; Rakotonirina, S. V.; Tan, P. V.; Azay, J.; Dongo, E.; Cros, G. J Ethnopharmacol, 83, 183-191. 2002.

173. Ong, P. L.; Weng, B. C.; Lu, F. J.; Lin, M. L.; Chang, T. T.; Hung, R. P.; Chen, C. H. Food and Chemical Toxicology, 46, 1535-1547. 2008.

174. Wu, L. W.; Chiang, Y. M.; Chuang, H. C.; Wang, S. Y.; Yang, G. W.; Chen, Y. H.; Lai, L. Y.; Shyur, L. F. Pharm Res, 21, 2112-2119. 2004.

175. Bennini, B.; Chulia, A. J.; Kaouadji, M.; Thomasson, F. Phytochemistry, 31, 24832486. 1992.

176. Markham, K. R.; Ternai, B.; Stanley, R.; Geiger, H.; Mabry, T. J. Tetrahedron, 34, 1389-1397. 1978.

177. Ossipov, V.; Nurmi, K.; Loponen, J.; Prokopiev, N.; Haukioja, E.; Pihlaja, K. Biochemical Systematics and Ecology, 23, 213-222. 1995.

178. Brentan da Silva, D.; Tulli, E. C. O.; Garcez, W. S.; Nascimento, E. A.; de Siqueira, J. M. Journal of the Brazilian Chemical Society, 18, 1560-1565. 2007.

179. Bauer, R.; Redl, K.; Davis, B. Phytochemistry, 31, 2035-2037. 1992.

180. Wang, J.; Ishii, H.; Harayama, T.; Gao, Y.; Hui, Q.; Zhang, H.; Chen, J. Chinese Chemical Letters 3, 287-288. . 1992.

181. Christensen, L. P.; Lam, J. Phytochemistry, 30, 11-49. 1991.

182. Oyama, K.-i.; Kondo, T. Tetrahedron, 60, 2025-2034. 2004.

183. Hoffmann, B.; Holzl, J. Planta Med, 54, 52-54. 1988. 
184. Stothers, J. B. Carbon-13 NMR Spectroscopy., Vol. 24; Academic Press: New York: 1972.

185. Scott, A. I. Interpretation of the Ultraviolet Spectra of Natural Products. , Vol.; Pergamon Press.: London. 1964.

186. Bremer, K. Biological Relationships between Africa and South America, 105-135

630. 1993.

187. Pizzolatti, M. G.; Verdi, L. G.; Brighente, I. M. C.; Neiva, T. D. C.; Schripsema, J.; Braz, R. Natural Product Communications, 1, 37-42. 2006.

188. Verdi, L. G.; Brighente, I. M. C.; Pizzolatti, M. G. Quimica Nova, 28, 85-94. 2005.

189. Ferreira, M. J. P.; Brant, A. J. C.; Rufino, A. R.; Alvarenga, S. A. V.; Magri, F. M. M.; Emerenciano, V. P. Phytochemical Analysis, 15, 389-396. 2004.

190. Emerenciano, V. P.; Militao, J. S.; Campos, C. C.; Romoff, P.; Kaplan, M. A.; Zambon, M.; Brant, A. J. Biochem Syst Ecol, 29, 947-957. 2001.

191. Emerenciano, V. P.; Ferreira, M. J. P.; Barbosa, K. O.; Scotti, M. T.; Magenta, M.; Stefani, R. Natural Products an Indian Journal, 2, 35-44. 2006.

192. Christensen, L. P.; Lam, J. Phytochemistry, 30, 2453-2476. 1991.

193. Ferreira, M. J. P.; Brant, A. J. C.; Alvarenga, S. A. V.; Emerenciano, V. P. Chemistry \& Biodiversity, 2, 633-644. 2005.

194. Harborne, J. B.; Williams, C. A. Phytochemistry, 55, 481-504. 2000.

195. Hollman, P. C. H.; Tijburg, L. B. M.; Yang, C. S. Critical reviews in food science and nutrition, 37, 691. 1997.

196. Jansen, R. K.; Holsinger, K. E.; Michaels, H. J.; Palmer, J. D. Evolution, 44, 20052081. 1990.

197. Ganders, F. R.; Bohm, B. A.; Mccormick, S. P. Systematic Botany, 15, 231-239. 1990.

198. Brandao, M. G. L.; Krettli, A. U.; Soares, L. S. R.; Nery, C. G. C.; Marinuzzi, H. C. Journal of Ethnopharmacology, 57, 131-138. 1997.

199. Horiuchi, M.; Seyama, Y. Journal of Health Science, 54, 294-301. 2008.

200. Horiuchi, M.; Seyama, Y. Journal of Health Science, 52, 711-717. 2006.

201. Costa, R. D.; Diniz, A.; Mantovania, M. S.; Jordao, B. Q. Journal of Ethnopharmacology, 118, 86-93. 2008.

202. Pott, A.; Pott, V. J. Plantas do Pantanal, Vol., $1^{\text {a }}$ ed.; Embrapa Informação Tecnológica: Corumbá, MS. 1994.

203. Lorenzi, H.; Souza, H. M. Plantas ornamentais no Brasil: arbustivas, herbáceas e trepadeiras, Vol., $3^{\text {a }}$ ed.; Instituto Plantarum: Nova Odessa, SP. 2001.

204. Botsaris, A. Journal of Ethnobiology and Ethnomedicine, 3, 18.2007.

205. Behr, S.; Duret, P.; Gendron, N.; Guay, J.; Lavalle, B.; Page, B. In World International Property Organization: Canadá; 2006. 
206. CYR, B. In World International Property Organization; INC., B. D. I. Ed.: Canadá; 2002.

207. CYR, B. In World International Property Organization; INC., B. D. I. Ed.: Canadá; 2006.

208. Zeid, A. H. S. A.; Motawe, H. M. Bulletin of the Faculty of Pharmacy, 40, p. 189-199. 2002.

209. Pelletier, S. W. Chemical and biological perspectives, , Vol. 5 Ed. Johny Wiley \& Sons: Nova Iorque, . 1987.

210. Navarro, V. R.; Sette, I. M. F.; Da-Cunha, E. V. L.; Sitva, M. S.; Barbosa-Filho, J. M.; S., M. J. G. Revista Brasileira de Plantas Medicinais, 3, 23-29. 2001.

211. Muhammad, I.; Dunbar, D. C.; Takamatsu, S.; Walker, L. A.; Clark, A. M. Journal of Natural Products, 64, 559-562. 2001.

212. Carollo, C. A.; de Siqueira, J. o. M.; Garcez, W. S.; Diniz, R.; Fernandes, N. G. Journal of Natural Products, 69, 1222-1224. 2006.

213. Brastianos, H. C.; Sturgeon, C. M.; Roberge, M.; Andersen, R. J. Journal of Natural Products, 70, 287-288. 2007.

214. Debourges, D.; Roblot, F. o.; Hocquemiller, R.; CavÃ®, A. Journal of Natural Products, 50, 664-673. 1987.

215. Debourges, D.; Roblot, F. o.; Hocquemiller, R.; CavÃ®, A. Journal of Natural Products, 50, 852-859. 1987.

216. Rasamizafy, S.; Hocquemiller, R.; CavÃ®), A.; Fournet, A. Journal of Natural Products, 50, 674-679. 1987.

217. Wang, Z. W.; Ma, W. W.; McLaughlin, J. L.; Gupta, M. P. Journal of Natural Products, 51, 382-382. 1988.

218. da Silva, D. B.; Tulli, E. C. O.; Garcez, W. S.; Nascimento, E. A.; de Siqueira, J. M. Journal of the Brazilian Chemical Society, 18, 1560-1565. 2007.

219. de Siqueira, J. M.; Bomm, M. D.; Pereira, N. F. G.; Garcez, W. S.; Boaventura, M. A. D. Quimica Nova, 21, 557-559. 1998.

220. de Siqueira, J. M.; Muller, L.; Carollo, C. A.; Garcez, W. S.; Boaventura, M. A. D.; Nascimiento, E. A. Journal of the Chilean Chemical Society, 48, 89-93. 2003.

221. Pereira, N. F. G.; Carollo, C. A.; Garcez, W. S.; de Siqueira, J. M. Quimica Nova, 26, 512-516. 2003.

222. Perez, E.; Saez, J.; Blair, S.; Franck, X.; Figadere, B. Letters in Organic Chemistry, 1, 102-104. 2004. .

223. Fischer, D. C. H.; Gualda, N. C. D.; Bachiega, D.; Carvalho, C. S.; Lupo, F. N.; Bonotto, S. V.; Alves, M. D.; Yogi, A.; Di Santi, S. M.; Avila, P. E.; Kirchgatter, K.; Moreno, P. R. H. Acta Tropica, 92, 261-266. 2004.

224. Guinaudeau, H.; Bohlke, M.; Lin, L. Z.; Angerhofer, C. K.; Cordell, G. A.; Ruangrungsi, N. Journal of Natural Products, 60, 258-260. 1997. 


\section{Apêndice A: Espectros Selecionados}




\subsection{Compostos 1-4 : aplicação de DOSY-2D}

\subsubsection{Dados de EM-ESI:}

O espectros de massa para os composto 1-4 apresentaram [M-H] em m/z 463.0871 ( \pm $1.2 \mathrm{ppm}), 463.0872$ ( $\pm 1.1 \mathrm{ppm}), 447.0937$ ( $\pm 2.2 \mathrm{ppm})$ e 433.0766 ( $\pm 1.1 \mathrm{ppm})$, respectivamente.

\subsubsection{Espectro de EM-ESI do composto 1}

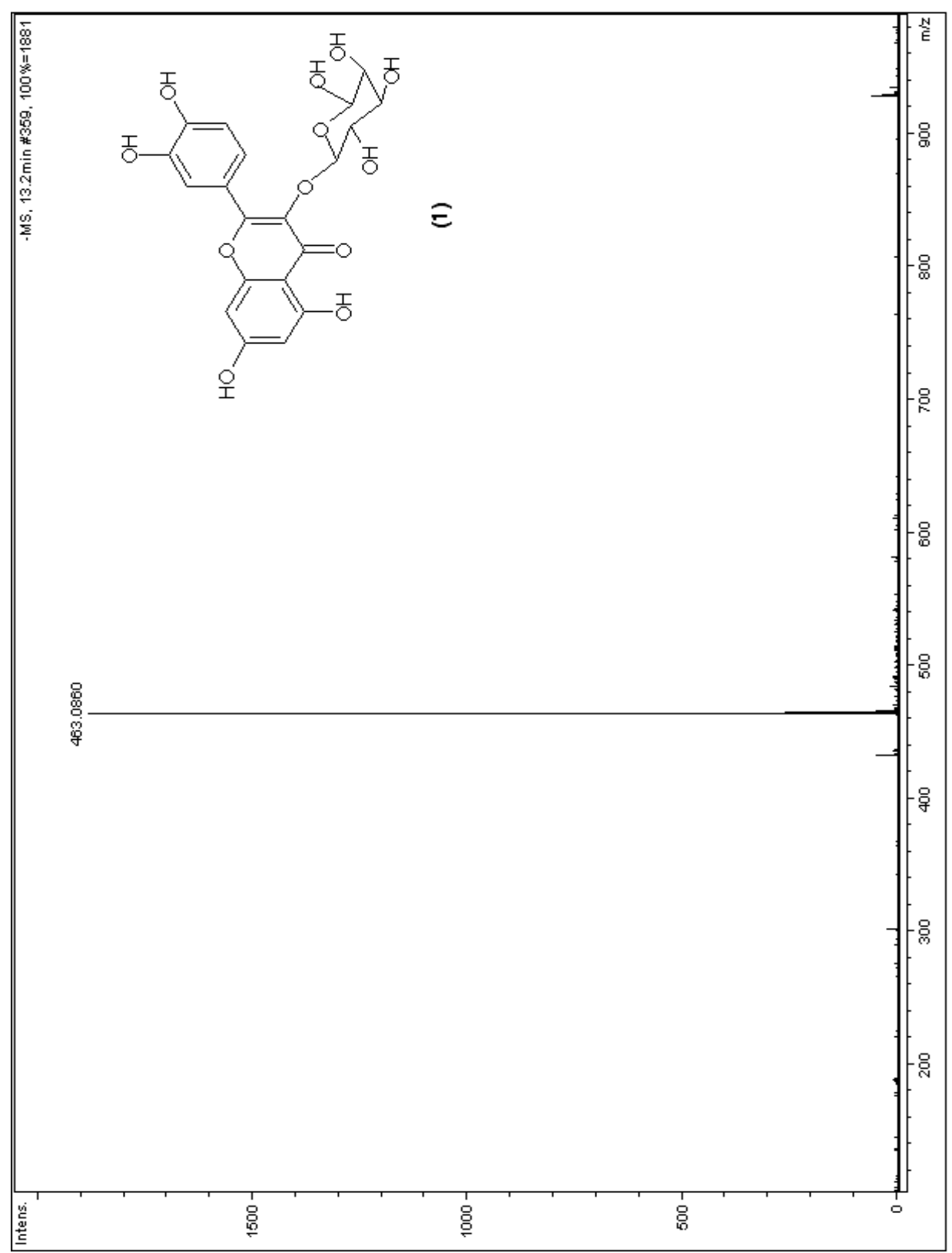




\subsubsection{Espectro de EM-ESI do composto 2}

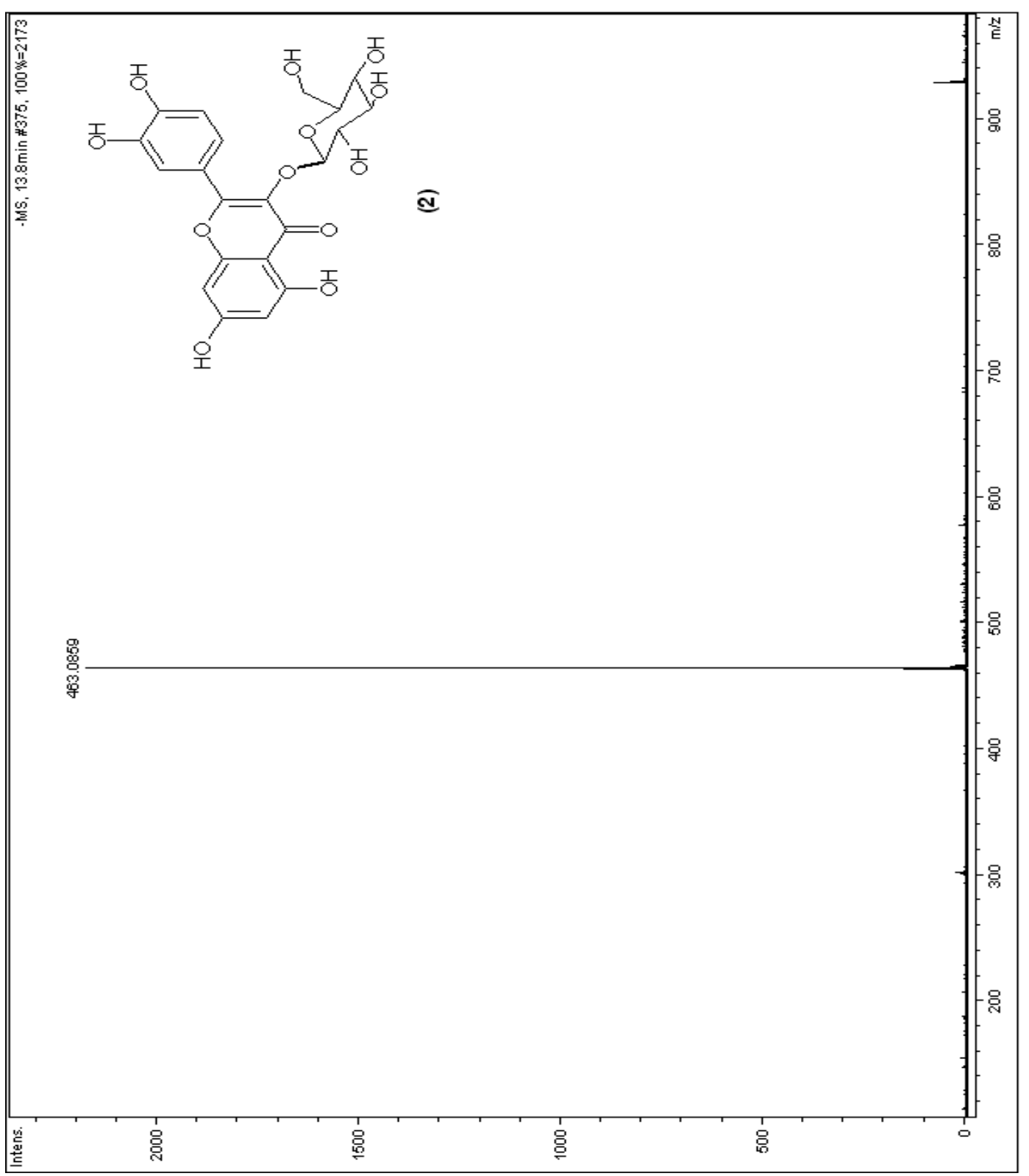




\subsubsection{Espectro de EM-ESI do composto 3}

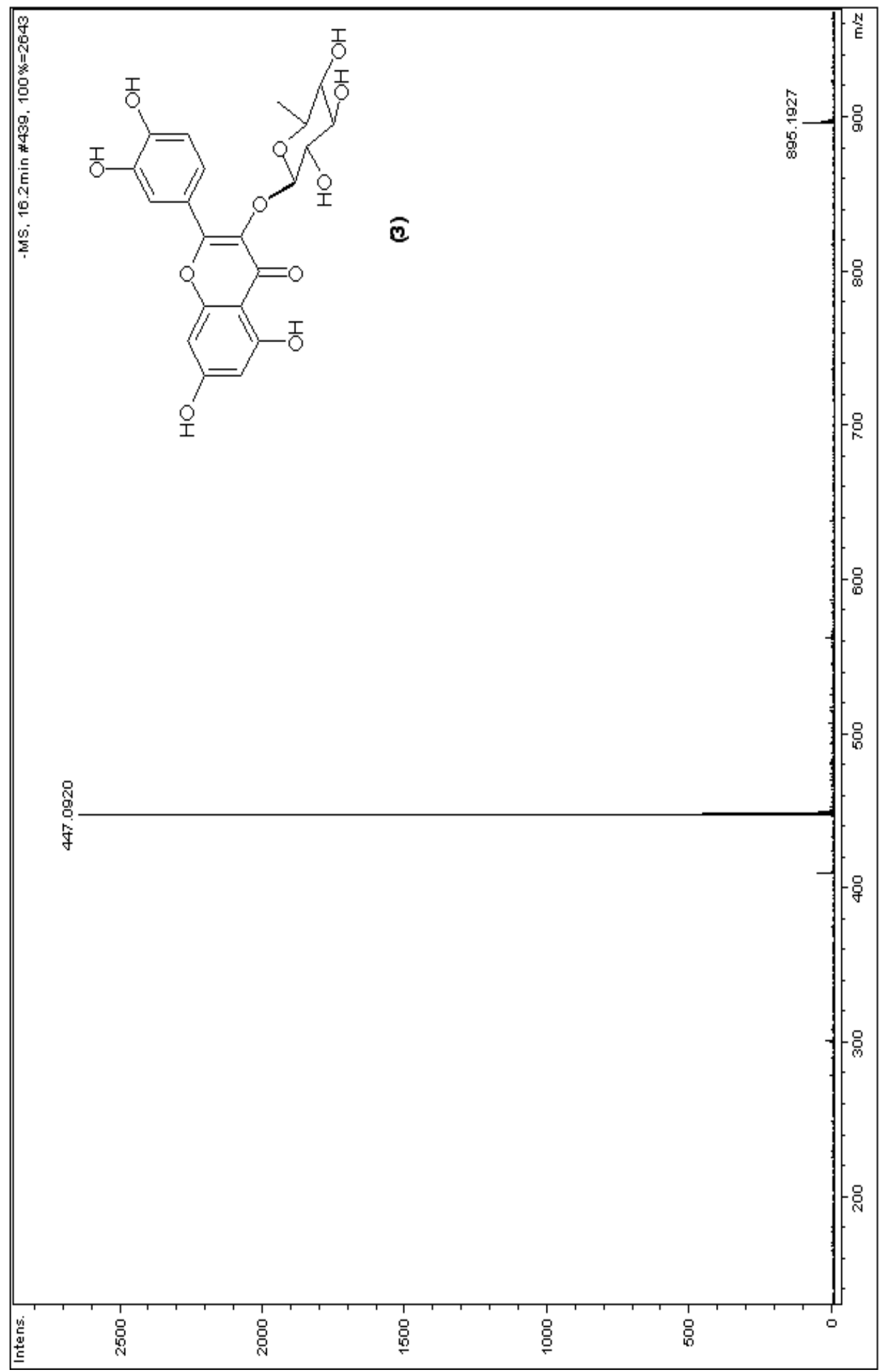


7.1.1.4 Espectro de EM-ESI do composto 4

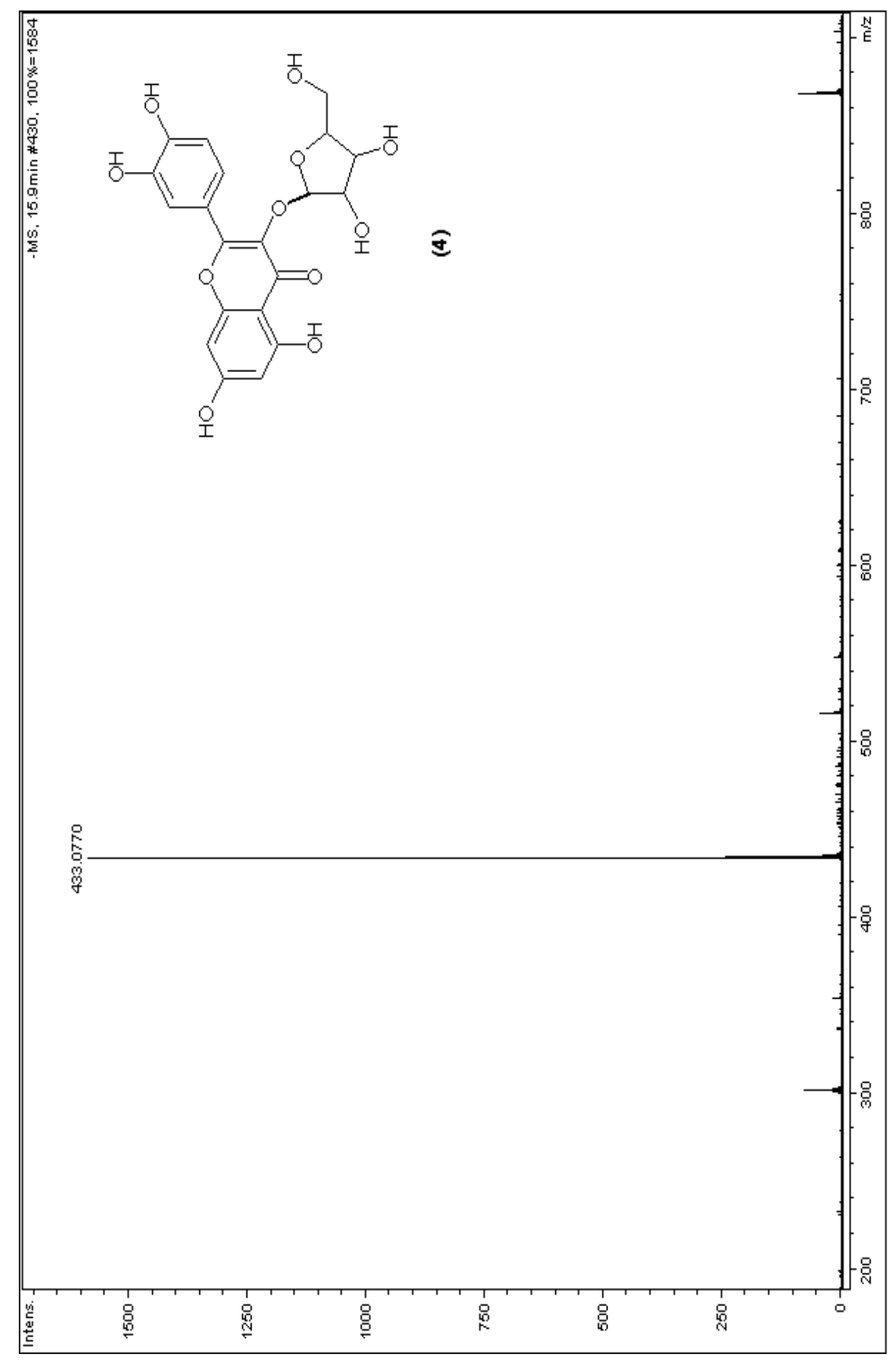




\subsubsection{Dados de UV:}

\subsubsection{Espectro de UV do composto 1}

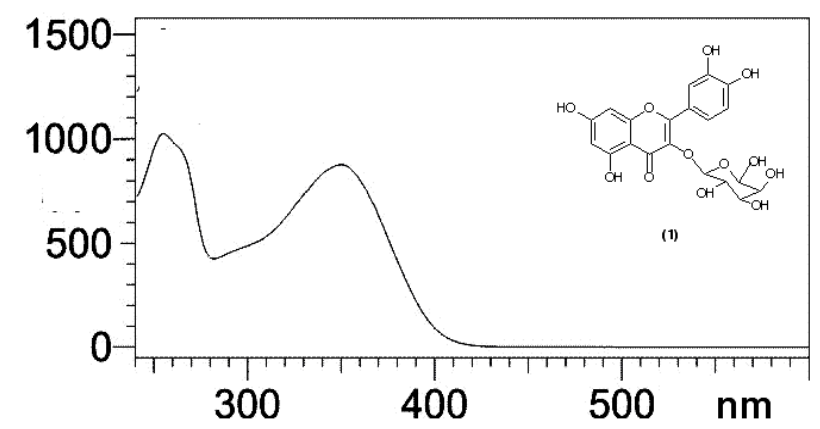

7.1.2.2 Espectro de UV do composto 2

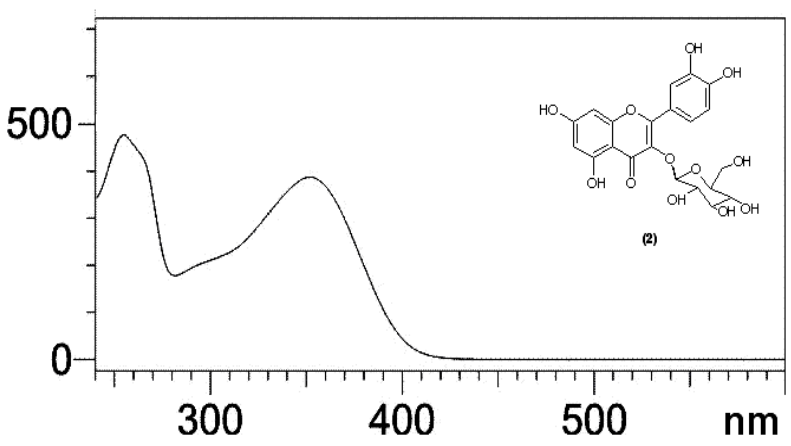

7.1.2.3 Espectro de UV do composto 3

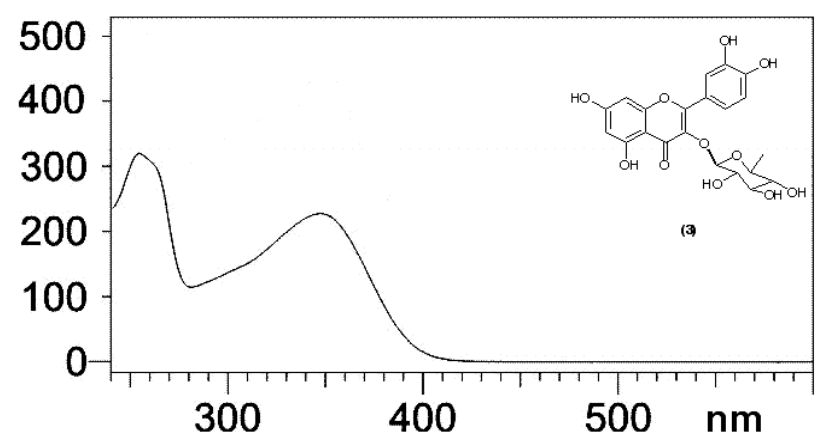

\subsubsection{Espectro de UV do composto 4}

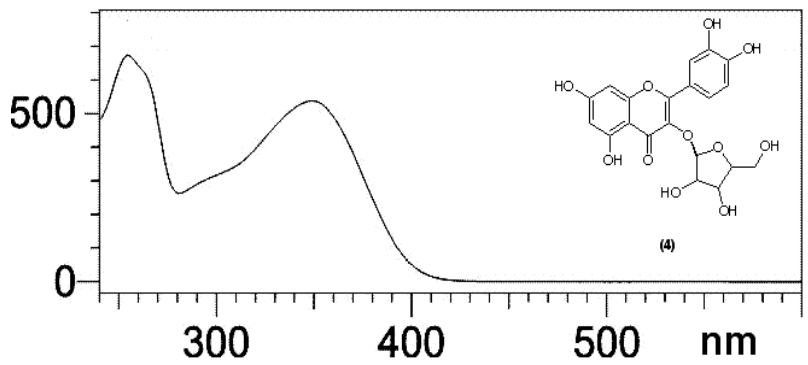




\subsubsection{Dados de RMN do composto 1:}

7.1.3.1 Espectro de RMN de ${ }^{1} \mathrm{H}(500 \mathrm{MHz})$ do composto 1 em DMSO-d . $^{.}$

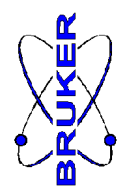

$900 \nabla^{\circ} \varepsilon$

$6 \mathrm{StS} \varepsilon$

$0 \varepsilon 99 \cdot$

$9979^{\circ} \varepsilon$

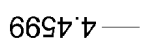

$8 \angle 988^{\circ}$

ट†EL' $\mathrm{S}$

टเ9\&'s

S9LE $\mathrm{S}$

$996+9$

$820+9$

67089

0टZ8.9

$2629^{\prime} L$

$9099^{\circ} L-$

$\angle L 99^{\circ} \angle$

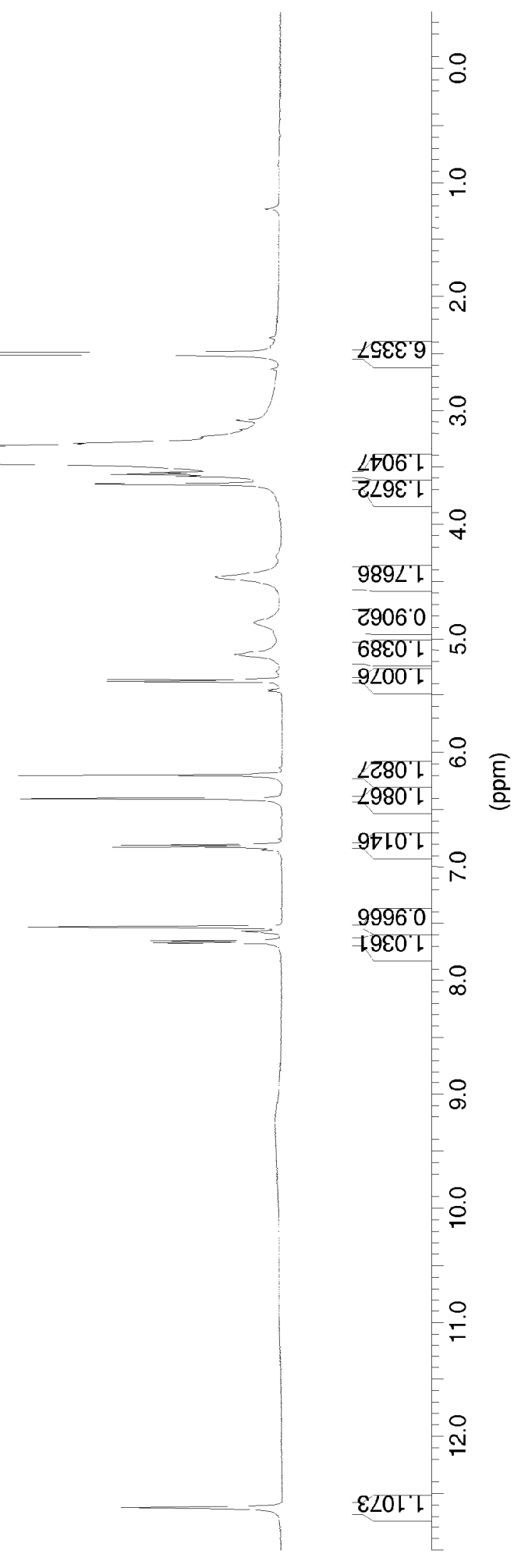

Estratégias de aumento de eficiência da análise de produtos naturais por $R M \mathcal{N}$ 


\subsubsection{Ampliações do Espectro de RMN de ${ }^{1} \mathrm{H}(500 \mathrm{MHz})$ do composto 1 em DMSO-d .}

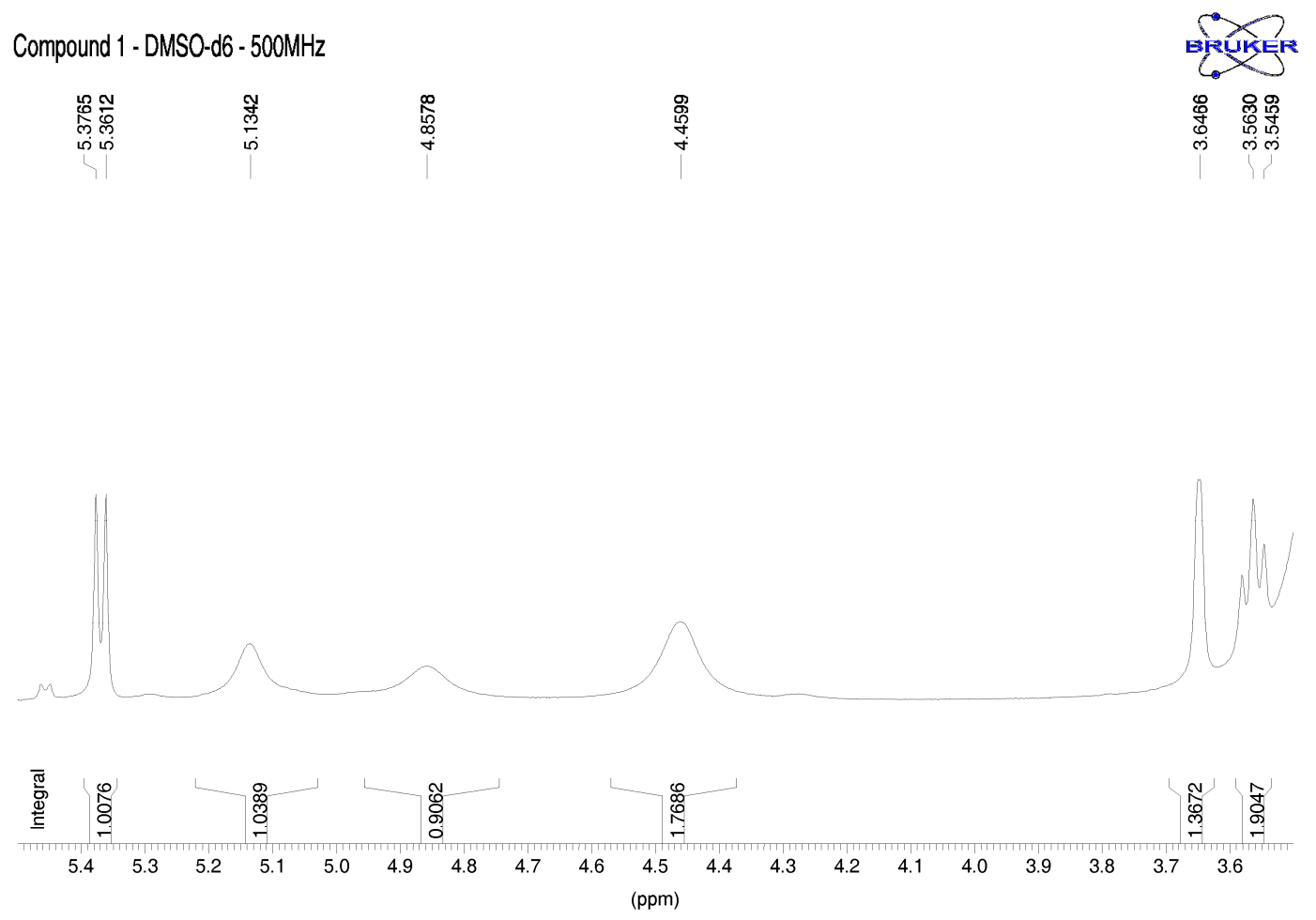

Compound 1 - DMSO-d6 - 500MHz

듕 त्ञ

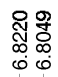

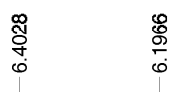

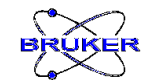
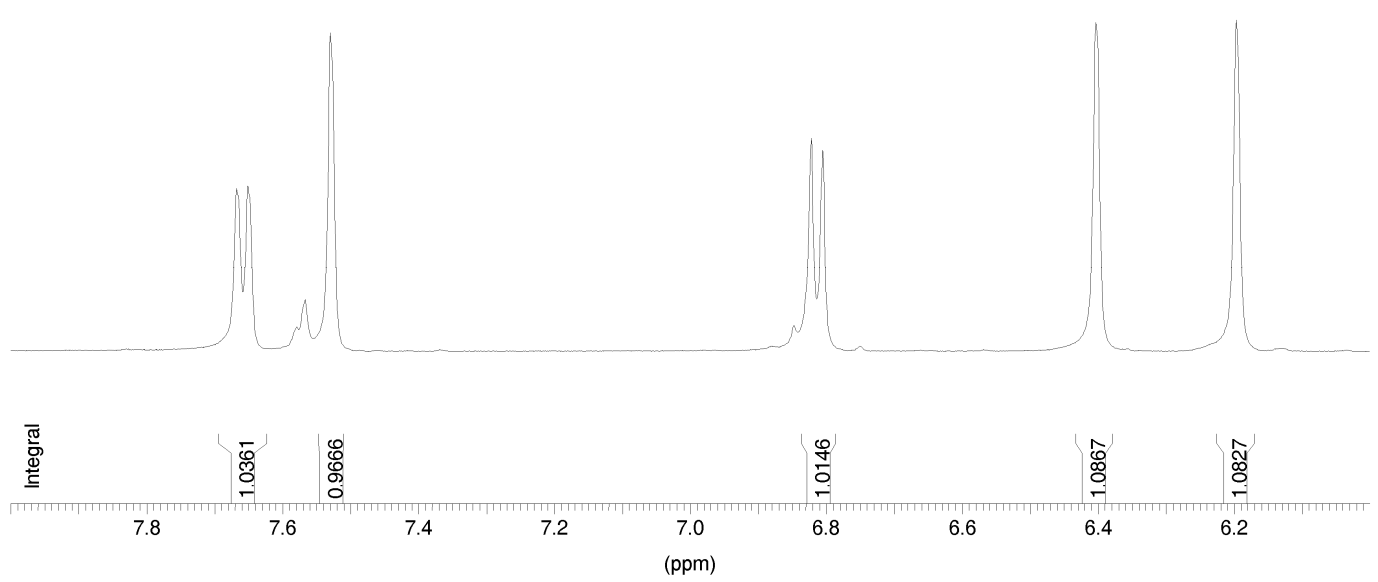
7.1.3.3 Ampliação do Espectro de $\mathrm{RMN}$ de ${ }^{1} \mathrm{H}(500 \mathrm{MHz})$ do composto 1 em DMSO-d .

Compound 1 - DMSO-d6 - 500MHz

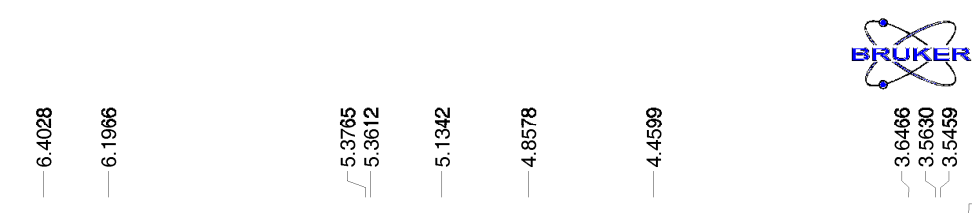

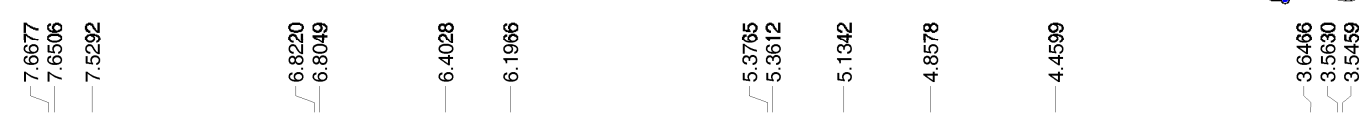
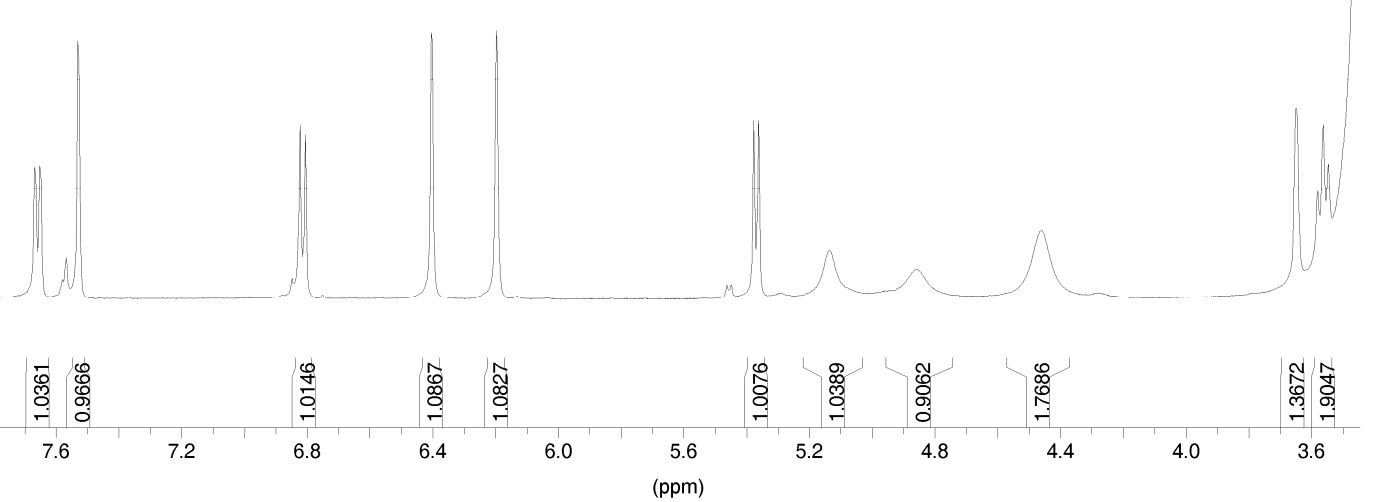
7.1.3.4 Espectro de RMN de $\left.{ }^{13} C_{\{}{ }^{1} \mathrm{H}\right\}(125 \mathrm{MHz})$ do composto 1 em DMSO-d .

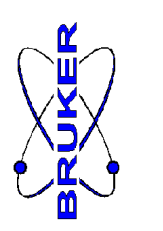

$2+9 \cdot 6 \varepsilon$

เ乙๕६' $6 \varepsilon$

$0009^{\circ} 6 \varepsilon$

$6 \angle 99^{\circ} 6 \varepsilon$

$89 \varepsilon 86 \varepsilon$

StEเ 09

งеะ6: $\angle 9$

$8 \angle E Z ' L$

$\varepsilon+L Z E L$

$8808^{\circ} \mathrm{S} L$

†०९9' $\varepsilon 6$

$\forall \angle L \angle 86$

$\checkmark 060^{\circ} \mathrm{ZO}$

ऽ066 $\mathrm{EOL}$

LL9Z'SH

เLOL.9L

こ6ZZ'เZ।-T

8L96. LIL -

8069 ๕๕เ

8LLLttD -

เELE $8+1$

SOLE 99 - -

SLEt 9S1

잉 $\quad$ ¿tSG $091-$

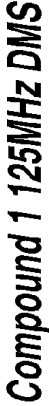

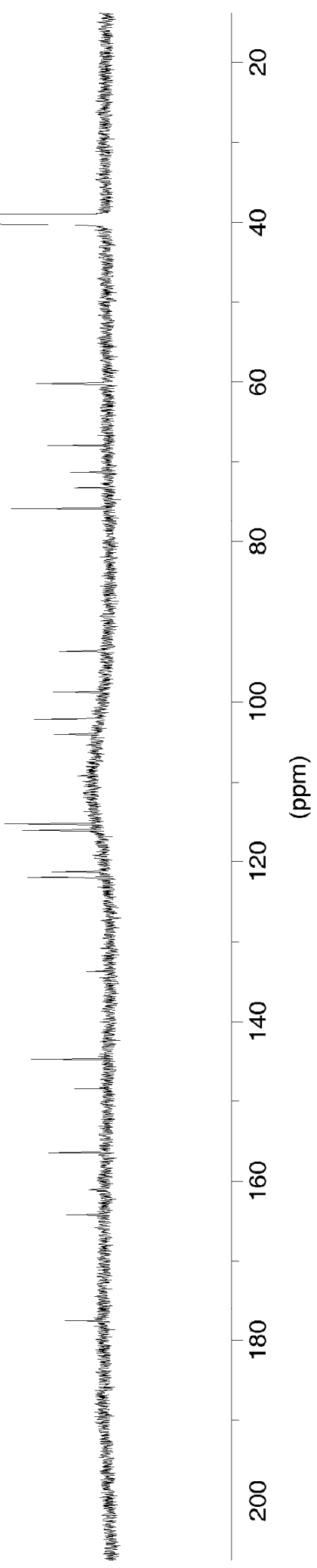


7.1.3.5 Espectro de RMN de ${ }^{13} \mathrm{C}\left(\mathrm{DEPT} 135^{\circ}\right.$, $\left.125 \mathrm{MHz}\right)$ do composto 1 em DMSO-d ${ }_{6}$.
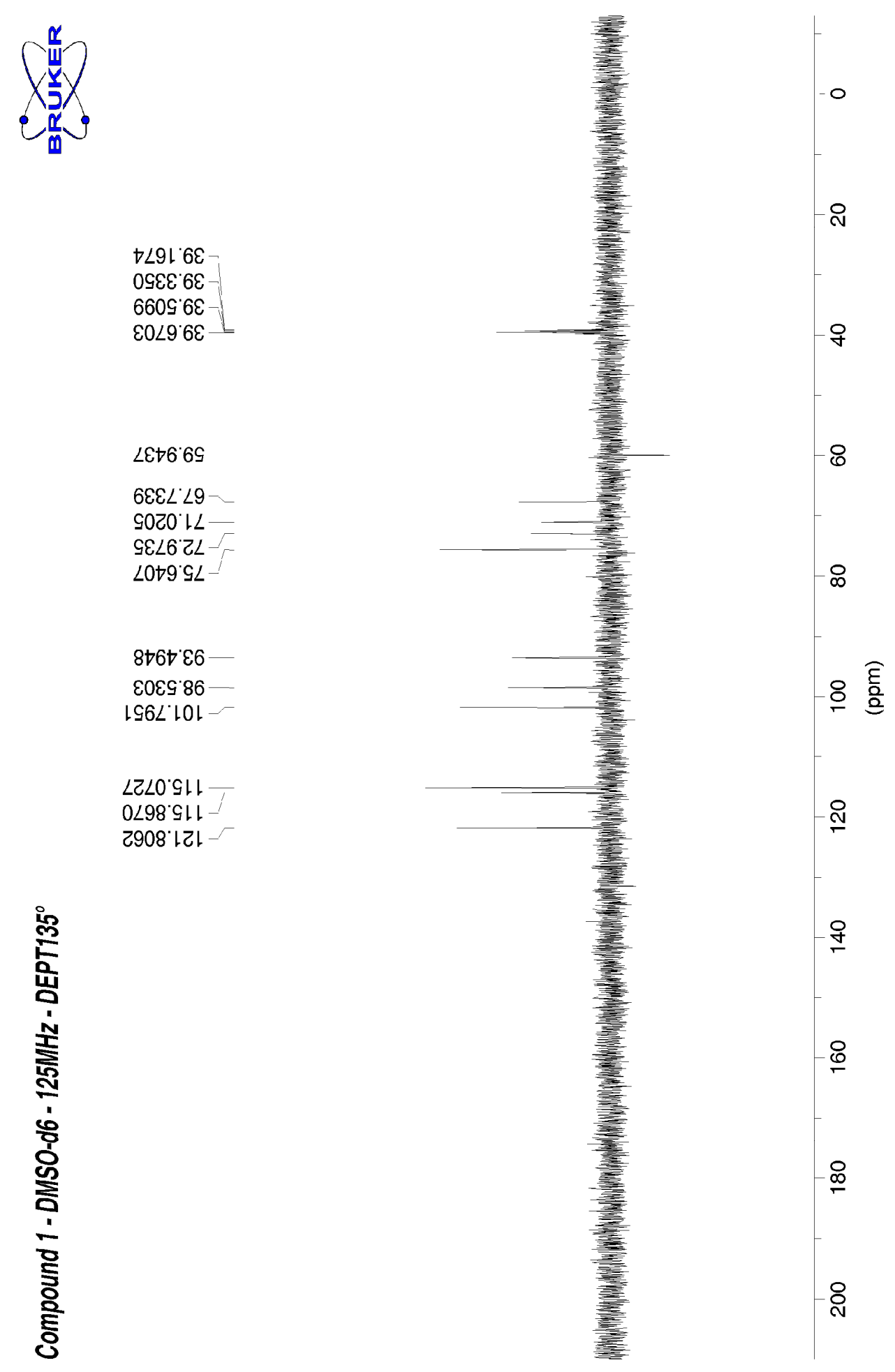
7.1.3.6 Mapa de contorno gerado a partir do experimento HMQC $\left({ }^{13} \mathrm{C}: 125\right.$ $\mathrm{MHz},{ }^{1} \mathrm{H}: 500 \mathrm{MHz}$ ) do composto $1 \mathrm{em} \mathrm{DMSO-d_{6 }}$

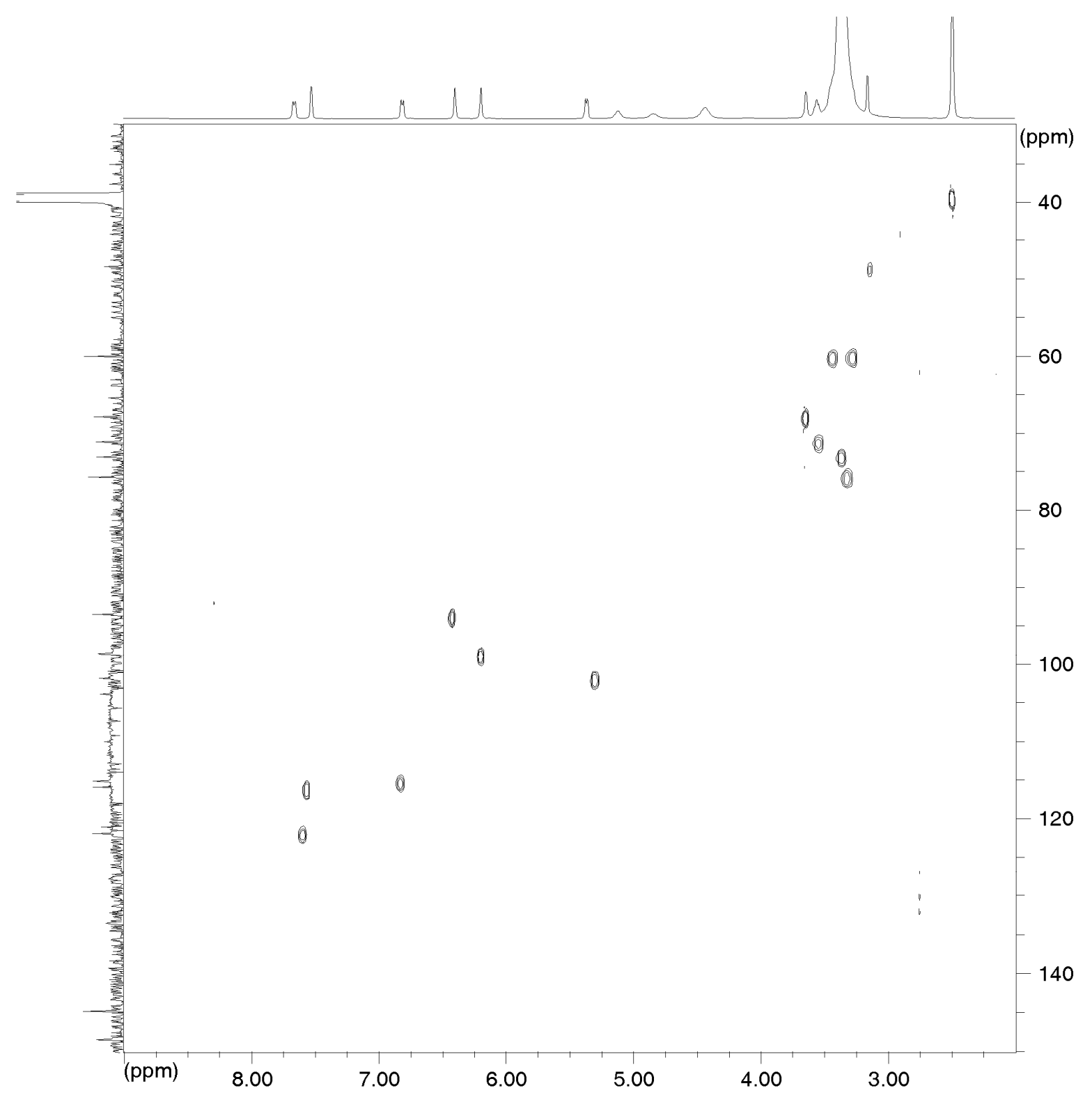


7.1.3.7 Mapa de contorno gerado a partir do experimento $\mathrm{COSY} 90^{\circ}\left({ }^{1} \mathrm{H},{ }^{1} \mathrm{H}: 500\right.$ $\mathrm{MHz}$ ) do composto $1 \mathrm{em}$ DMSO-d . $_{\text {. }}$

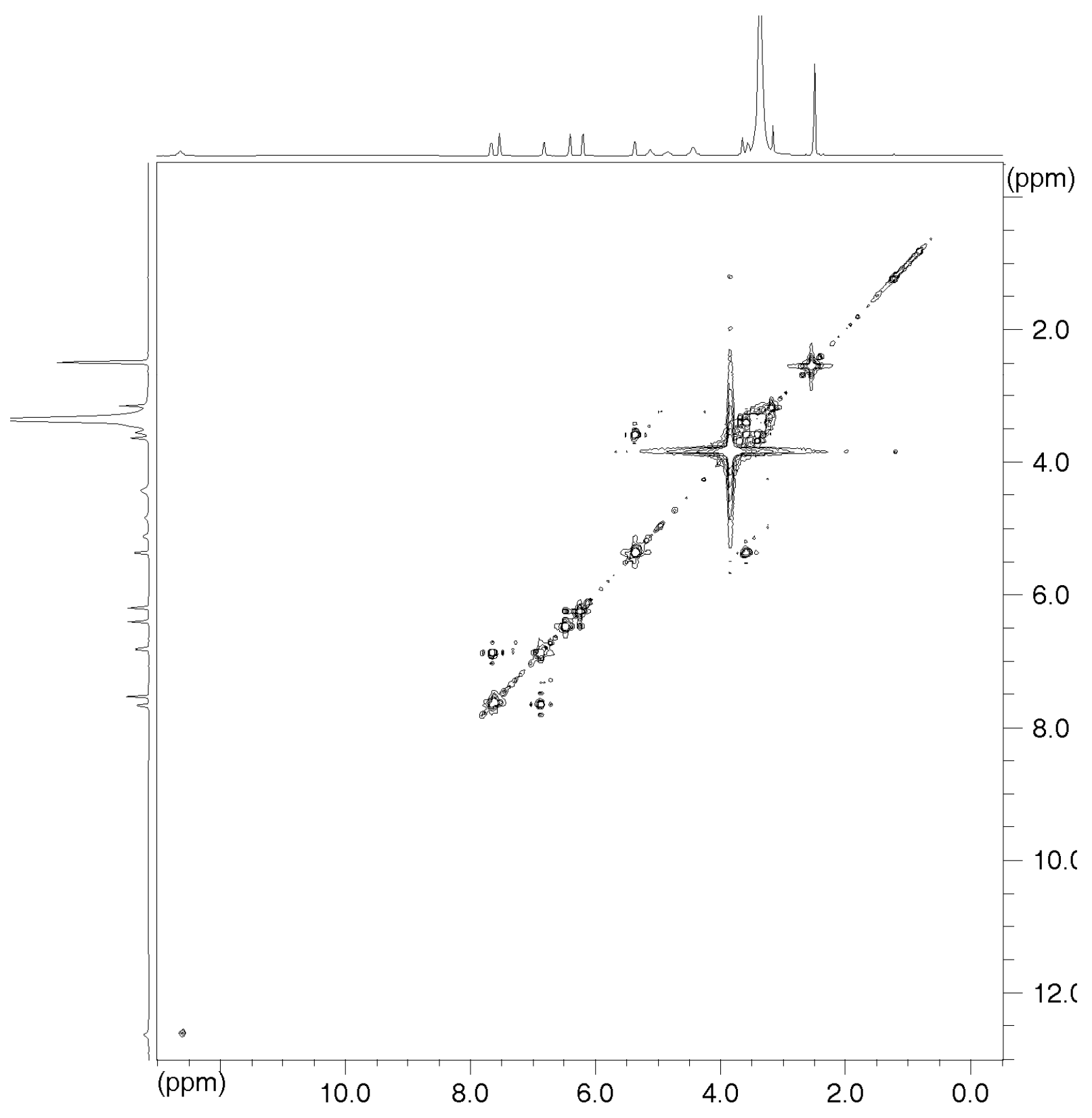


7.1.3.8 Mapa de contorno gerado a partir do experimento HMBC $\left({ }^{13} \mathrm{C}: 125\right.$ $\mathrm{MHz},{ }^{1} \mathrm{H}: 500 \mathrm{MHz}$ ), modulado para ${ }^{2} \mathrm{~J}_{\mathrm{CH}}=8 \mathrm{~Hz}$, do composto 1 em DMSO-d .

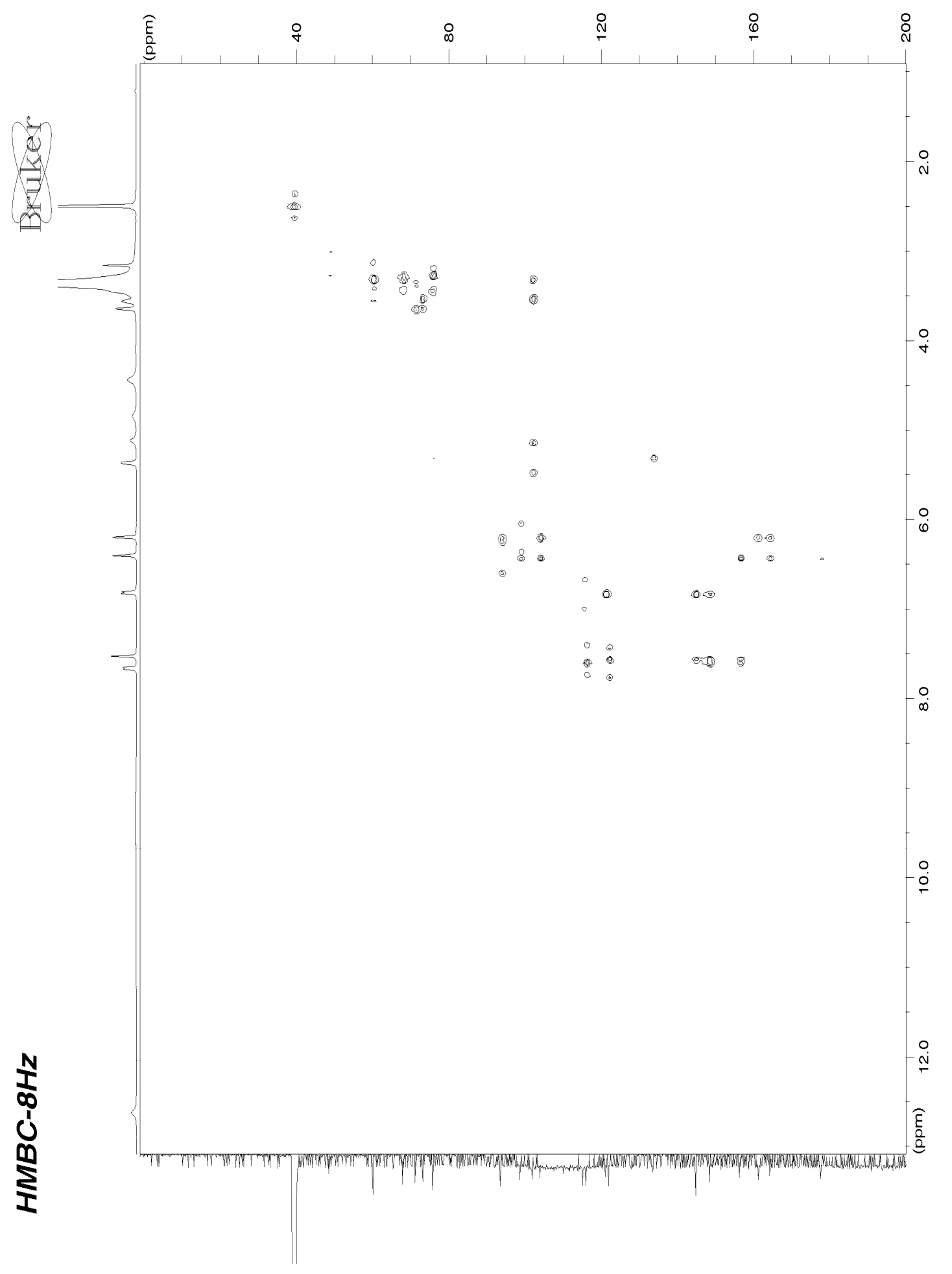


7.1.3.9 Mapa de contorno gerado a partir do experimento HMBC $\left({ }^{13} \mathrm{C}: 125\right.$ $\mathrm{MHz},{ }^{1} \mathrm{H}: 500 \mathrm{MHz}$ ), modulado para ${ }^{2} \mathrm{~J}_{\mathrm{CH}}=4 \mathrm{~Hz}$, do composto 1 em DMSO-d .

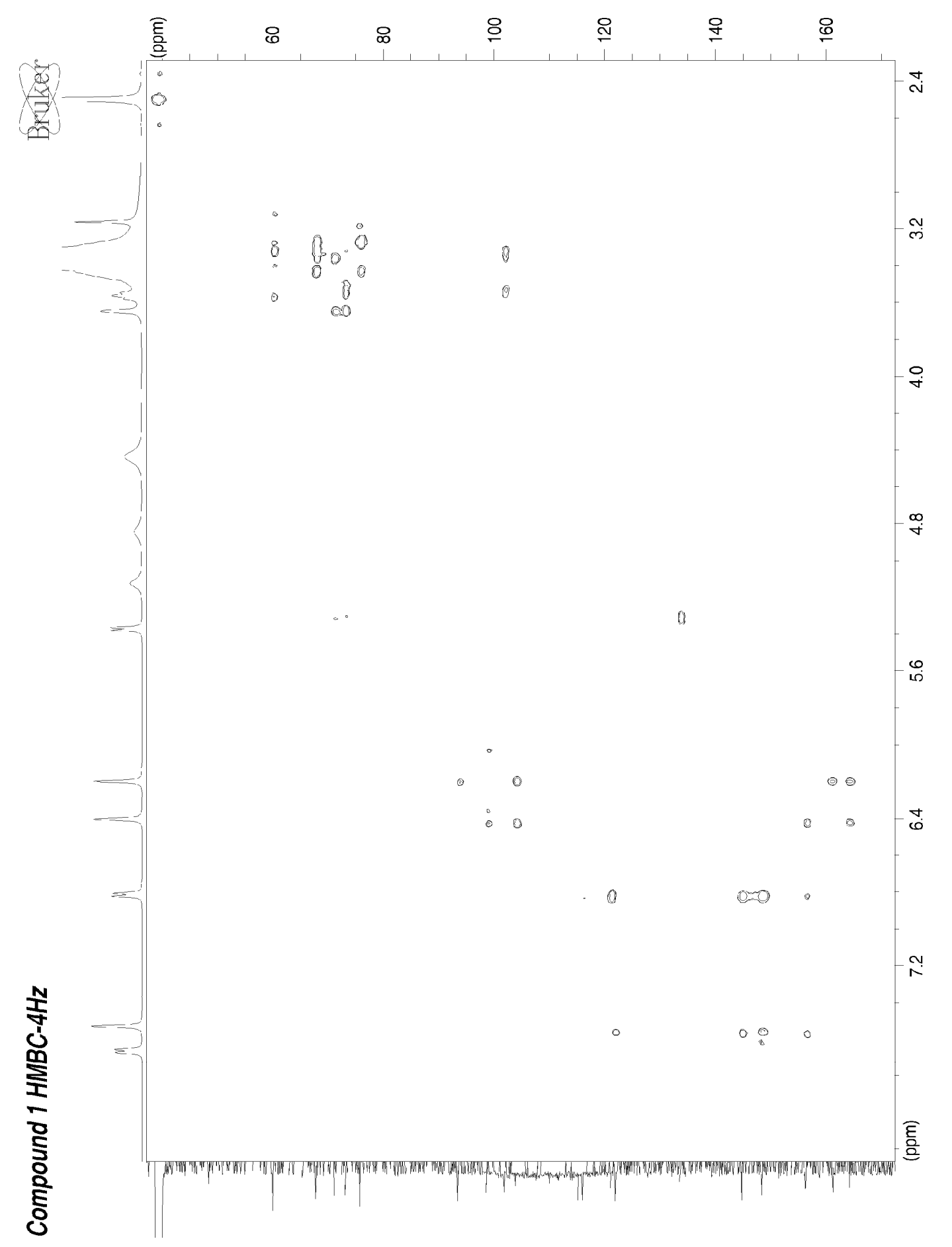




\subsubsection{Dados de RMN do composto 2}

\subsubsection{Espectro de RMN de ${ }^{1} \mathrm{H}(500 \mathrm{MHz})$ do composto 2 em DMSO-d . $^{\circ}$}

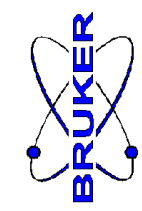

$000 \mathcal{S}^{\prime} \mathrm{C}$

$\varsigma 980^{\circ} \varepsilon$

S†9म' $\varepsilon$

乙LZZ $\varepsilon$

ISIE' $\varepsilon$

$89 \varepsilon \varepsilon^{\prime} \varepsilon$

$69 t \nabla \cdot \varepsilon$

$\downarrow \varepsilon 99^{\prime} \varepsilon$

$1989^{\circ} \varepsilon$

$\angle 6 \angle Z^{\prime} \triangleright$

$7896 \circ$

IZLO'G

$\varepsilon L 6 Z$ '

$\varepsilon S t$ G

969t'

ट००ट'9

$080 t^{\circ} 9$

เE\&8: 9

$8098 \cdot 9$

9899' $L$

LZLG' $L$

$S L L S^{\circ} L$

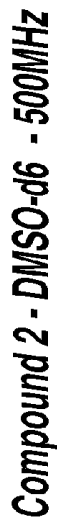

เงว9こレ

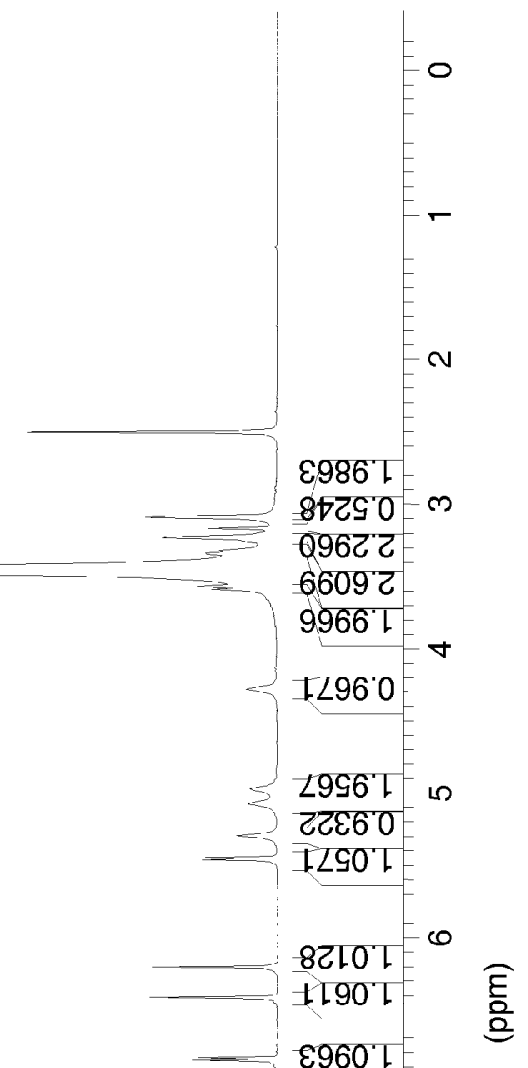


7.1.4.2 Ampliações do Espectro de RMN de ${ }^{1} \mathrm{H}(500 \mathrm{MHz})$ do composto 2 em DMSO-d .

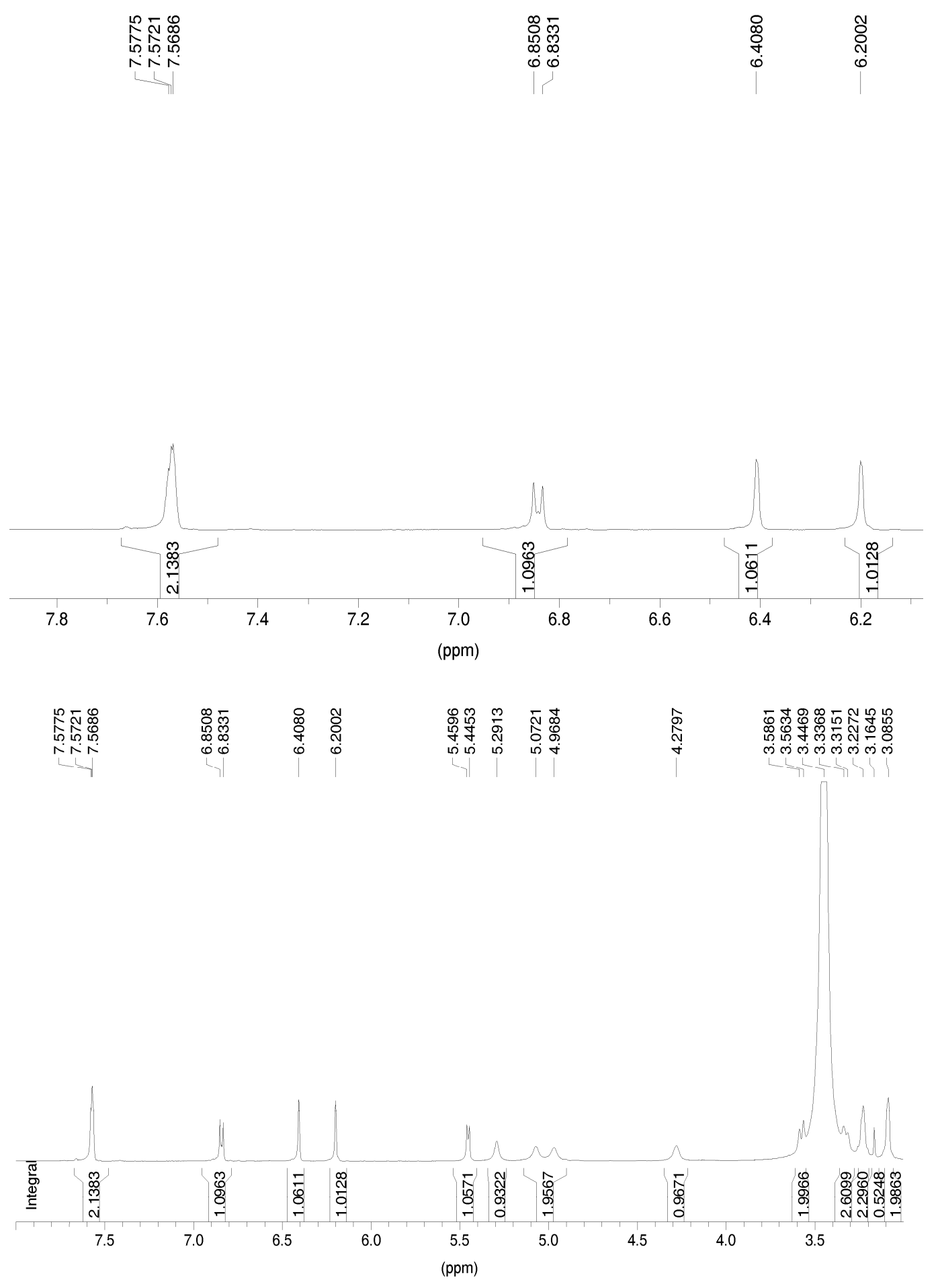


7.1.4.3 Espectro de RMN de $\left.{ }^{13} C_{\{}{ }^{1} \mathrm{H}\right\}(125 \mathrm{MHz})$ do composto 2 em DMSO-d ${ }^{\text {. }}$

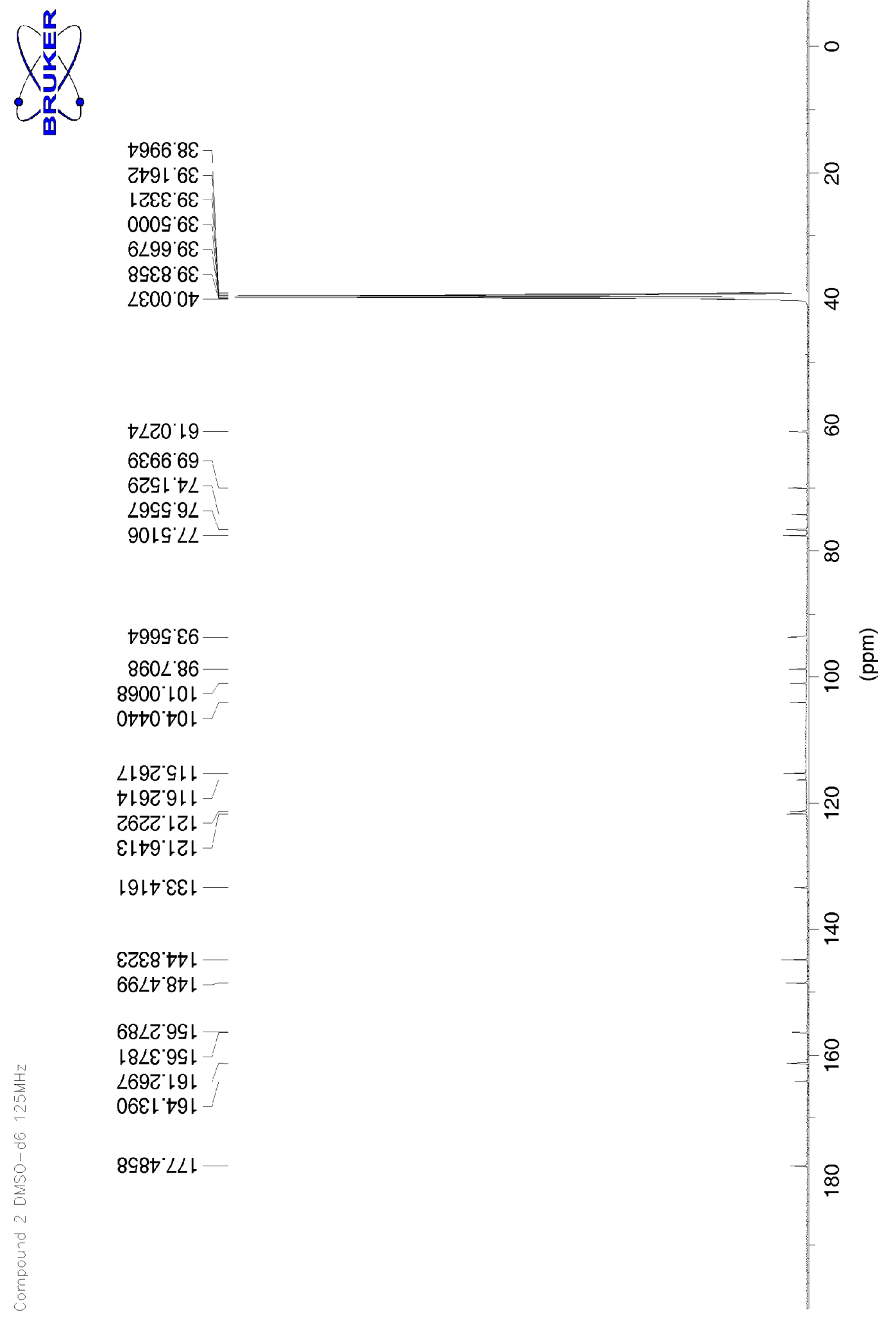


7.1.4.4 Espectro de RMN de ${ }^{13} \mathrm{C}\left(\mathrm{DEPT} 135^{\circ}\right.$, $\left.125 \mathrm{MHz}\right)$ do composto 2 em DMSO-d ${ }_{6}$.
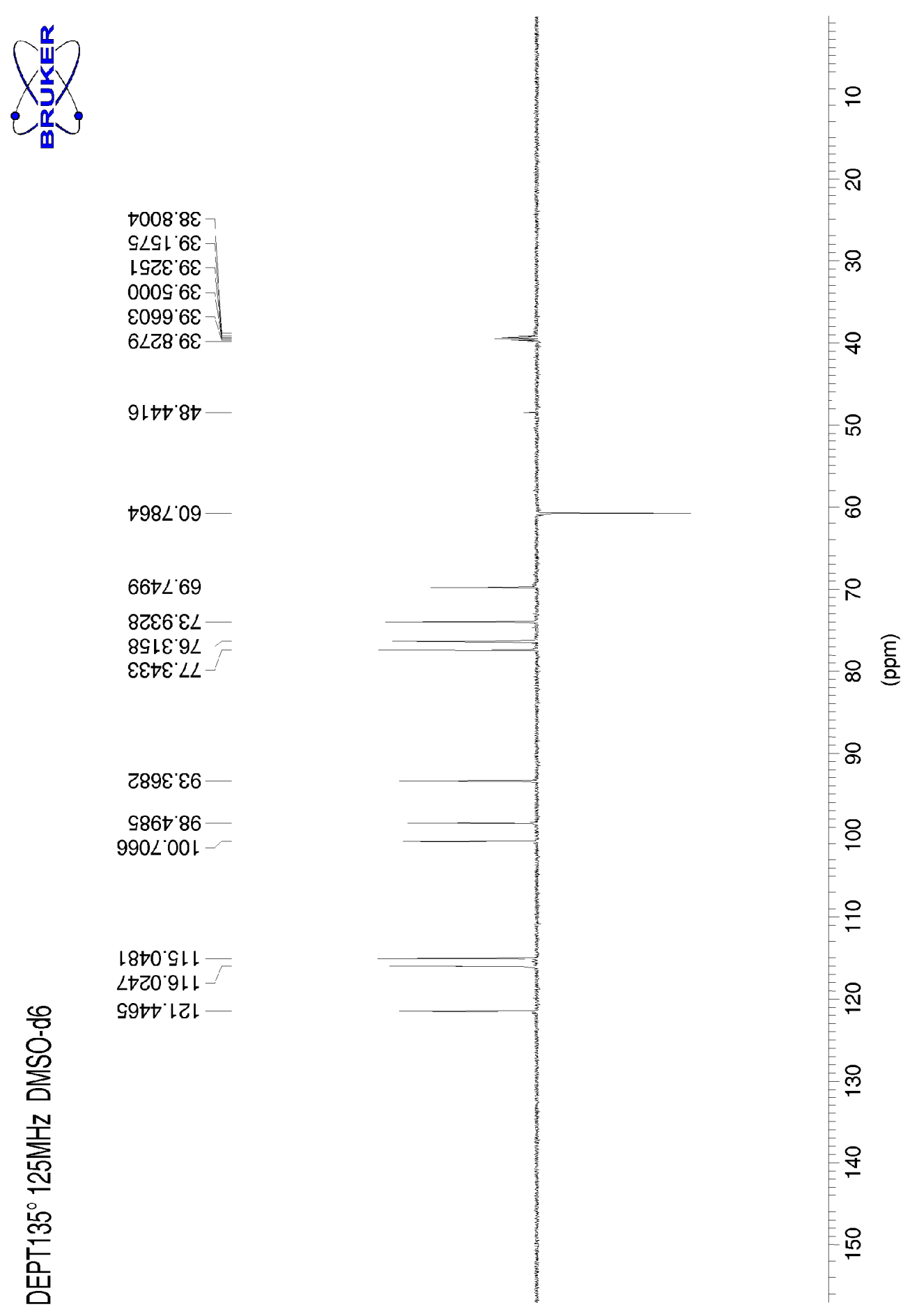
7.1.4.5 Mapa de contorno gerado a partir do experimento HMQC $\left({ }^{13} \mathrm{C}: 125\right.$ $\mathrm{MHz},{ }^{1} \mathrm{H}: 500 \mathrm{MHz}$ ) do composto 2 em DMSO-d ${ }_{6}$.

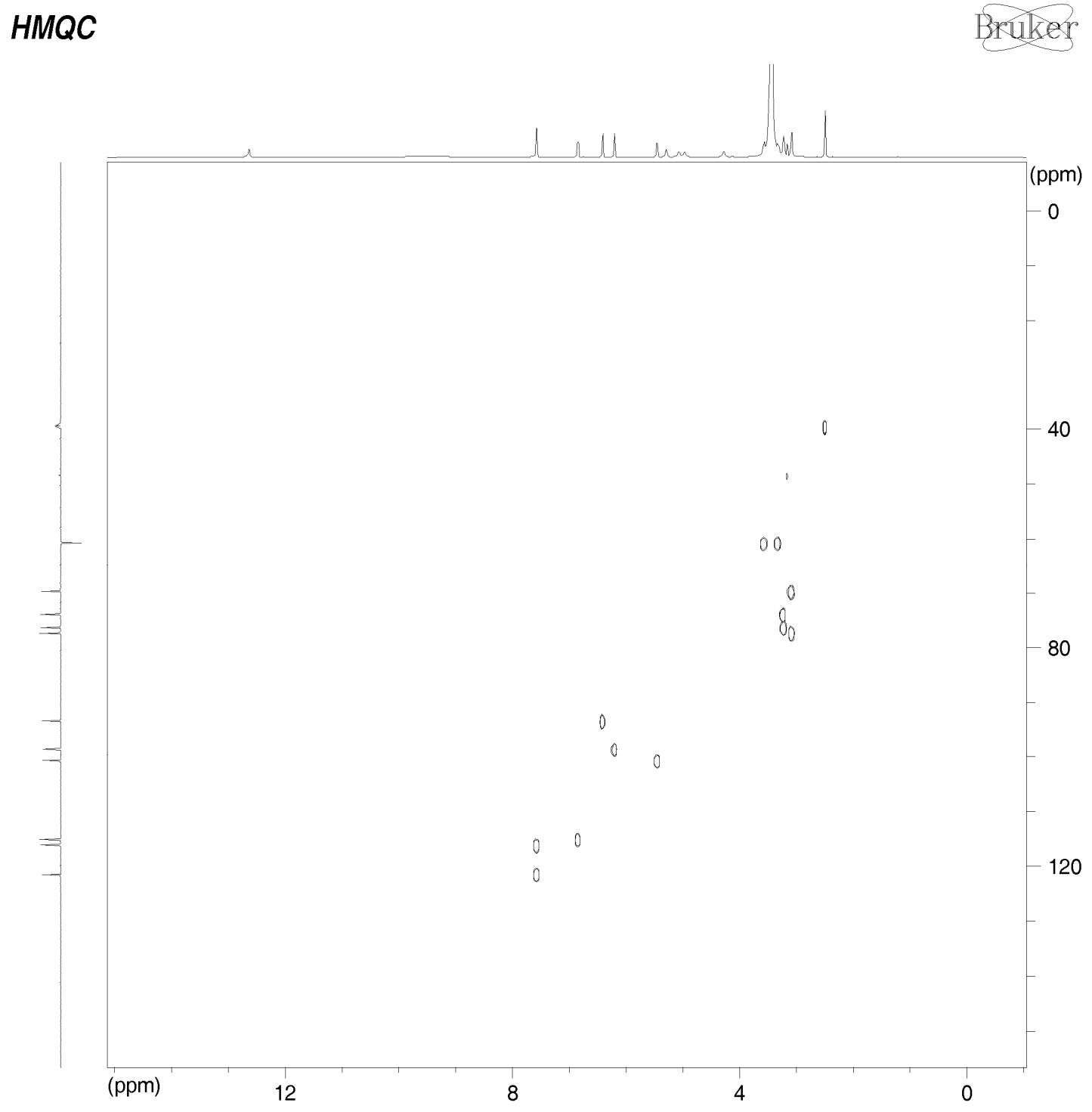


Espectros selecionados

119

7.1.4.6 Mapa de contorno gerado a partir do experimento $\operatorname{COSY} 90^{\circ}\left[{ }^{1} \mathrm{H},{ }^{1} \mathrm{H}: 500\right.$ $\mathrm{MHz}]$ do composto $2 \mathrm{em} \mathrm{DMSO}-\mathrm{d}_{6}$.

COSY 90 DMSO-d6 500MHz

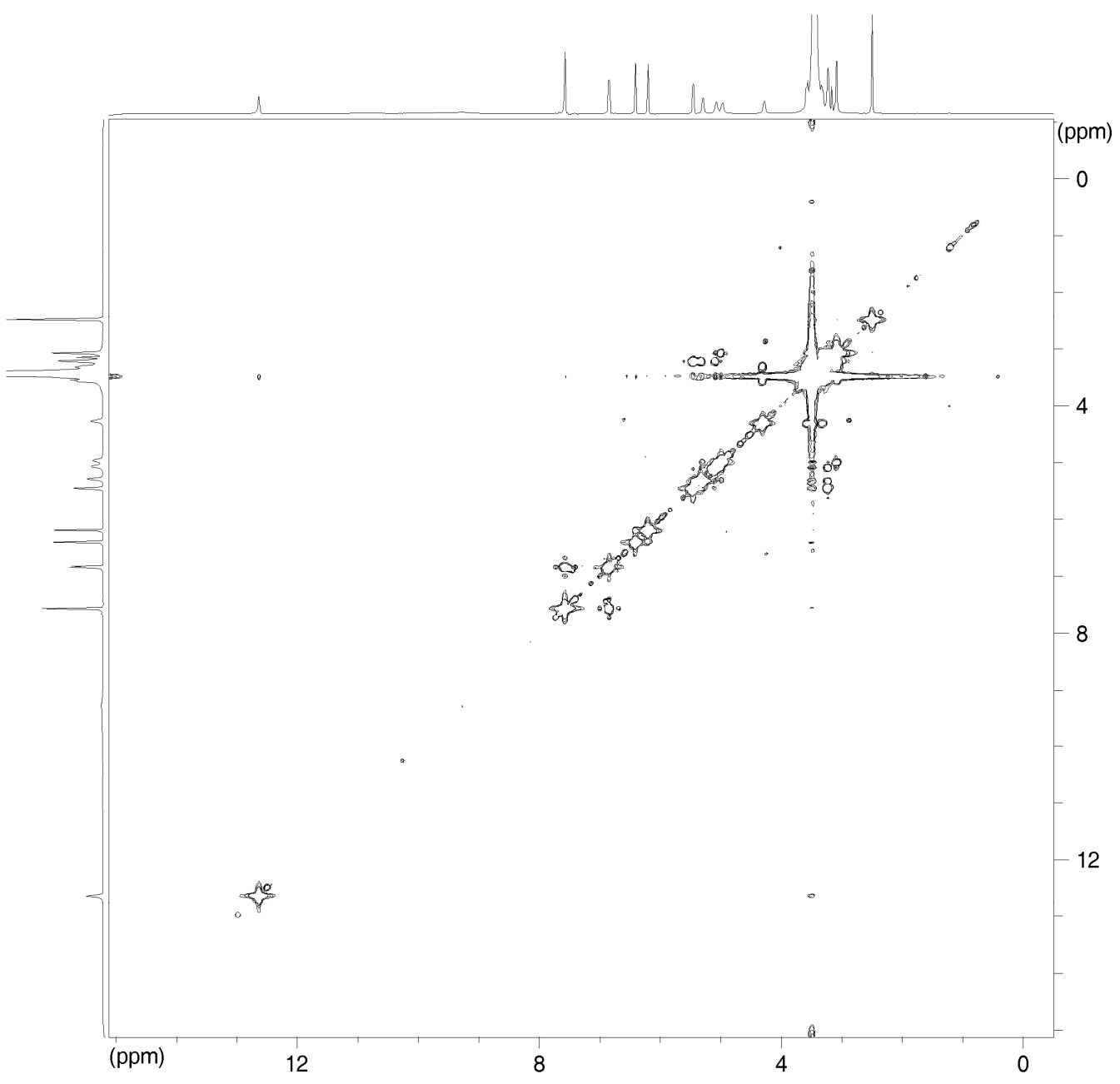

Estratégias de aumento de eficiência da análise de produtos naturais por $\mathbb{R M N}$ 
7.1.4.7 Mapa de contorno gerado a partir do experimento HMBC $\left({ }^{13} \mathrm{C}: 125\right.$ $\mathrm{MHz},{ }^{1} \mathrm{H}: 500 \mathrm{MHz}$ ), modulado para ${ }^{2} \mathrm{~J}_{\mathrm{CH}}=8 \mathrm{~Hz}$, do composto 2 em DMSO-d .

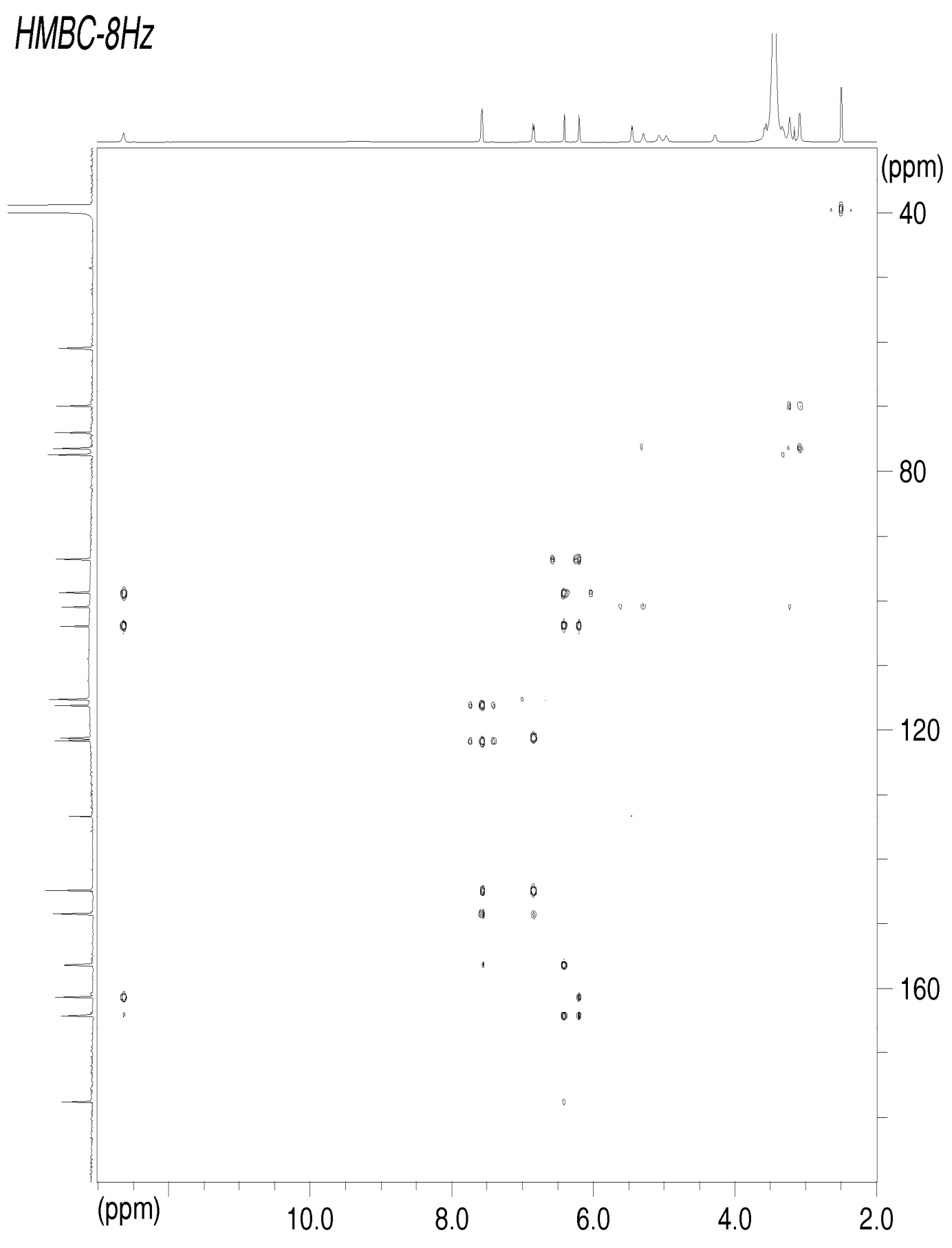


7.1.4.8 Mapa de contorno gerado a partir do experimento HMBC $\left({ }^{13} \mathrm{C}: 125\right.$ $\left.\mathrm{MHz},{ }^{1} \mathrm{H}: 500 \mathrm{MHz}\right)$, modulado para ${ }^{2} \mathrm{~J}_{\mathrm{CH}}=4 \mathrm{~Hz}$, do composto 2 em DMSO-d

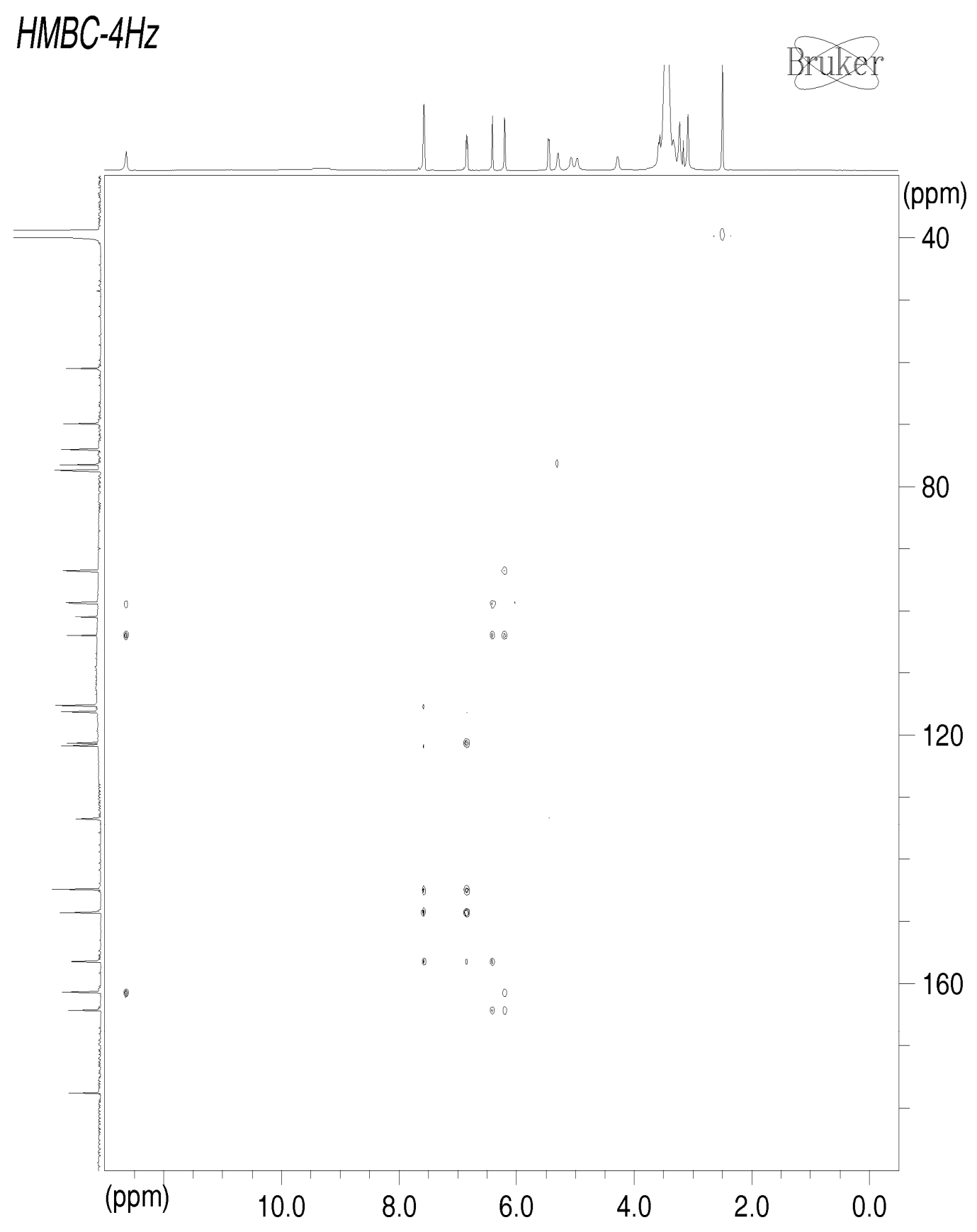




\subsubsection{Dados de RMN do composto 3:}

7.1.5.1 Espectro de RMN de ${ }^{1} \mathrm{H}(500 \mathrm{MHz})$ do composto 3 em DMSO-d.

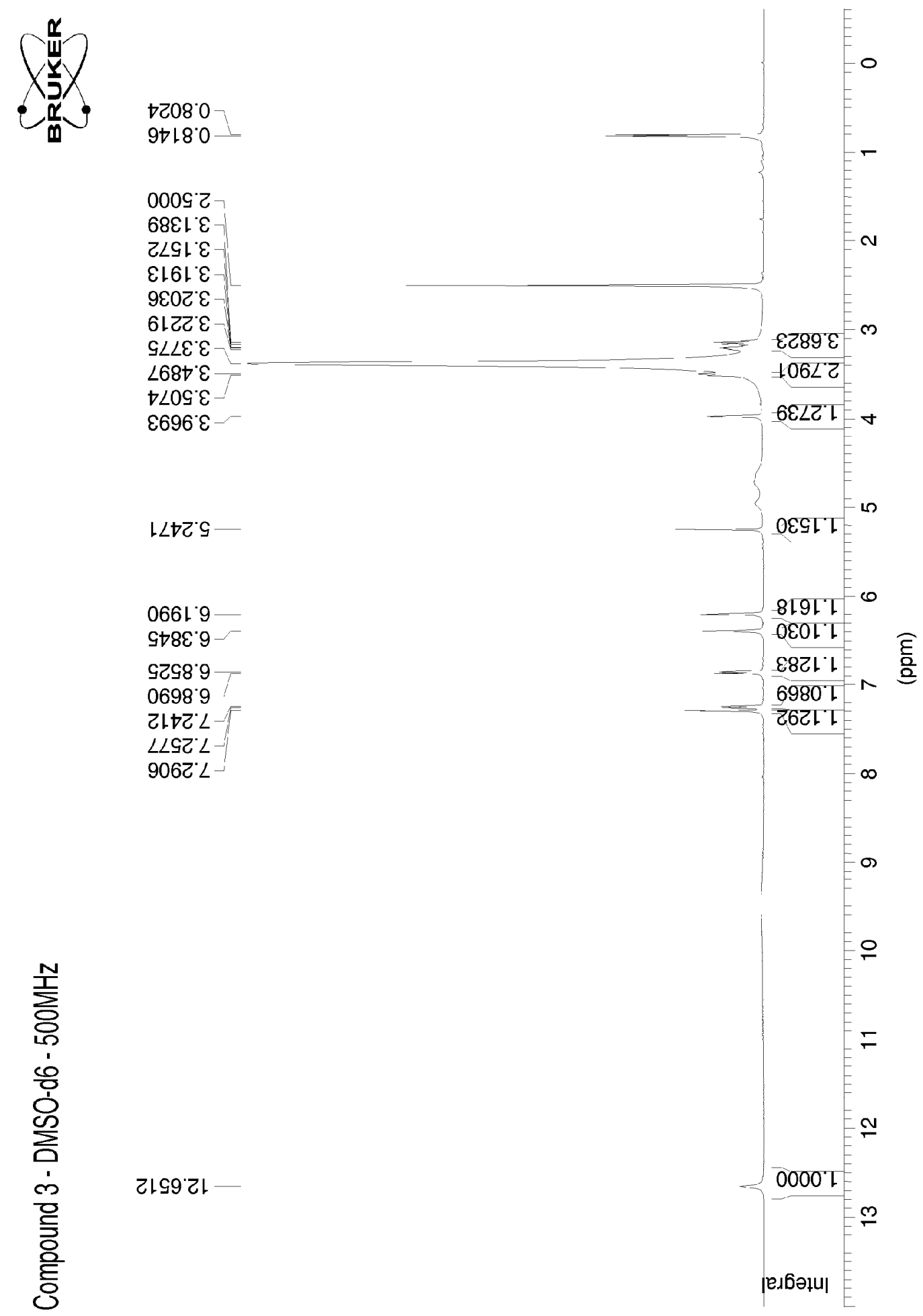




\subsubsection{Ampliações do Espectro de RMN de ${ }^{1} \mathrm{H}(500 \mathrm{MHz})$ do composto 3 em DMSO-d .}

Compound 3 DMSO-d6 500MHz
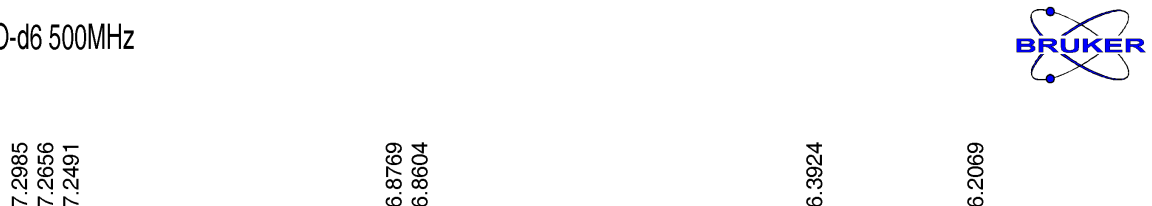

$\begin{array}{ll}0 & 0 \\ 0 & 0 \\ 00 \\ 00 \\ 00\end{array}$

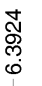

\&్లి

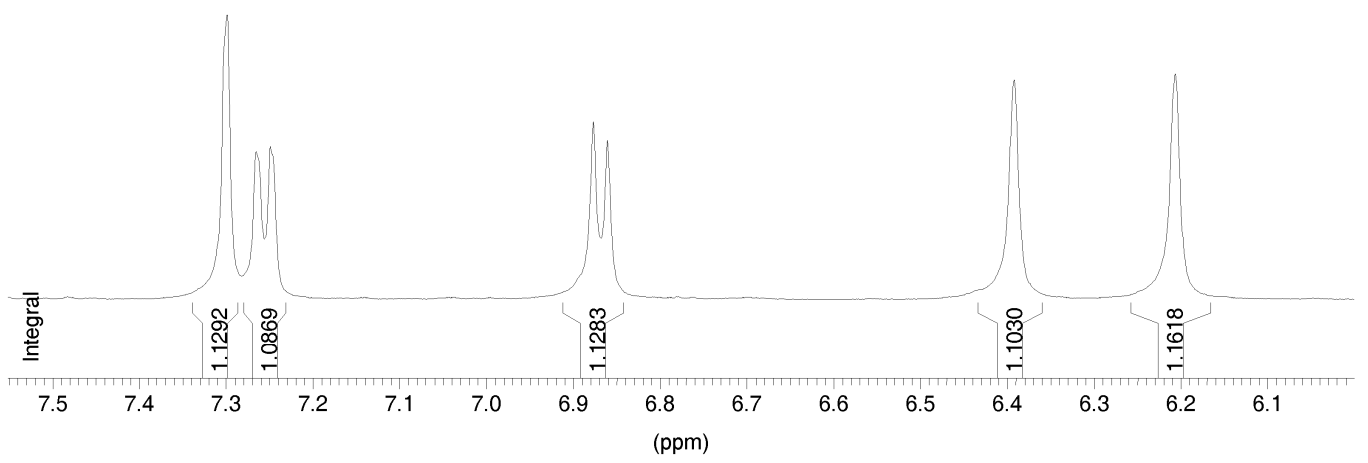

Compound 3 DMSO-d6 500MHz
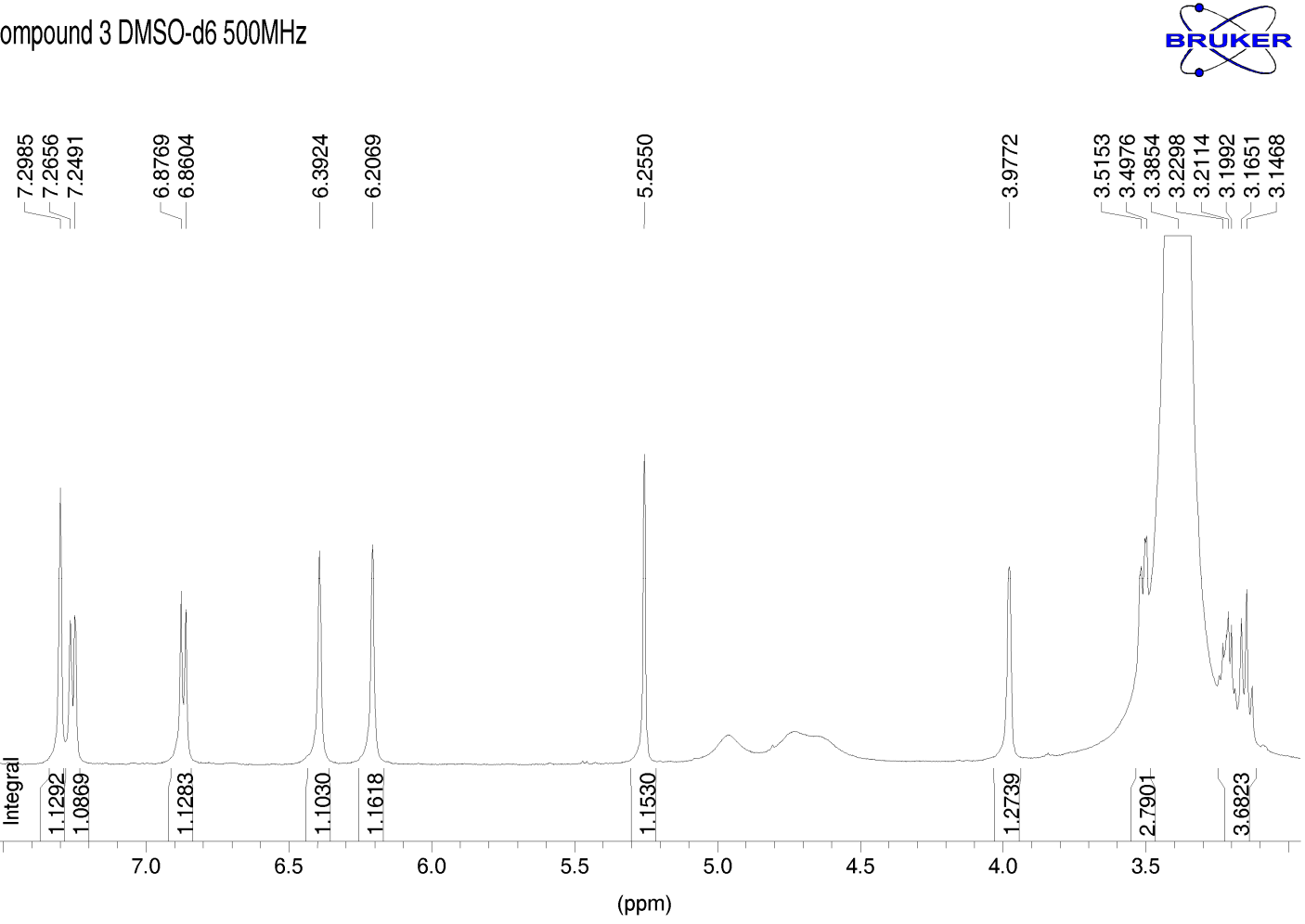
7.1.5.3 Ampliação do Espectro de $\mathrm{RMN}$ de ${ }^{1} \mathrm{H}(500 \mathrm{MHz})$ do composto 3 em DMSO-d .

Compound 3 - DMSO-d6 - 500MHz
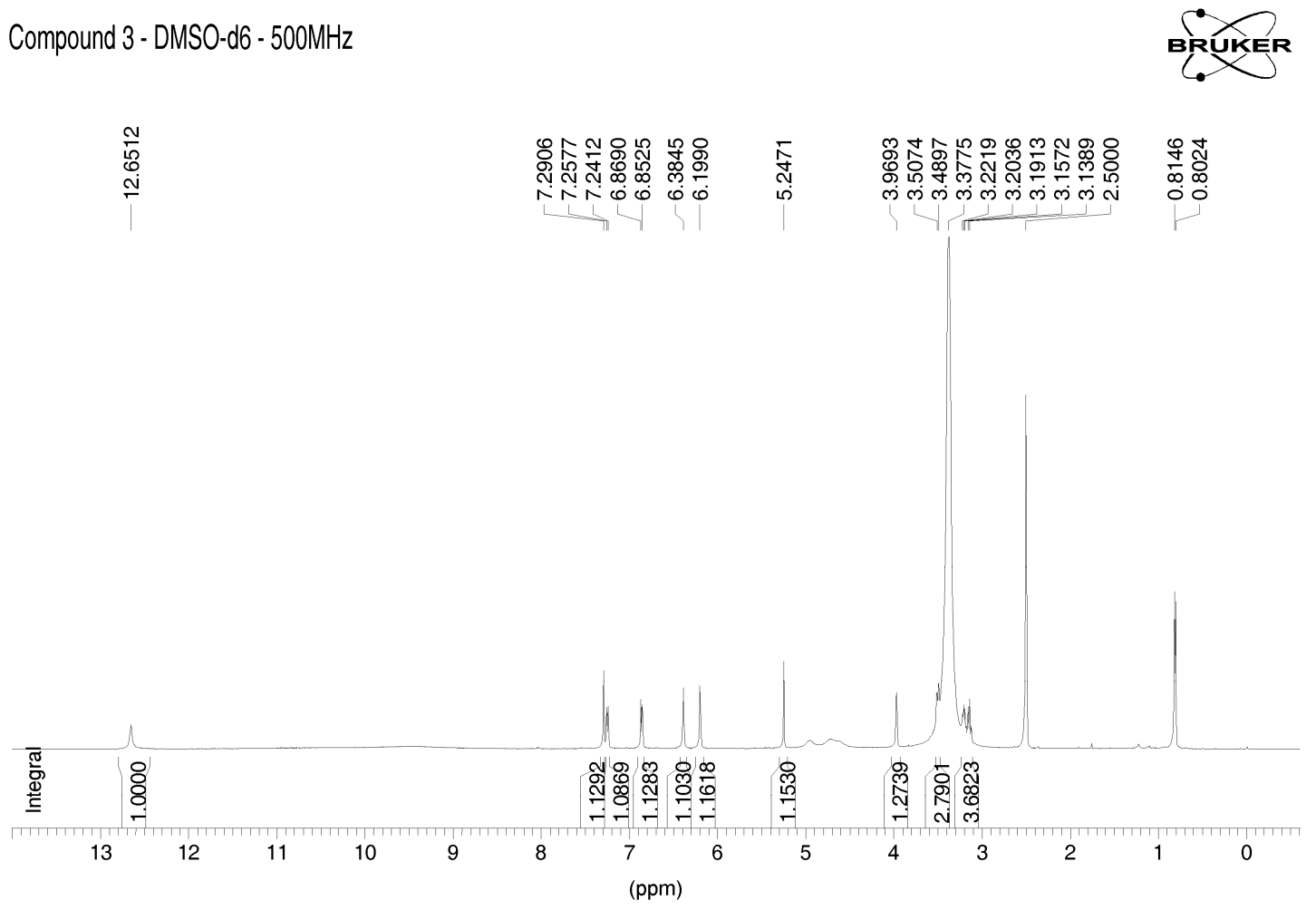
7.1.5.4 Espectro de RMN de $\left.{ }^{13} C_{\{}{ }^{1} H\right\}(125 \mathrm{MHz})$ do composto 3 em DMSO-d .

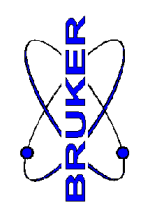

乙† $\angle L \angle L$

$\varepsilon 966$ ' $8 \varepsilon$

टt9L $6 \varepsilon$

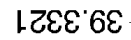

O009 $6 \varepsilon$

$6 \angle 99^{\circ} 6 \varepsilon$

$89 \varepsilon 86 \varepsilon$

$\angle 800^{\circ} 0 \mathrm{~T}$

$890 \varepsilon^{\circ} 0 L$

$\triangle 709^{\circ} 0 \angle$

$\angle 0 \angle 6^{\circ} O \angle$

ट9Et'L

$\varepsilon 69$ ` $^{\circ} 6$

$8880^{\circ} 66$

8Etเ'ZOL

$\varepsilon L \angle t ヤ O L-$

ย6ฤ8・งเ -

6เ00'9L L

†90Z เ乙L

Z†99.เฉ

$0099^{\circ} \nabla \varepsilon L$

乙LSE'St -

$\varepsilon \angle 19{ }^{\circ} 8 t$

๕己เ6.9Sเ

$\nabla 6 \mathrm{~S} L \angle \mathrm{Sl}$

$09 t \varepsilon \cdot 191$

G6St๋

$8990^{\circ} 8 \angle L$

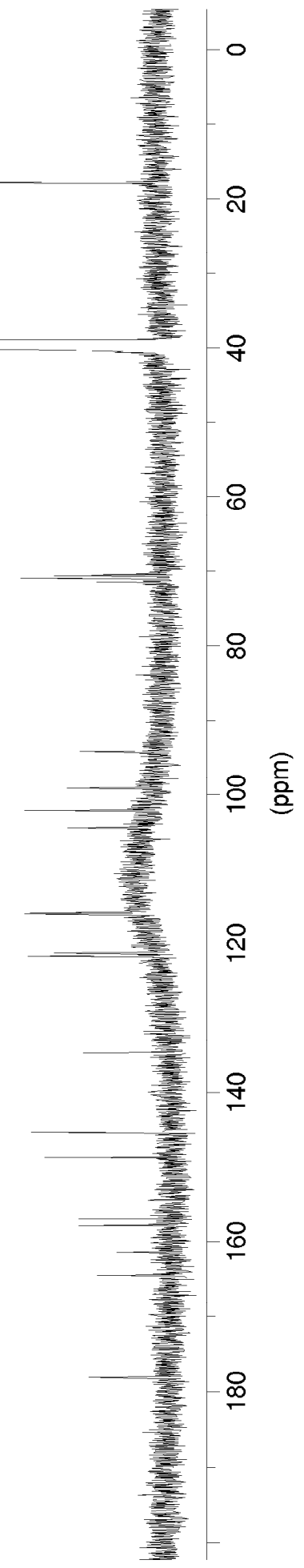


7.1.5.5 Espectro de RMN de ${ }^{13} \mathrm{C}\left(\mathrm{DEPT} 135^{\circ}\right.$, $\left.125 \mathrm{MHz}\right)$ do composto 3 em DMSO-d .
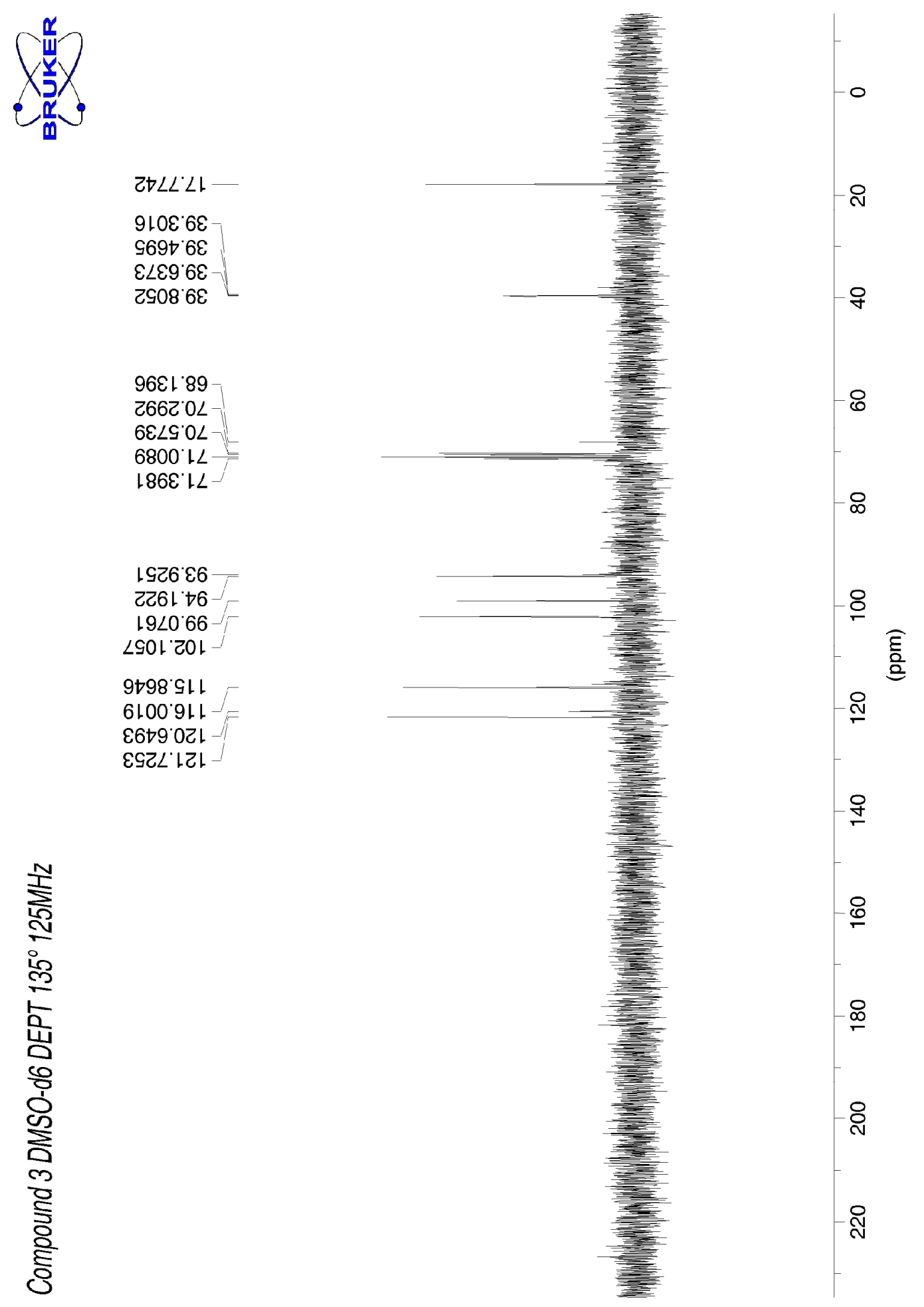
7.1.5.6 Mapa de contorno gerado a partir do experimento HMQC $\left({ }^{13} \mathrm{C}: 125\right.$ $\mathrm{MHz},{ }^{1} \mathrm{H}: 500 \mathrm{MHz}$ ) do composto 3 em DMSO-d ${ }_{6}$.

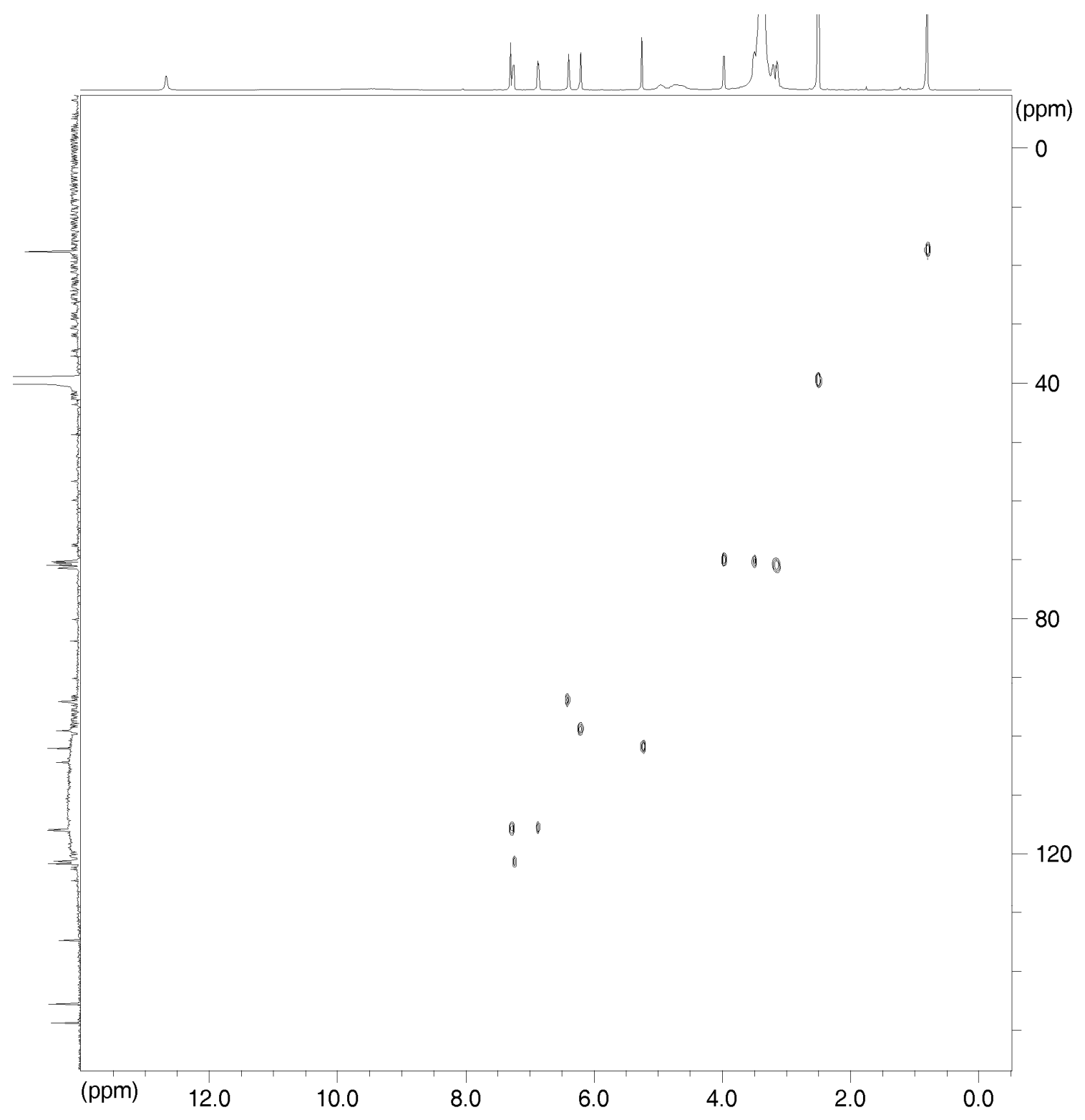


7.1.5.7 Mapa de contorno gerado a partir do experimento $\mathrm{COSY} 90^{\circ}\left({ }^{1} \mathrm{H},{ }^{1} \mathrm{H}: 500\right.$ $\mathrm{MHz}$ ) do composto $3 \mathrm{em}$ DMSO-d.

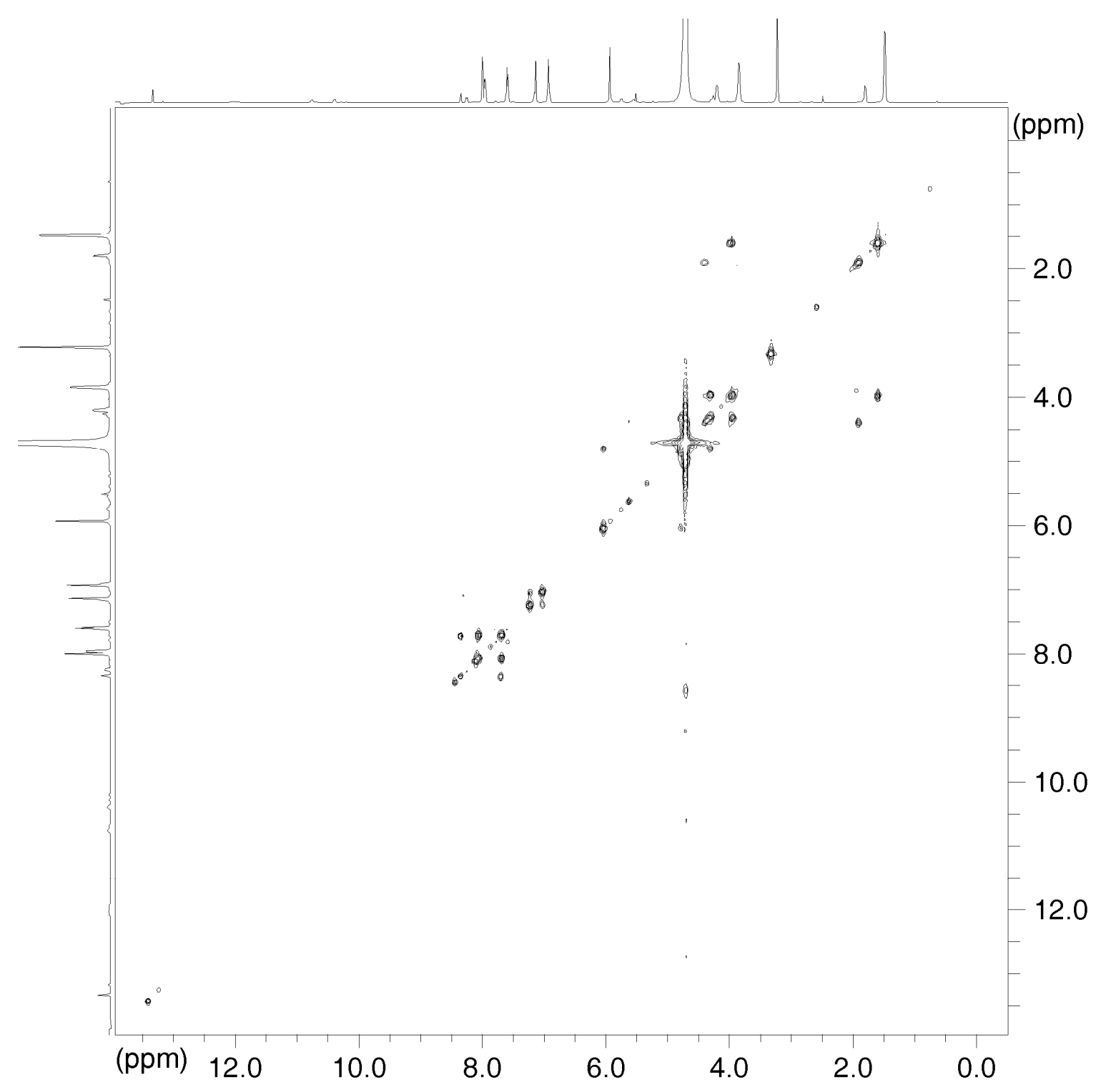


7.1.5.8 Mapa de contorno gerado a partir do experimento HMBC $\left({ }^{13} \mathrm{C}: 125\right.$ $\left.\mathrm{MHz},{ }^{1} \mathrm{H}: 500 \mathrm{MHz}\right)$, modulado para ${ }^{2} \mathrm{~J}_{\mathrm{CH}}=8 \mathrm{~Hz}$, do composto $3 \mathrm{em}$ DMSO-d .

\section{HMBC-8Hz}

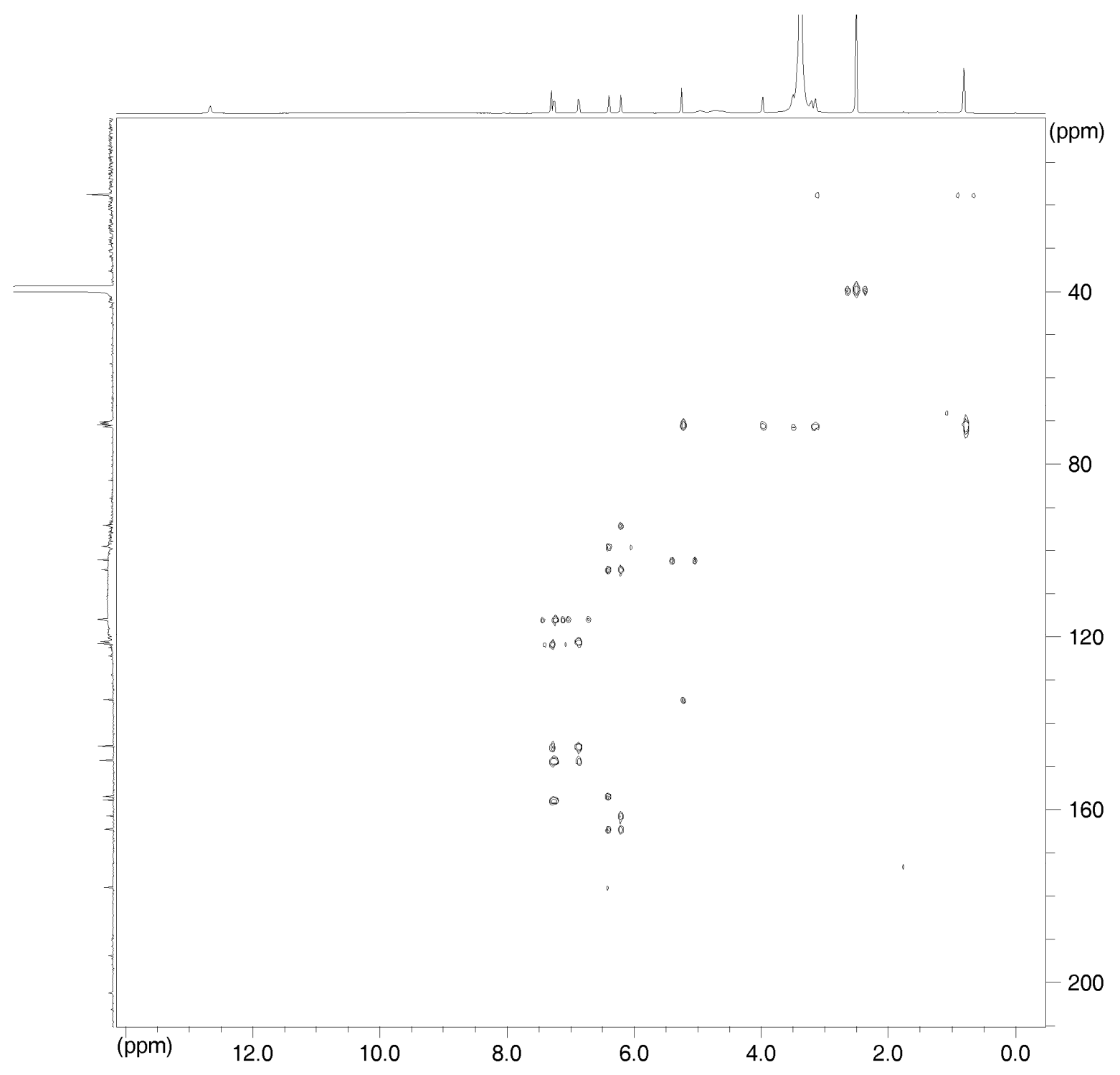


7.1.5.9 Mapa de contorno gerado a partir do experimento HMBC $\left({ }^{13} \mathrm{C}: 125\right.$ $\left.\mathrm{MHz},{ }^{1} \mathrm{H}: 500 \mathrm{MHz}\right)$, modulado para ${ }^{2} \mathrm{~J}_{\mathrm{CH}}=4 \mathrm{~Hz}$, do composto 3 em DMSO-d ${ }_{6}$.

$\mathrm{HMBC}-4 \mathrm{~Hz}$

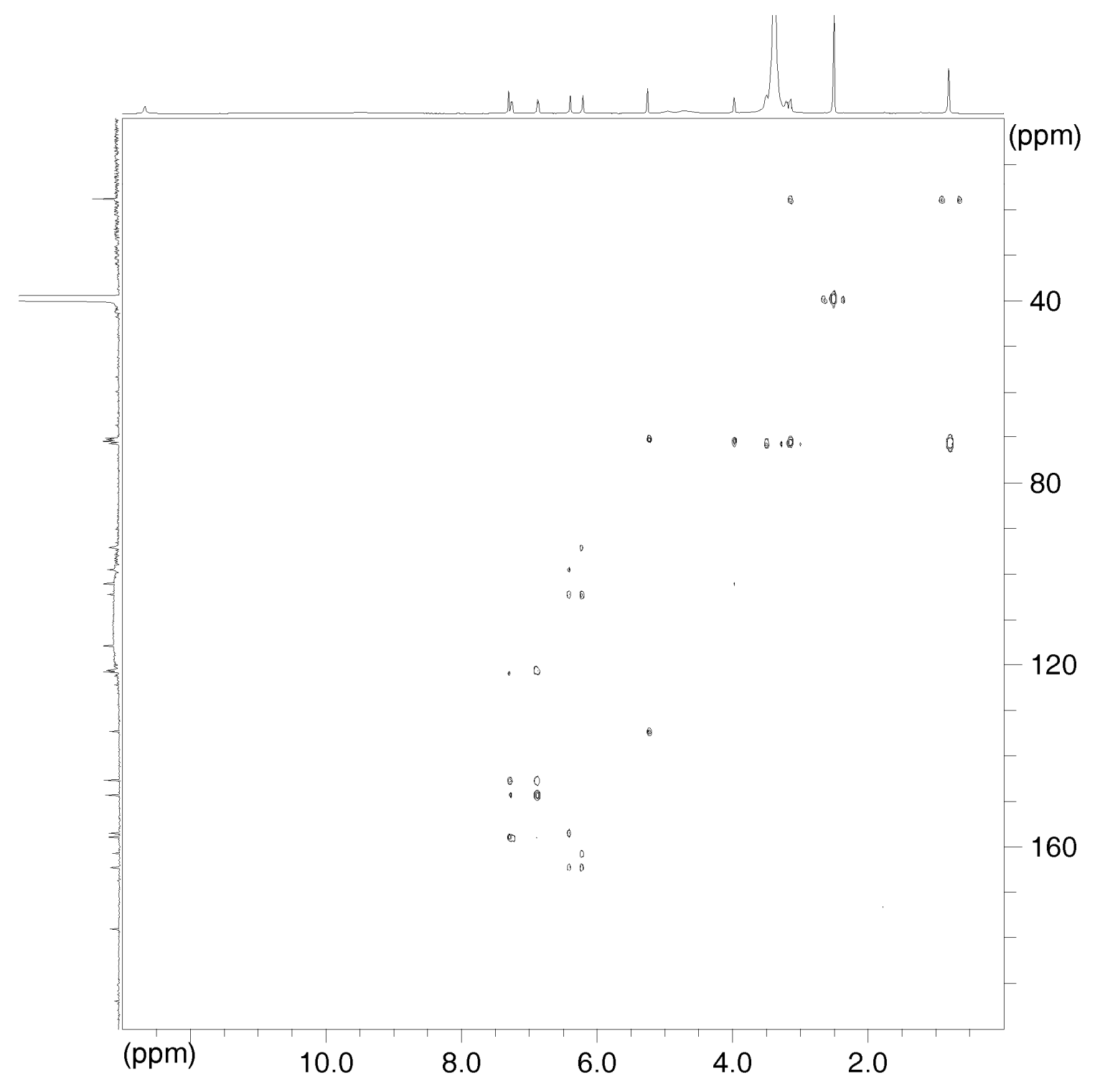




\subsubsection{Dados de RMN do composto 4:}

\subsubsection{Espectro de RMN de ${ }^{1} \mathrm{H}(500 \mathrm{MHz})$ do composto 4 em DMSO-d .}
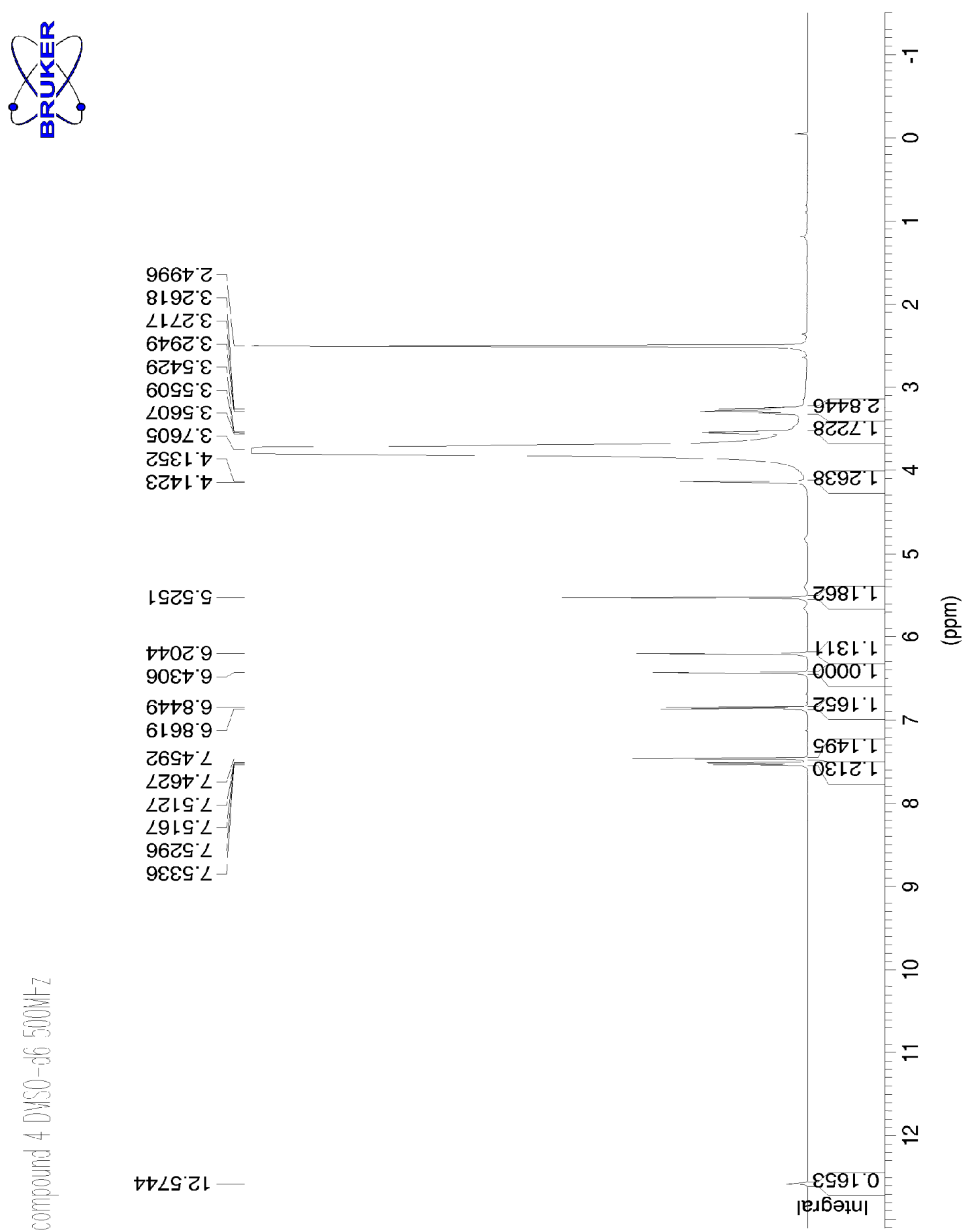
7.1.6.2 Ampliações do Espectro de RMN de ${ }^{1} \mathrm{H}(500 \mathrm{MHz})$ do composto 4 em DMSO-d .
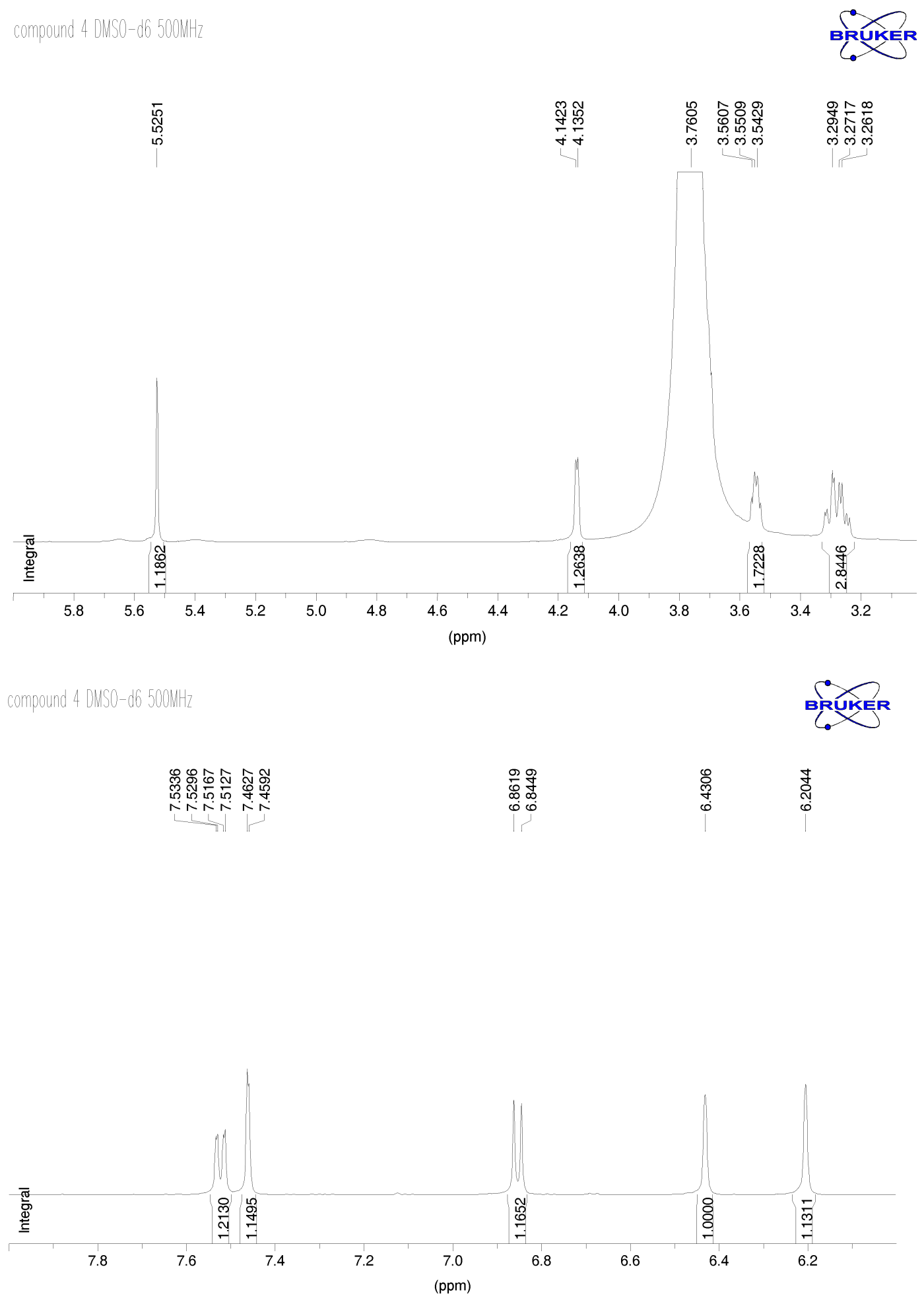
7.1.6.3 Espectro de RMN de $\left.{ }^{13} C_{\{}{ }^{1} H\right\}(125 \mathrm{MHz})$ do composto 4 em DMSO-d .

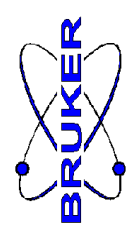

$\nabla \varepsilon+6.09$
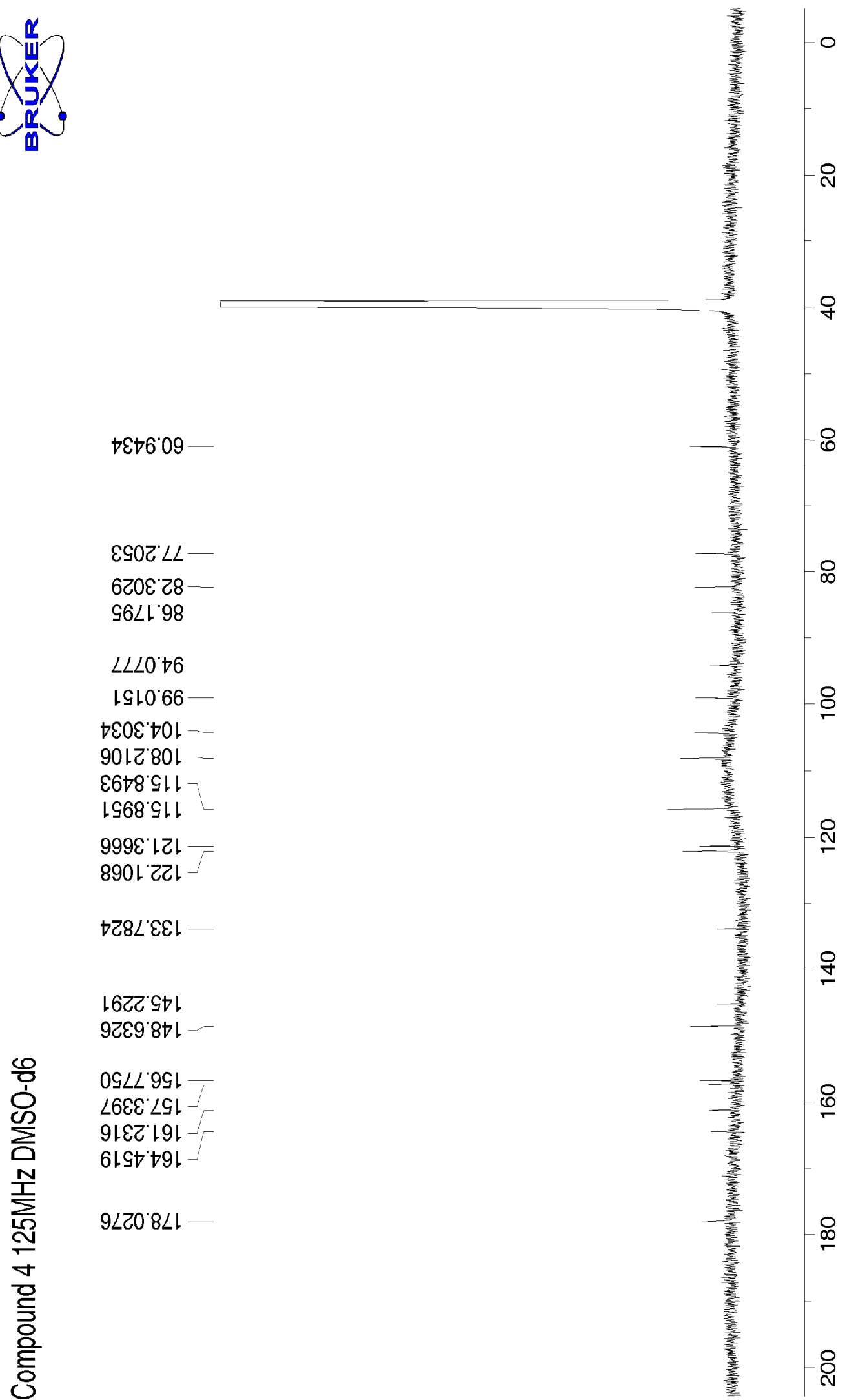

8

$\infty$

$8 \widehat{\widehat{\xi}}$

$\stackrel{ }{\circ}$

옴

$\stackrel{8}{8}$

$\stackrel{\infty}{\infty}$

유 
7.1.6.4 Espectro de RMN de ${ }^{13} \mathrm{C}\left(\mathrm{DEPT} 135^{\circ}, 125 \mathrm{MHz}\right)$ do composto 4 em DMSO-d $d_{6}$.
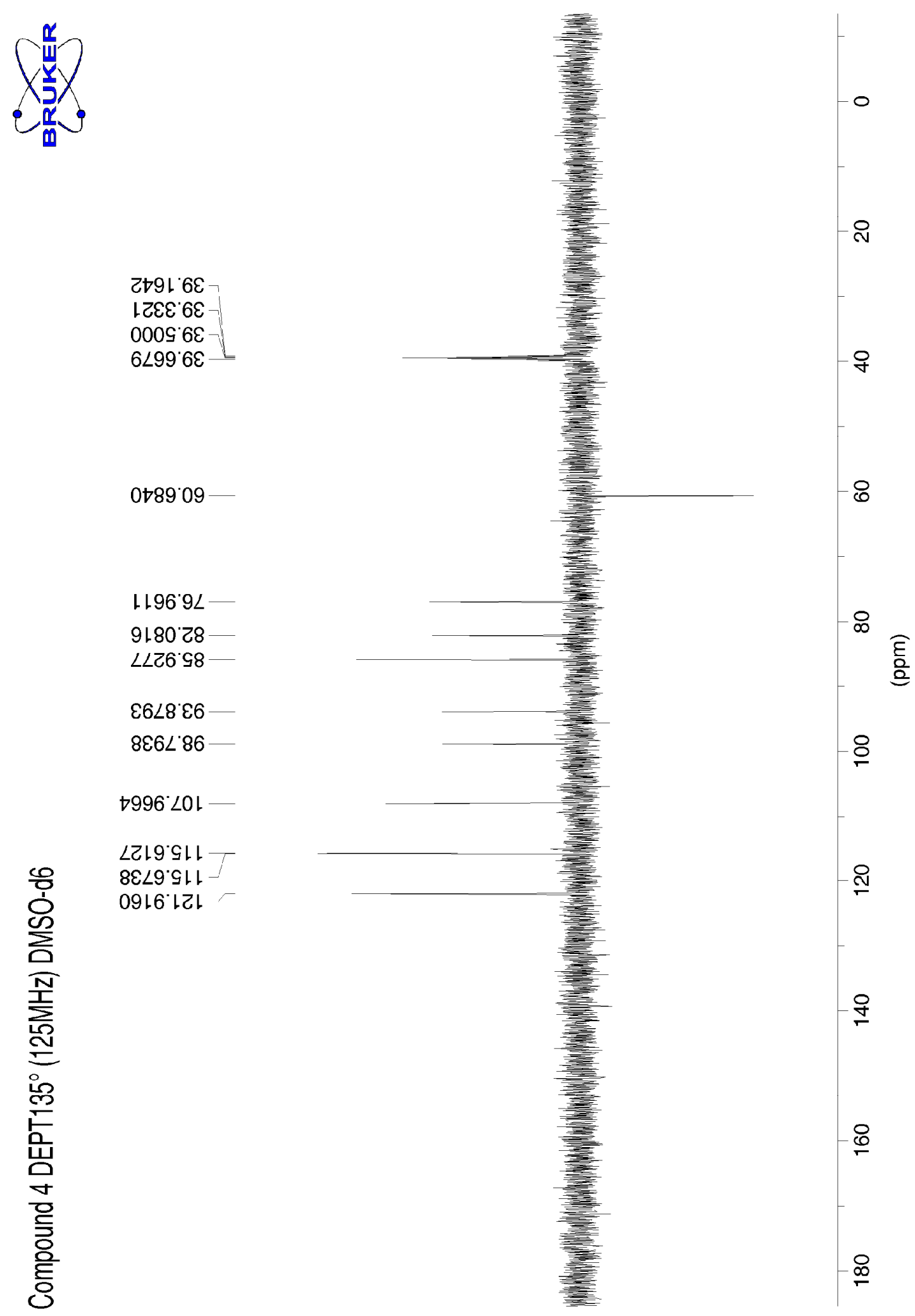
7.1.6.5 Mapa de contorno gerado a partir do experimento HMQC $\left({ }^{13} \mathrm{C}: 125\right.$ $\mathrm{MHz},{ }^{1} \mathrm{H}: 500 \mathrm{MHz}$ ) do composto 4 em DMSO-d ${ }_{6}$.

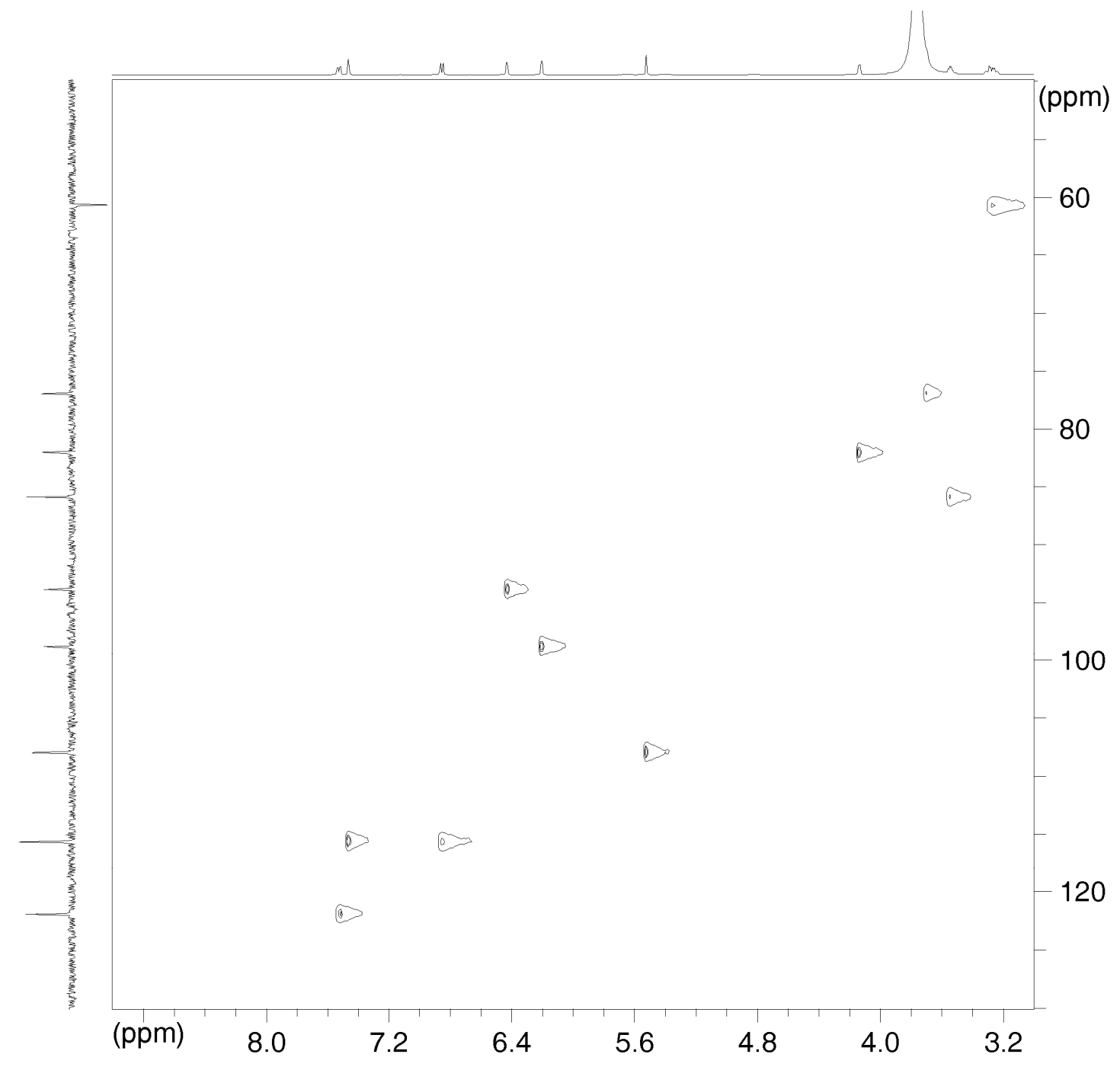


7.1.6.6 Mapa de contorno gerado a partir do experimento $\mathrm{COSY} 90^{\circ}\left({ }^{1} \mathrm{H},{ }^{1} \mathrm{H}: 500\right.$ $\mathrm{MHz}$ ) do composto $4 \mathrm{em} \mathrm{DMSO}-d_{6}$.

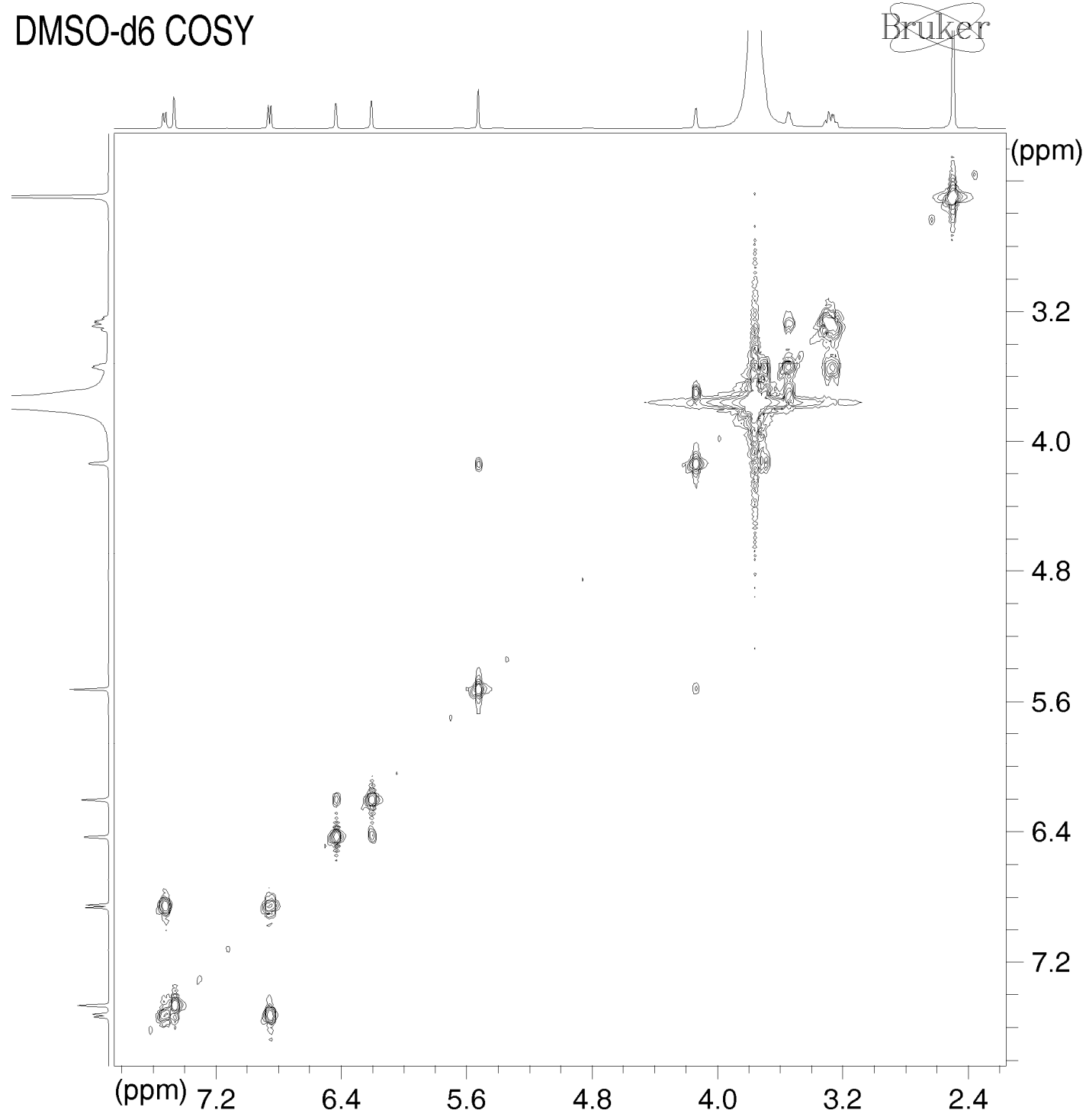


7.1.6.7 Mapa de contorno gerado a partir do experimento HMBC $\left({ }^{13} \mathrm{C}: 125\right.$ $\mathrm{MHz},{ }^{1} \mathrm{H}$ : $500 \mathrm{MHz}$ ), modulado para ${ }^{2} \mathrm{~J}_{\mathrm{CH}}=8 \mathrm{~Hz}$, do composto $3 \mathrm{em}$ DMSO-d

g-HMBC 500MHz DMSO-d6

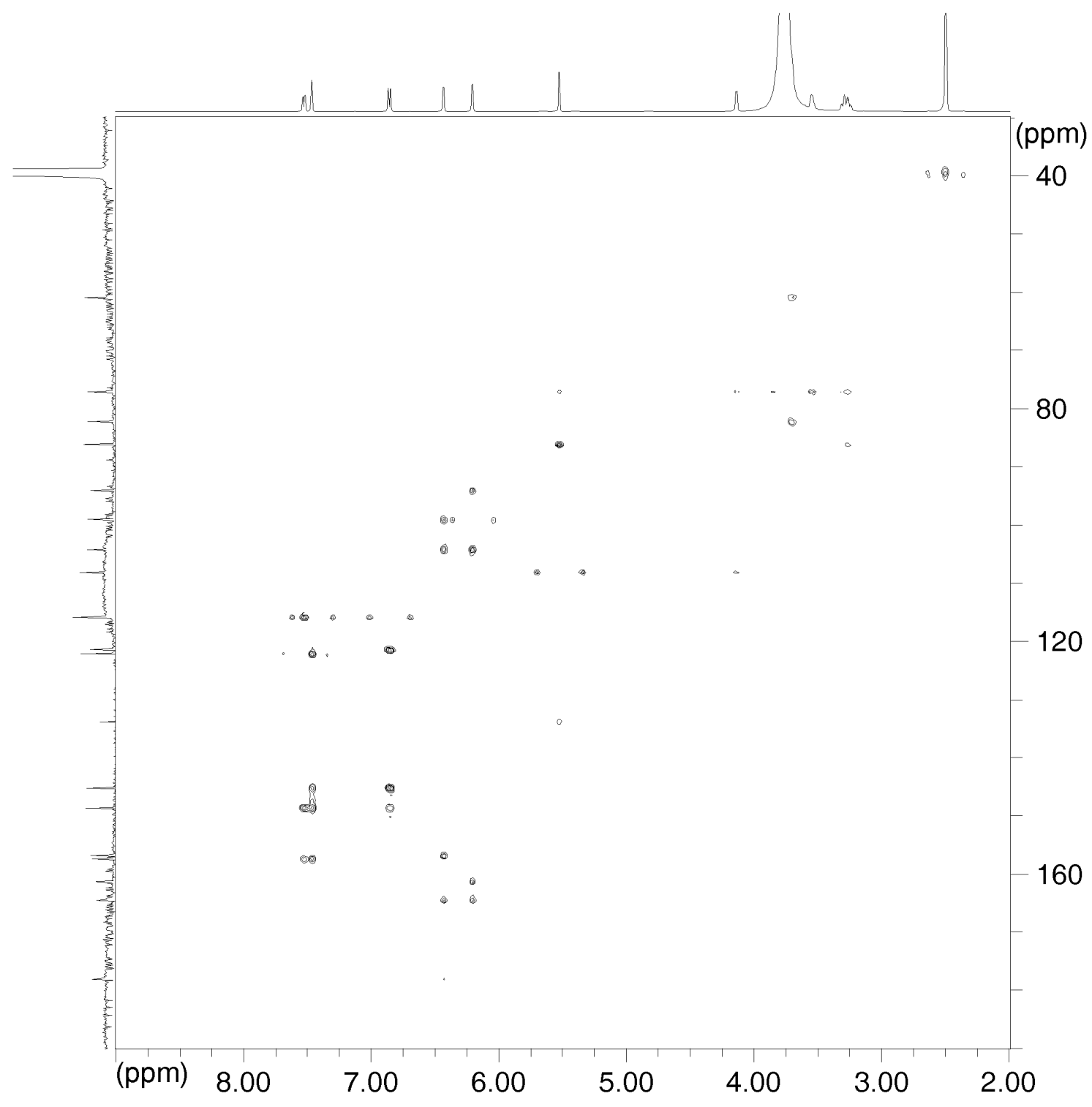




\subsection{Dados dos compostos 5-9: aplicação do método de seccionamento e limpeza do sinal por processamento}

\subsubsection{Dados de RMN dos componentes da Fração DF:}

7.2.1.1 Espectro de RMN de ${ }^{1} \mathrm{H}(500 \mathrm{MHz})$ da Fração DF em $\mathrm{CDCl}_{3}$.

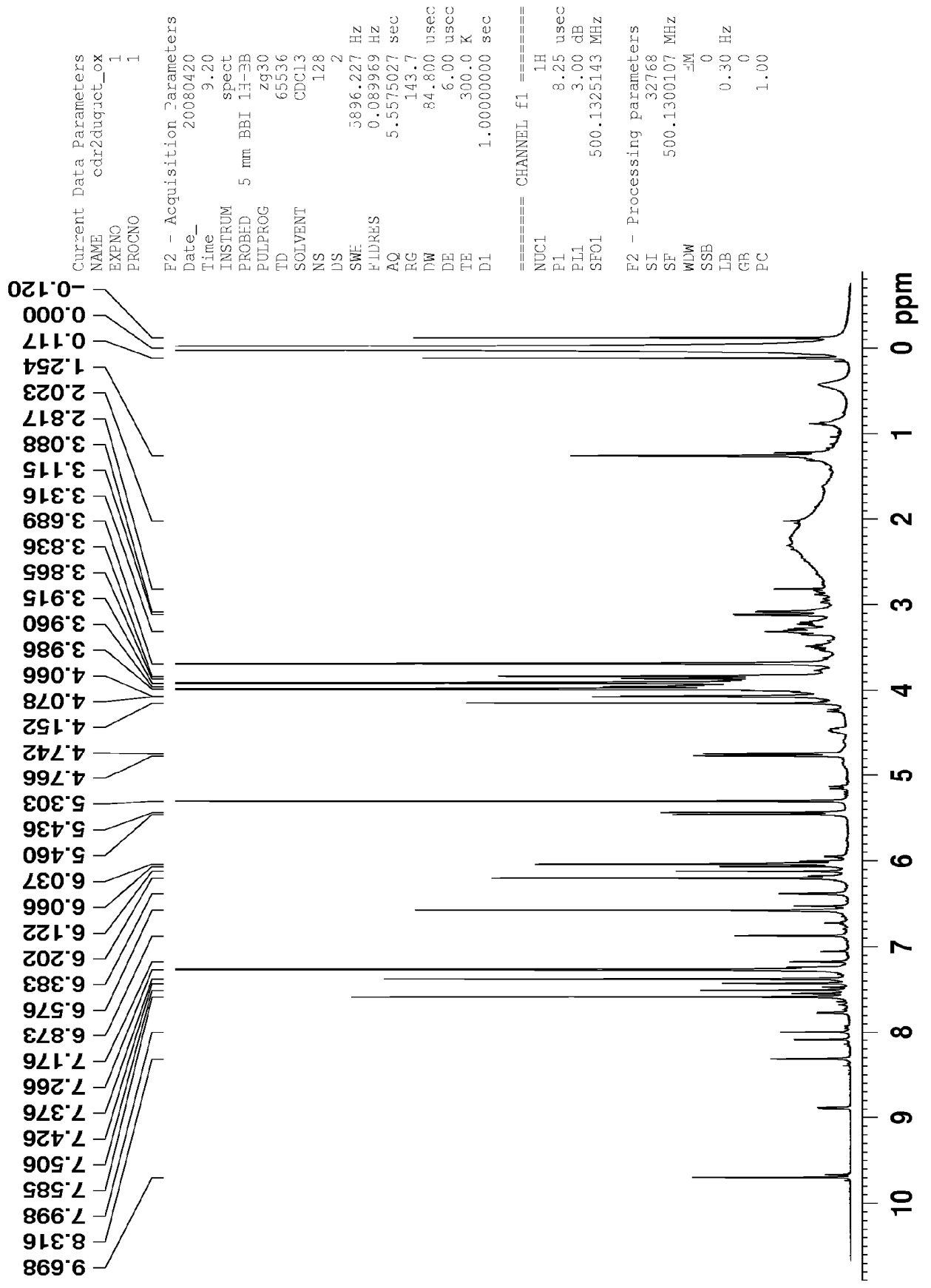


7.2.1.2 Espectros de RMN de $\left.{ }^{13} C_{\{}{ }^{1} \mathrm{H}\right\}(125 \mathrm{MHz})$ da Fração DF em $\mathrm{CDCl}_{3}$.

\subsection{Espectro original}

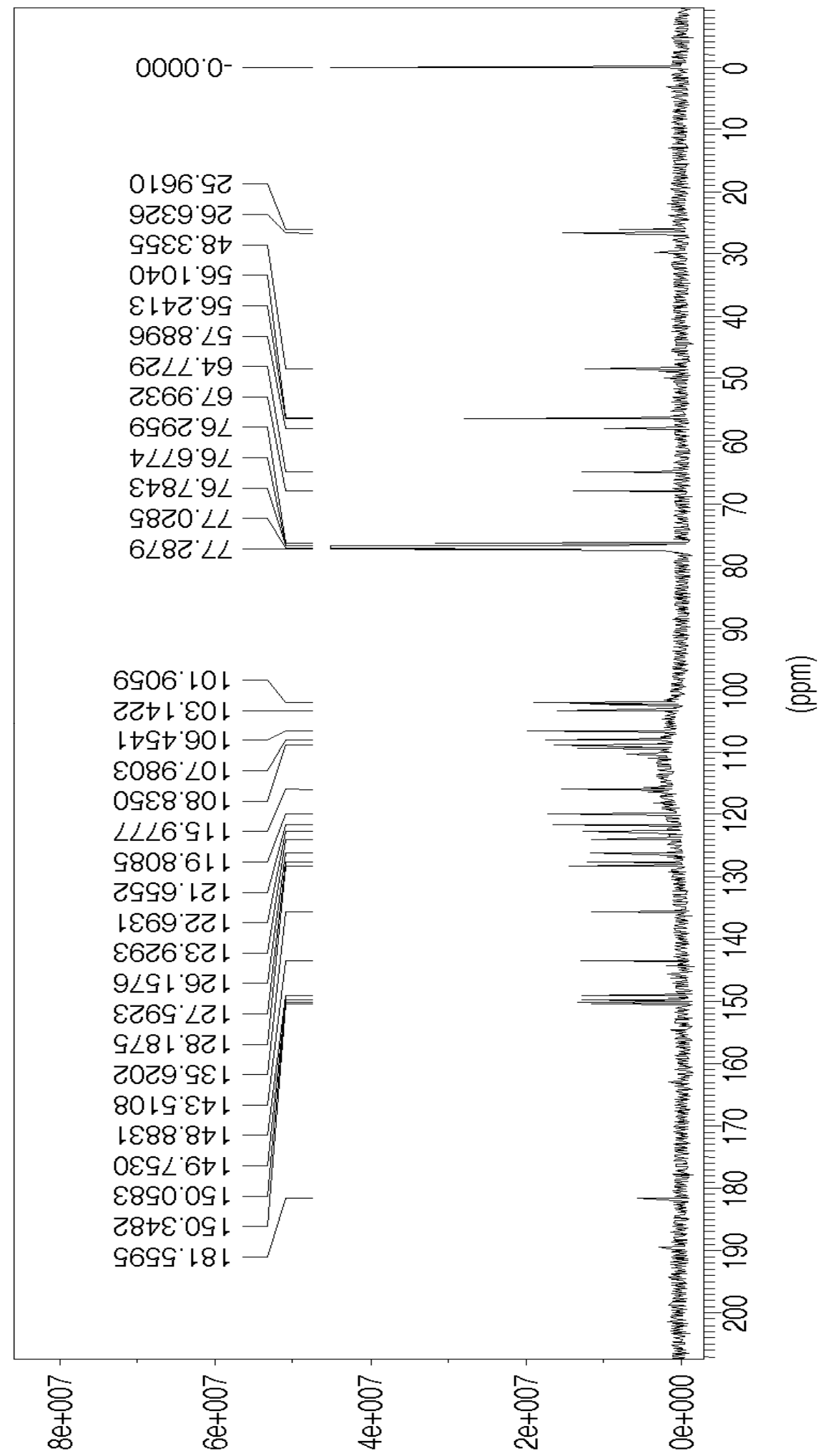




\subsection{Espectro tratado pelo método de seccionamento e limpeza de sinal}

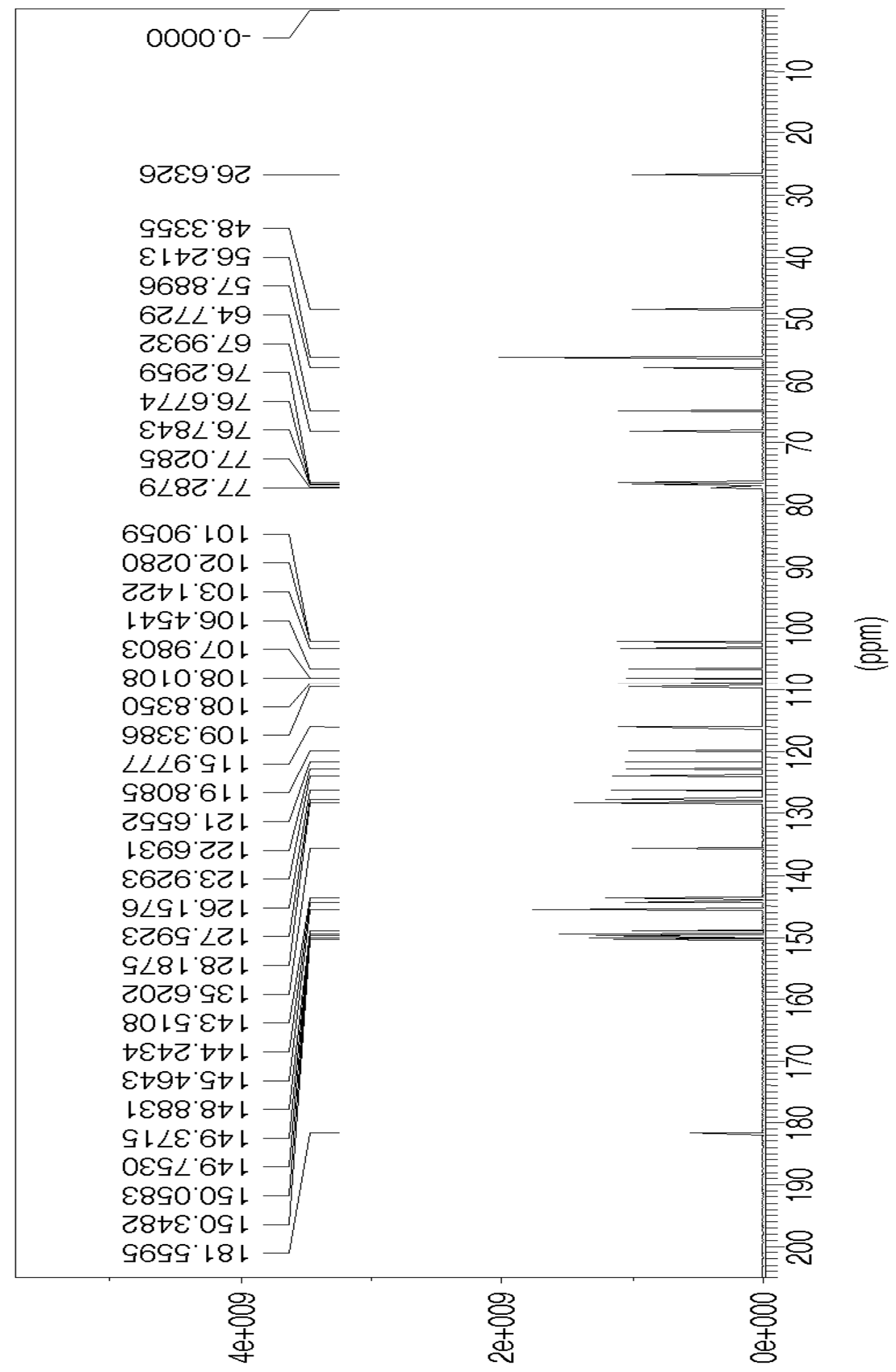


7.2.1.3 Espectro de RMN de ${ }^{13} \mathrm{C}\left(\mathrm{DEPT} 135^{\circ}, 125 \mathrm{MHz}\right)$ da Fração DF em $\mathrm{CDCl}_{3}$.
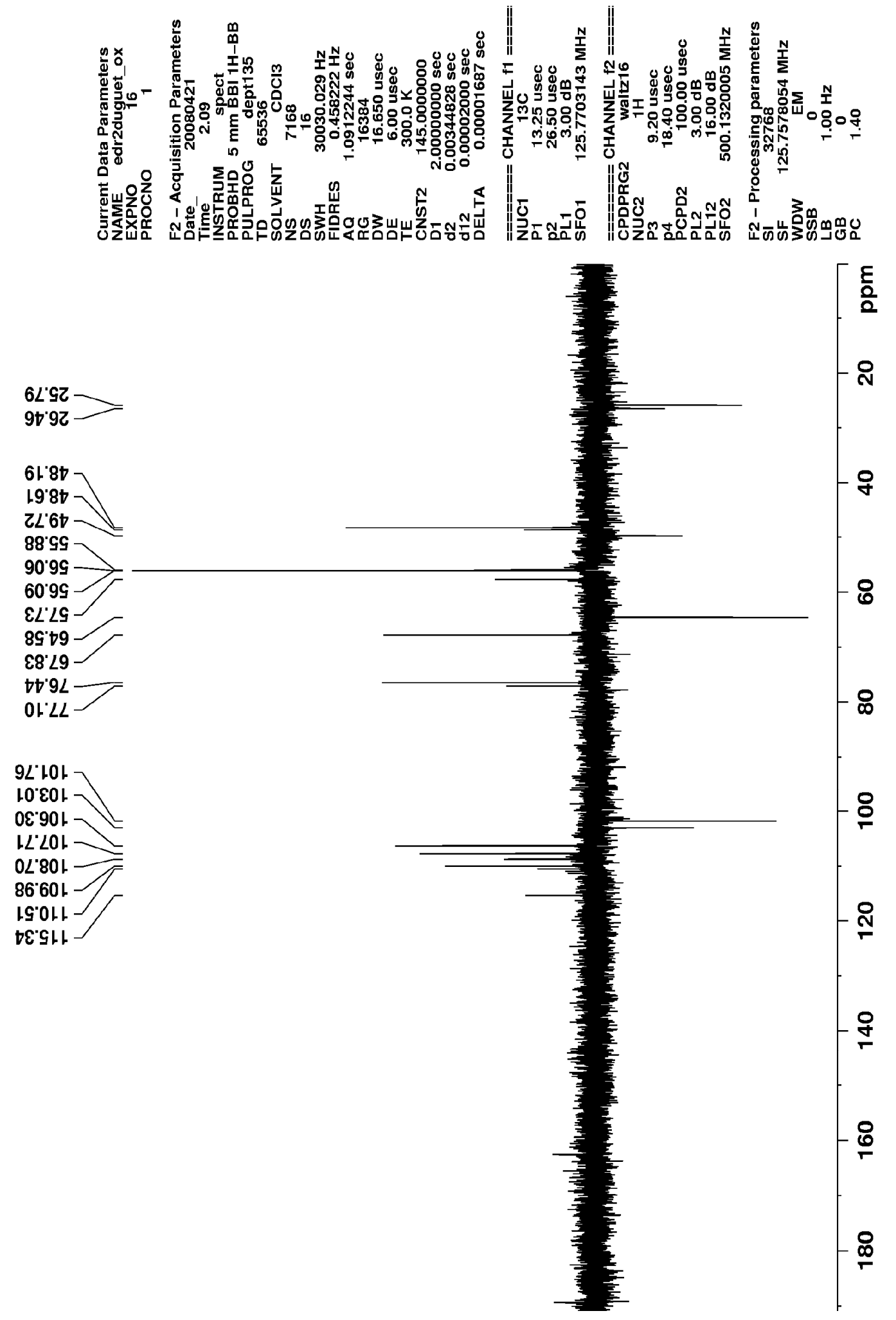


\subsubsection{Dados de RMN do composto 7}

\subsubsection{Espectro de RMN de ${ }^{1} \mathrm{H}(300 \mathrm{MHz})$ do composto 7 em Metanol-d ${ }_{4}$}
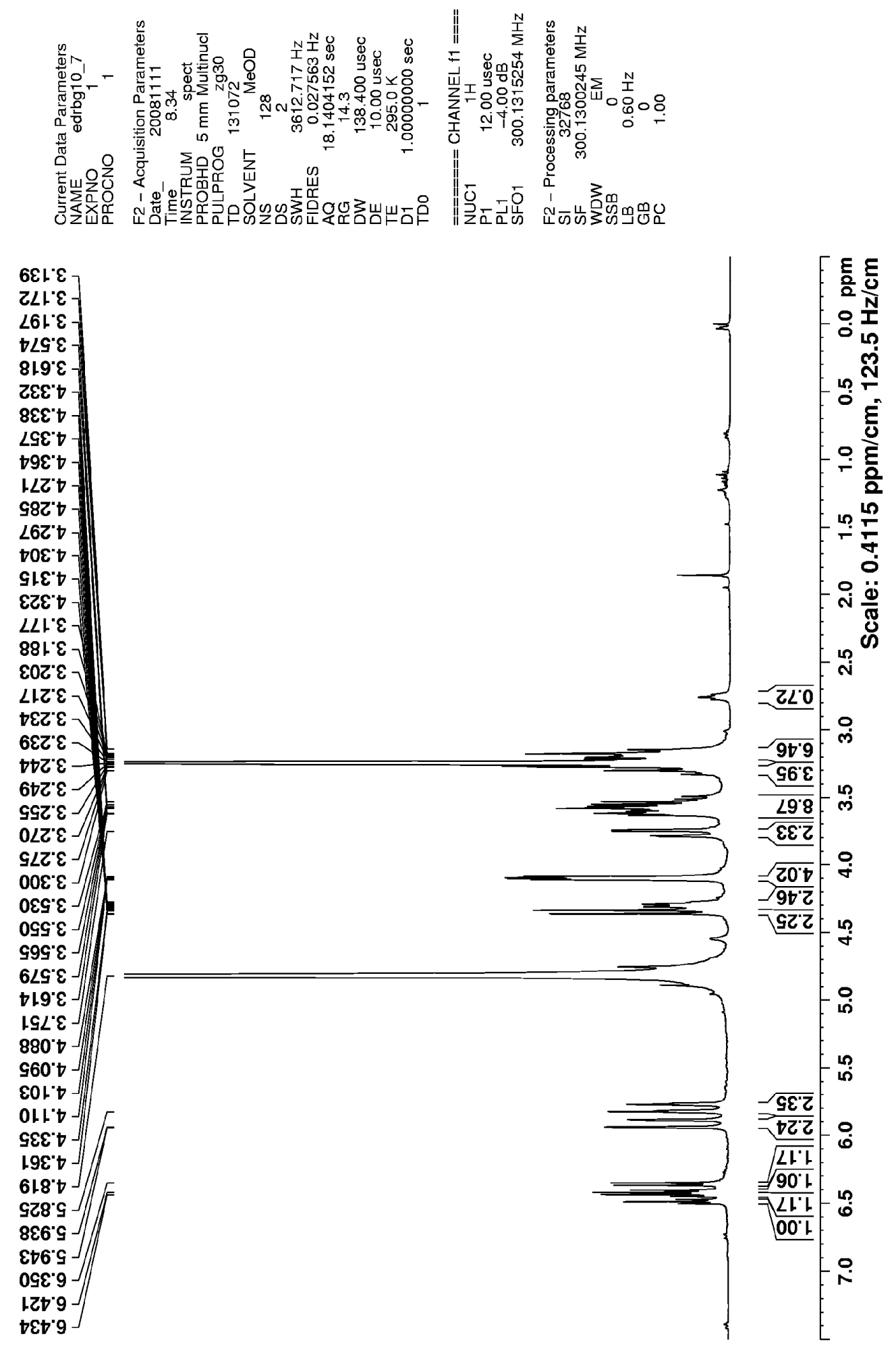


\subsubsection{Ampliações do Espectro de $\mathrm{RMN}$ de ${ }^{1} \mathrm{H}(300 \mathrm{MHz})$ do composto 7 em} Metanol-d 4 .
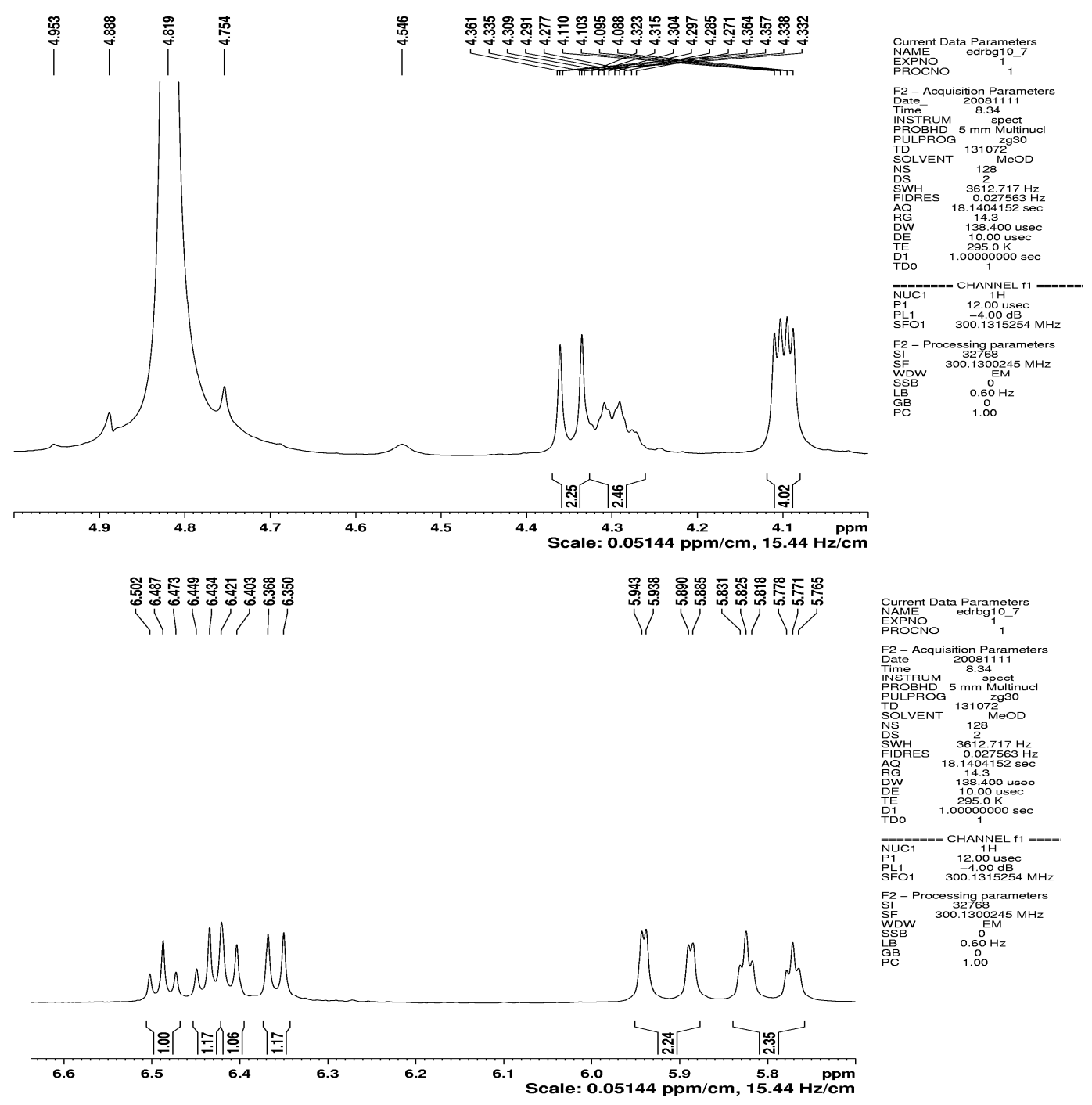

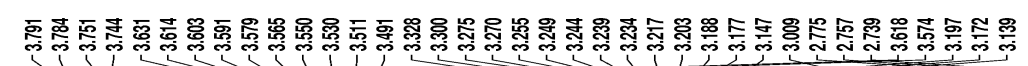

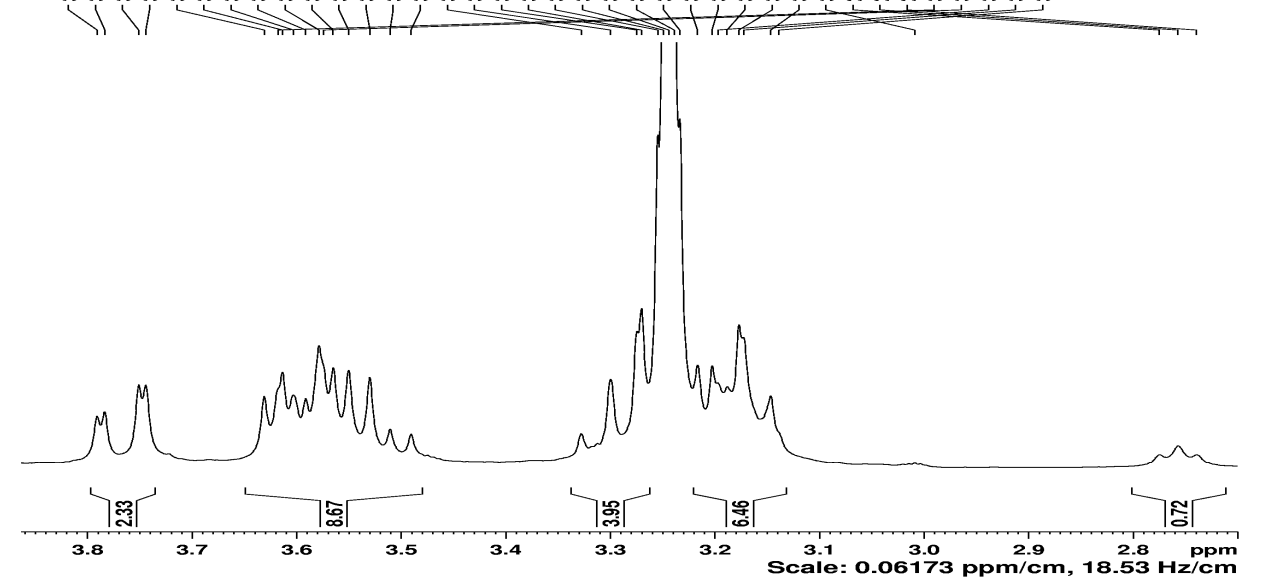


7.2.2.3 Espectros de RMN de $\left.{ }^{13} C_{\{}{ }^{1} \mathrm{H}\right\}(75 \mathrm{MHz})$ do composto 7 em Metanol-d 4 .

\subsection{Espectro original}

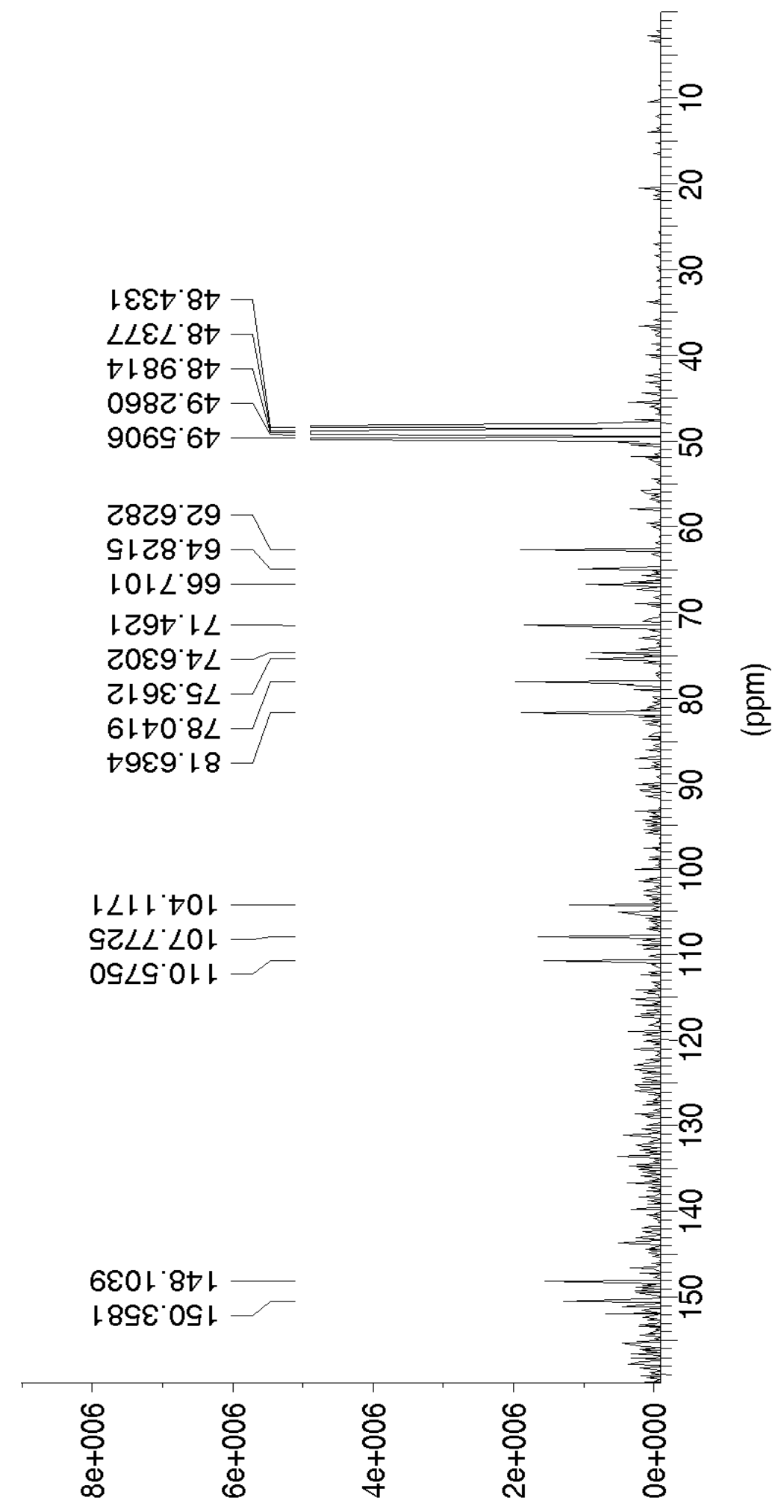


7.2.2.3.2 Espectro tratado pelo método de seccionamento sinal

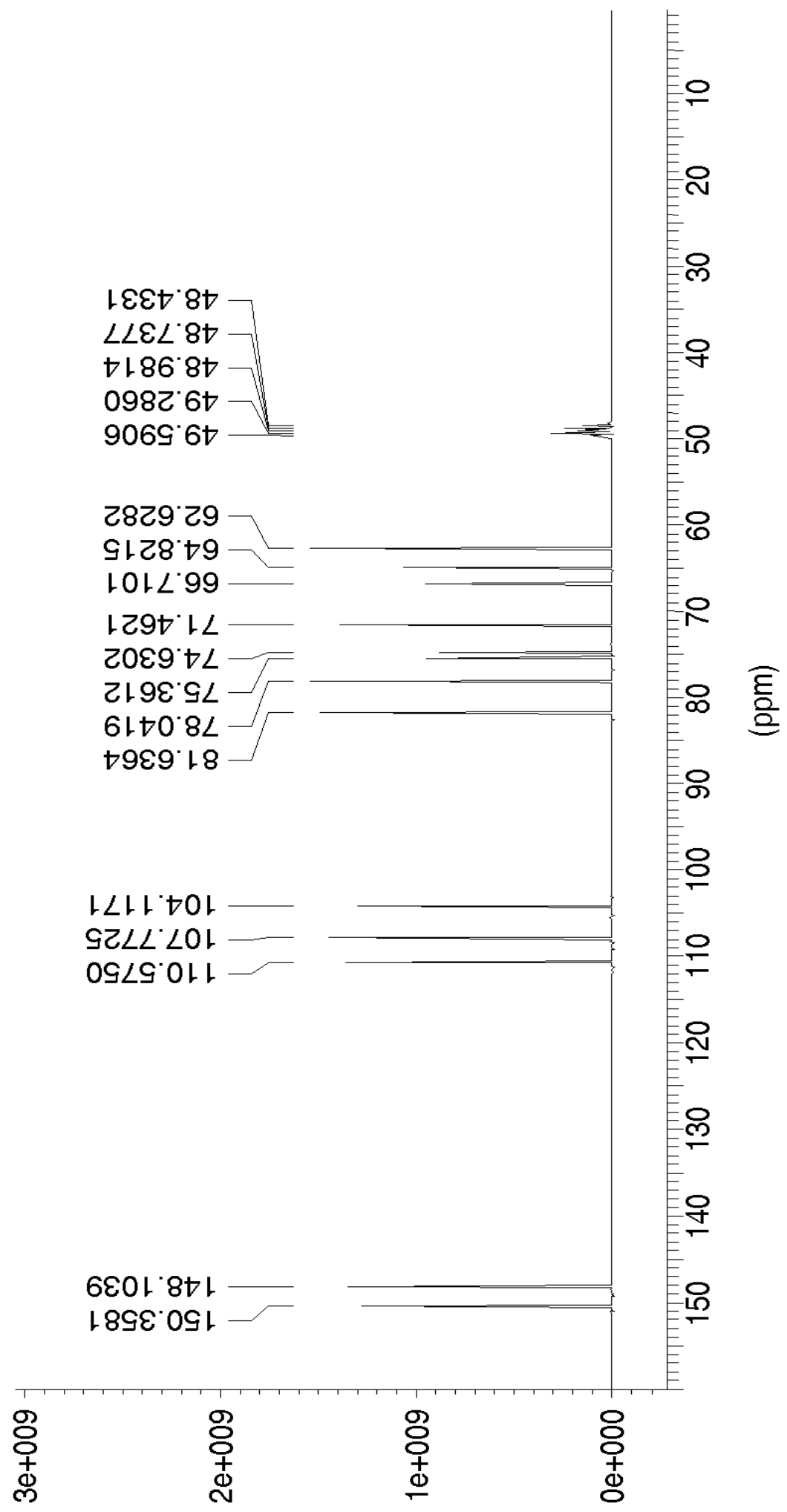


7.2.2.4 Espectro de RMN de $13 \mathrm{C}\left(\mathrm{DEPT} 135^{\circ}, 75 \mathrm{MHz}\right)$ do composto 7 Metanol-d4,.
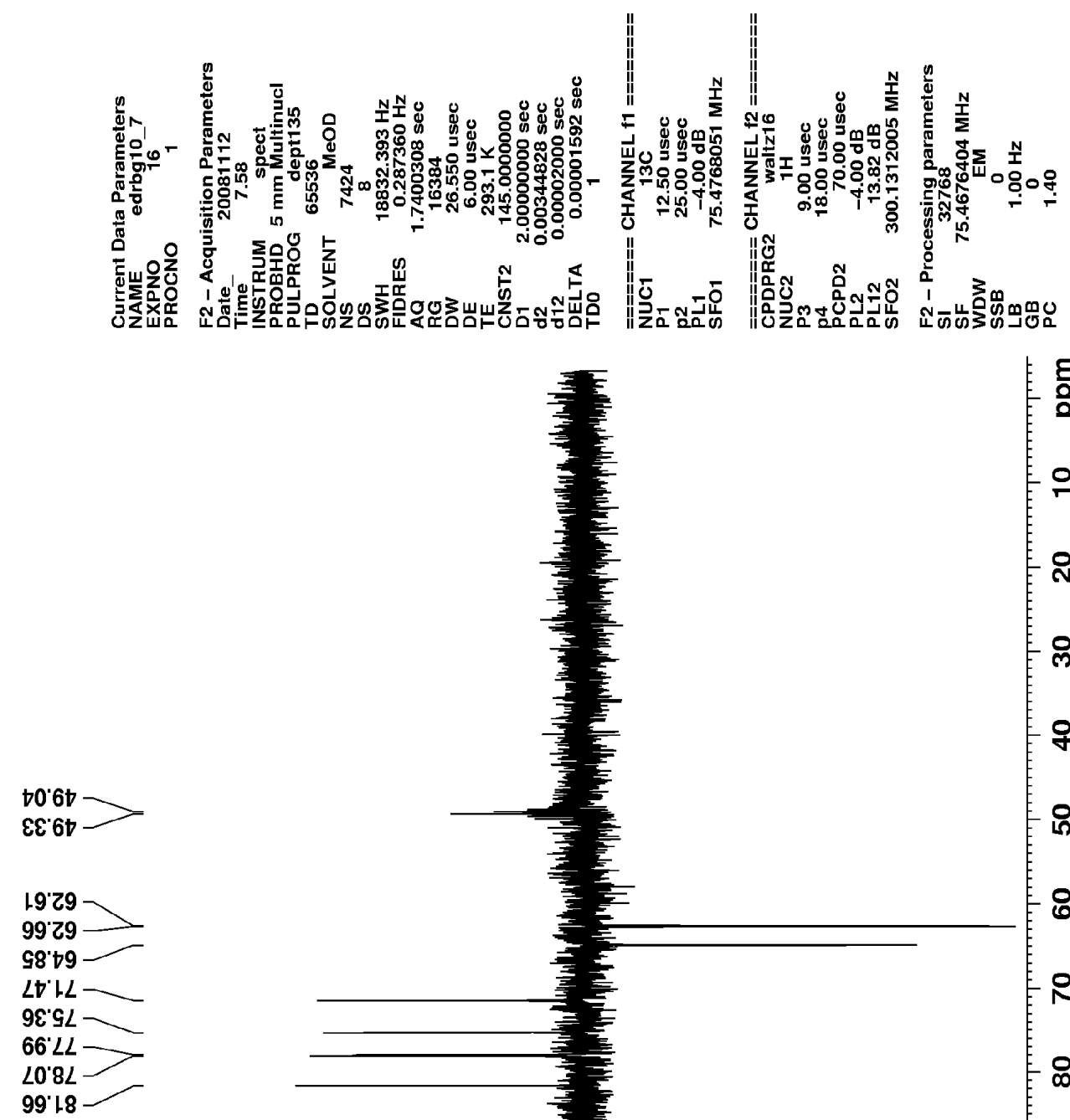

st'to

$\angle L 20$

69'아 - -
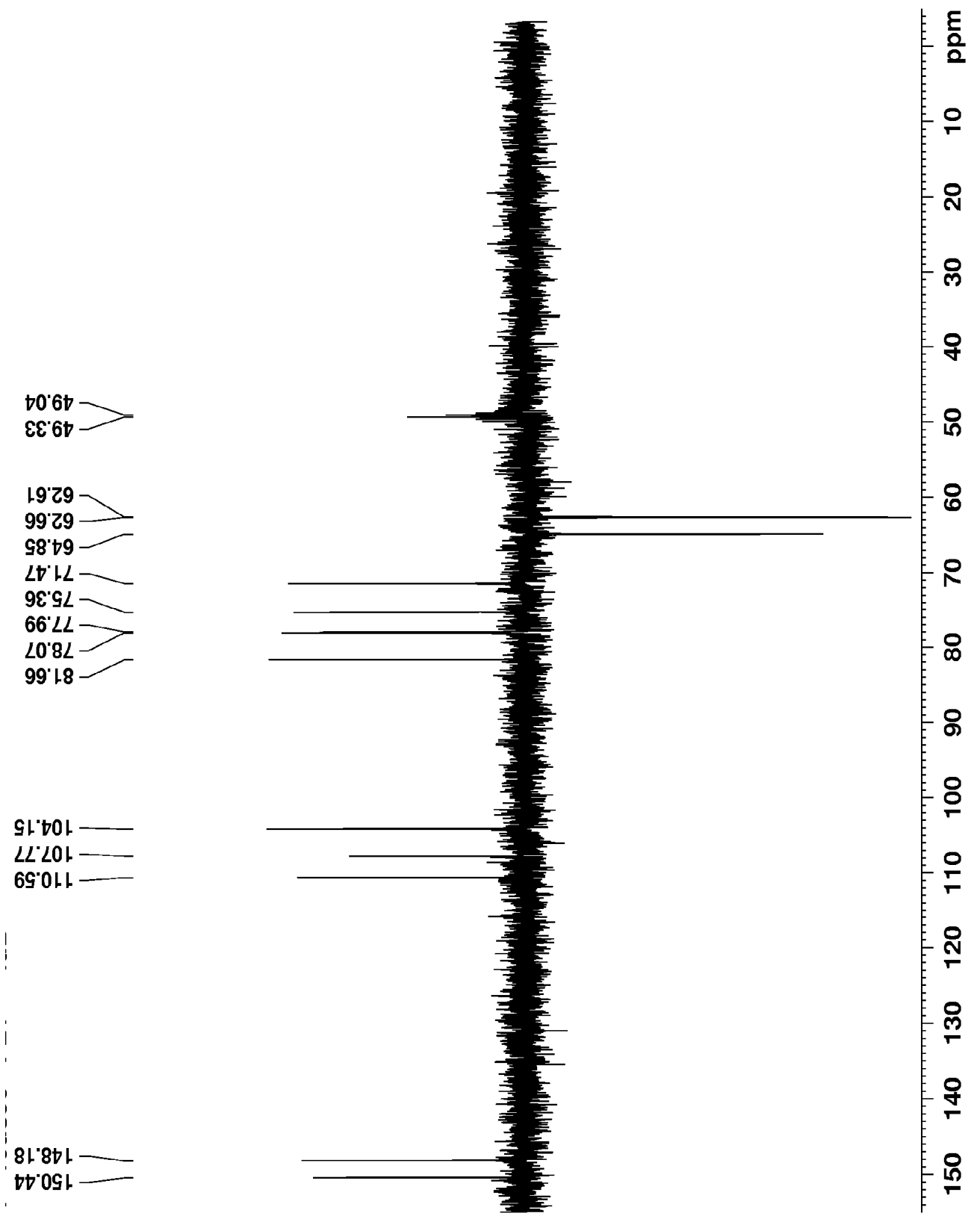
7.2.2.5 Mapa de contorno gerado a partir do experimento HMQC (13C: 125 MHz e 1H: 500 MHz) do composto 7 em DMSO-d6,
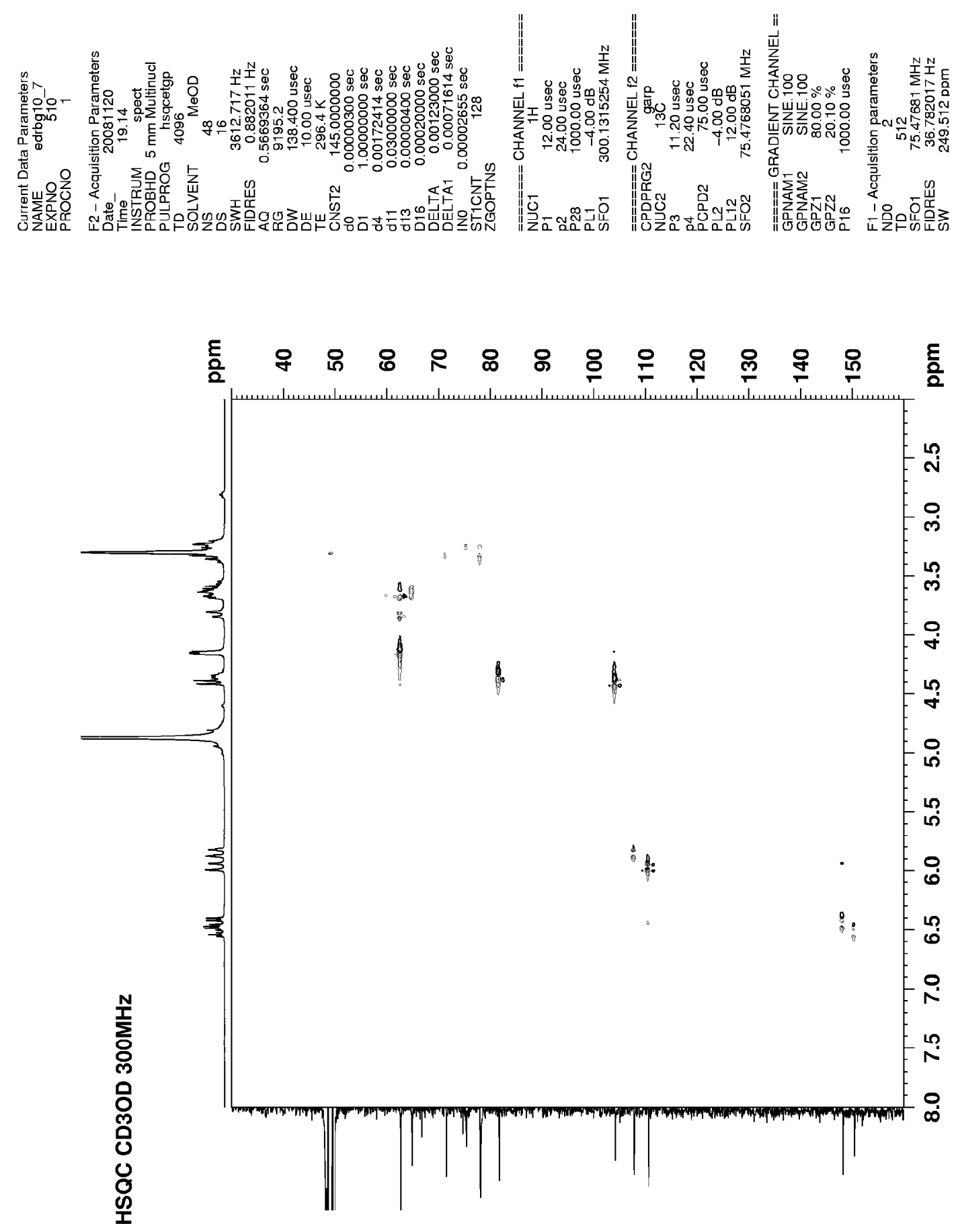
7.2.2.6 Mapa de contorno gerado a partir do experimento COSY 90 $[1 \mathrm{H}, 1 \mathrm{H}]$ do composto 7 em DMSO-d6, (500 MHz)
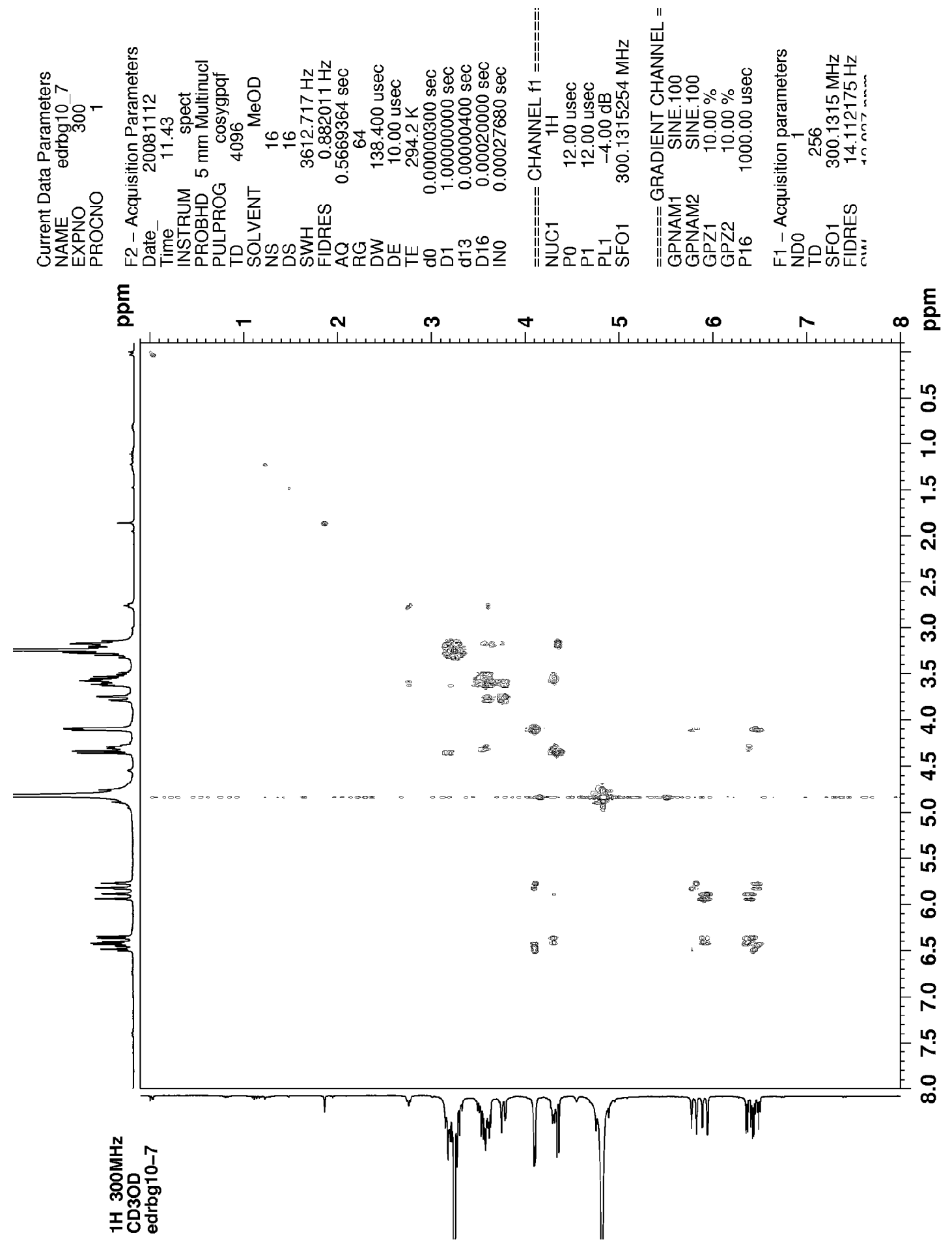
7.2.2.7 Ampliações do Mapa de contorno gerado a partir do experimento COSY $90^{\circ}[1 \mathrm{H}, 1 \mathrm{H}]$ do composto $7 \mathrm{em}$ DMSO-d6, (500 MHz)

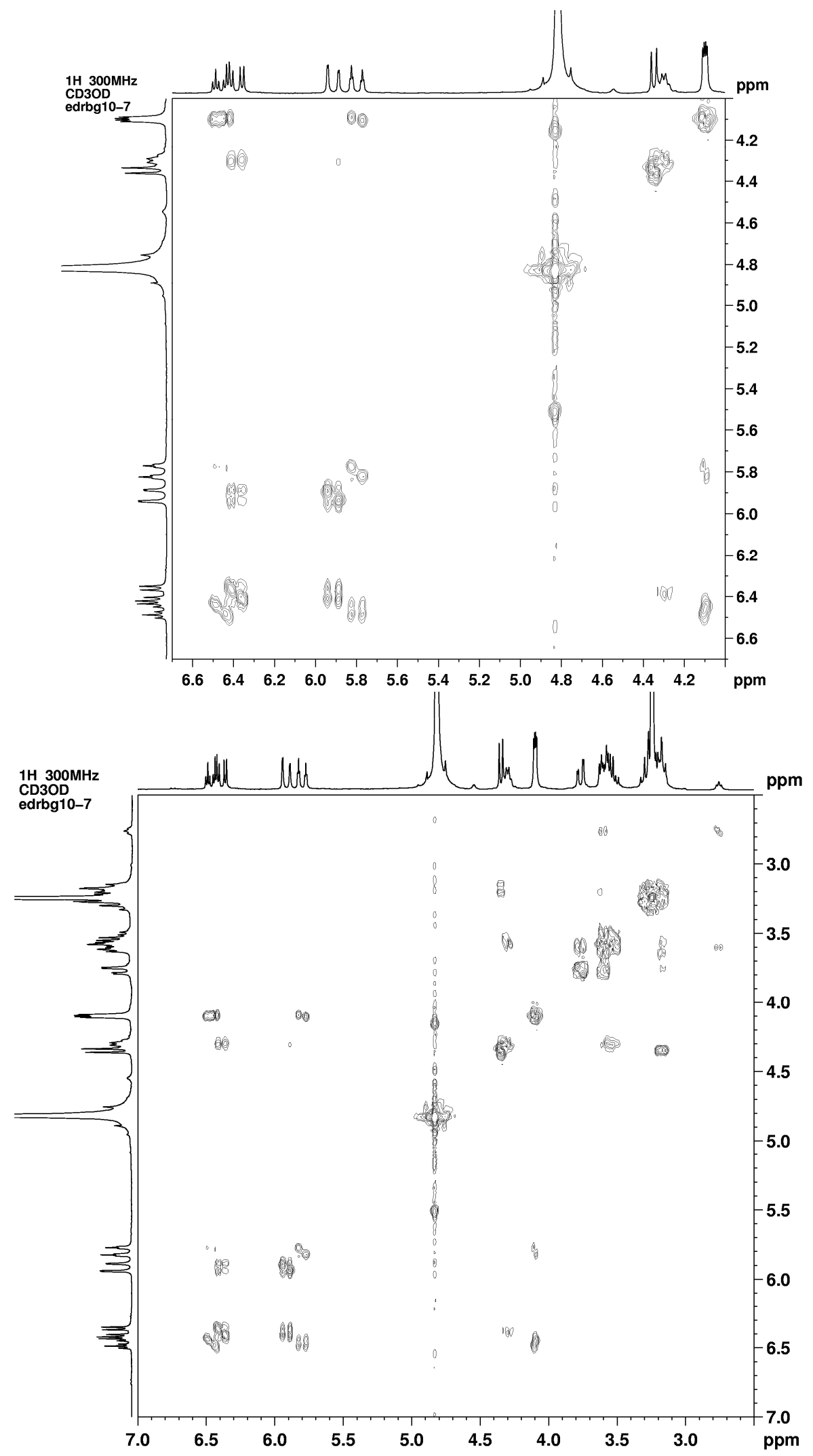


7.2.2.8 Mapa de contorno gerado a partir do experimento $\mathrm{HMBC}[13 \mathrm{C}, 1 \mathrm{H}]$, modulado para $2 \mathrm{JCH}=8 \mathrm{~Hz}$, do composto 7 em DMSO-d6, (13C: 125 MHz e 1H: 500 MHz)
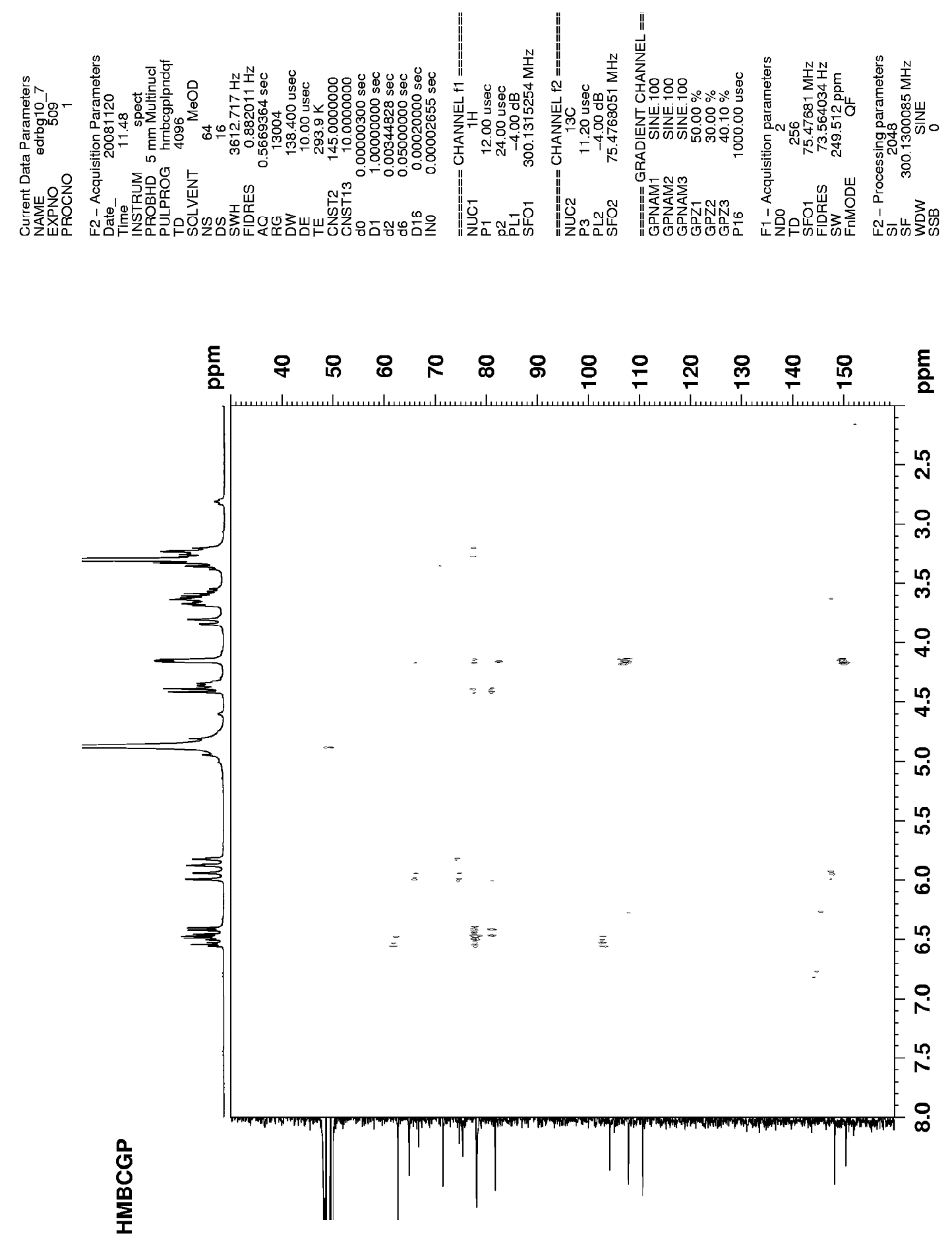
7.2.2.9 Mapa de contorno gerado a partir do experimento g-NOESY [1H, 1H] do composto 7 em DMSO-d6, (1H: 500 MHz)

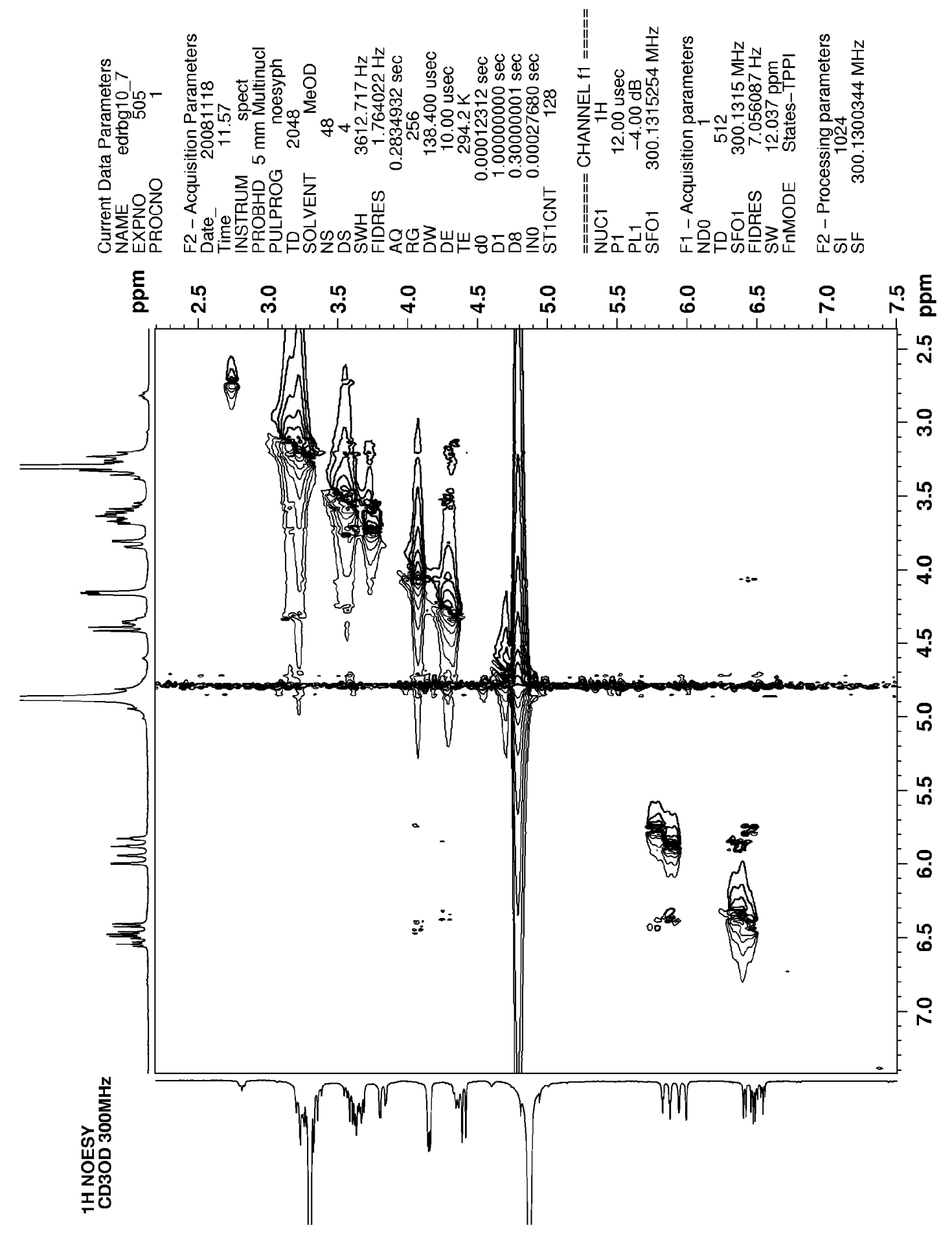




\subsubsection{Dados de RMN do composto 8:}

\subsubsection{Espectro de RMN de 1H do composto 8 em DMSO-d6, 500 MHz.}
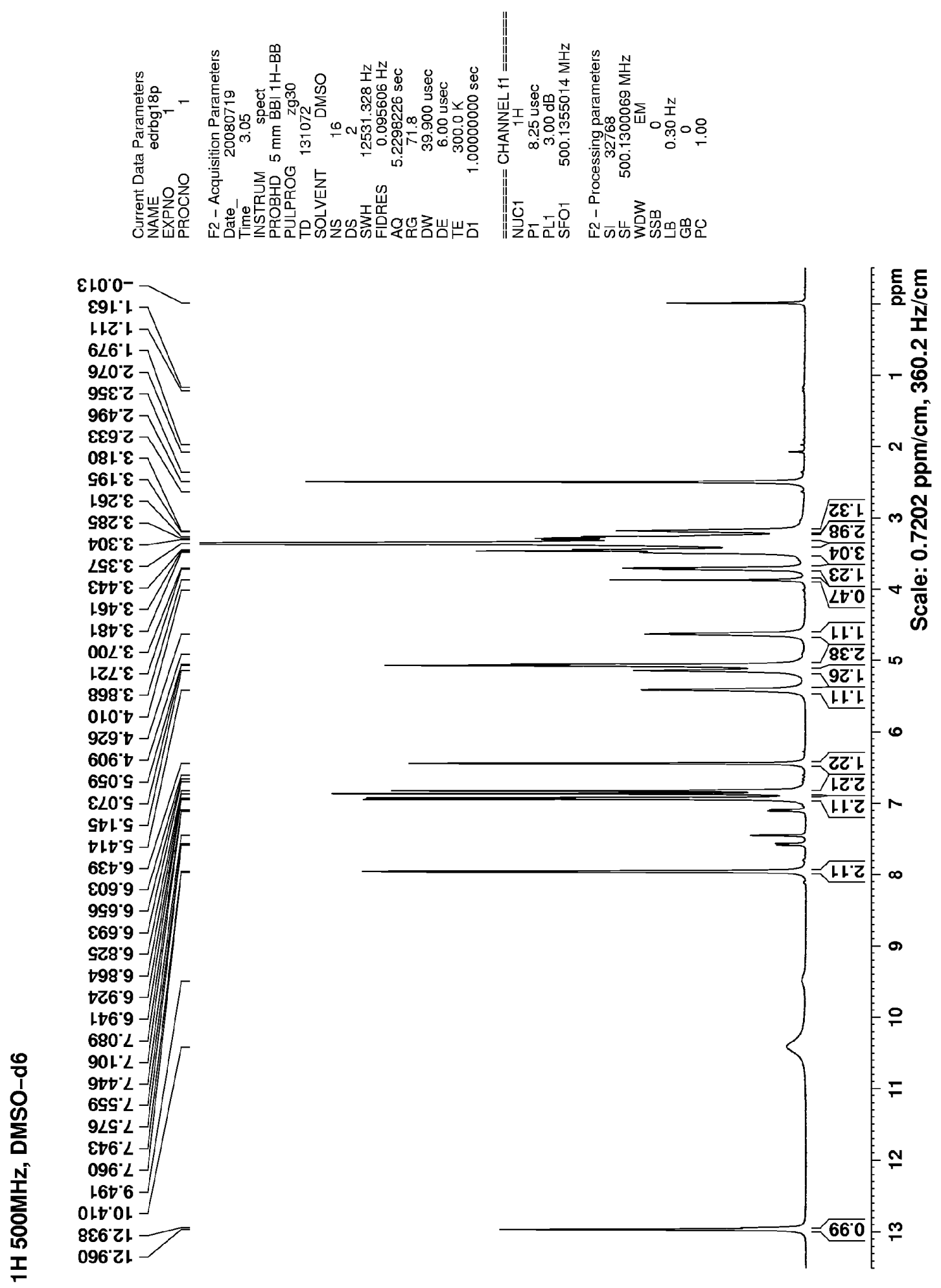


\subsubsection{Ampliações do Espectro de RMN de ${ }^{1} \mathrm{H}$ do composto 8 em DMSO-d6, $500 \mathrm{MHz}$.}

1H 500MHz, DMSO-d6

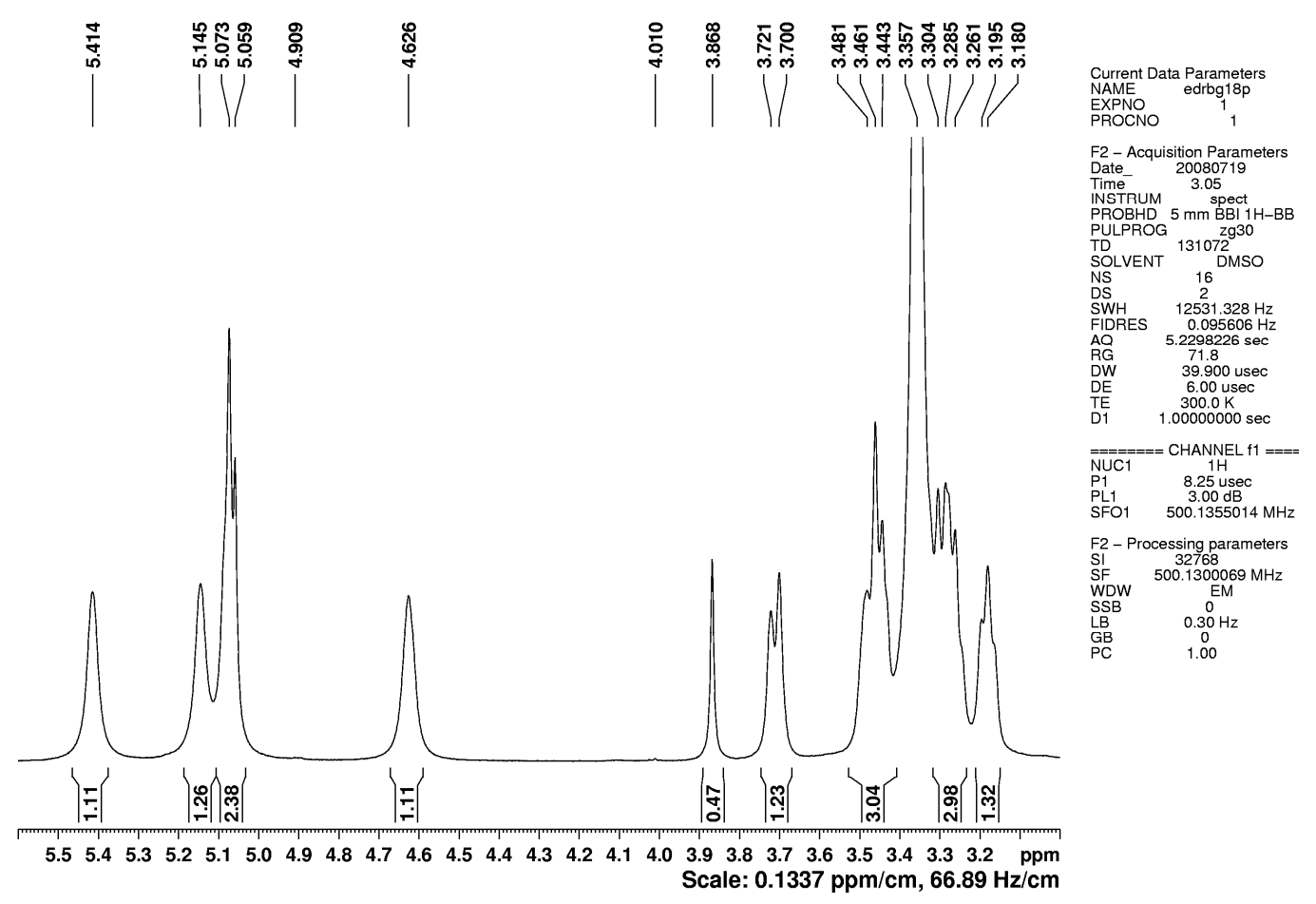

1H 500MHz, DMSO-d6

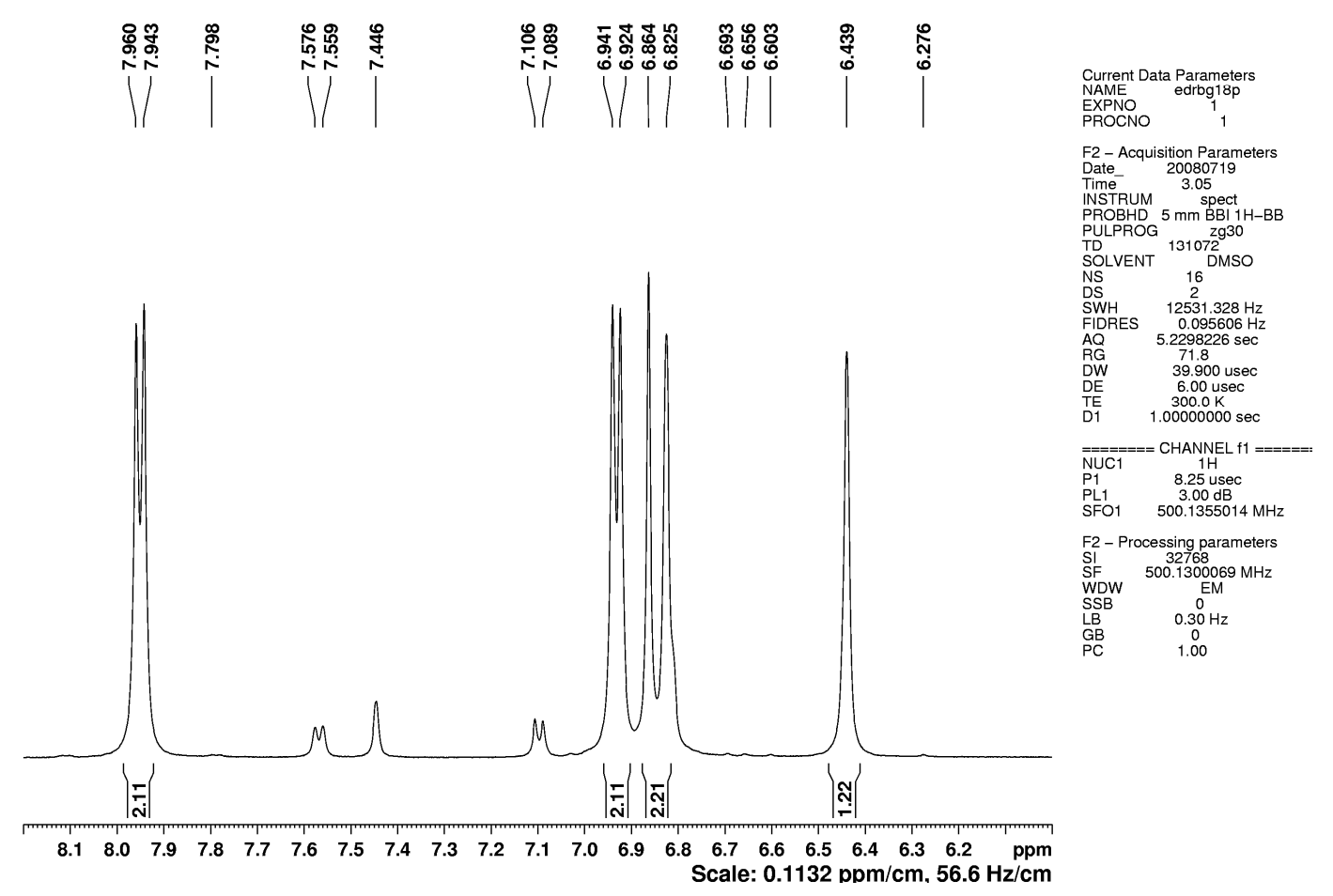


7.2.3.3 Espectro de RMN de $\left.{ }^{13} C^{1}{ }^{1} H\right\}(125 \mathrm{MHz})$ do composto 8 em DMSO-d . $_{\text {. }}$

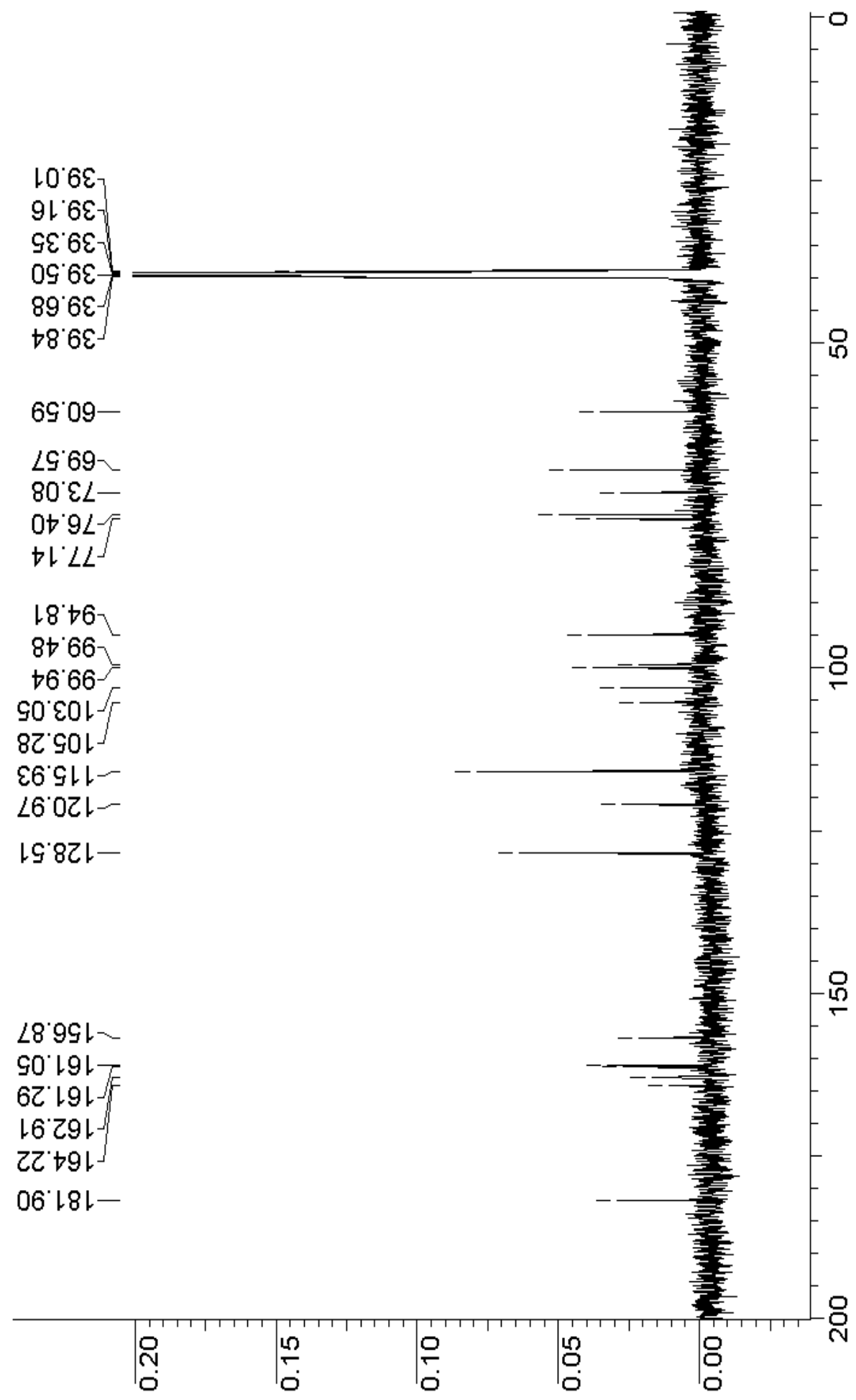


7.2.3.4 Espectro de RMN de ${ }^{13} \mathrm{C}\left(\mathrm{DEPT} 135^{\circ}, 125 \mathrm{MHz}\right)$ do composto 8 em DMSO-d6,.
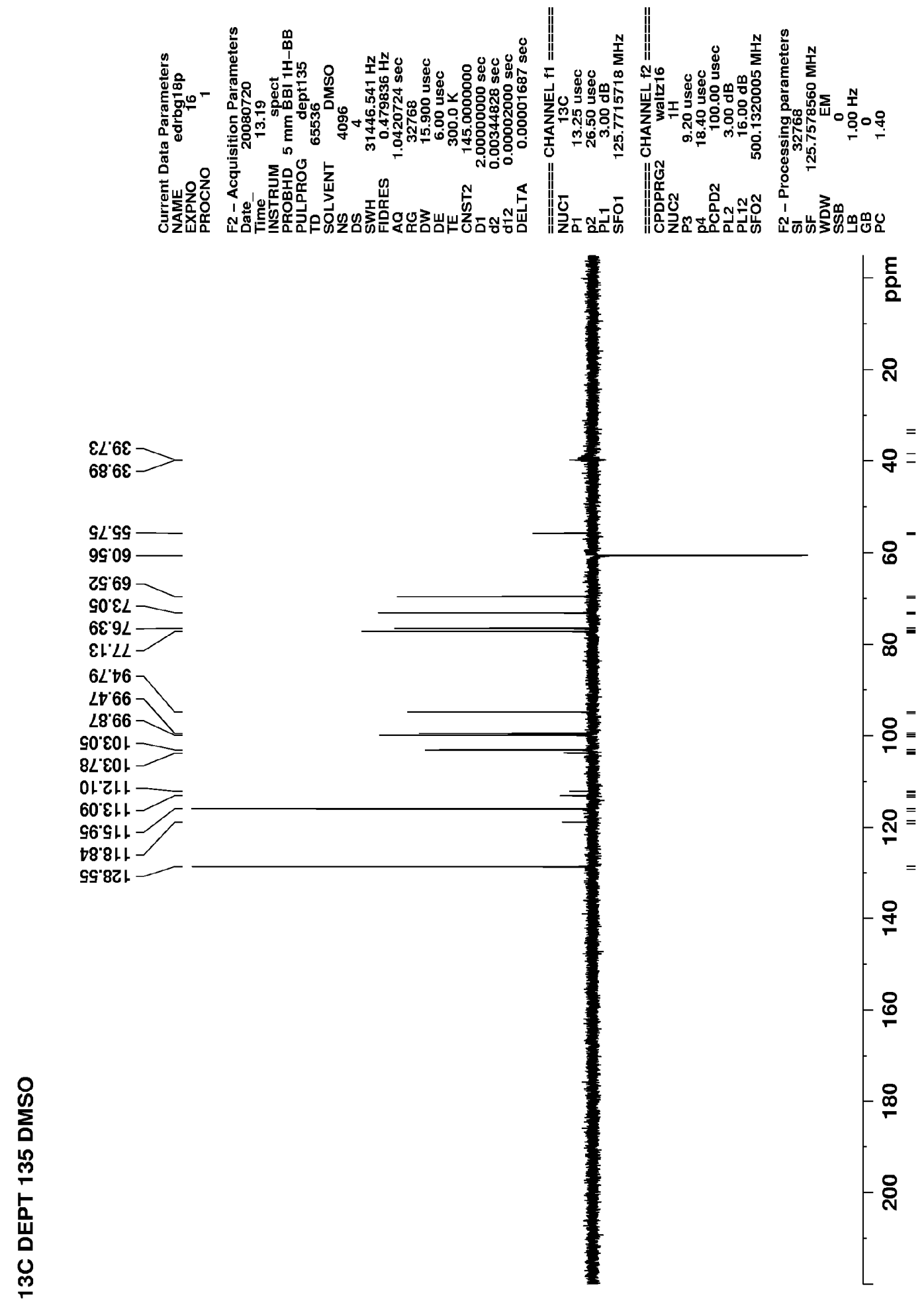
7.2.3.5 Espectro de RMN de ${ }^{13} \mathrm{C}\left(\mathrm{DEPT} 90^{\circ}\right.$, $\left.125 \mathrm{MHz}\right)$ do composto 8 em DMSO-d6,.
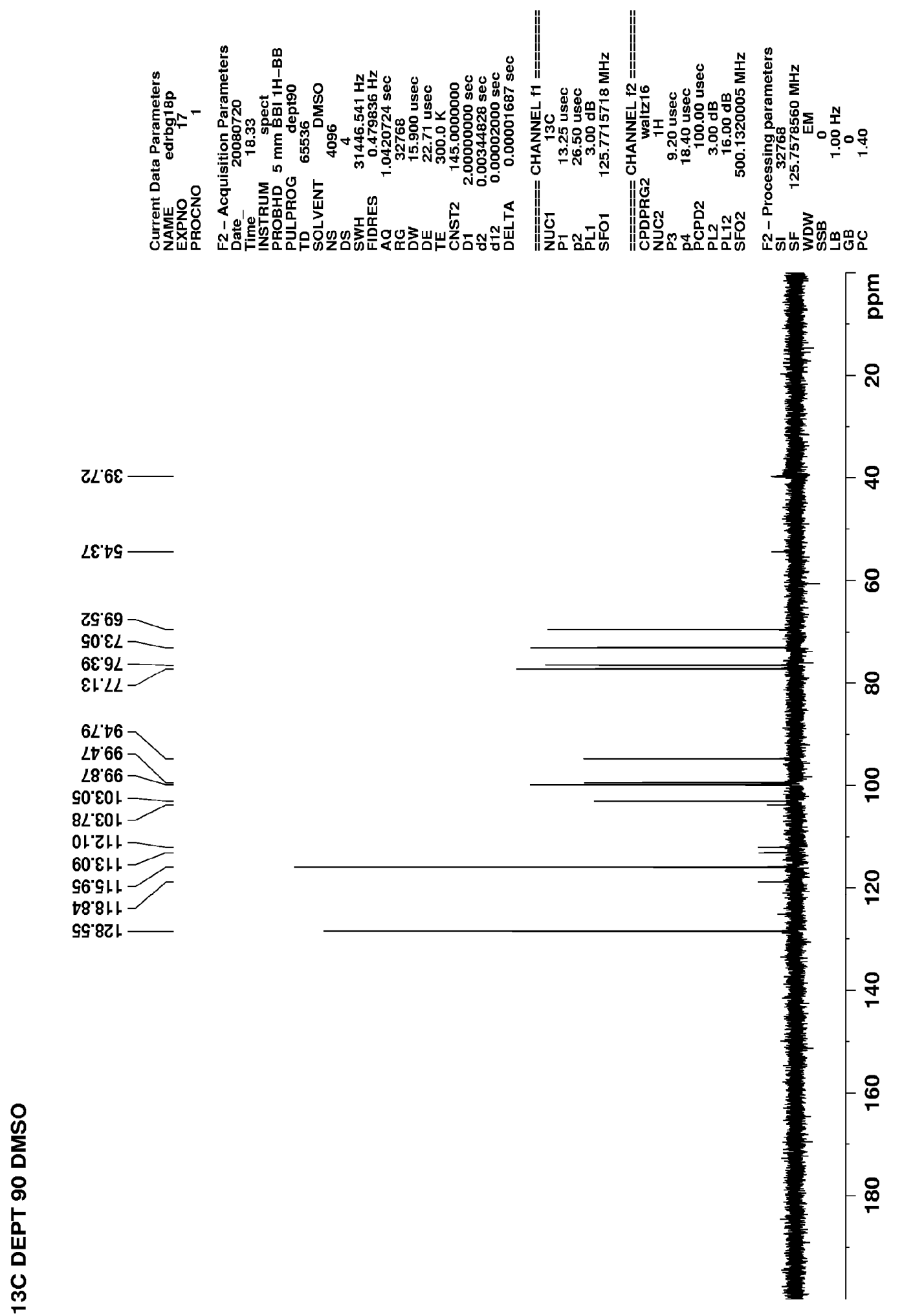
7.2.3.6 Mapas de contorno gerado a partir do experimento $\mathrm{HMQC}\left({ }^{13} \mathrm{C}: 125\right.$ $\mathrm{MHz}$ e ${ }^{1} \mathrm{H}: 500 \mathrm{MHz}$ ) do composto 8 em DMSO-d 6 .

HMQC
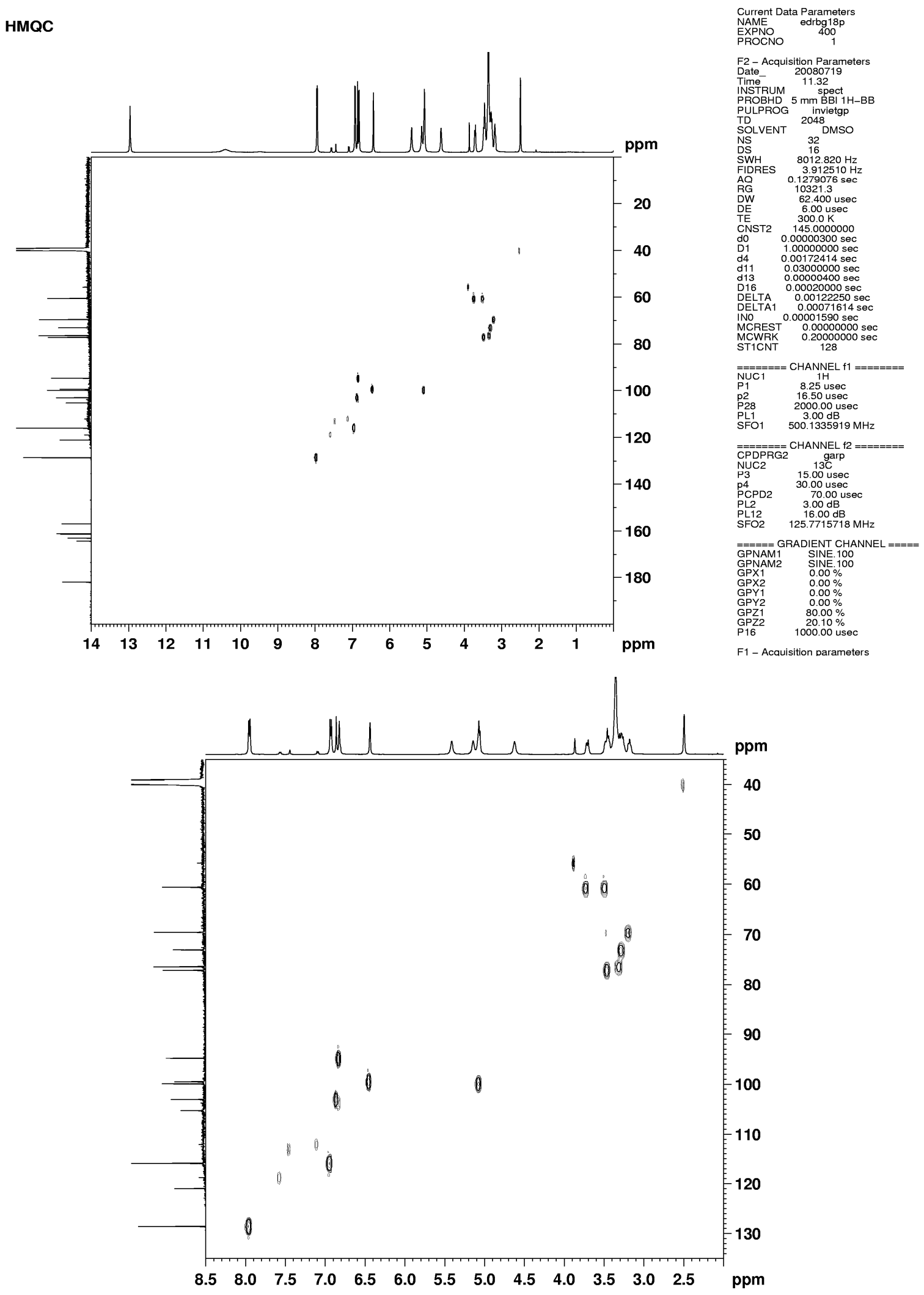
7.2.3.7 Mapas de contorno gerado a partir do experimento $\mathrm{COSY} 90^{\circ}\left({ }^{1} \mathrm{H},{ }^{1} \mathrm{H}\right.$ : $500 \mathrm{MHz}$ ) do composto 8 em DMSO-d.
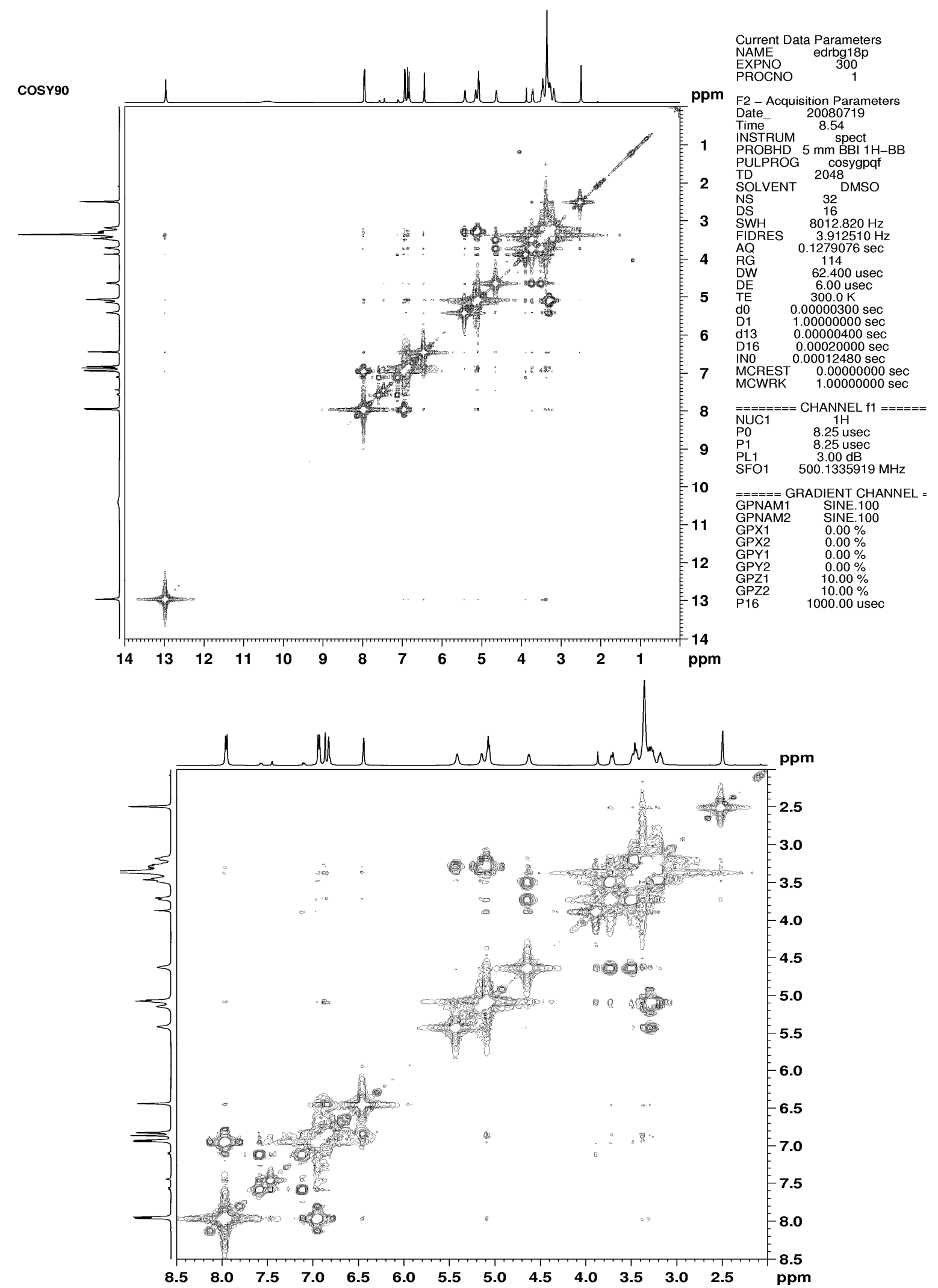
7.2.3.8 Mapa de contorno gerado a partir do experimento $\mathrm{HMBC}\left({ }^{13} \mathrm{C}: 125\right.$ $\mathrm{MHz}$ e ${ }^{1} \mathrm{H}: 500 \mathrm{MHz}$ ), modulado para ${ }^{2} \mathrm{~J}_{\mathrm{CH}}=8 \mathrm{~Hz}$, do composto 8 em DMSO-d ${ }_{6}$.
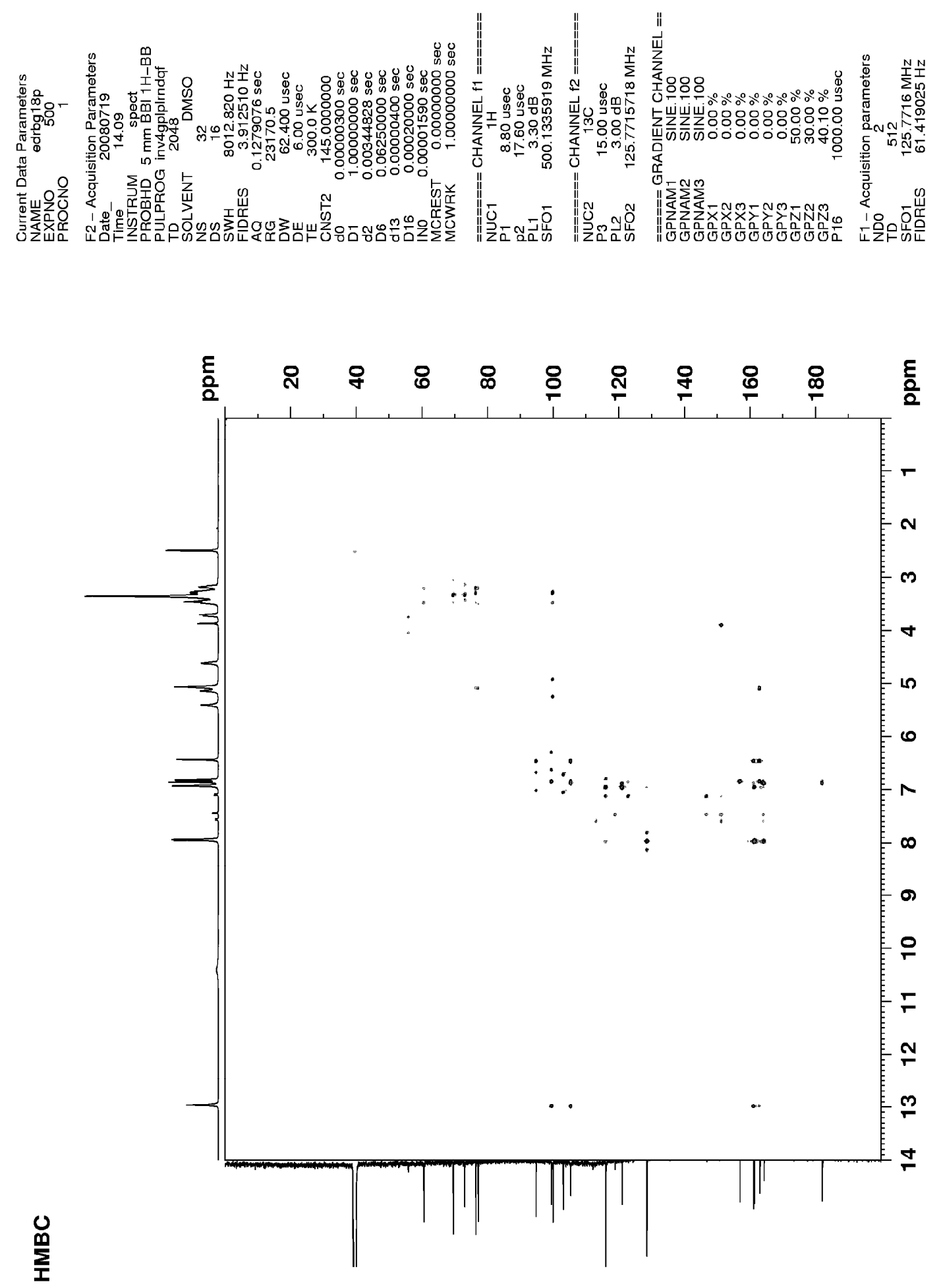
7.2.3.9 Mapa de contorno gerado a partir do experimento $\mathrm{HMBC}\left({ }^{13} \mathrm{C}: 125\right.$ $\mathrm{MHz}$ e ${ }^{1} \mathrm{H}: 500 \mathrm{MHz}$ ), modulado para ${ }^{2} \mathrm{~J}_{\mathrm{CH}}=4 \mathrm{~Hz}$, do composto 8 em DMSO-d ${ }_{6}$.

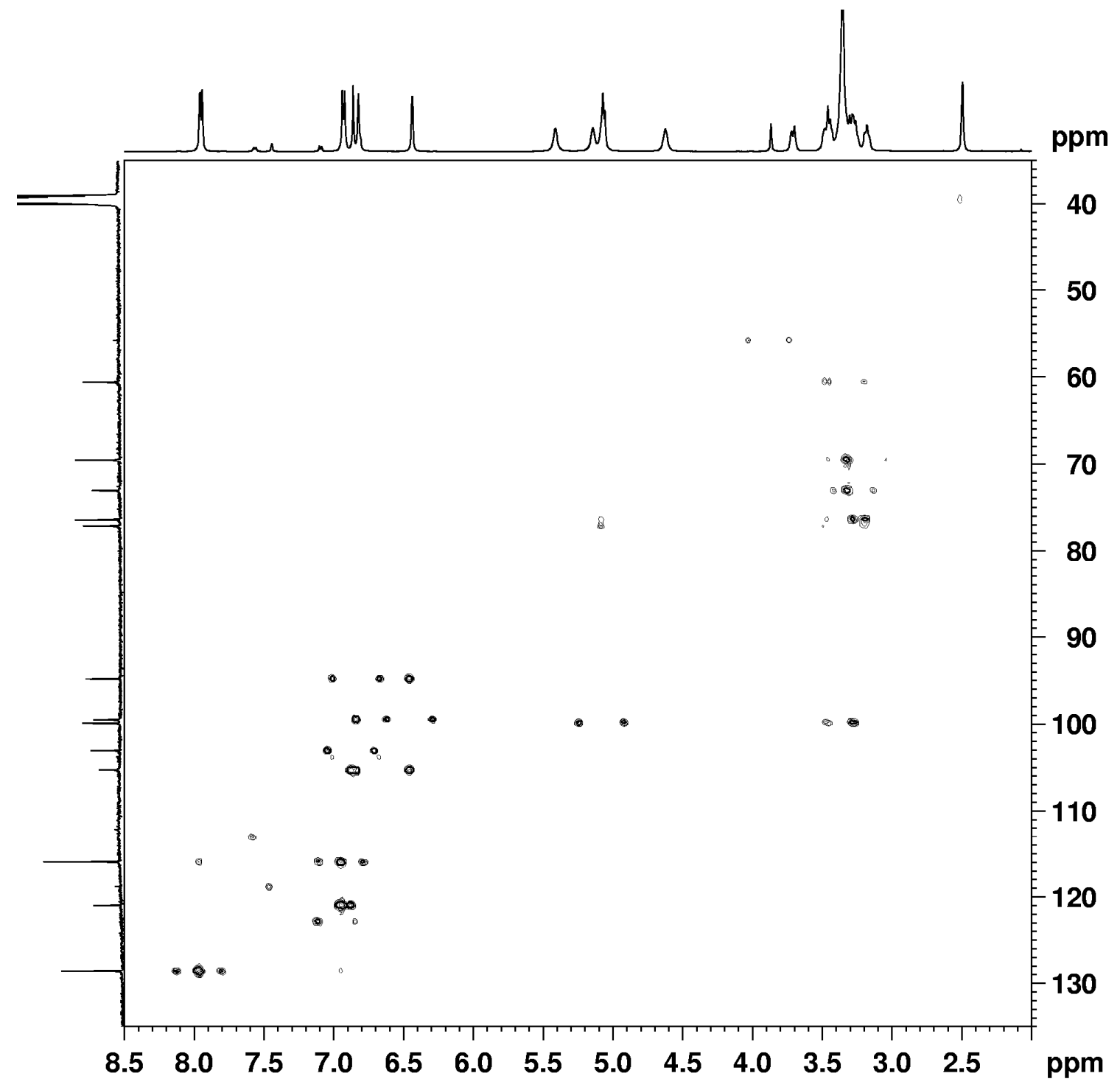


7.2.3.10 Mapa de contorno gerado a partir do experimento g-NOESY $\left({ }^{1} \mathrm{H}: 500\right.$ $\mathrm{MHz}$ ) do composto 8 em DMSO-d . $_{\text {. }}$
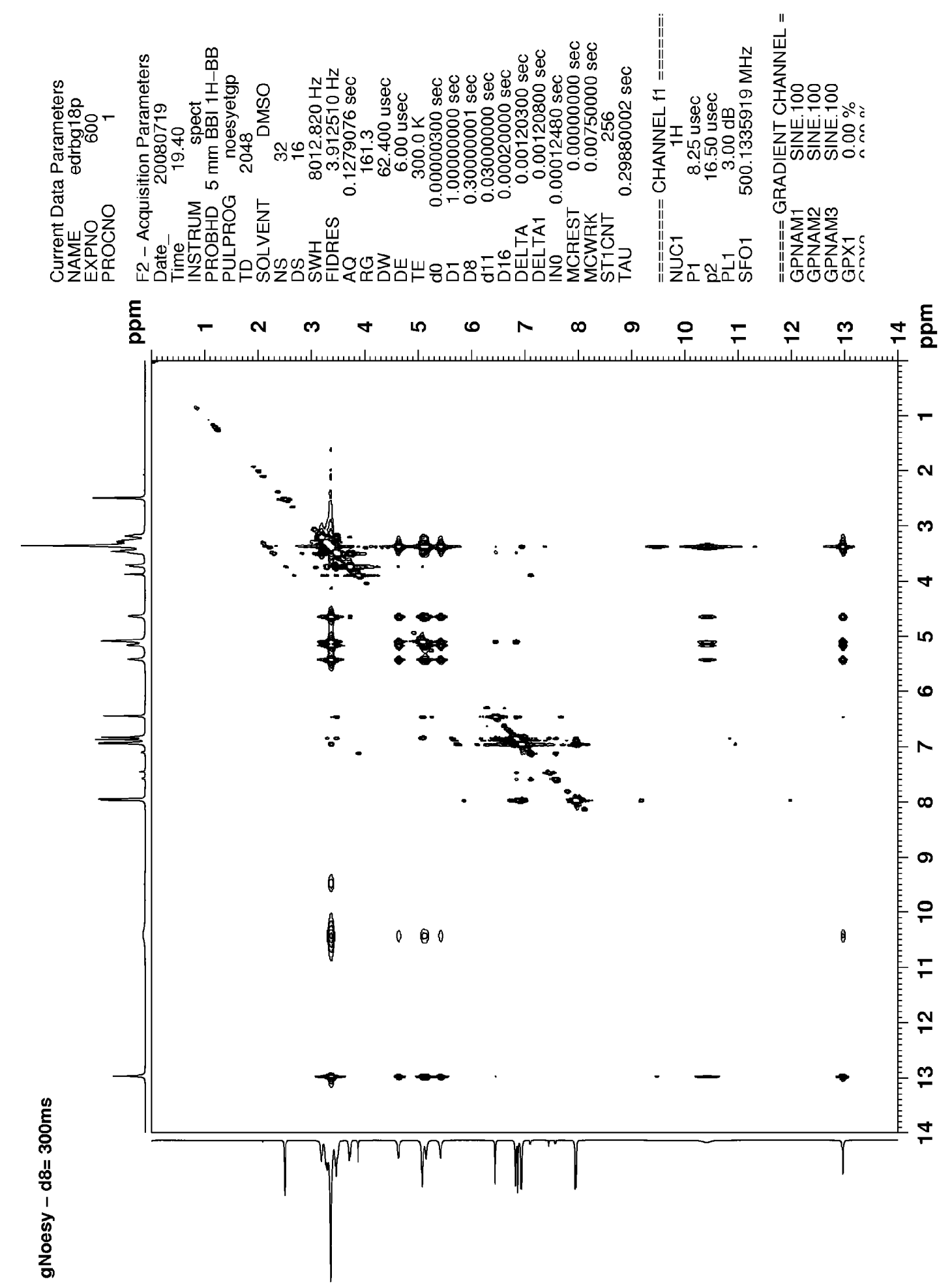
7.2.3.11 Ampliação do mapa de contorno gerado a partir do experimento gNOESY ( $\left.{ }^{1} \mathrm{H}: 500 \mathrm{MHz}\right)$ do composto 8 em DMSO-d ${ }_{6}$.

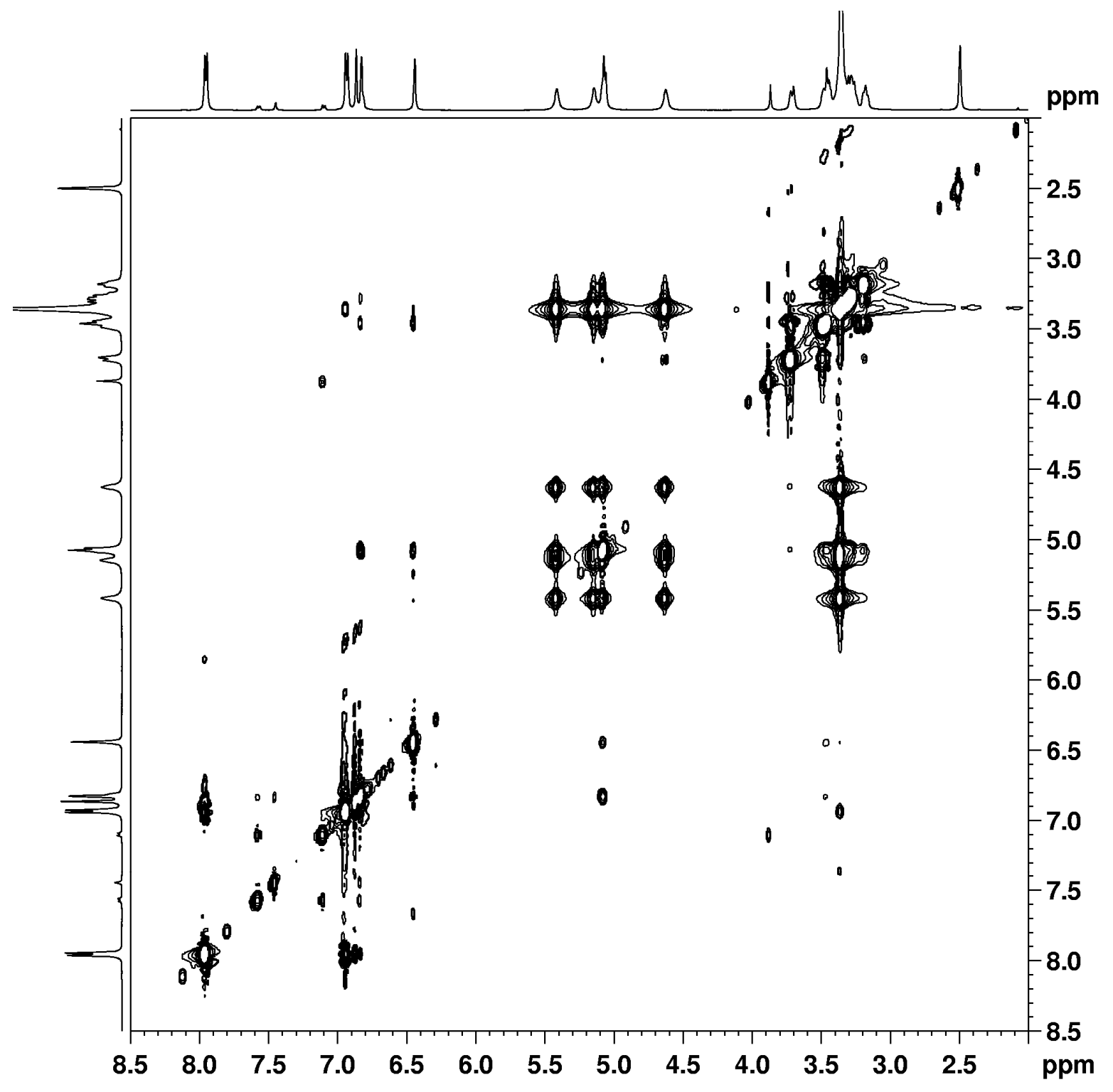


7.2.3.12 Mapa de contorno gerado a partir do experimento $\mathrm{ROESY}\left[{ }^{1} \mathrm{H},{ }^{1} \mathrm{H}\right] \mathrm{do}$ composto 8 em DMSO-d6, ( $\left.{ }^{1} \mathrm{H}: 500 \mathrm{MHz}\right)$
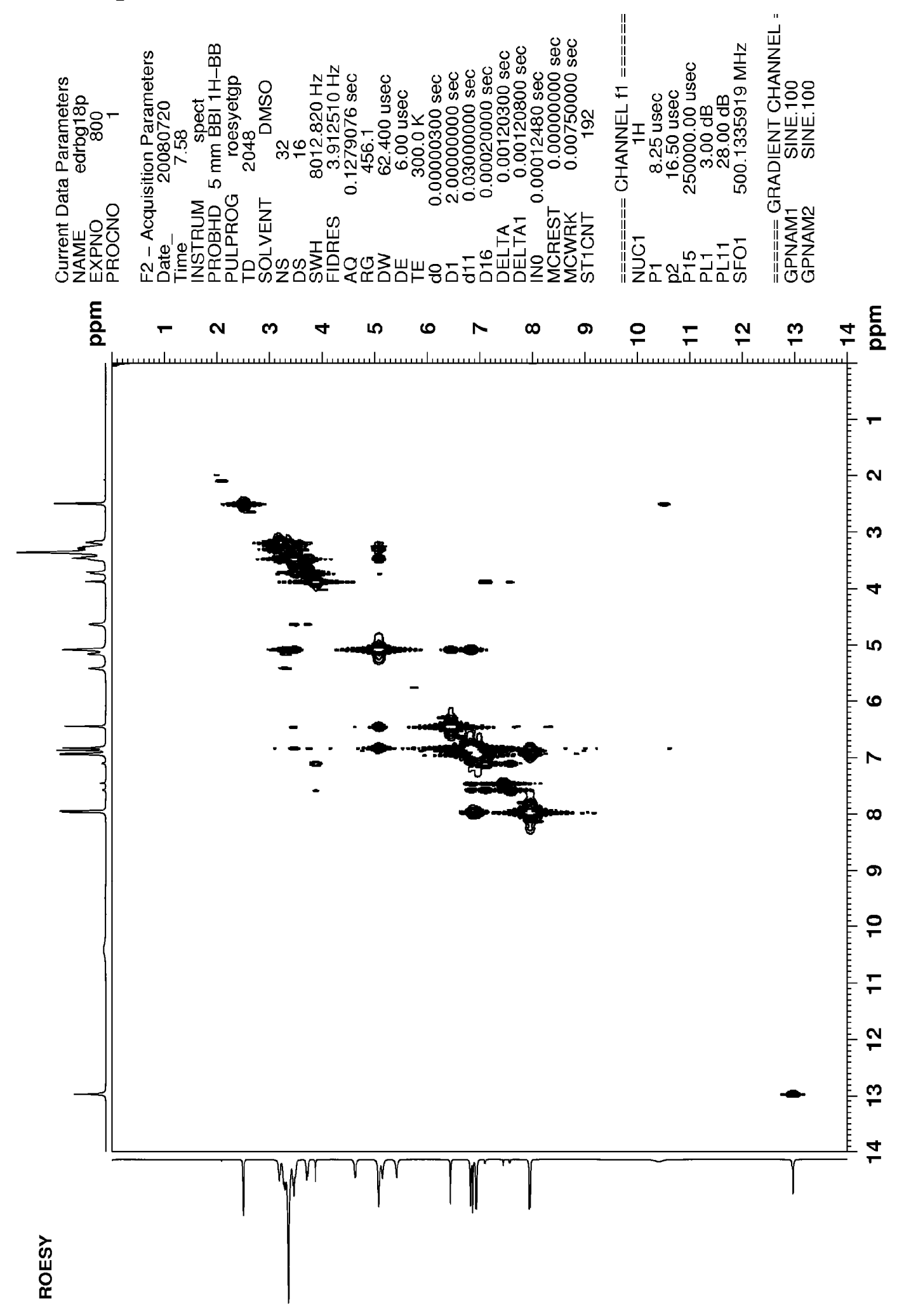
7.2.3.13 Ampliação do mapa de contorno gerado a partir do experimento ROESY $\left[{ }^{1} \mathrm{H},{ }^{1} \mathrm{H}\right]$ do composto 8 em DMSO-d6, ( $\left.{ }^{1} \mathrm{H}: 500 \mathrm{MHz}\right)$

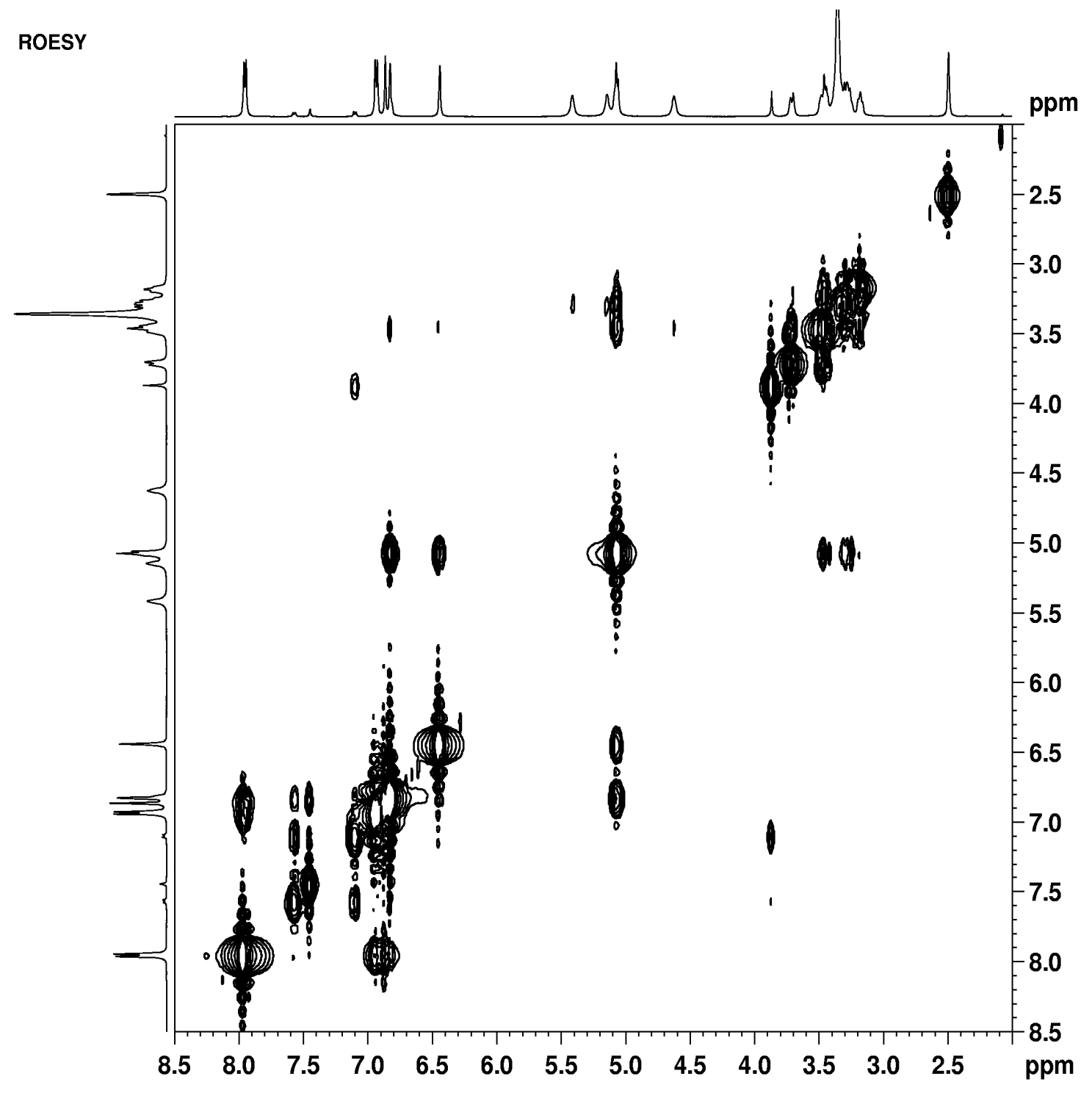




\subsubsection{Dados de RMN do composto 9:}

\subsubsection{Espectro de RMN de ${ }^{1} \mathrm{H}$ do composto 9 em DMSO-d6, $500 \mathrm{MHz}$.}
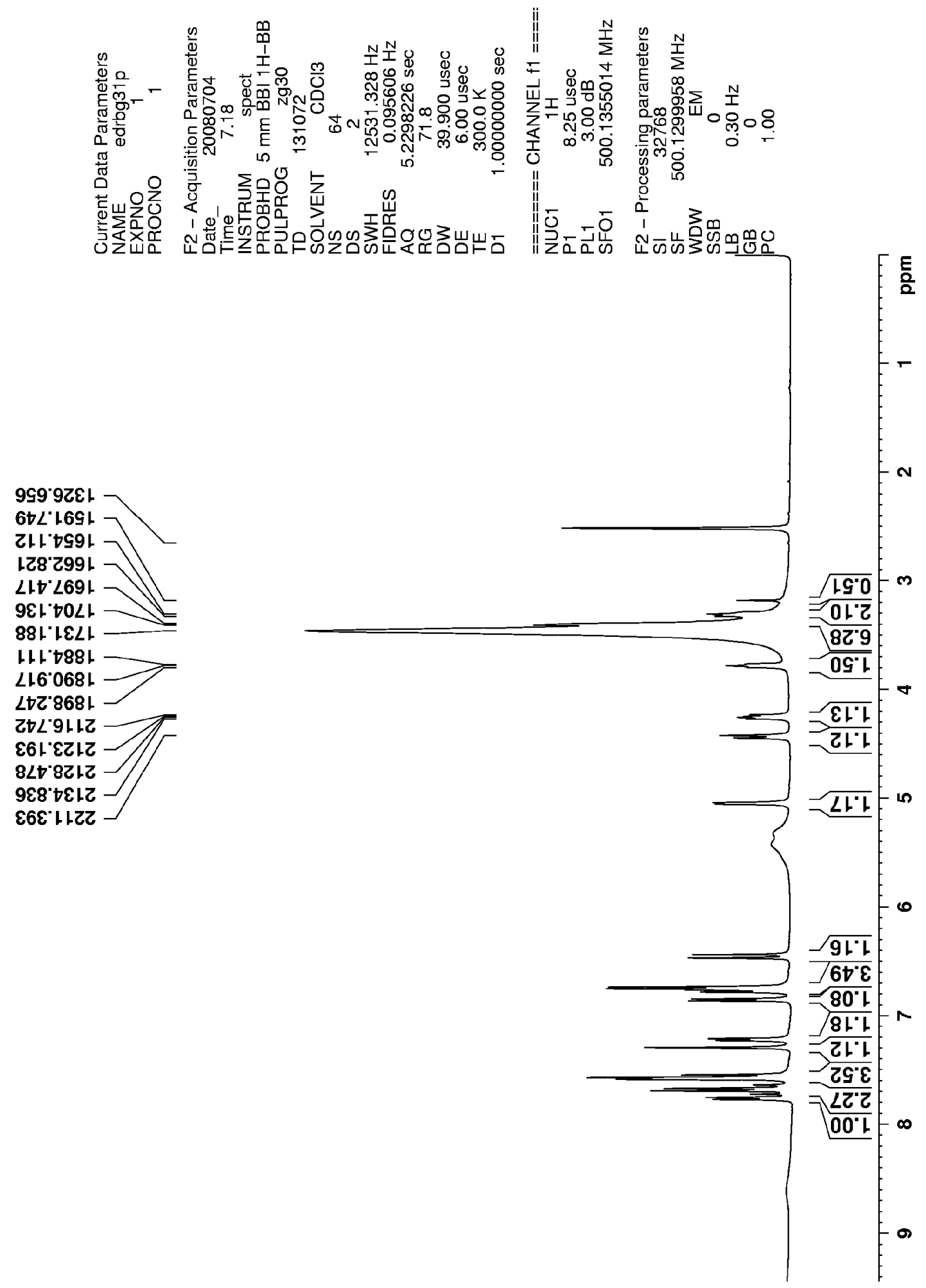


\subsubsection{Ampliações do Espectro de RMN de ${ }^{1} \mathrm{H}$ do composto 9 em DMSO-d6,} $500 \mathrm{MHz}$.

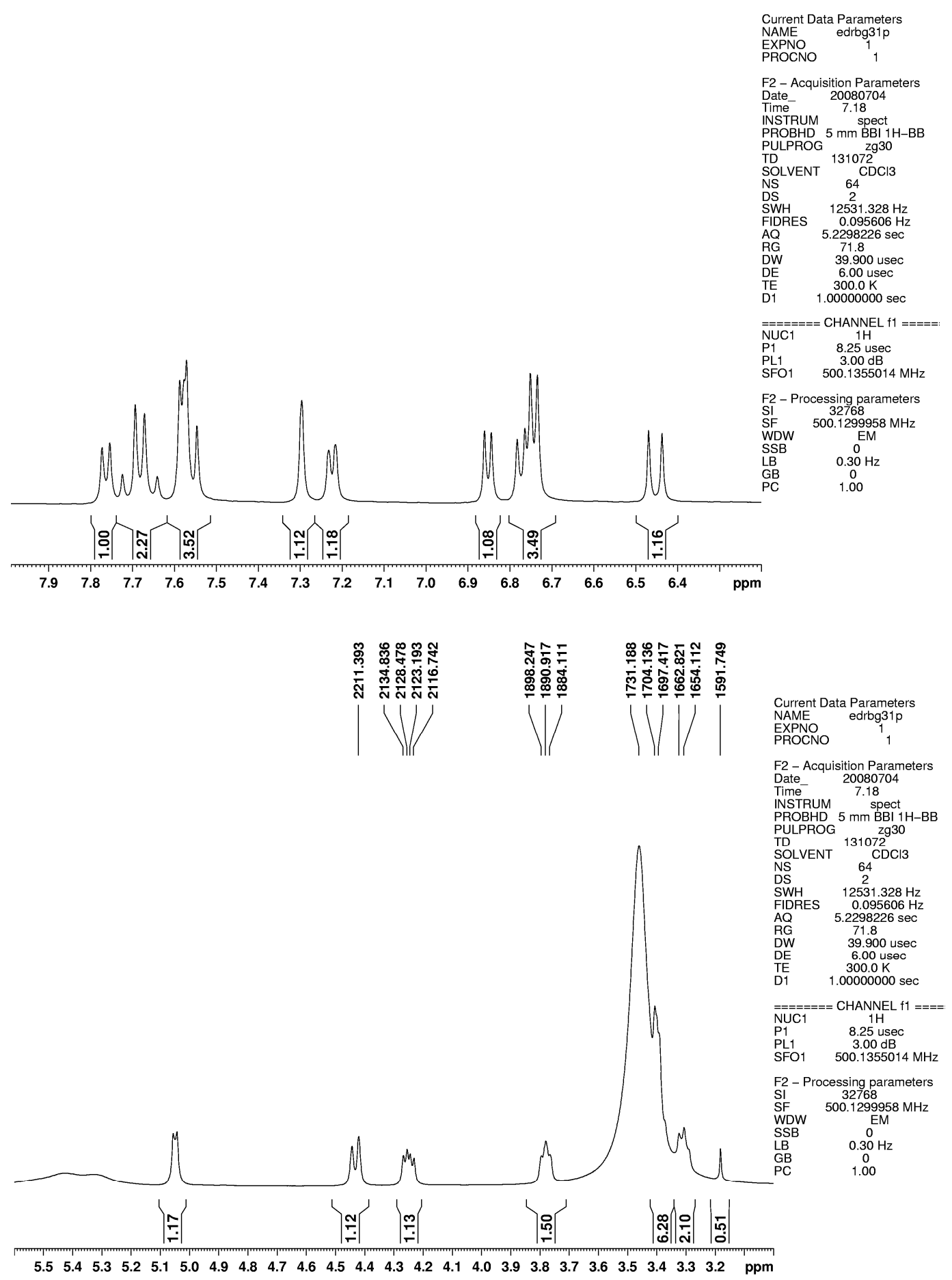


7.2.4.3 Espectro de RMN de $\left.{ }^{13} C_{\{}{ }^{l} \mathrm{H}\right\}(125 \mathrm{MHz})$ do composto 9 em DMSO-d

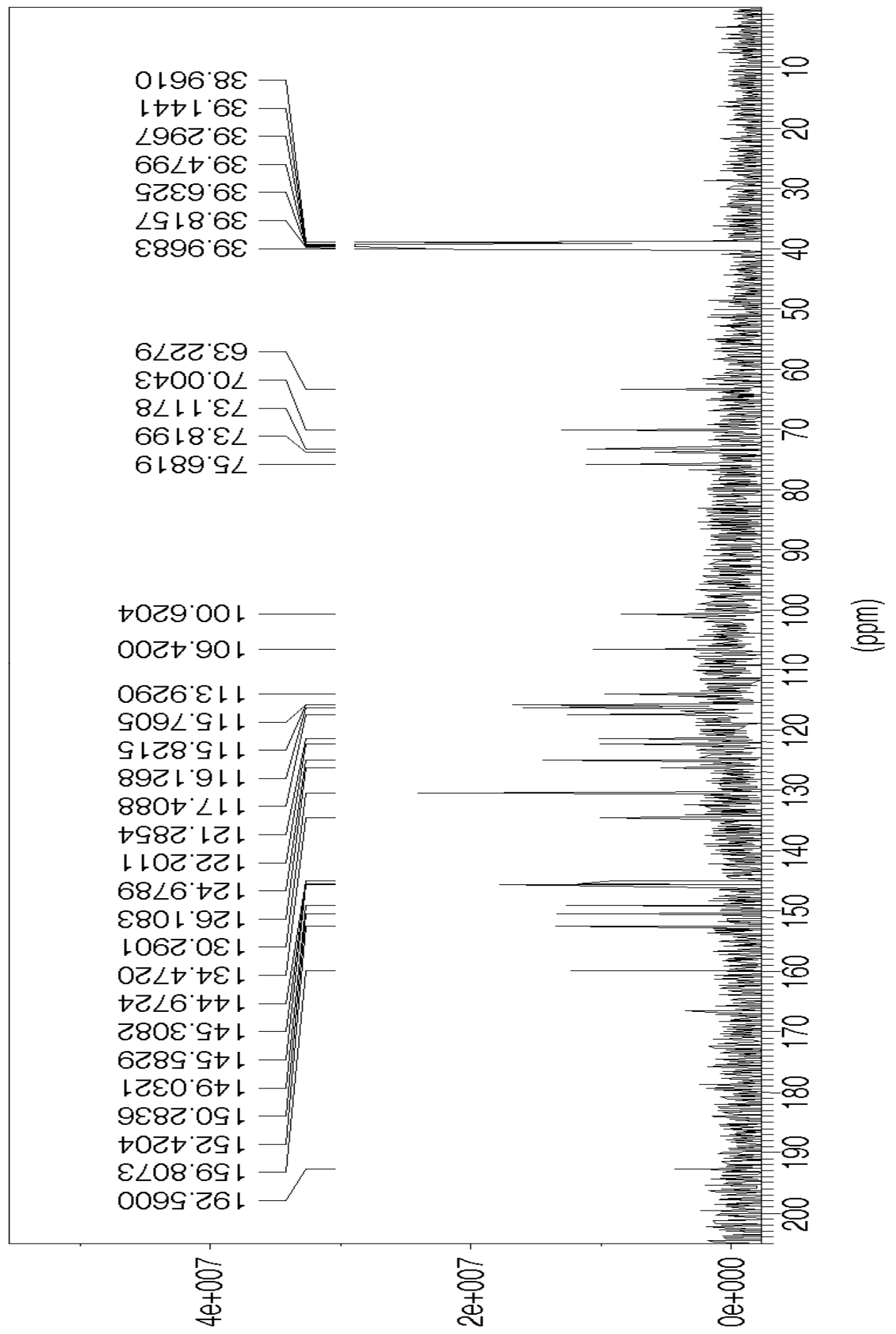


7.2.4.4 Espectro de RMN de ${ }^{13} \mathrm{C}\left(\mathrm{DEPT} 135^{\circ}, 125 \mathrm{MHz}\right)$ do composto $9 \mathrm{em}$ DMSO-d $d_{6}$.
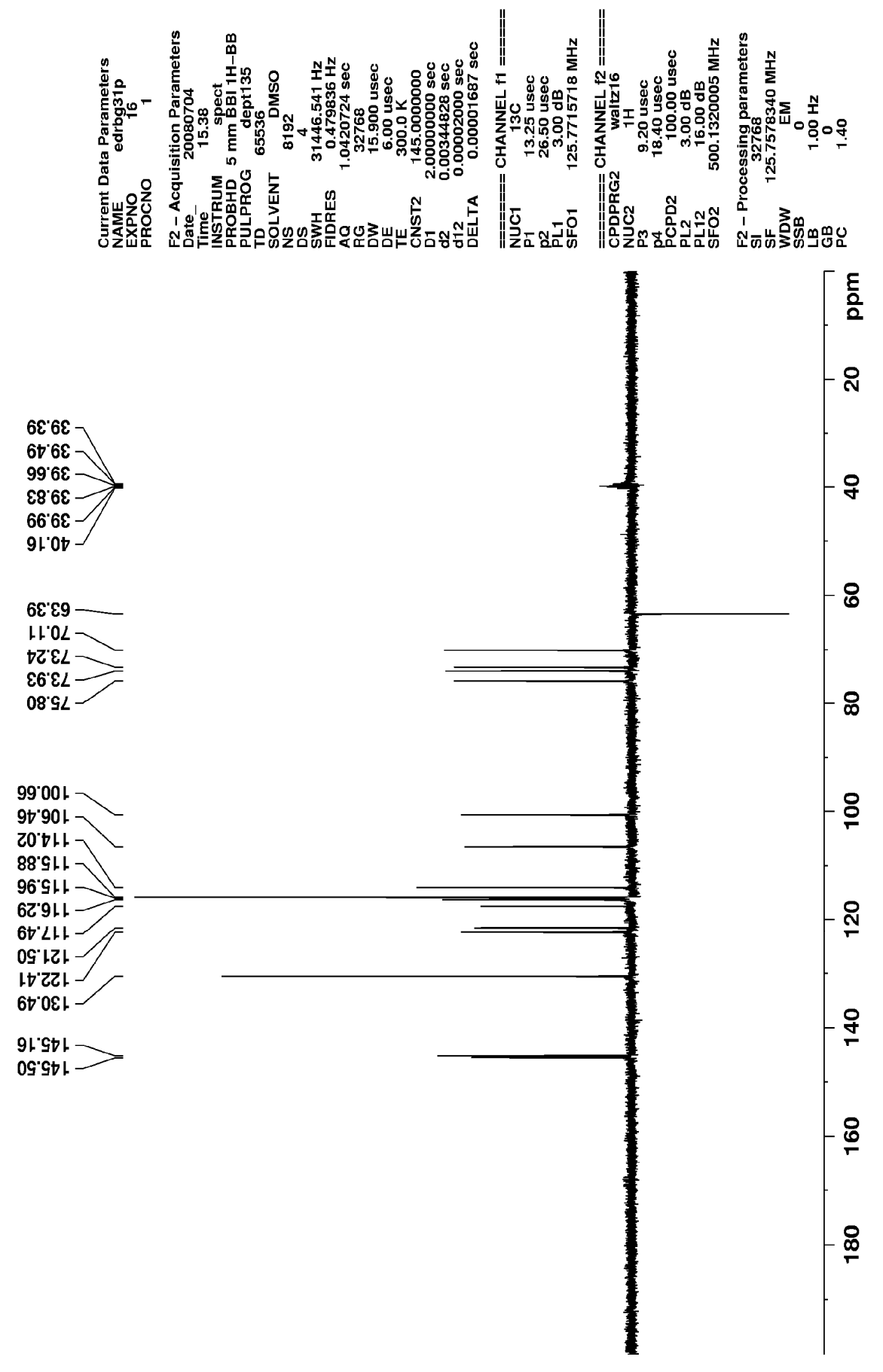

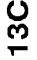


7.2.4.5 Mapa de contorno gerado a partir do experimento HMQC $\left({ }^{13} \mathrm{C}: 125\right.$ MHz e ${ }^{1} \mathrm{H}: 500 \mathrm{MHz}$ ) do composto 9 em DMSO-d ${ }_{6}$.

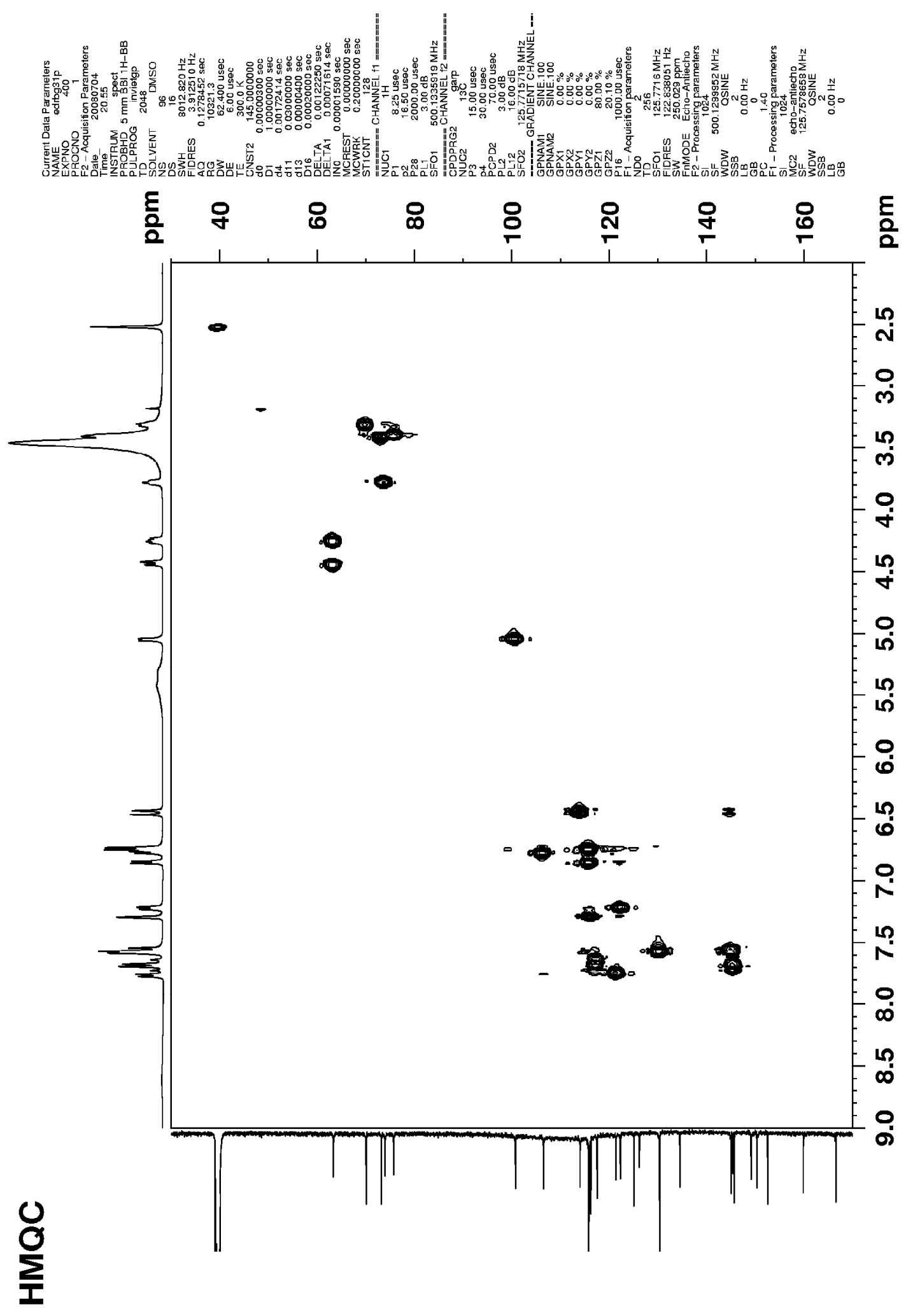


7.2.4.6 Mapa de contorno gerado a partir do experimento $\mathrm{COSY} 90^{\circ}\left({ }^{1} \mathrm{H},{ }^{1} \mathrm{H}\right.$, $500 \mathrm{MHz}$ ) do composto 9 em DMSO-d .
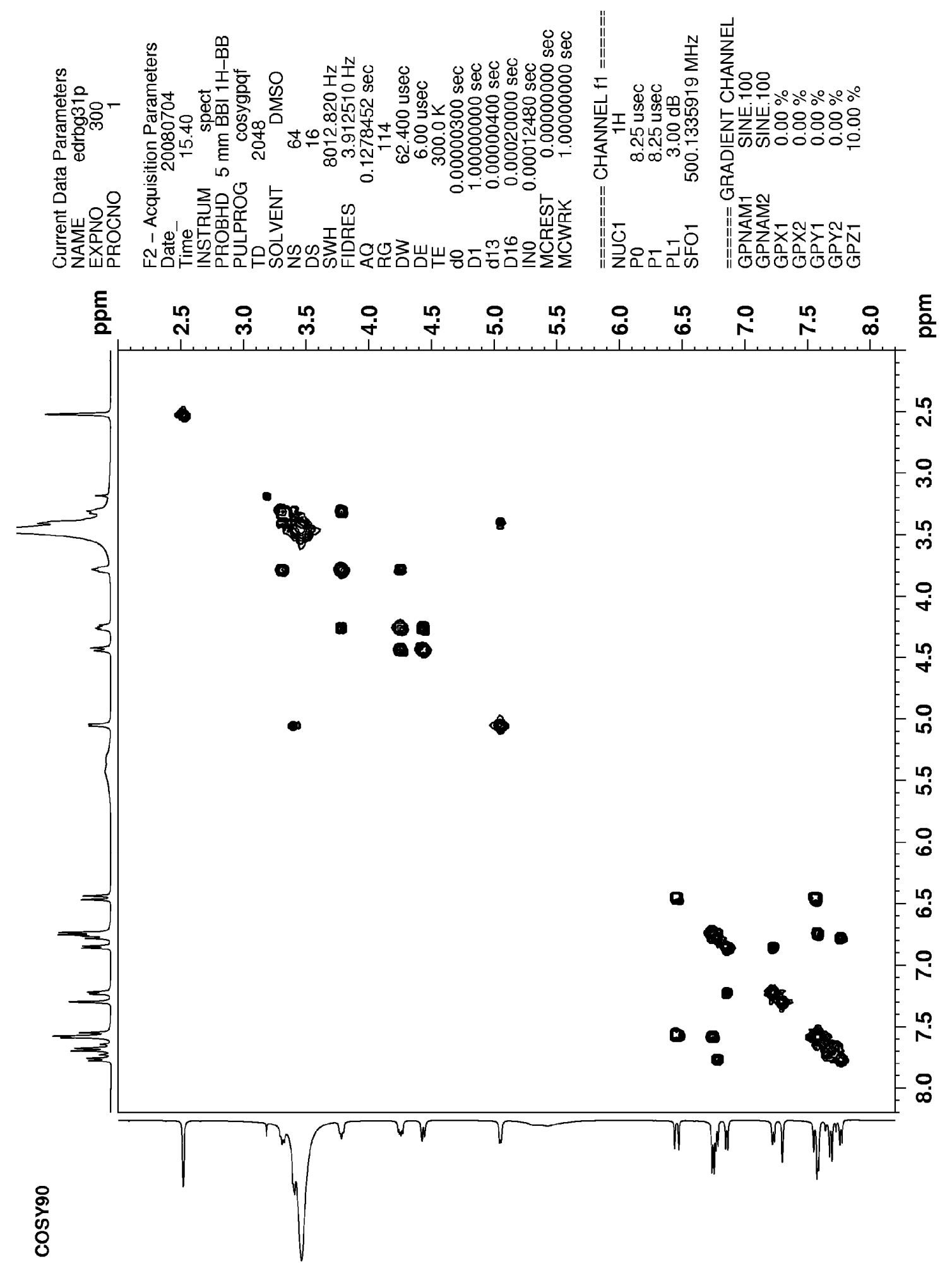
7.2.4.7 Mapa de contorno gerado a partir do experimento HMBC $\left({ }^{13} \mathrm{C}: 125\right.$ $\mathrm{MHz}$ e $\left.{ }^{1} \mathrm{H}: 500 \mathrm{MHz}\right)$, modulado para ${ }^{2} J_{C H}=8 \mathrm{~Hz}$, do composto 9 em DMSO-d . $^{2}$
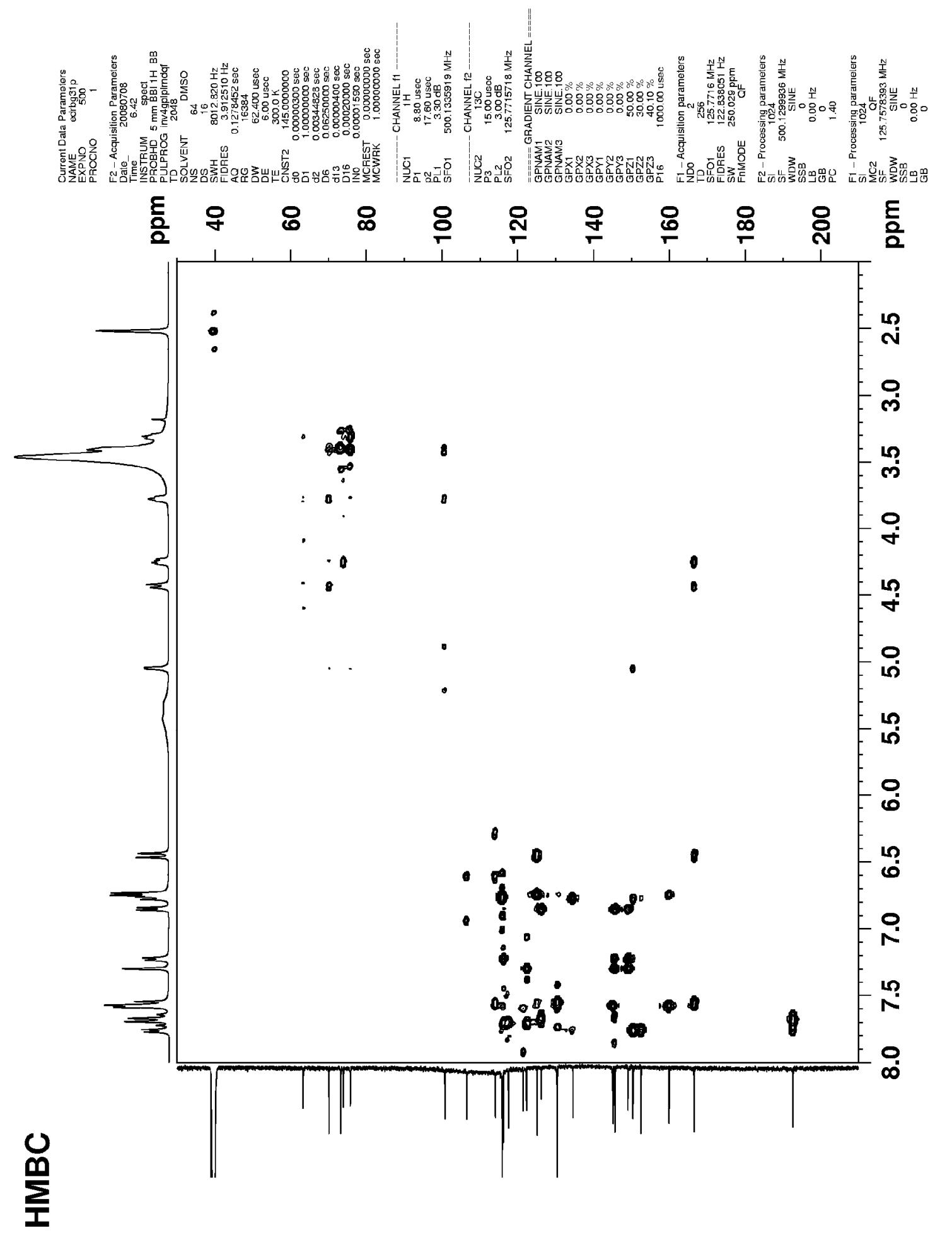


\subsubsection{Dados de RMN do composto 10:}

\subsubsection{Espectro de RMN de ${ }^{1} \mathrm{H}(500 \mathrm{MHz})$ do composto 10 em DMSO-d . $^{\circ}$}
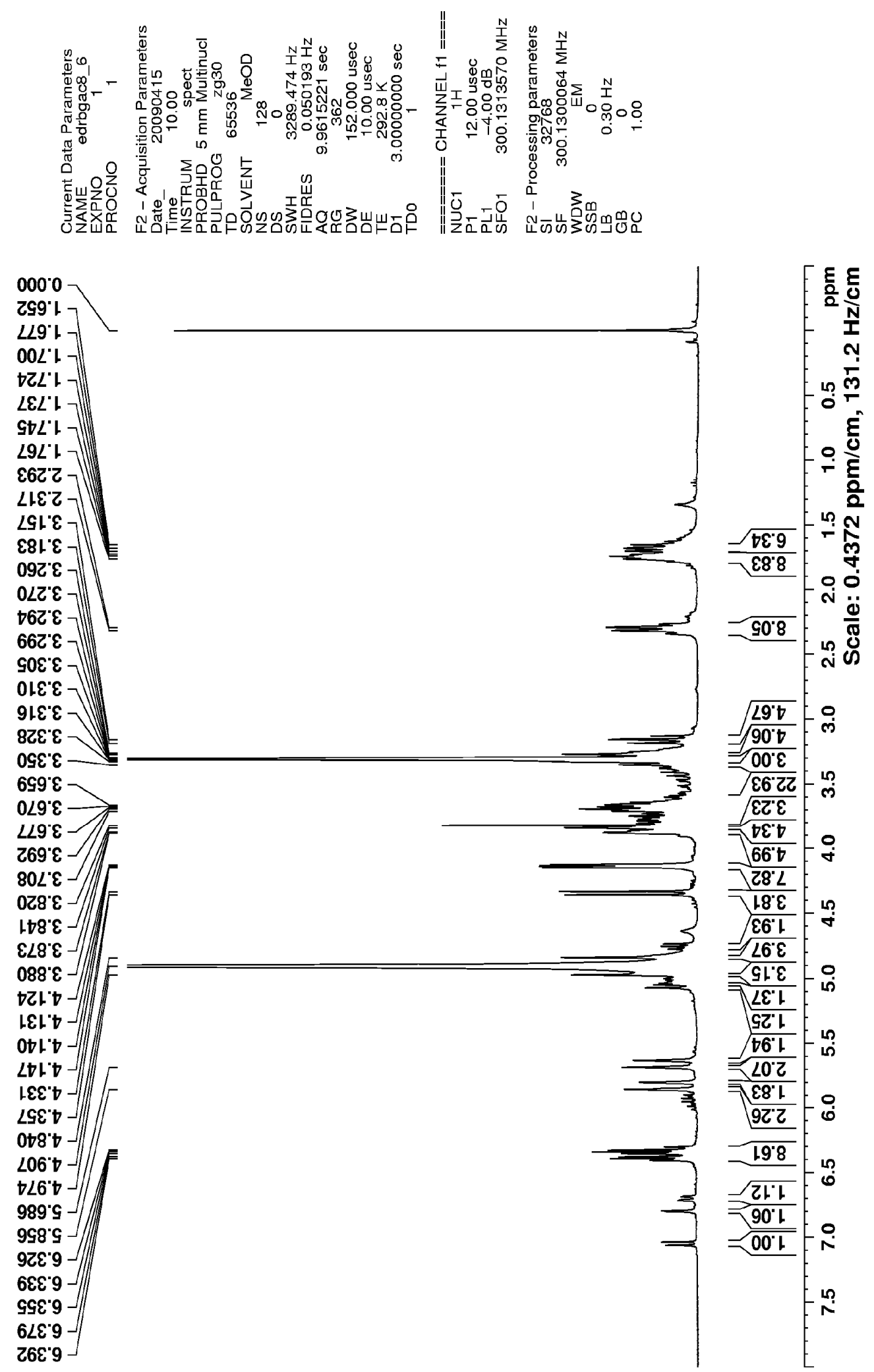


\subsubsection{Ampliações do Espectro de RMN de ${ }^{1} \mathrm{H}(500 \mathrm{MHz})$ do composto 10 em DMSO-d .}
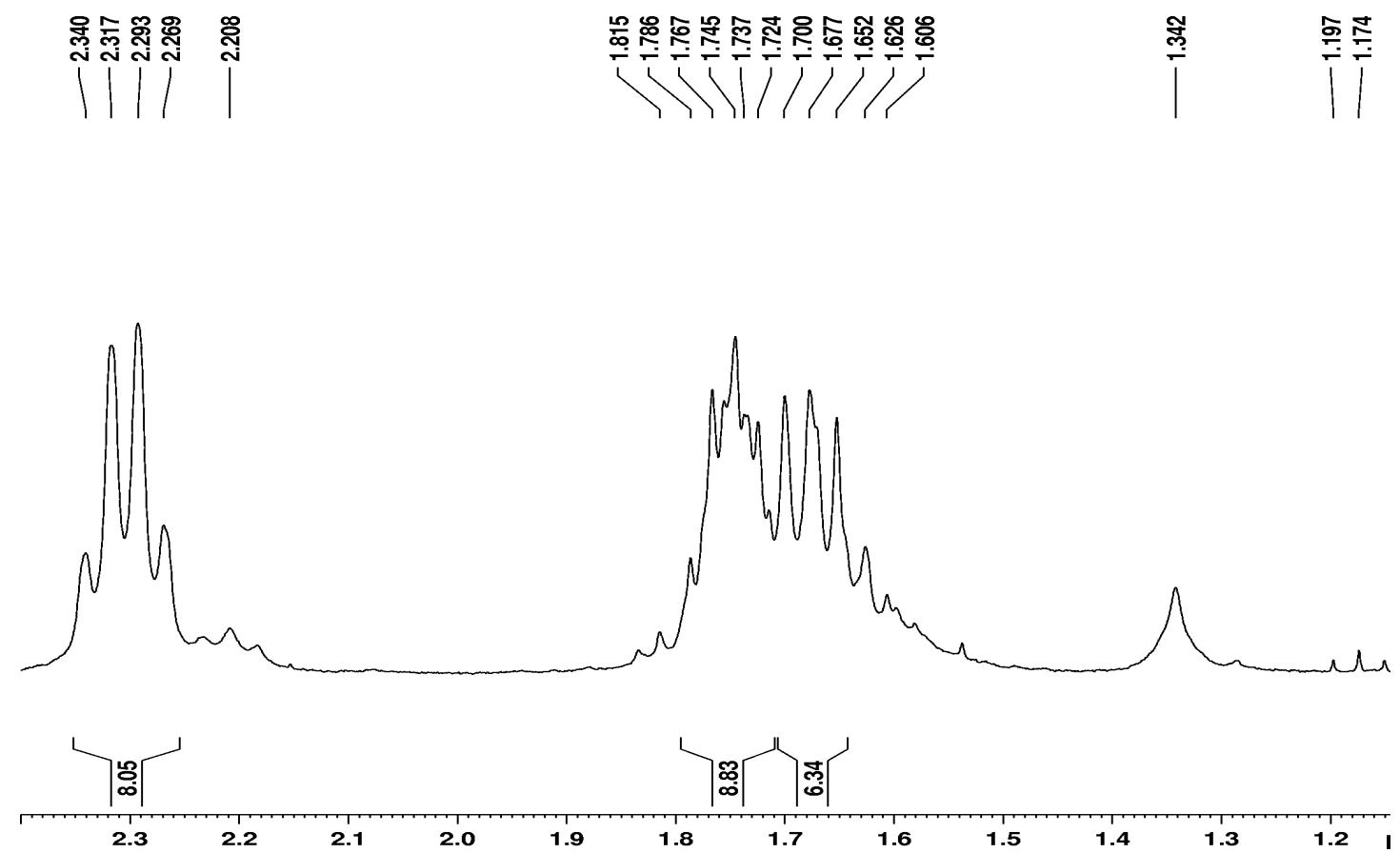

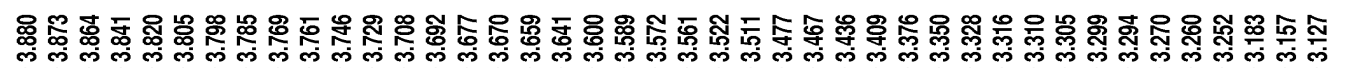

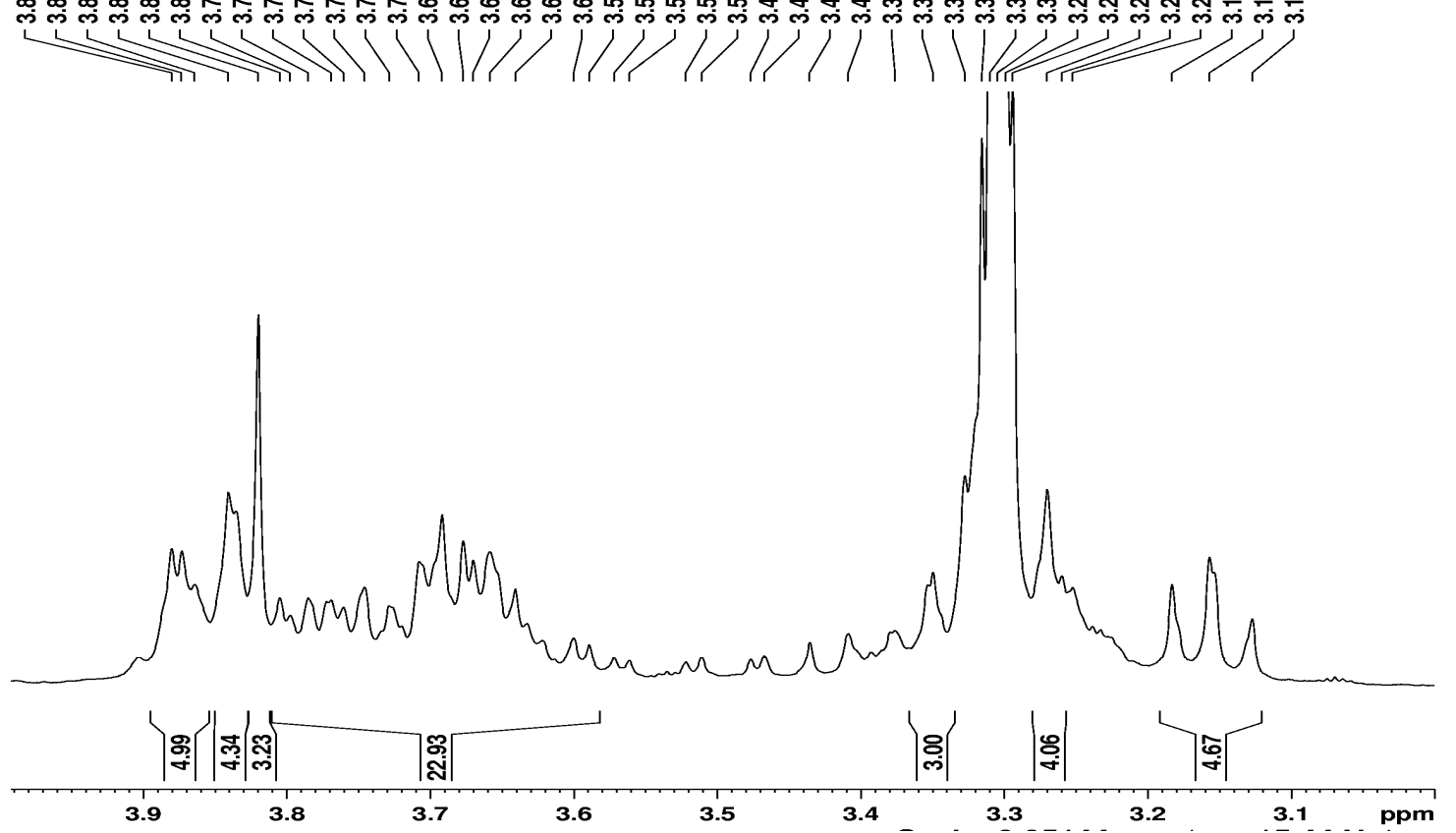


7.2.5.3 Ampliações do Espectro de RMN de ${ }^{1} \mathrm{H}(500 \mathrm{MHz})$ do composto 10 em DMSO-d . $_{\text {. }}$
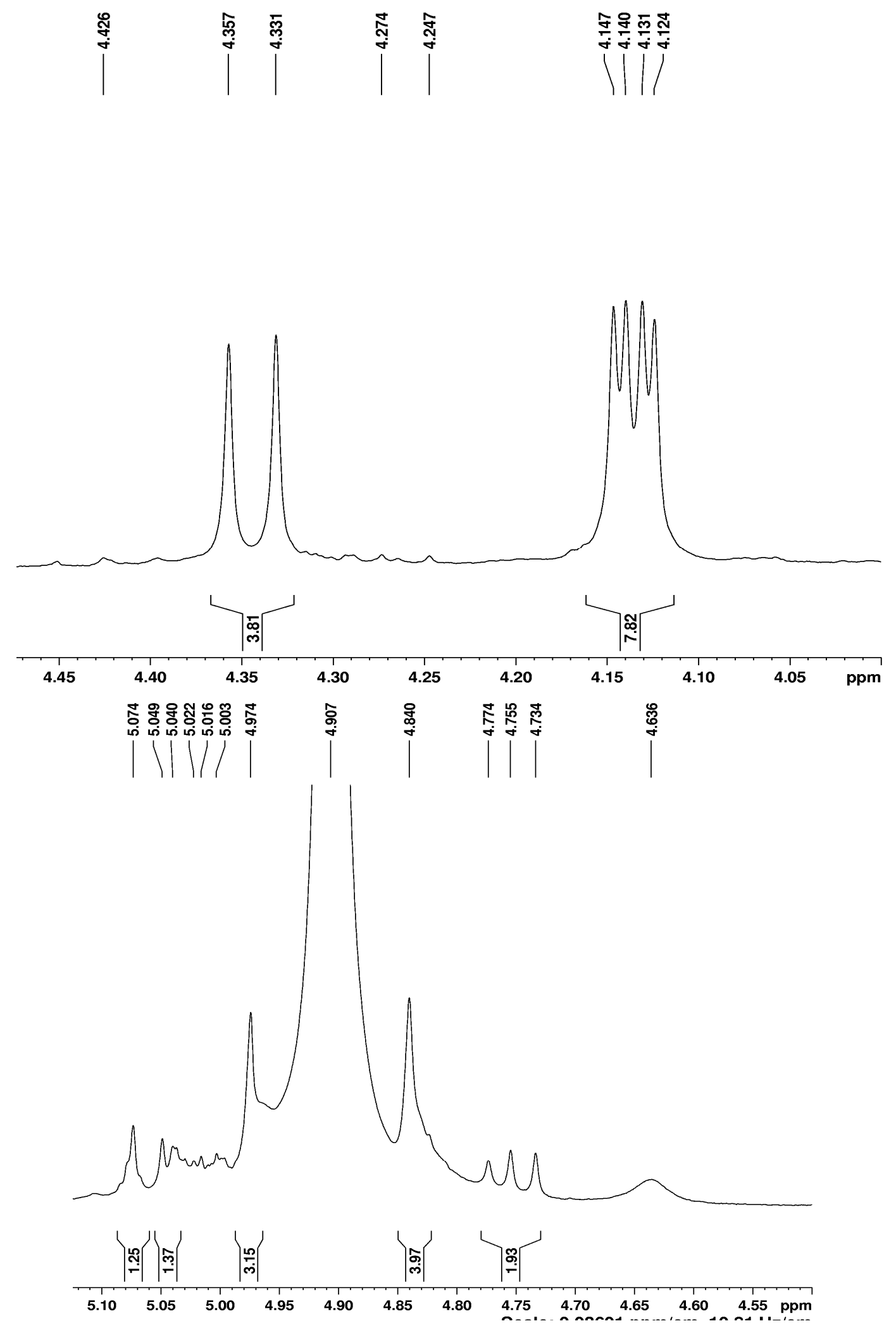

Estratégias de aumento de eficiência da análise de produtos naturais por $\mathbb{R M M}$ 
7.2.5.4 Ampliações do Espectro de RMN de ${ }^{1} \mathrm{H}(500 \mathrm{MHz})$ do composto $10 \mathrm{em}$ DMSO-d .

|
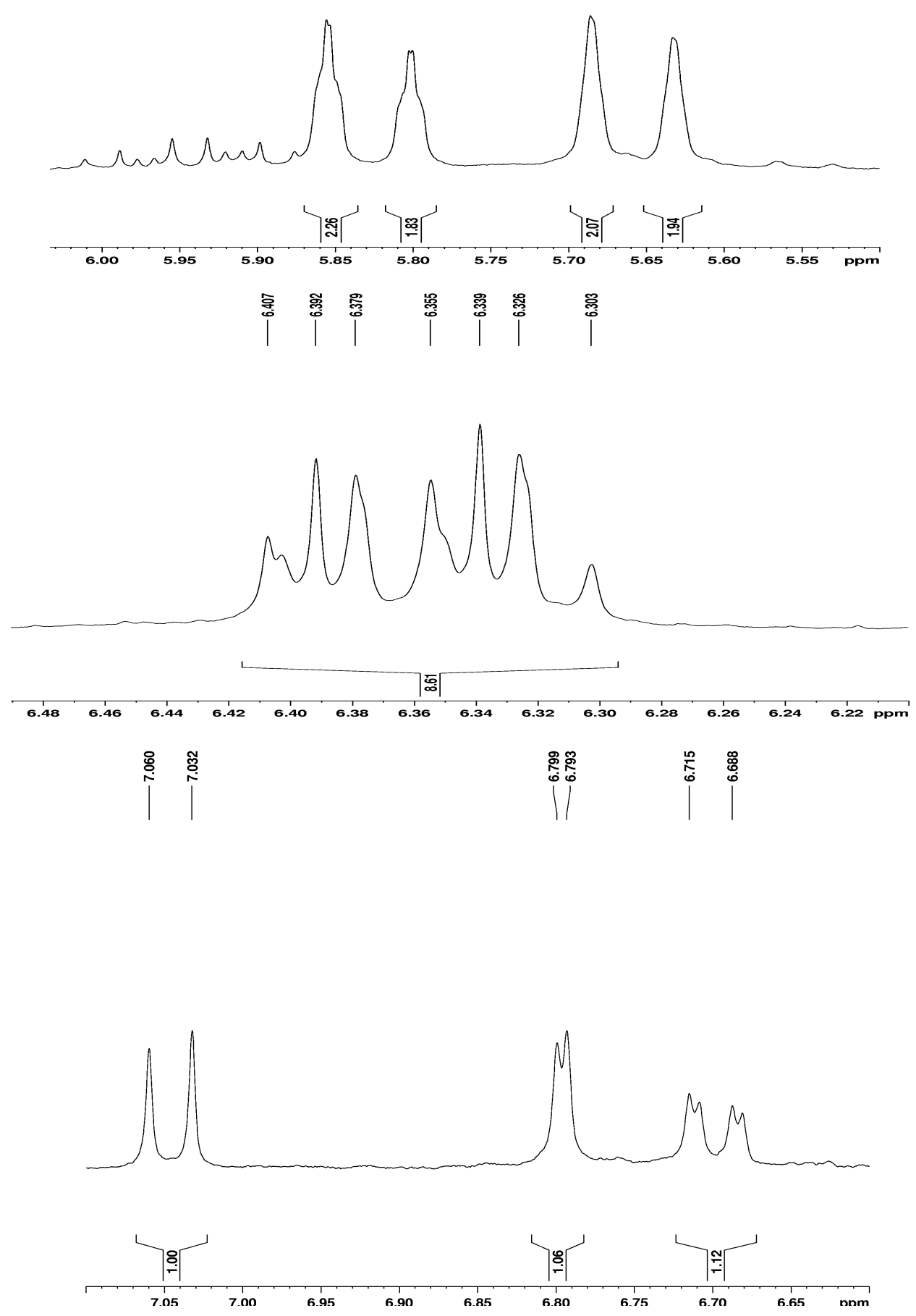
7.2.5.5 Espectro de RMN de $\left.{ }^{13} C_{\{}{ }^{1} H\right\}(125 \mathrm{MHz})$ do composto 10 em DMSO-d . $^{\circ}$
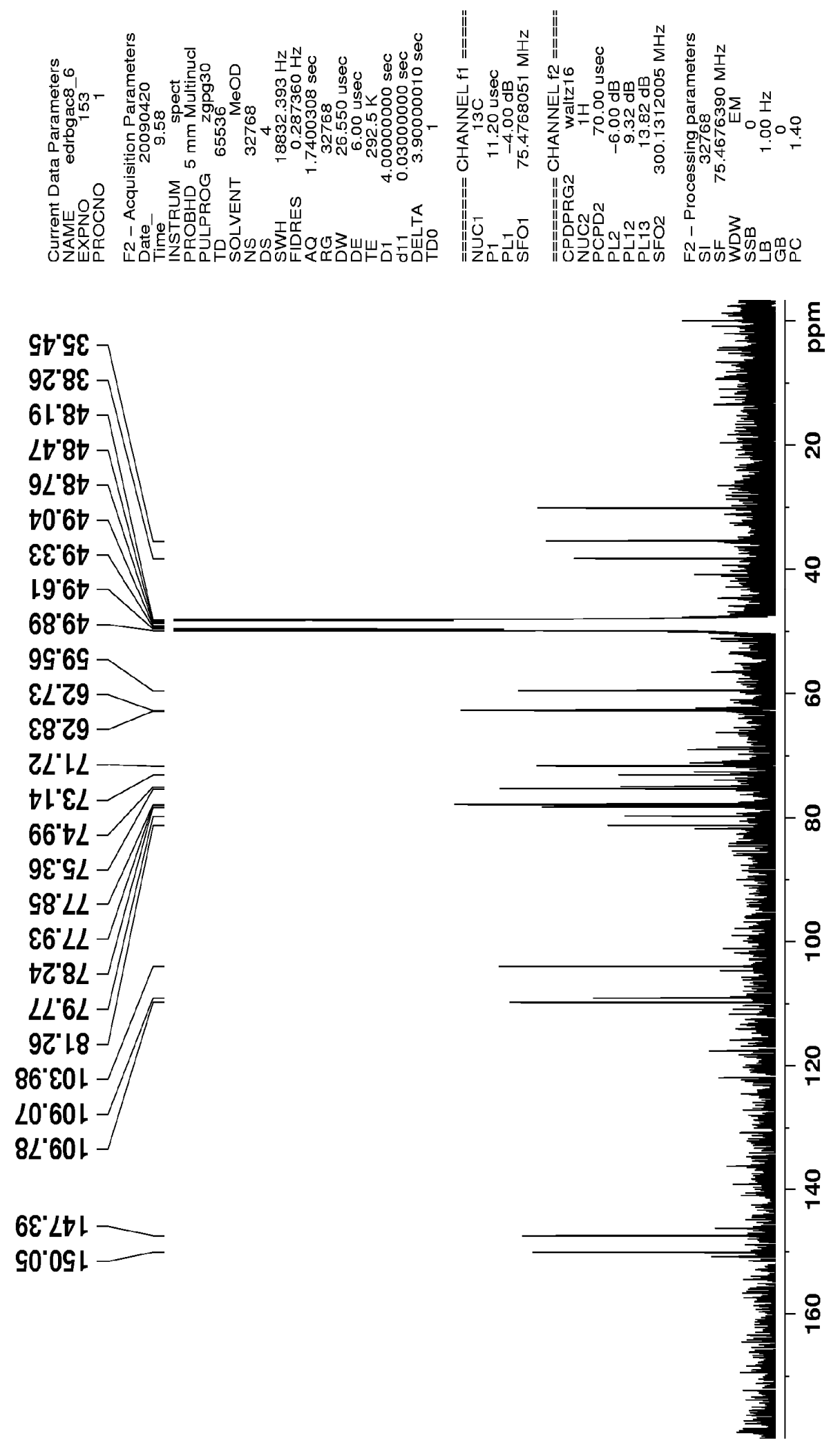
7.2.5.6 Espectro de RMN de ${ }^{13} \mathrm{C}\left(\mathrm{DEPT} 135^{\circ}, 125 \mathrm{MHz}\right)$ do composto $10 \mathrm{em}$ DMSO-d $d_{6}$.
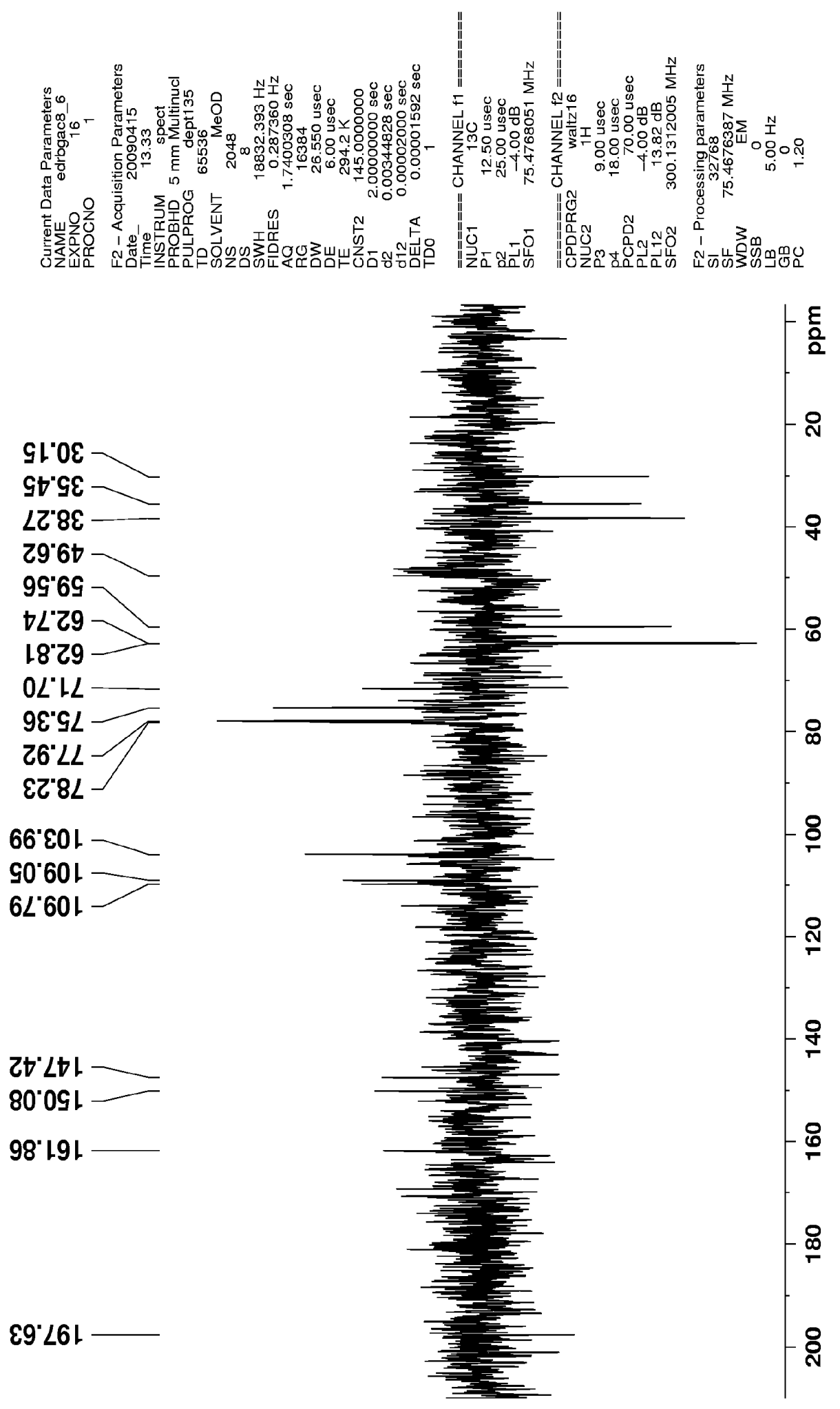
7.2.5.7 Mapa de contorno gerado a partir do experimento HSQC $\left({ }^{13} \mathrm{C}: 125\right.$ MHz e ${ }^{1} \mathrm{H}: 500 \mathrm{MHz}$ ) do composto 10 em DMSO-d.
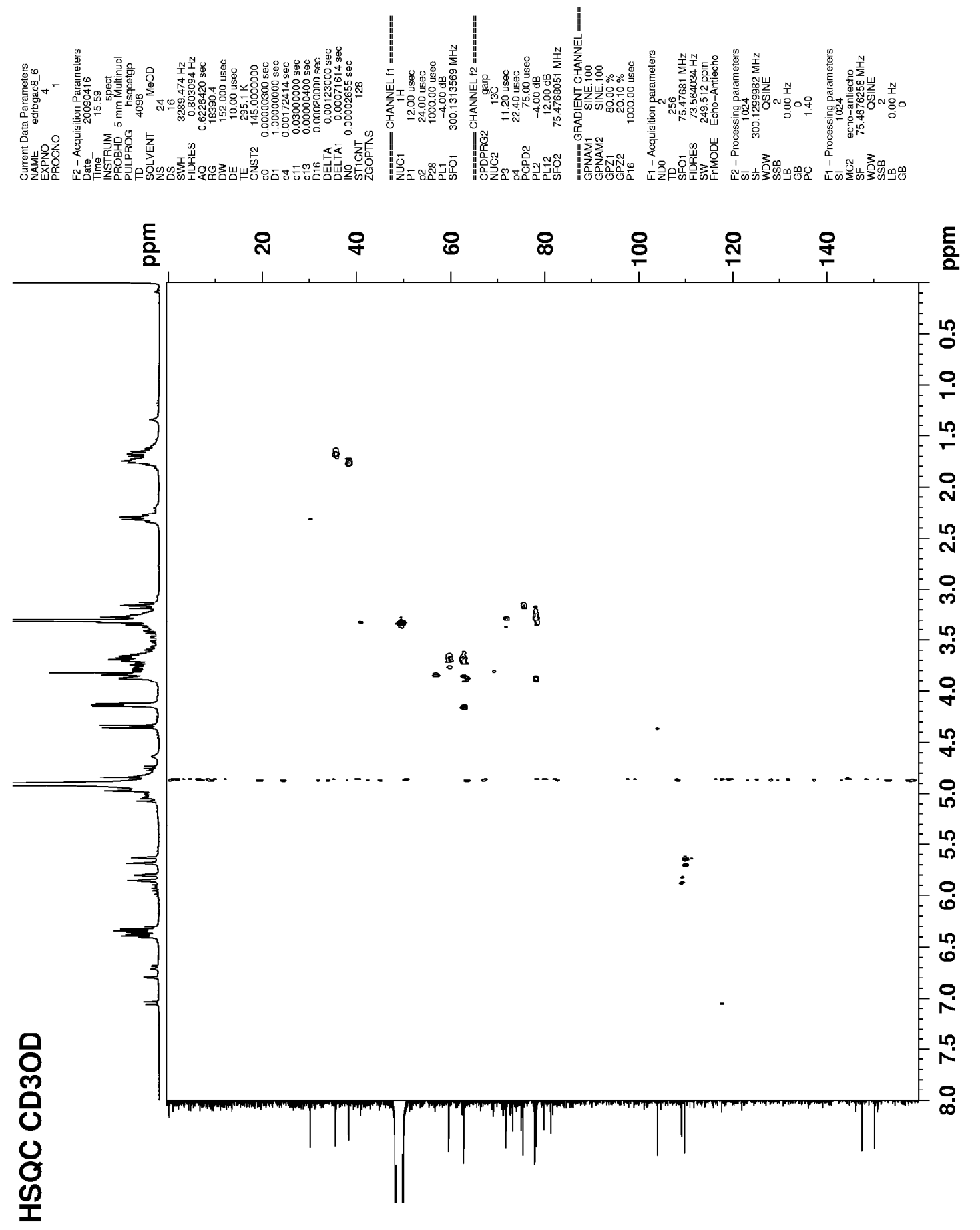
7.2.5.8 Mapa de contorno gerado a partir do experimento TOCSY $\left({ }^{1} \mathrm{H},{ }^{1} \mathrm{H}, 500\right.$ $\mathrm{MHz}$ ) do composto 10 em DMSO-d.

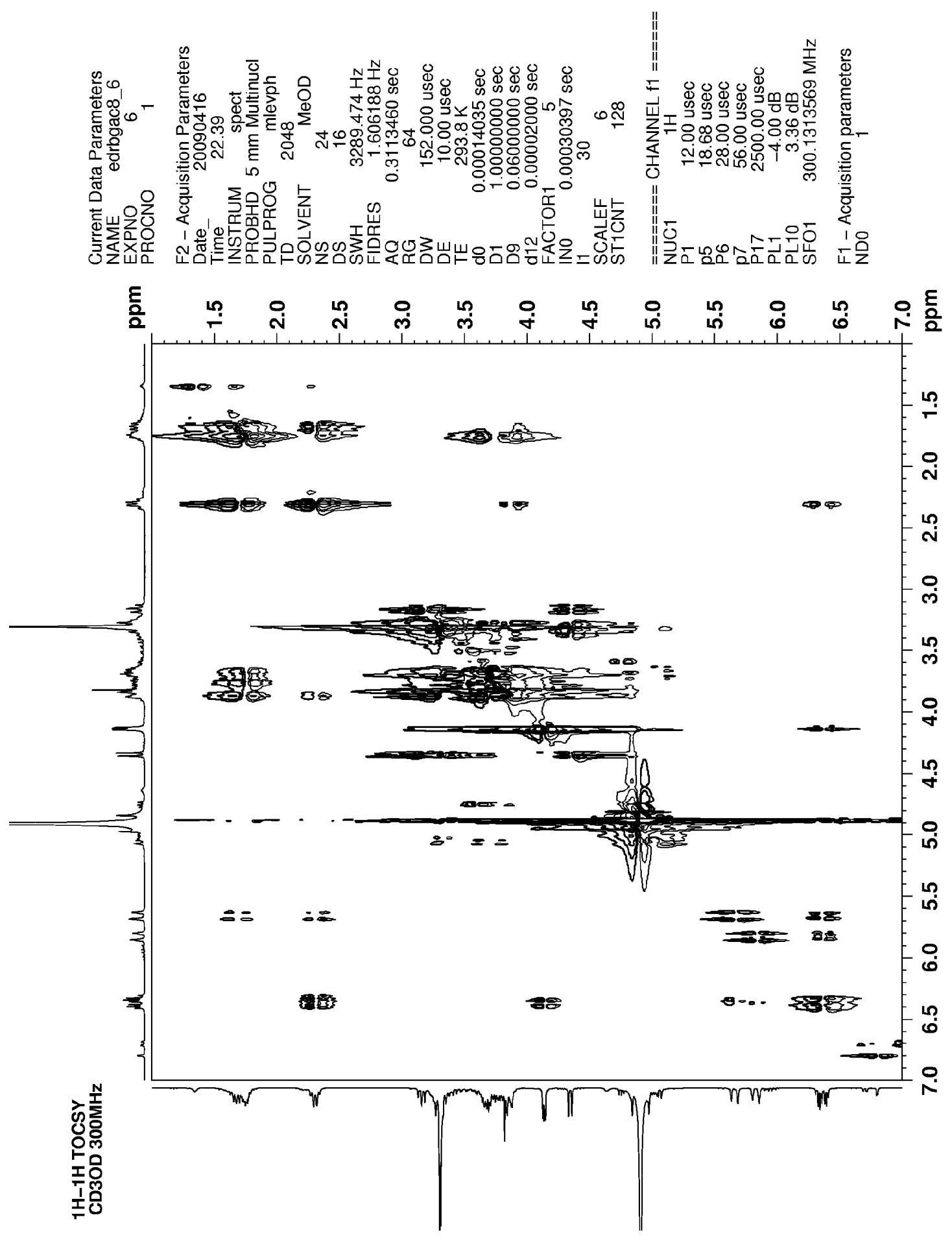


7.2.5.9 Mapa de contorno gerado a partir do experimento $\mathrm{HMBC}\left({ }^{13} \mathrm{C}: 125\right.$ $\mathrm{MHz}$ e ${ }^{1} \mathrm{H}: 500 \mathrm{MHz}$ ), modulado para ${ }^{2} \mathrm{~J}_{\mathrm{CH}}=8 \mathrm{~Hz}$, do composto $10 \mathrm{em}$ DMSO-d ${ }_{6}$.
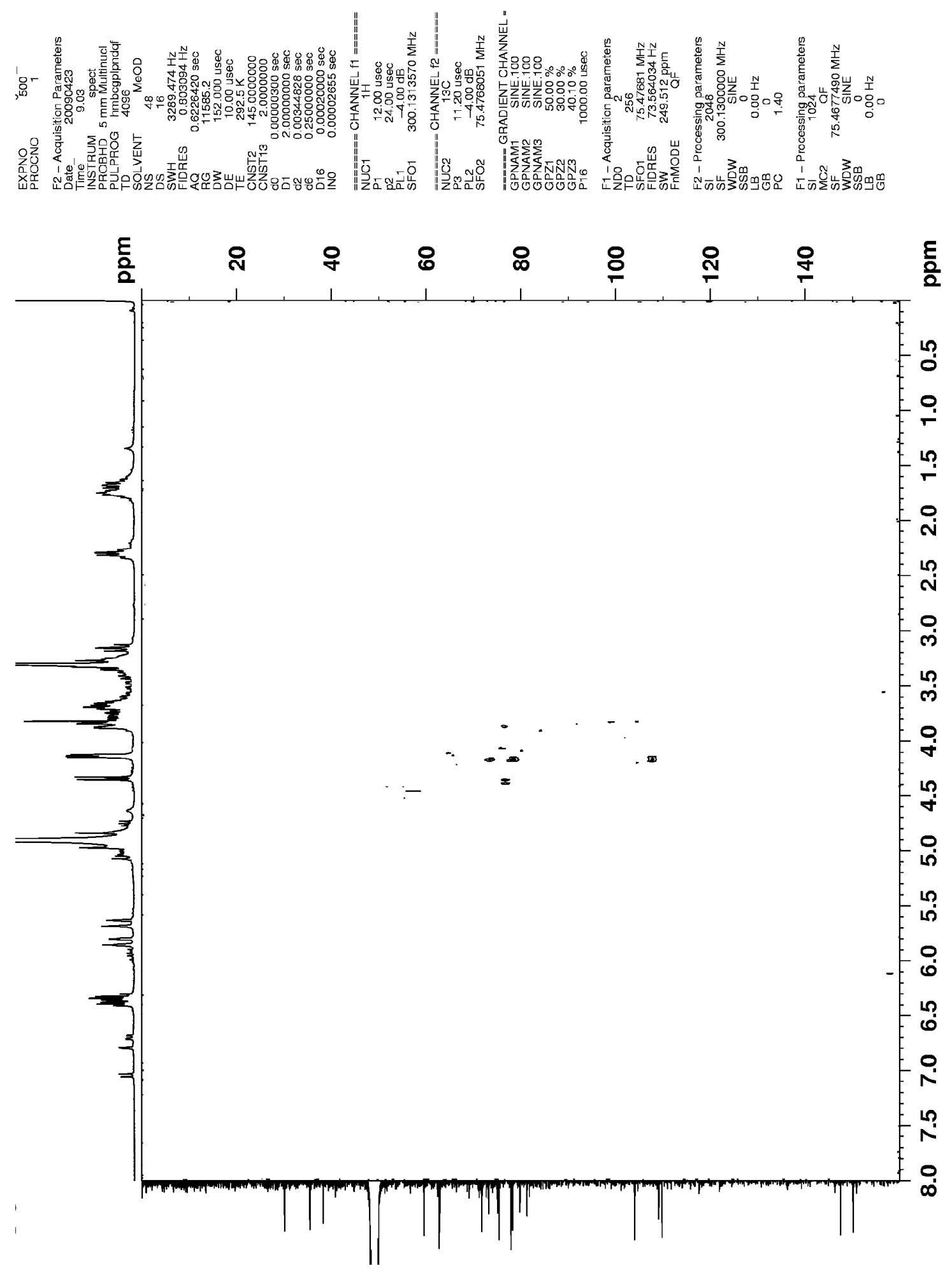
7.2.5.10 Mapa de contorno gerado a partir do experimento NOESY $\left({ }^{1} \mathrm{H},{ }^{1} \mathrm{H}, 500\right.$ $\mathrm{MHz}$ ) do composto $10 \mathrm{em} \mathrm{DMSO}-\mathrm{d}_{6}$.
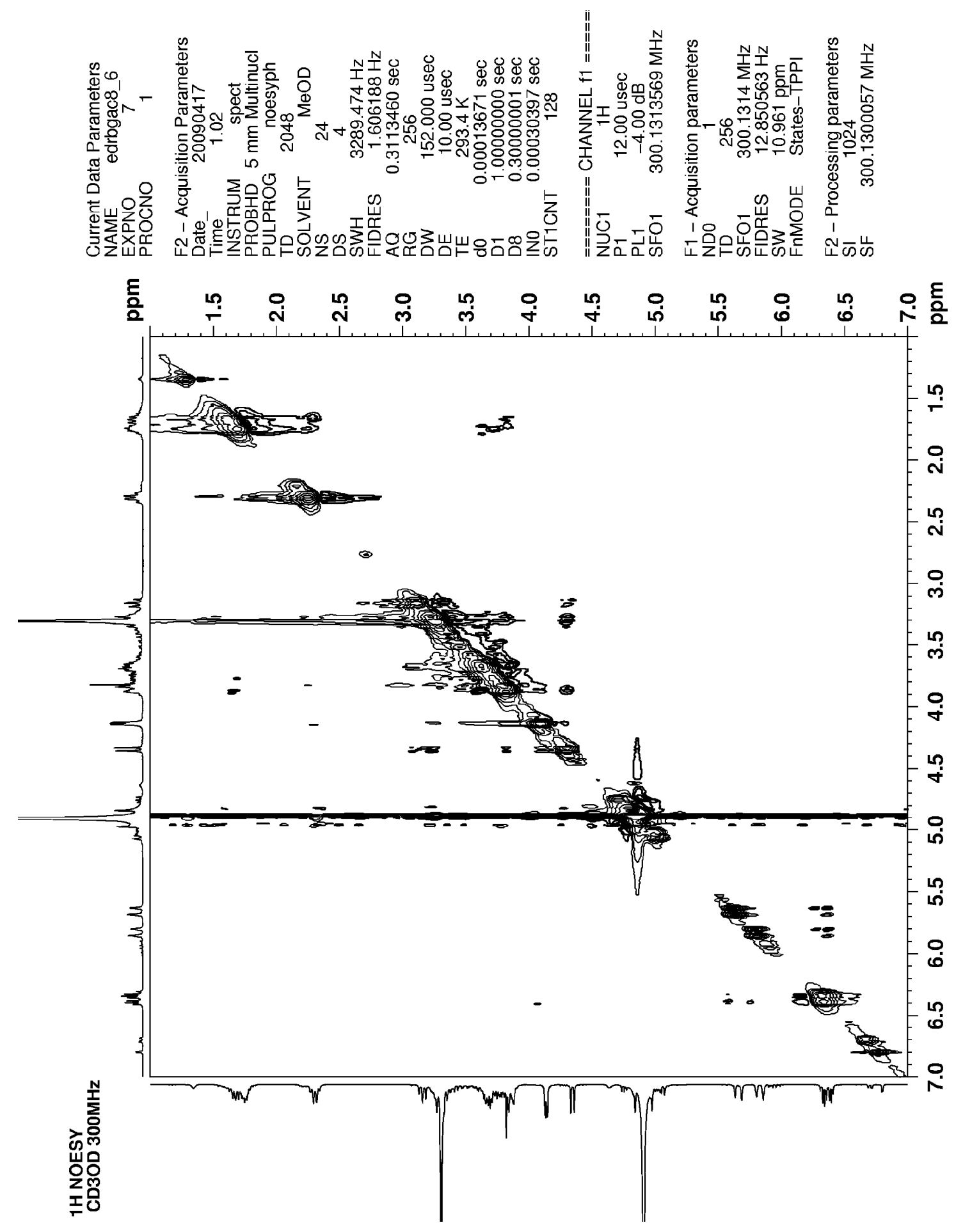
7.2.5.11 Mapa de contorno gerado a partir do experimento J-resolved $\left({ }^{1} \mathrm{H},{ }^{1} \mathrm{H}\right.$, $500 \mathrm{MHz}$ ) do composto $10 \mathrm{em}$ DMSO-d .
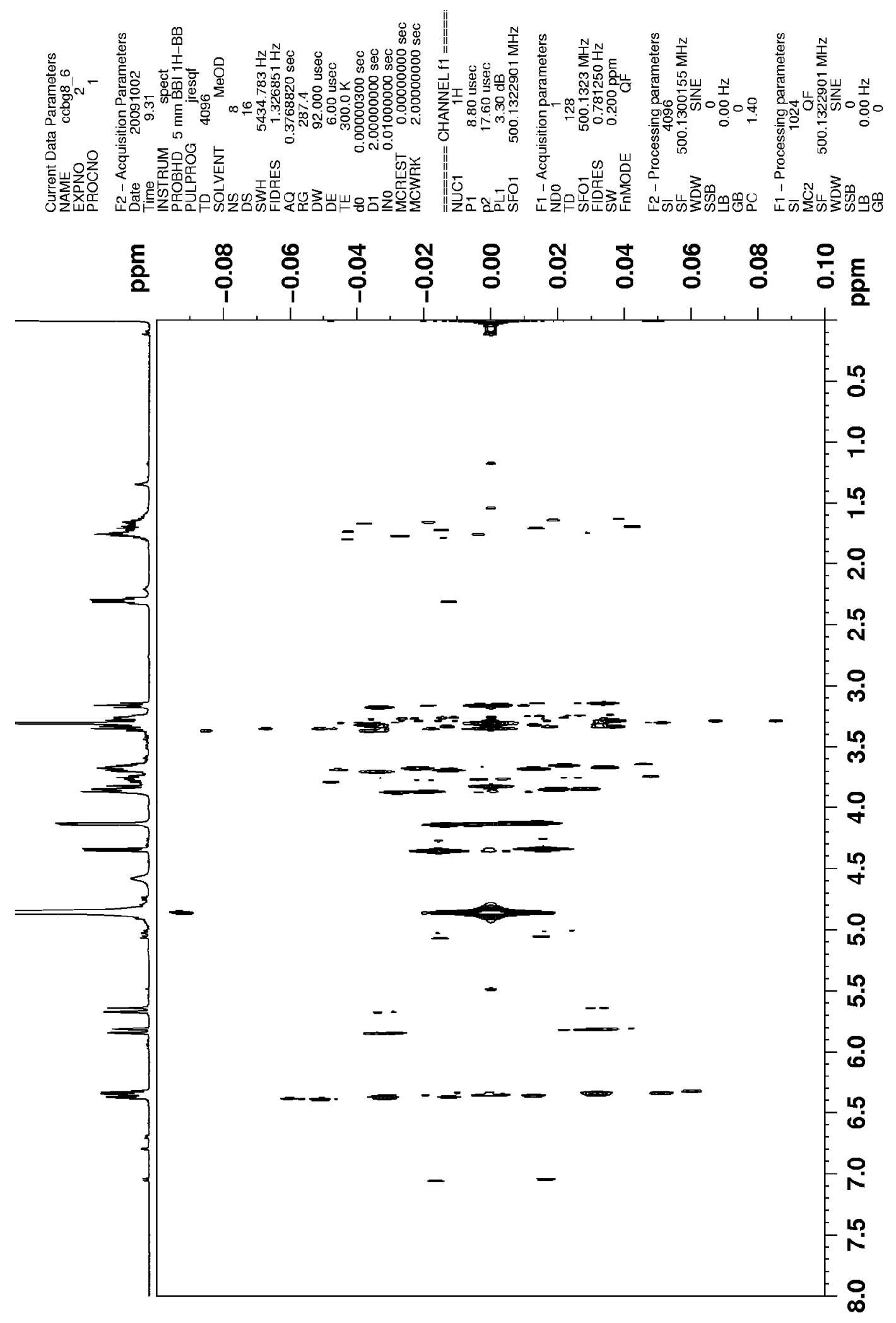


\subsubsection{Dados de RMN do composto 11:}

\subsubsection{Espectro de RMN de ${ }^{1} \mathrm{H}(500 \mathrm{MHz})$ do composto 11 em DMSO-d}
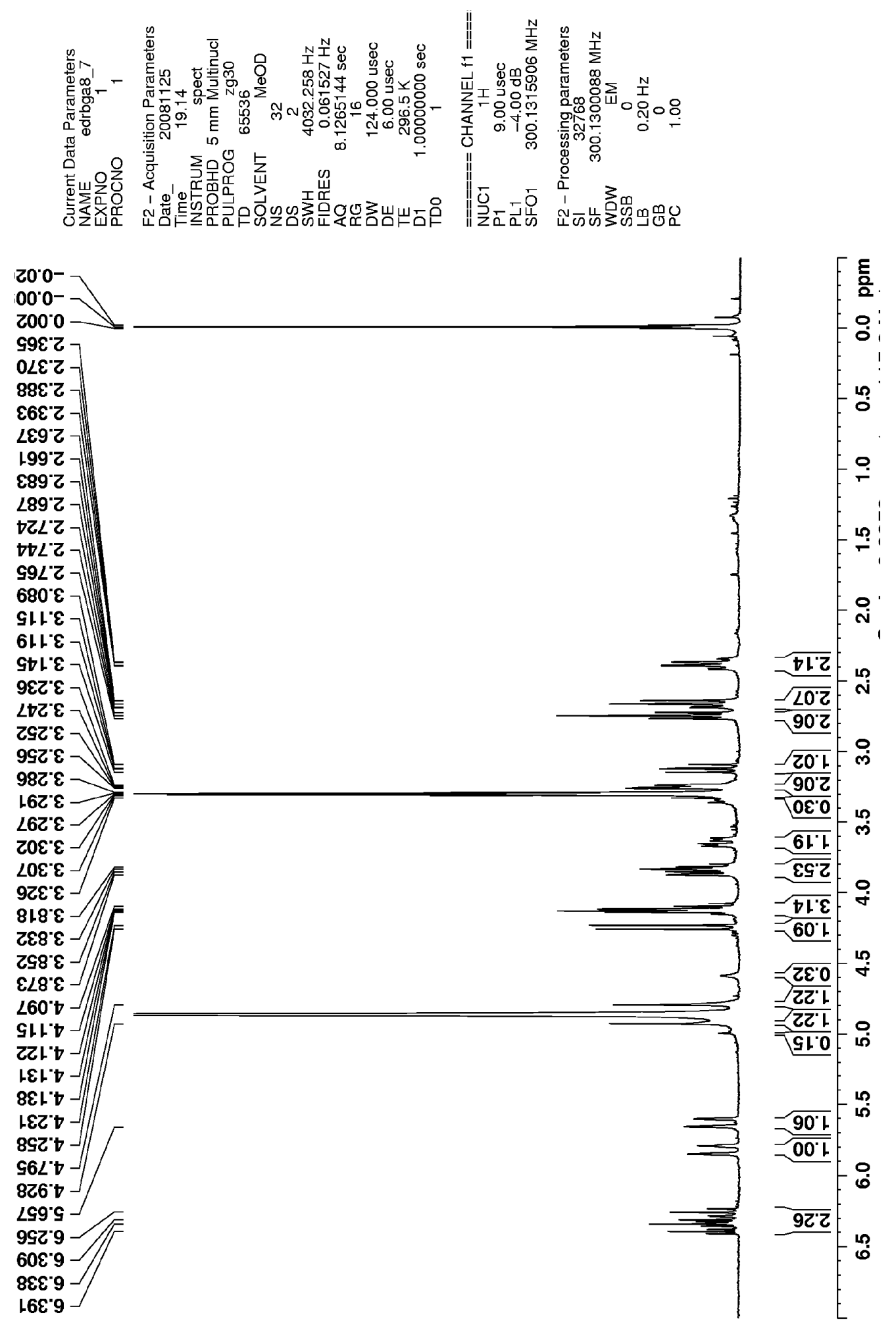
7.2.6.2 Ampliações do Espectro de RMN de ${ }^{1} \mathrm{H}(500 \mathrm{MHz})$ do composto 11 em DMSO-d . .
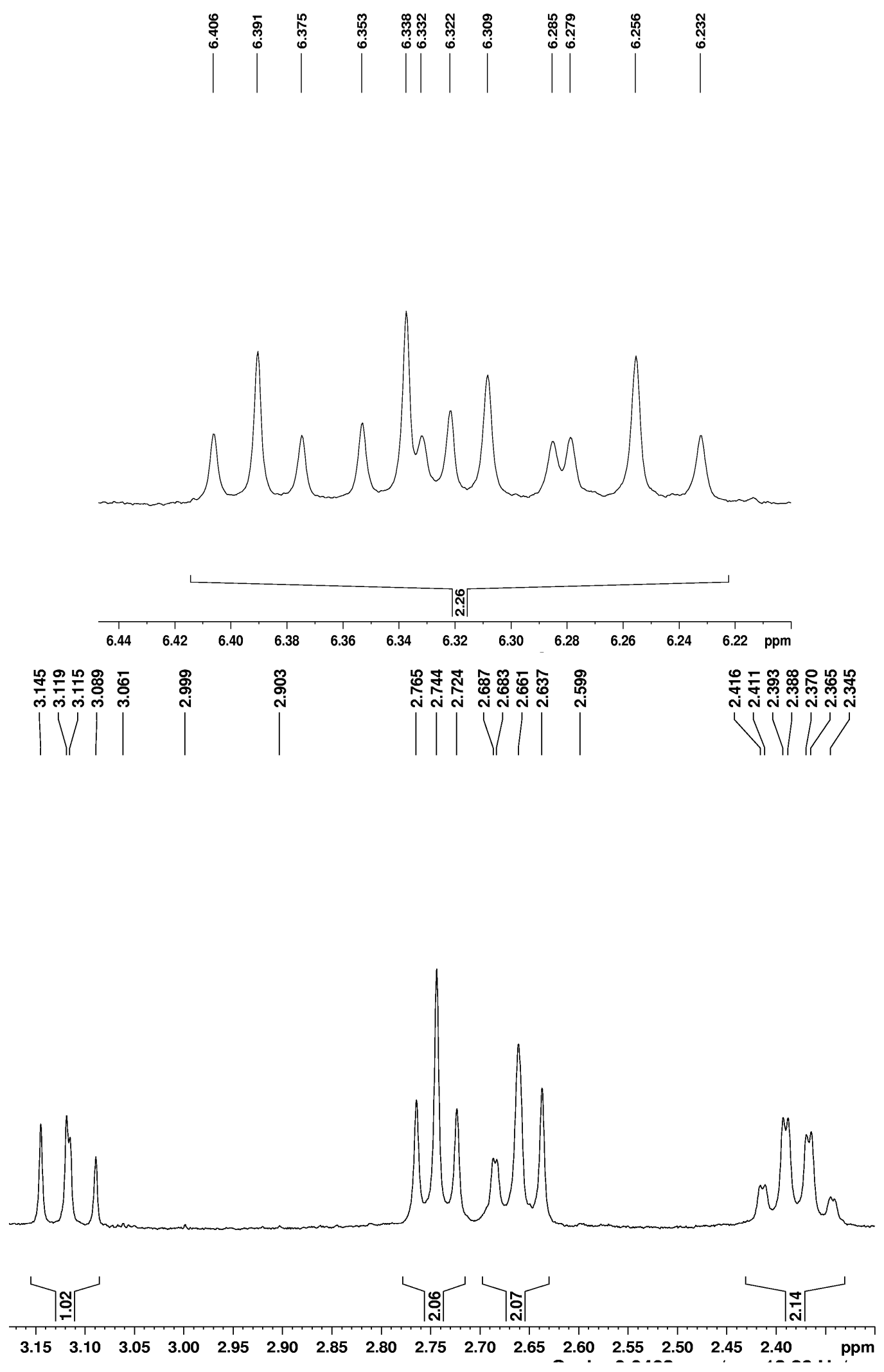
7.2.6.3 Ampliações do Espectro de RMN de ${ }^{1} \mathrm{H}(500 \mathrm{MHz})$ do composto 11 em DMSO-d .
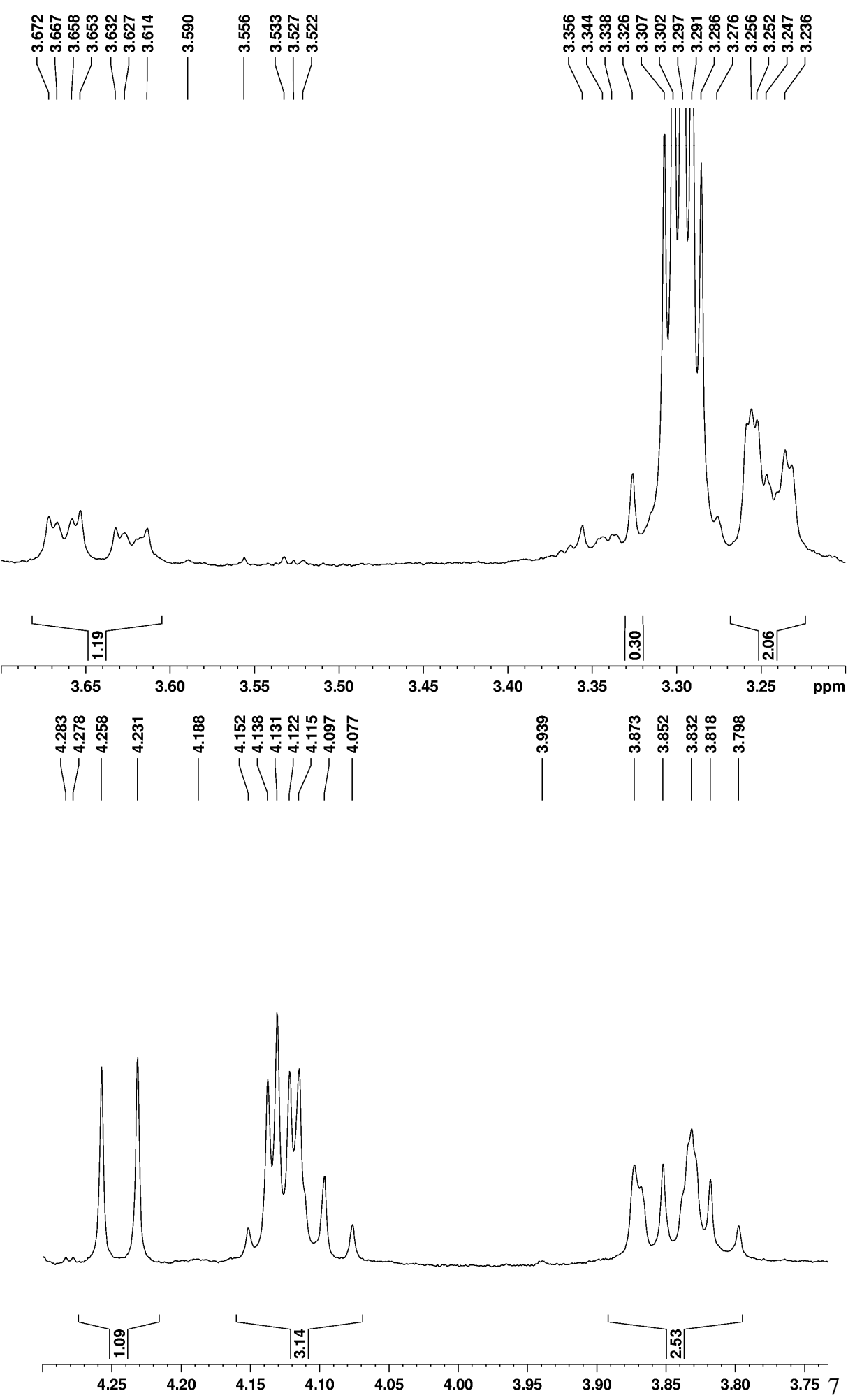
7.2.6.4 Espectro de RMN de $\left.{ }^{13} \mathrm{C}_{\{}{ }^{1} \mathrm{H}\right\}(125 \mathrm{MHz})$ do composto 11 em DMSO-d ${ }_{6 \text {. }}$
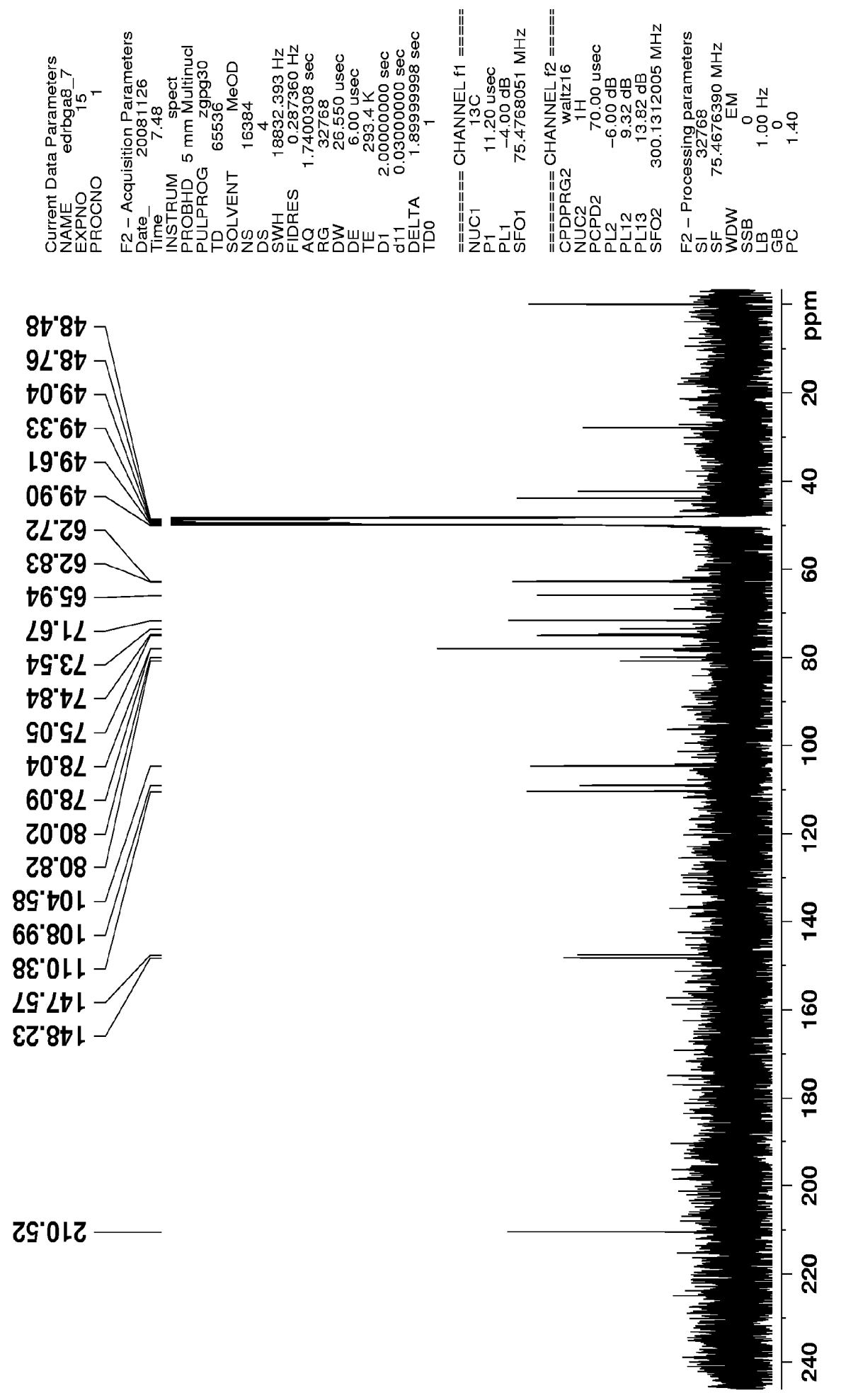
7.2.6.5 Espectro de RMN de ${ }^{13} \mathrm{C}\left(\mathrm{DEPT} 135^{\circ}, 125 \mathrm{MHz}\right)$ do composto $11 \mathrm{em}$ DMSO-d $d_{6}$.
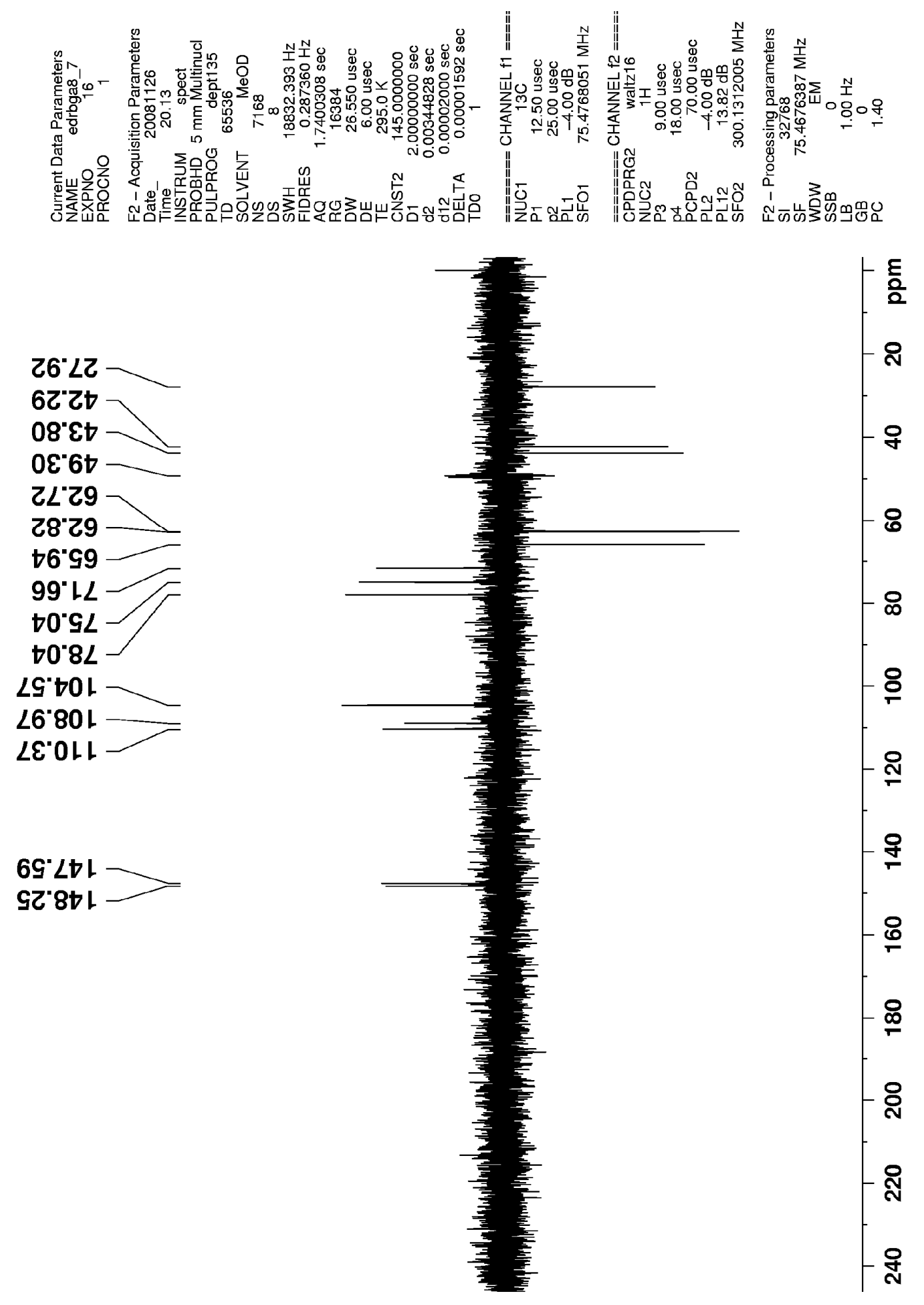
7.2.6.6 Mapa de contorno gerado a partir do experimento $\mathrm{HSQC}\left({ }^{13} \mathrm{C}: 125\right.$ MHz e $\left.{ }^{1} \mathrm{H}: 500 \mathrm{MHz}\right)$ do composto $11 \mathrm{em}$ DMSO-d .
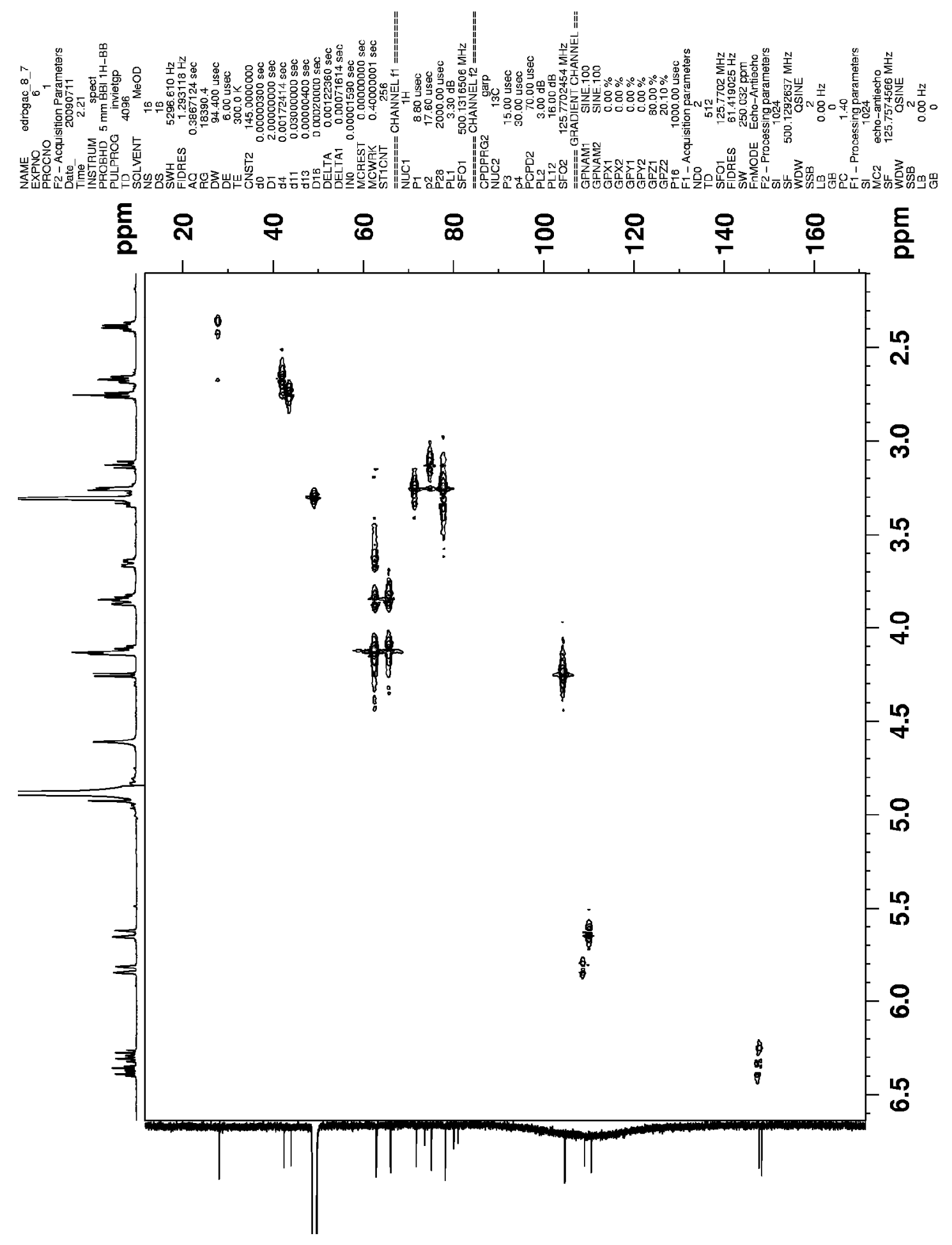
7.2.6.7 Mapa de contorno gerado a partir do experimento HMBC $\left({ }^{13} \mathrm{C}: 125\right.$ $\mathrm{MHz}$ e ${ }^{1} \mathrm{H}: 500 \mathrm{MHz}$, modulado para ${ }^{2} \mathrm{~J}_{\mathrm{CH}}=4 \mathrm{~Hz}$, do composto 11 em DMSO-d ${ }_{6}$.

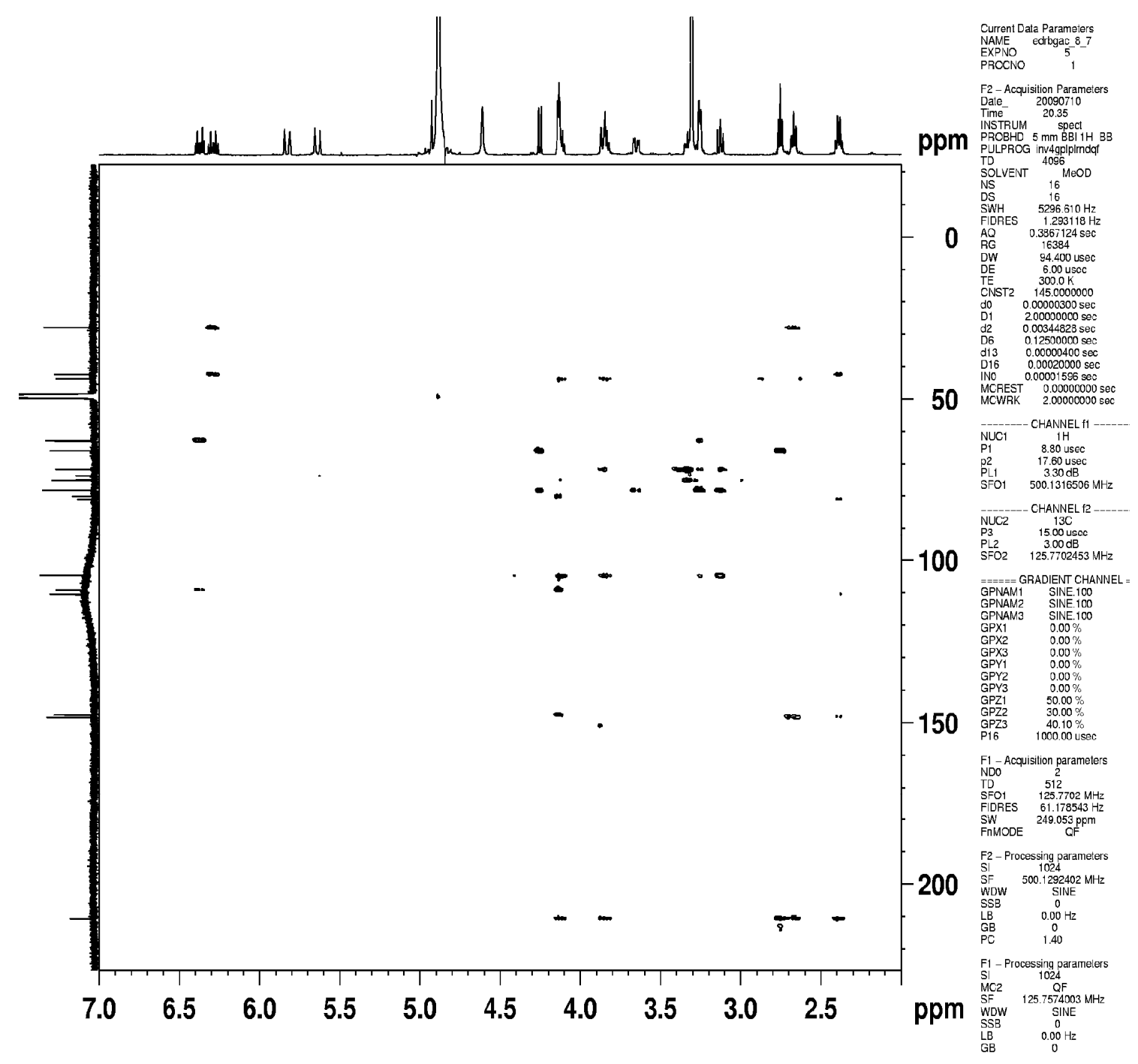


7.2.6.8 Mapa de contorno gerado a partir do experimento J-resolved $\left({ }^{1} \mathrm{H},{ }^{1} \mathrm{H}\right.$, $500 \mathrm{MHz}$ ) do composto $10 \mathrm{em} \mathrm{DMSO}-\mathrm{d}_{6}$.
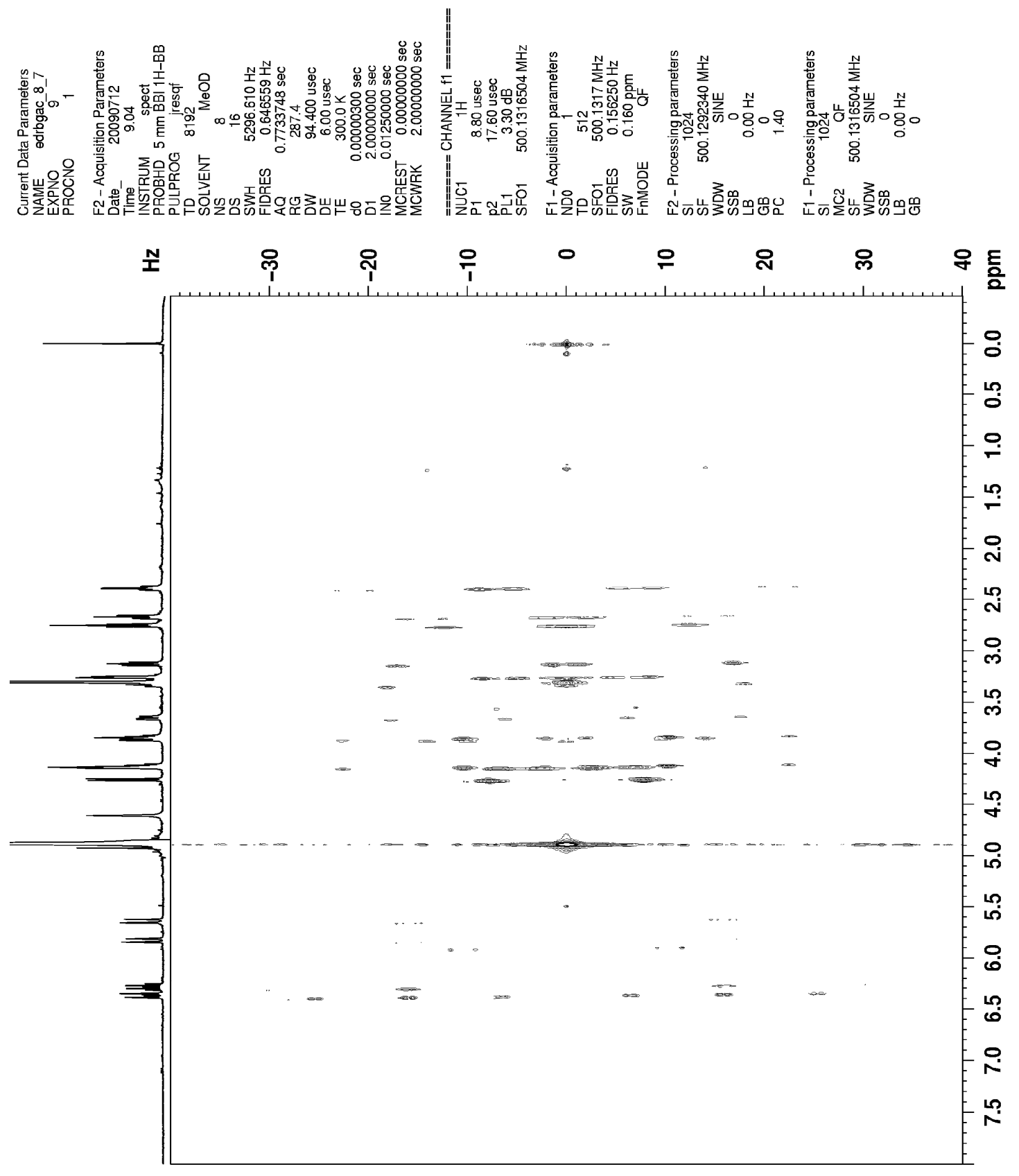
7.2.6.9 Mapa de contorno do G-BIRD ${ }_{R-X} C P M G-H S Q M B C$ para o composto 10.

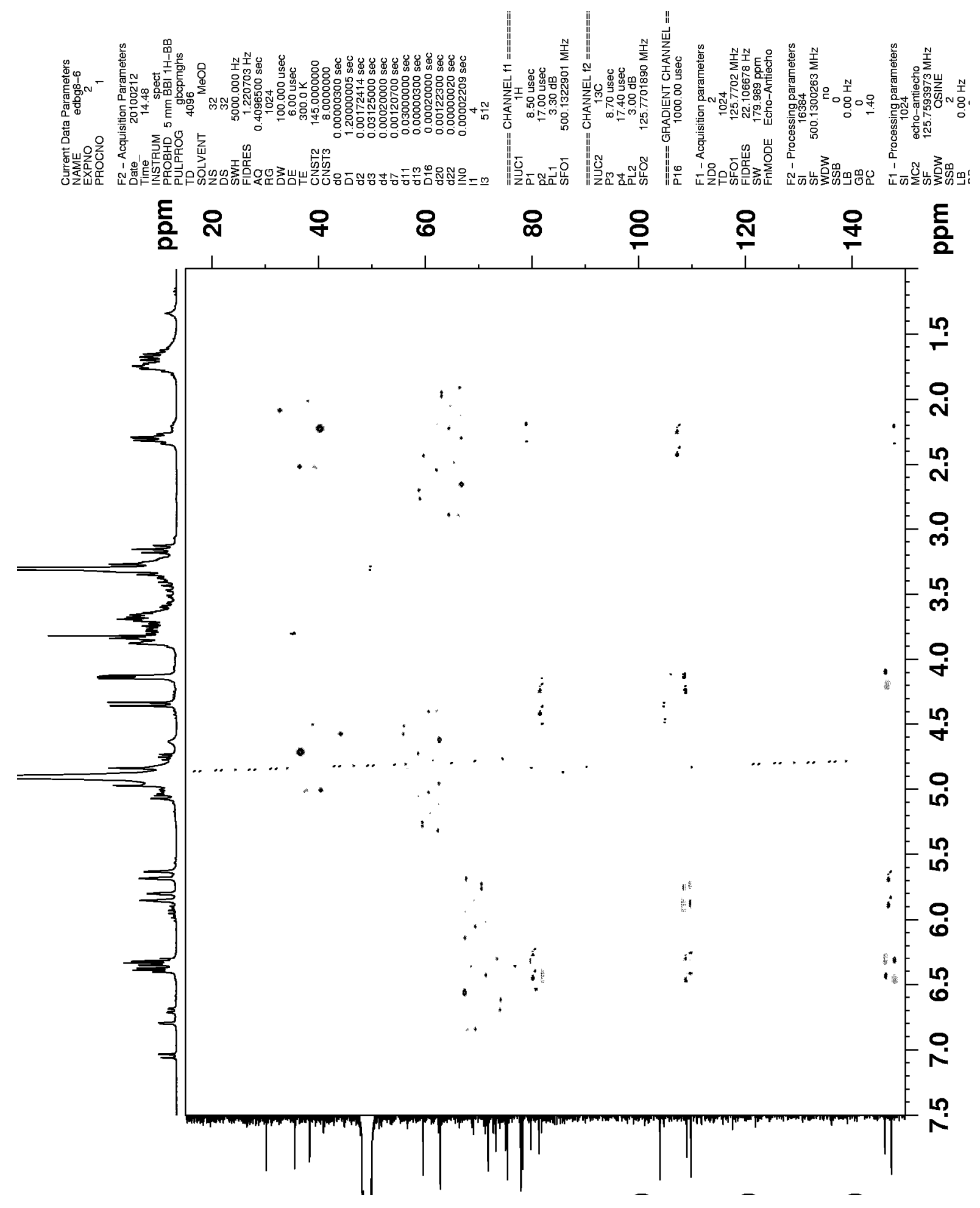




\section{Apêndice B: Descrição das Fontes dos Produtos Naturais Analisados}


Neste trabalho foram analisadas substâncias puras e/ou mistura de produtos naturais obtidos de duas plantas da família Asteraceae (Bidens sulphurea e Bidens gardneri) e uma da família Annonaceae (Duguetia furfuracea). Tais plantas são descritas a seguir.

\subsection{Plantas da Família Asteraceae}

A família Asteraceae compreende cerca de 1.300 gêneros e 25.000 espécies, que estão divididas em três subfamílias e 17 tribos segundo Bremer (1994). Aproximadamente, 98\% dos gêneros são constituídos por plantas de pequeno porte, sendo encontradas em todos os tipos de habitats, principalmente nas regiões tropicais da América do Sul ${ }^{[186]}$.

As espécies desta família são amplamente difundidas na medicina popular, como a Artemisia absinthium e as espécies do gênero Bacchari ${ }^{[187,188]}$. Vários gêneros dessa família já foram extensamente estudados quanto a sua constituição química, como o gênero Artemisia em que $62 \%$ de suas espécies já foram investigadas fitoquimicamente ${ }^{[189]}$.

Das plantas desta família revelaram o isolamento de benzofuranos, monoterpenos, sesquiterpenos, diterpenos, triterpenos, cumarinas, poliacetilenos, lactonas sesquiterpênicas e flavonóides, sendo que os três últimos são considerados descritos como marcadores quimiotaxonômicos ${ }^{[186,190,191]}$. As Asteráceas abordadas no presente trabalho são do gênero Bidens, o qual é pertencente à tribo Heliantheae e subtribo Coreopsidinae.

\subsubsection{Tribo Heliantheae}

A tribo Heliantheae é uma das maiores e mais diversas do ponto de vista morfológico. Várias substâncias foram isoladas e identificadas a partir de espécie desta tribo, entre elas: poliacetilenos, flavonóides, derivados do tiofeno, alquilamidas e outros ${ }^{[181,191,192,193]}$.

Os marcadores desta tribo são flavonóides. Entre os obtidos de plantas desta tribo, 46 \% são flavonóis, $21 \%$ flavonas, $16 \%$ chalconas e $10 \%$ auronas, sendo que a alta incidência de chalconas e auronas só ocorre nesta tribo de Asteraceae ${ }^{[190]}$.

Em Heliantheae, há também uma maior ocorrência de flavonóides oxidados no anel A, sendo estes O-metilflavonóides e O-glicosilflavonóides. As flavonas são, principalmente, 
substituídas em 6 e 5, 3',4', os flavonóis em 5, 7, 3' e 4', e as flavanonas em 5, 3' e 4' (Figura 14) ${ }^{[190]}$.

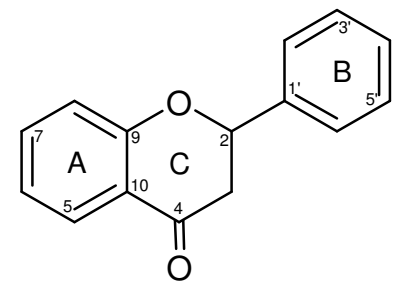

(A)

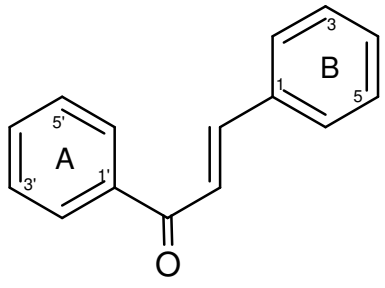

(B)

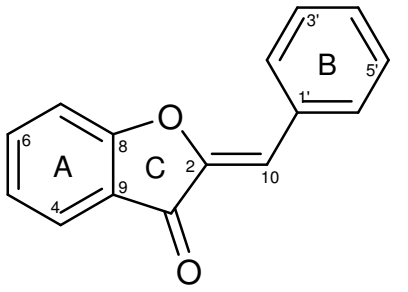

(C)

Figura 45. Esqueleto básico dos flavonóides (A), chalconas (B) e auronas (C)

Os flavonóides apresentam diversas atividades biológicas, como antioxidante, inibição de enzimas (respiração mitocondrial), anti-inflamatória, inibição da agregação plaquetária, vasodilatação, antitumoral, antiespasmolítica, antidiarreica, hepatoprotetora, antifúngica e analgésica ${ }^{[194]}$. Os heterosídeos flavonoídicos possuem maior absorção pelo trato intestinal, quando comparados com as agliconas, como também se destacam por possuírem algumas atividades mais potentes do que as agliconas ${ }^{[195]}$.

\subsubsection{Subtribo Coreopsidinae}

A subtribo Coreopsidinae, a qual se encontra o gênero Bidens, é uma das maiores em Heliantheae e compreende 31 gêneros e 480 espécies, sendo que destas, até 2006, apenas 168 foram estudadas quimicamente ${ }^{[186,191]}$.

Os principais metabólitos encontrados nesta subtribo foram os monoterpenos, sesquiterpenos, flavonóides e poliacetilenos, sendo que estes dois últimos são os de maior ocorrência nesta subtribo ${ }^{[191]}$.

Dentre os flavonóides, há uma maior incidência daqueles oxidados no anel A (Figura 14), sendo majoritariamente O-glicosilflavonóides ${ }^{[190]}$ e pertencentes a classes das auronas e chalconas ${ }^{[196]}$. Além desses, também há muitos relatos do isolamento de acetilenos, sendo estes principalmente do tipo eno-tetraino-eno (Figura 15) e seus derivados oxigenados são típicos dentro do gênero Bidens ${ }^{[181]}$. 


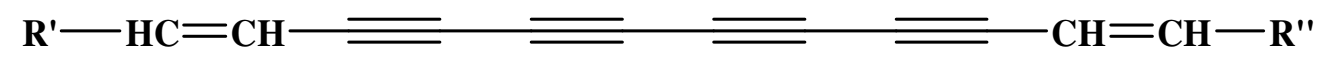

eno-tetraino-eno

Figura 46. Acetileno típico de Bidens

\subsection{Gênero Bidens}

O gênero Bidens, pertencente à tribo Heliantheae e subtribo Coreopsidinae, compreende cerca de 230 espécies que estão presentes nas Américas, África, Polinésia, Europa e nordeste da Ásia ${ }^{[197]}$. Há poucas espécies deste gênero que foram estudadas quimicamente, tornando o gênero Bidens pouco conhecido. A partir dos relatos encontrados na literatura, pôde-se observar uma maior incidência de poliacetilenos (34 \%), chalconas (12 $\%$ ), fenilpropanóides (9\%), flavonóis (9\%), derivados do tiofeno (9\%) e auronas (5\%) no gênero Bidens (Gráfico 1) ${ }^{[163]}$.

Várias espécies de Bidens foram avaliadas biologicamente e apresentaram atividades como antiúlcera, citoprotetora, antioxidante, anti-inflamatória, imunomodulatória, antihipertensiva, antimicrobiana, antialérgica, antidiabética, antiviral, mutagênica, antitumoral e antimalárica $^{[168,198,199,200,201]}$.

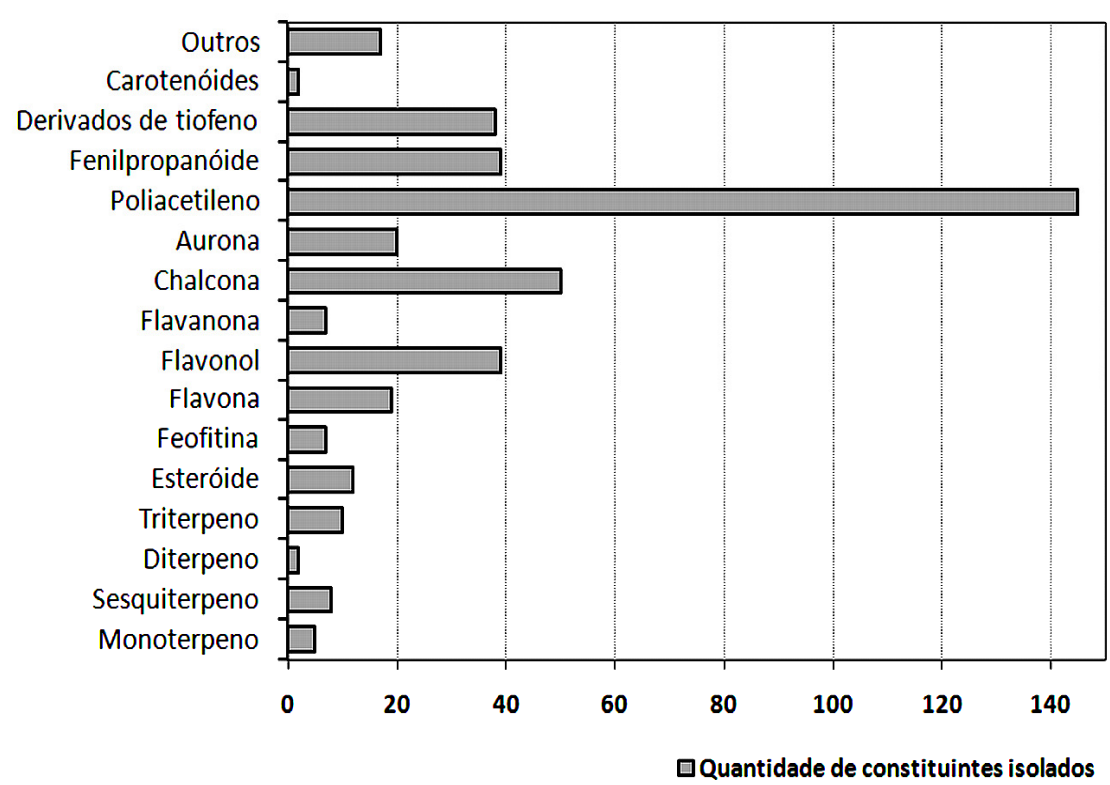

Figura 47. Ocorrência de metabólitos no gênero Bidens ${ }^{[163]}$ 


\subsection{Bidens gardneri Bak.}

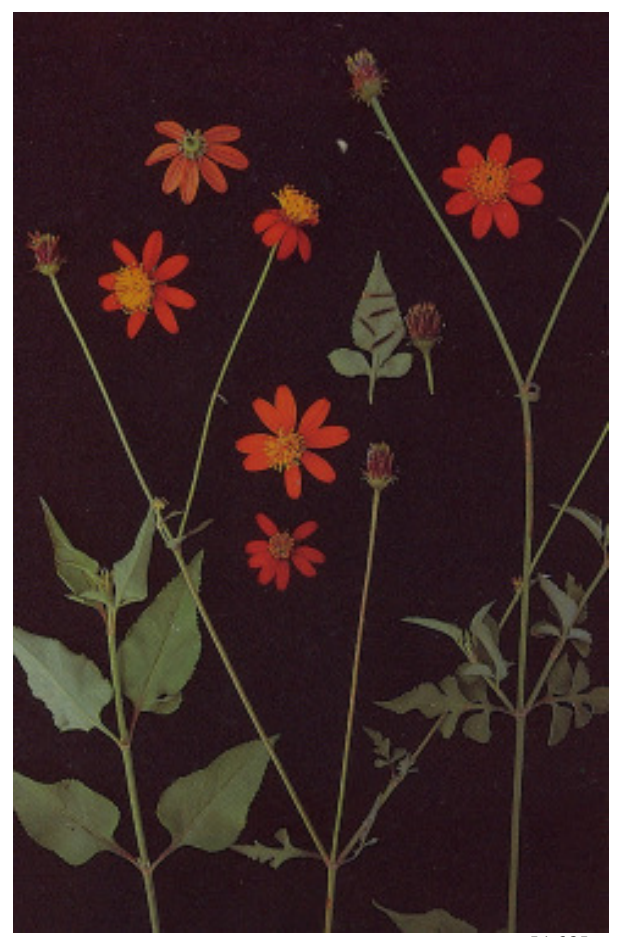

Figura 48. Aspectos morfológicos da Bidens gardneri Bak. ${ }^{[163]}$

A espécie Bidens gardneri Bak. (Figura 17), conhecida vulgarmente como picão e picão-do-pantanal, é uma erva de 0,4-1,5 m de altura com produção de flores e sementes o ano todo.

Há registros de coletas desta espécie em São Paulo, Bahia, Goiás, Espírito Santo e em poucas regiões da Bolívia e Paraguai (www.herbario.iac.sp.gov.br), porém é na região do Pantanal que esta espécie, considerada invasora nesta localidade, encontra-se abundantemente distribuída ${ }^{\text {[202]. }}$

B. gardneri Bak. é utilizada popularmente para fins diuréticos, tratamento de icterícia e de úlceras crônicas. Possui altos teores de cálcio (0,67 \%), fósforo $(0,44 \%)$, magnésio $(0,39 \%)$, cobre $(17 \mathrm{ppm})$ e zinco $(40 \mathrm{ppm})^{[202]}$.

O primeiro estudo químico desta espécie foi feito por Brentan da Silva ${ }^{[163]}$, que relata a presença majoritária de sesquiterpenos ( $\beta$-cariofileno, germacreno D e biciclogermacreno, Figura 18) na fração de volátil das partes aéreas, flores e frutos de B. gardneri. Já a fração hexânica das partes aéreas de B. gardneri apresentou como componentes majoritários os metabólitos $\beta$-estigmasterol e o trans-fitol. 


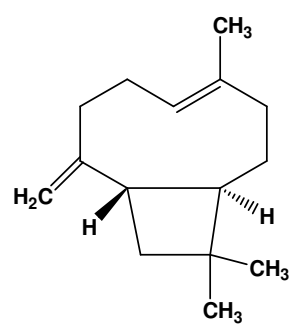

$\beta$-cariofileno

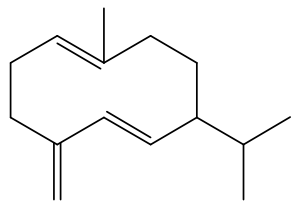

germacreno $D$

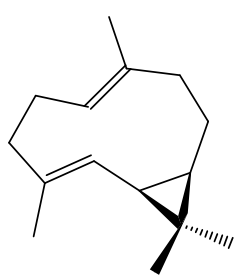

biciclogermacreno

Figura 49. Substâncias majoritárias da fração volátil das partes aéreas de Bidens gardneri Bak. [163]

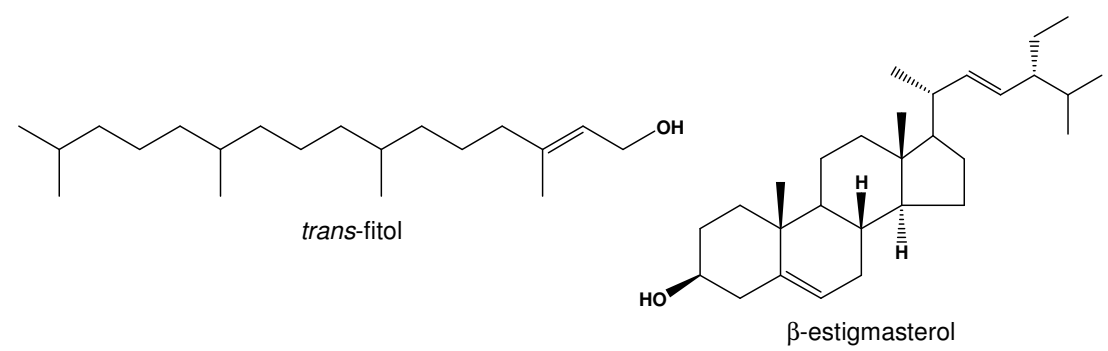

Figura 50. Componentes majoritários da fração hexânica do extrato etanólico das partes aéreas de B. gardneri Bak. ${ }^{[163]}$

O fracionamento do extrato etanólico das partes aéreas de $B$. gardneri resultou no isolamento das seguintes substâncias (Figura 20 ${ }^{[163]}$ ):

Quatro ácidos clorogênicos:

○ Ácido 3,4-di-O-E-cafeoilquínico;

○ Ácido 5-O-E-cafeoilquínico;

○ Ácido 1-metil-5-O-E-cafeoilquínico;

$\checkmark$ Ácido 3,5-di- $O$-E-cafeoilquínico;

$\checkmark$ Dois novos poliacetilenos tipo eno-diino-eno:

○ 1-O- $\beta$-glicopiranosil-14-hidróxi-tetradeca-6(E),12(E)-dieno-8,10-diino-3-ona;

○ 3-O- $\beta$-glicopiranosil-tetradeca-6(E),12(E)-dieno-8,10-diino-1,14-diol);

$\checkmark$ Um poliacetileno tipo eno-triino-eno:

○ 2-O- $\beta$-glicopiranosil-trideca-3(E),11(E)-dieno-5,7,9-triino-1,13-diol;

$\checkmark$ Duas flavonas:

○ 7-O- $\beta$-glicopiranosil-apigenina;

○ 7-O- $\beta$-glicopiranosil-luteolina;

$\checkmark$ Três novas flavanonas:

○ 4'-metóxi-7-O- $\beta$-glicopiranosil-8,3'-diidróxi-flavanona;

○ 4'-metóxi-7-O- $\beta$-(6"-acetil)-glicopiranosil-8,3'-diidróxi-flavanona;

○ 7-O- $\beta$-(6"-trans-p-cumaroil)-glicopiranosil-8,3'4'-triidróxi-flavanona);

$\checkmark$ Duas chalconas:

○ 4-metóxi-4'-O- $\beta$-glicopiranosil-ocanina;

○ 4'-O- $\beta$-(6"-trans-p-cumaroil)-glicopiranosil-ocanina. 


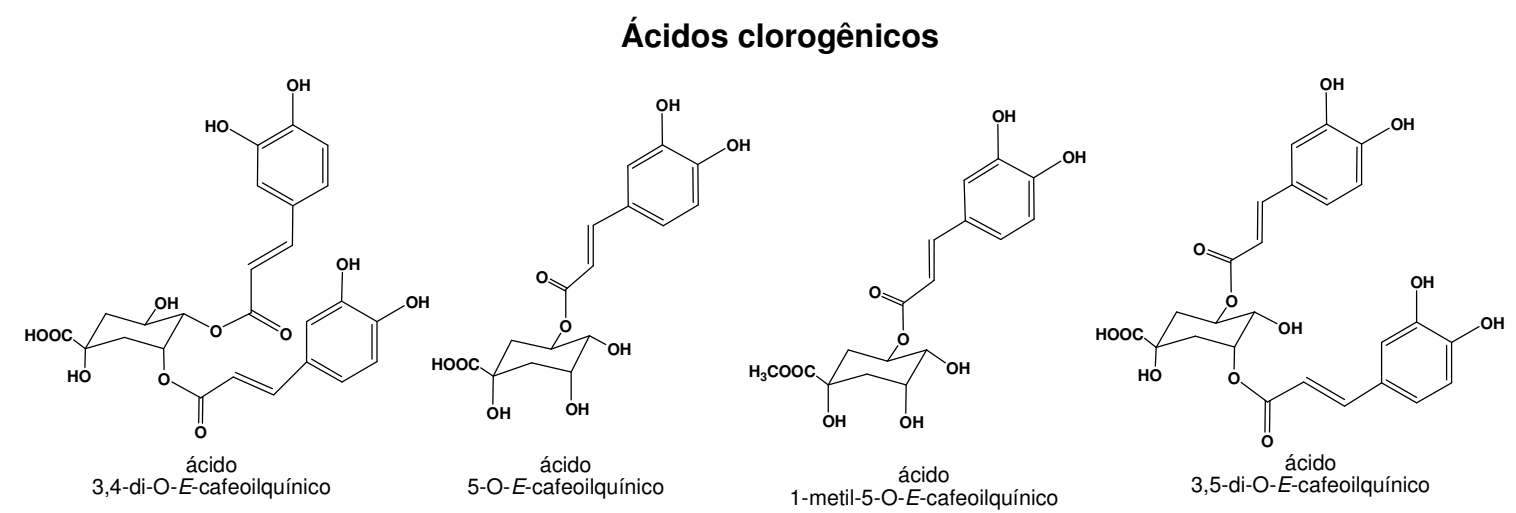

\section{Poliacetilenos}

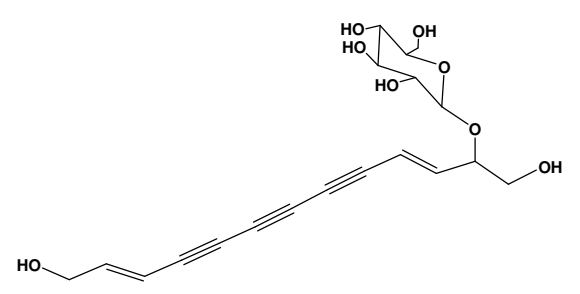

2-O- $\beta$-glicopiranosil-trideca-3(E),11(E)-dieno-5,7,9-triino-1,13-diol

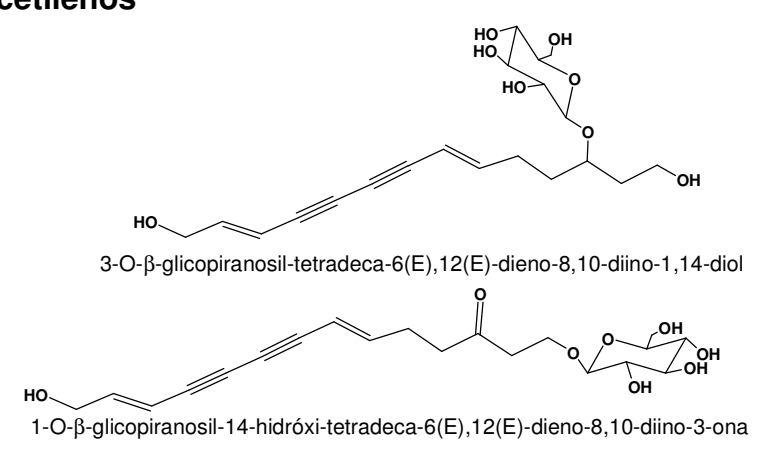

Flavonas

Novas Flavanonas

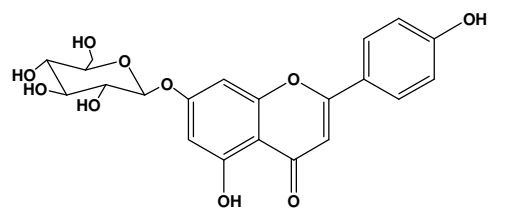

7-O-ß-glicopiranosil-apigenina<smiles>O=c1cc(-c2ccc(O)c(O)c2)oc2cc(OC(OCC(O)C3COC3)C(O)CO)cc(O)c12</smiles>

7-O-ß-glicopiranosil-luteolina<smiles>COc1ccc(C2CC(=O)c3ccc(OC(OC(=O)CO)C(O)C(O)O)c(O)c3O2)cc1O</smiles>

4'-metóxi-7-O- $\beta$-glicopiranosil8,3'-diidróxi-flavanona<smiles>COc1ccc(C2CC(=O)c3ccc(OC(OC(C)=O)C(O)C(O)O)c(O)c3O2)cc1O</smiles>

4'-metóxi-7-O- $\beta$-(6"-acetil)-glicopiranosil$8,3^{\prime}$-diidróxi-flavanona

\section{Chalconas}<smiles></smiles>

4-metóxi-4'-O- $\beta$-glicopiranosil-ocanina

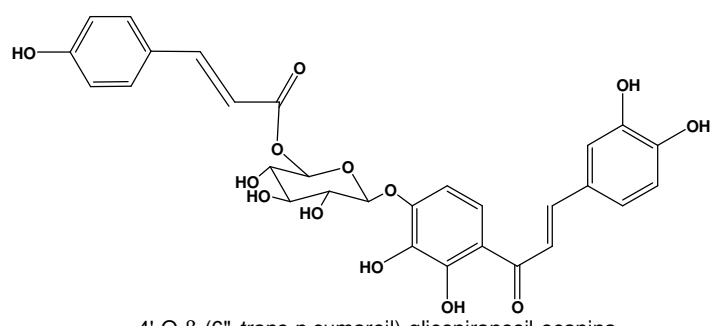

Figura 51. Substâncias isoladas a partir de Bidens gardneri Bak. ${ }^{[163]}$ 


\subsection{Bidens sulphurea (Cav.) Sch. Bip.}

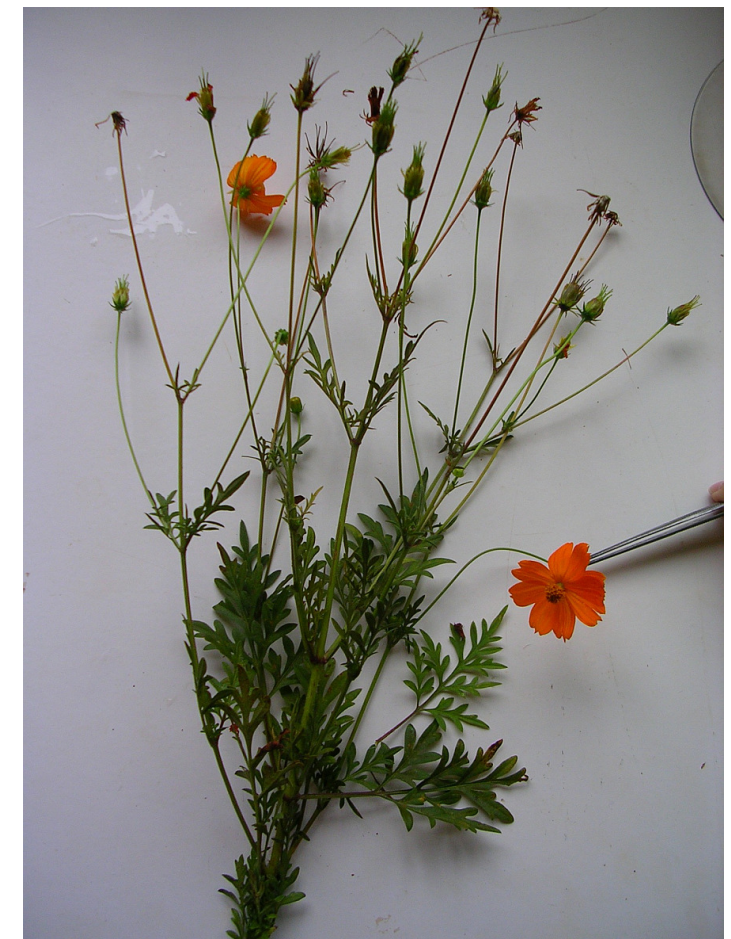

Figura 52. Bidens sulphurea (Cav.) Sch. Bip. ${ }^{[163]}$

A espécie B. sulphurea (Cav.) Sch. Bip. (sinônimos: Cosmos sulphureus Cav., Cosmos asthemisioefolius Jacq.) é uma herbácea anual, ereta, muito ramificada, originária do México, intensamente disseminada e naturalizada no território brasileiro. Popularmente é conhecida como cosmo-amarelo, picão-grande e áster-do-méxico, sendo muito valorizada pelo seu potencial ornamental e considerada uma planta invasora ${ }^{[203]}$.

Esta espécie, muito comum no Brasil, é popularmente utilizada para o tratamento da icterícia, febre intermitente (malária), esplenomegalia e como hepatoprotetor ${ }^{[204]}$.

A mistura dos extratos de $B$. sulphurea com de outras espécies é utilizada em formulações dermatológicas pela atividade de inibição proteases ${ }^{[205,206]}$ e em composições para o tratamento de câncer ${ }^{[207]}$. Além disso, o extrato apolar das folhas desta espécie apresentou significante atividade citotóxica ${ }^{[208]}$.

A análise dos voláteis por SPME/CG-EM das partes aéreas, flores e frutos de Bidens sulphurea também realizada por Brentan da Silva ${ }^{[163]}$ mostrou que os componentes majoritários desta espécie também os são sequiterpenos: $\beta$-cariofileno, germacreno $\mathrm{D}$ e 
biciclogermacreno (Figura 18). No entanto, a fração hexânica desta espécie apresentou uma composição diferente da B. gardneri.

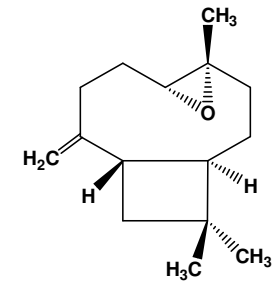

óxido de cariofileno

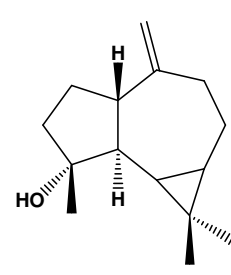

espatulenol

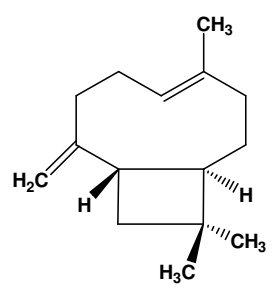

$\beta$-cariofileno

Figura 53. Substâncias majoritárias da fração hexânica do extrato etanólico das partes aéreas de Bidens sulphurea (Cav.) Sch. Bip. ${ }^{[163]}$.

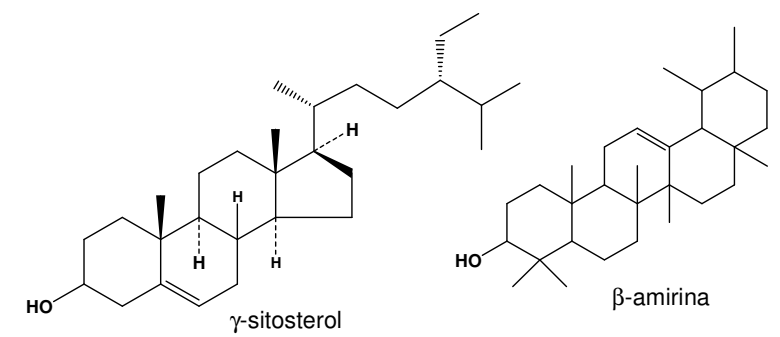

Figura 54. Componentes majoritários da fração hexânica do extrato etanólico das partes aéreas de B. gardneri Bak. ${ }^{[163]}$.

Os constituintes majoritários da fração hexânica do extrato etanólico das partes aéreas de B. sulphurea foram o óxido de cariofileno, espatulenol e $\beta$-cariofileno (Figura 22), enquanto que na fração hexânica de suas flores os principais constituintes identificados foram $\beta$-amirina e $\gamma$-sitosterol (Figura 23) ${ }^{[163]}$.

O estudo químico da espécie B. sulphurea (partes aéreas e flores) conduziu ao isolamento de um sesquiterpeno, cinco flavonas, oito flavonóis, uma aurona e chalconas, conforme mostrado na Figura $24^{[163]}$. 
Sesquiterpeno<smiles>C=C1CCC(O)C2(C)CCC(C(C)C)[C@H](O)[C@H]12</smiles>

4(15)-eudesmeno-
$1 \beta, 6 \alpha$-diol
Aurona<smiles>O=C1/C(=C/c2ccc(O)c(O)c2)Oc2cc(O)ccc21</smiles>

sulfuretina<smiles>O=C(/C=C/c1ccc(O)c(O)c1)c1ccc(O)cc1O</smiles>

3,4,2',4'-tretaidróxi-chalcona

\section{Chalconas}

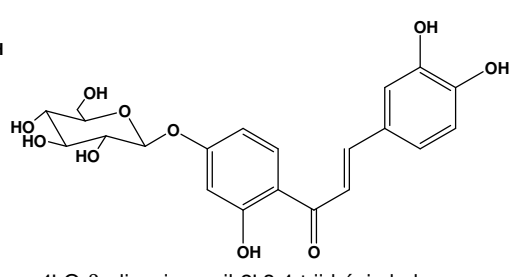

4'-O-ß-glicopiranosil-2',3,4-triidróxi-chalcona

Flavonas

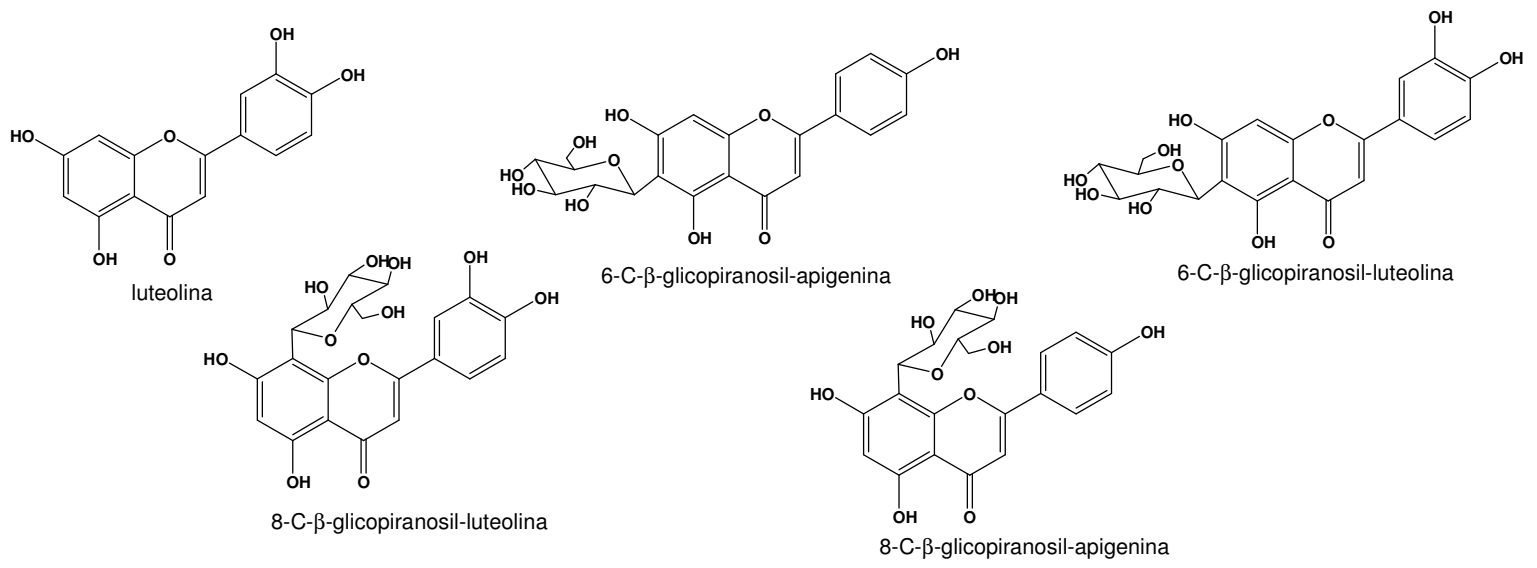

Flavonóis<smiles>O=C1c2c(O)cc(O)cc2OC(c2ccc(O)c(O)c2)C1O</smiles>

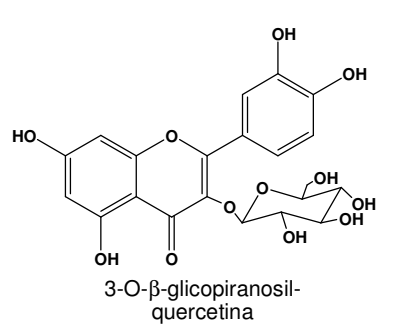

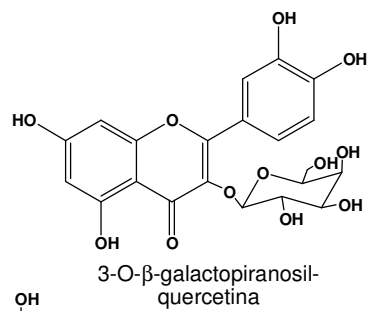<smiles></smiles>

3-O- $\beta$-xilopiranosilquercetina

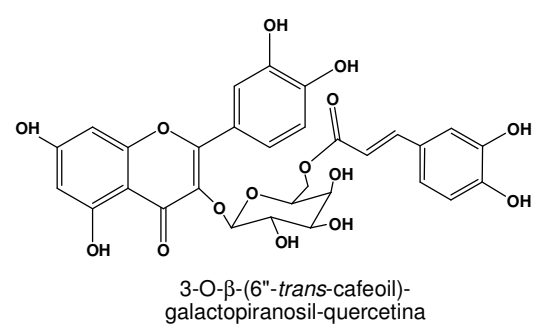<smiles>O=c1c(O)c(-c2ccc(O)c(O)c2)oc2cc(O)cc(O)c12</smiles>

3-O- $\alpha$-arabinofuranosil-<smiles>O=C1C(OC2CC2)=C(c2ccc(O)c(O)c2)c2oc3cc(O)cc(O)c3c(=O)c21</smiles>

3-O- $\alpha$-ramnopiranosilquercetina<smiles></smiles>

3-O- $\alpha$-arabinofuranosilcaempferol

Figura 55. Substâncias isoladas a partir da fração hexânica do extrato etanólico das flores de Bidens sulphurea (Cav.) Sch. Bip. ${ }^{[163] .}$ 


\subsection{Plantas da Família Annonaceae}

A família Annonaceae é maior família da ordem das Magnoliales, é típica das regiões tropicais e subtropicais, se distribui pela América do Sul e Central, Austrália, Ásia e Africa e compreende 2.500 espécies divididas em 135 gêneros.

É conhecida pelos seus frutos comestíveis, como pinha ('custard apple', Annona reticulata), graviola (A. muricata), biribá (Rollinia deliciosa) e fruta-do-conde (A. coriaceae), além das propriedades medicinais de várias de suas espécies. No Brasil foram, até o momento, identificadas 260 espécies divididas em 26 gêneros sendo o mais comum o Annona com 120 espécies $^{[209]}$.

As anonáceas são constituídas de árvores, arbustos e raramente cipós e são todas floridas. Suas folhas, flores e cascas de caule são aromáticas e algumas espécies são usadas como fonte de essências para perfume, como exemplo a espécie Cananga odorata. Várias espécies são usadas pela medicina popular e há vários relatos de avaliação biológica de várias espécies apresentando atividade antifúngica, bacteriostática, antimalária e citostática.

Estudos químicos de espécies anonáceas relatam a obtenção de flavonóides, alcalóides e acetogeninas. Além disso, algumas espécies amazônicas são usadas como fonte de madeira para confecção de maçanetas e de corantes amarelos e marrons. Algumas espécies são usadas como plantas ornamentais ${ }^{[164]}$.

\subsubsection{Gênero Duguetia}

O gênero Duguetia é o terceiro maior gênero da família Annonaceae e possui 93 espécies, sendo 89 nativas da América Central e do Sul e 4 da África. Suas espécies são conhecidas como araticum (D. riparia $=$ araticum-da-mata, $D$. furfuracea $=$ araticum seco). Estudos químicos deste gênero mostram que ele se caracteriza por conter caempferol (glicosilado e não) e isorramnetina e alcalóides, Figura 25. ${ }^{[164]}$

Estudos de espécies bolivianas, colombianas e brasileiras mostram que os alcalóides benziltetraidro-isoquinolínicos, aporfínicos (incluindo os 7-substituídos, como a duguetina, Figura 25) e oxaporfínicos, cujos esqueletos carbônicos são mostrados na Figura 26 [210,211,212]. 

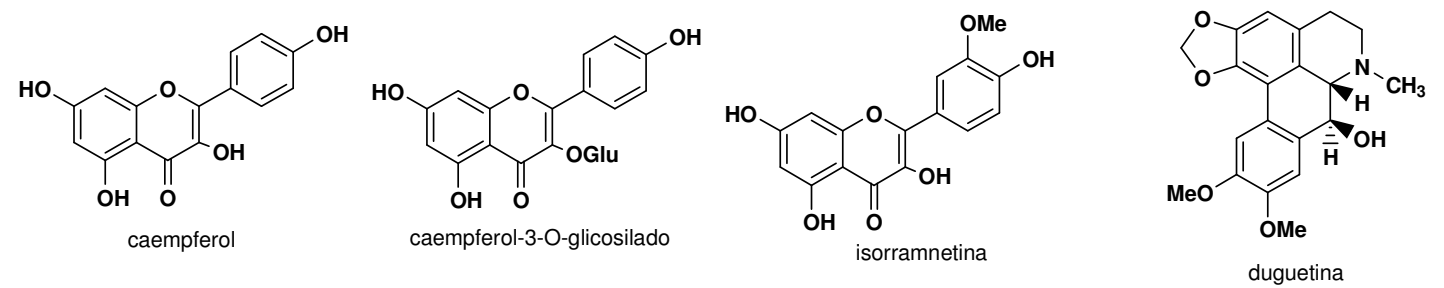

Figura 56. Estrutura do caempferol, do caempferol glicosilado, da isorramnetina e da duguetina ${ }^{[210,211,212]}$.
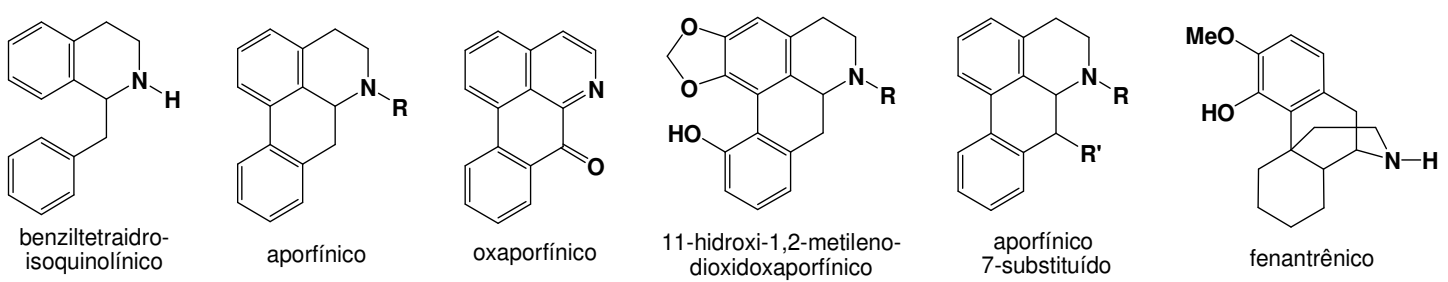

Figura 57. Tipos de alcalóides obtidos de espécies do gênero Duguetia ${ }^{[210,211,212]}$.

Na figura são apresentados exemplos de substâncias obtidas das espécies: D. eximia, D. panamensis, D. calycina, D. spixiana, D. obovata, D. glabriúscula, D. hadranta, D. vallicola. Observa-se que as espécies do gênero são ricas em alcalóides, sobretudo aporfínicos e derivados. Além disso, vale salientar que o primeiro alcalóide isolado a partir de uma espécie do gênero Duguetia foi a duguetina encontrada nas espécies $D$. eximia e $D$. panamensis $^{[211,212,213,214,215,216,217]}$.

Apesar da alta ocorrência de alcalóides nessas espécies, o marcador químico da família Annonaceae é o terpeno policarpol, obtido a partir da espécie D. glabriúscula, além do terpenos derivados do santalano e alcalóides oxaporfínicos e 7-hidroxi-aporfínicos $[218,219,220,221]$.

A espécie $D$. flagellaris também se mostrou rica em alcalóides, tendo sido isolados dela cinco alcalóides aporfínicos e cinco 7-hidroxi-aporfínicos ${ }^{[210]}$. Além disso, alcalóides isoquinolínicos isolados de D. vallicola tem sido avaliados quanto a atividade antiplasmódica, mas somente os alcalóides cleistopolina e (-)-oliverolina exibiram atividade contra o Plasmodium falciparum ${ }^{[222]}$. 


\section{D. panamensis}

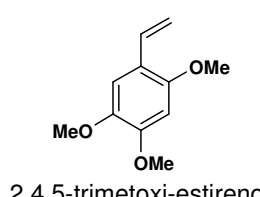

2,4,5-trimetoxi-estireno

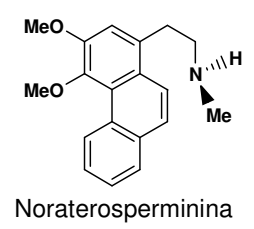

D.eximia

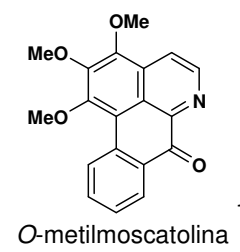

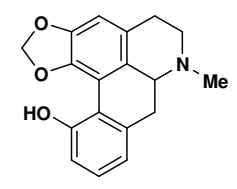

11-hidroxi-1,2-metilenodioxidoxaporfínico

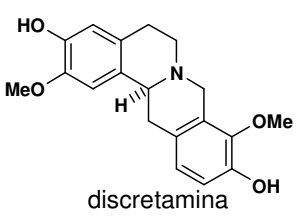

D. calycina

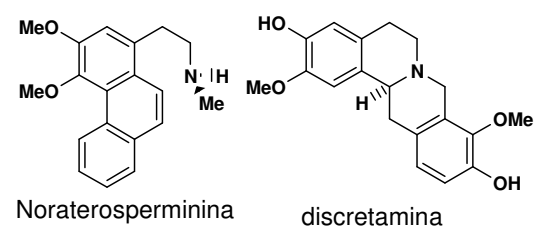

D. obovata

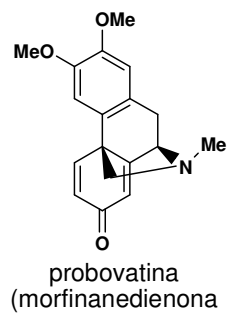

D. vallicola

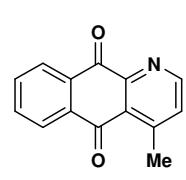

cleistopolina

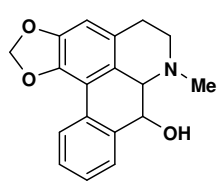

oliverolina

$\mathrm{R}_{1}=\mathrm{Me} \mathrm{R}_{2}=\mathrm{OMe}$ hadrantina $\mathrm{A}$

$\mathrm{R}=\mathrm{H} \quad$ sampangina

$\mathrm{R}=\mathrm{OMe} \quad$ 3-metóxi-sampangina

\section{D. spixiana}

\section{D. glabriúscula}
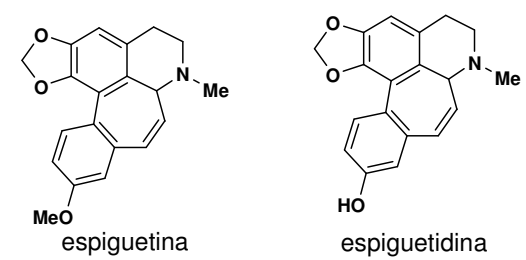

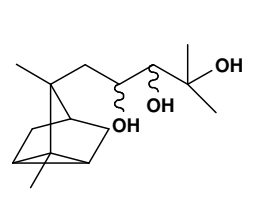

santalano

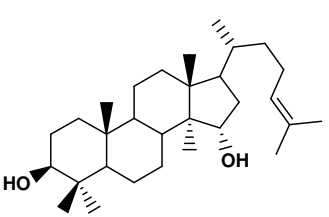

policarpol

Figura 58. Metabólitos isolados de espécies de Duguetia [210,211,212,213,214,215,216,217,218,219,220,221] [222]

\subsubsection{Espécie Duguetia furfuracea}

Duguetia furfuracea (A. St.-Hil.) Benth. \& Hook f. é um arbusto, típico do cerrado seco da região central do Brasil, principalmente nos estados de Mato Grosso do Sul, Mato Grosso, Goiás e Minas Gerais. Conhecida popularmente como “araticum seco”, é considerada uma planta daninha e, geralmente, forma grandes infestações de difícil controle.

A suspensão em água de suas sementes pulverizadas é, popularmente, utilizada como parasiticida, especialmente contra piolhos a infusão ou tisana de seus ramos e folhas é utilizada para combater o reumatismo ${ }^{[164]}$. 


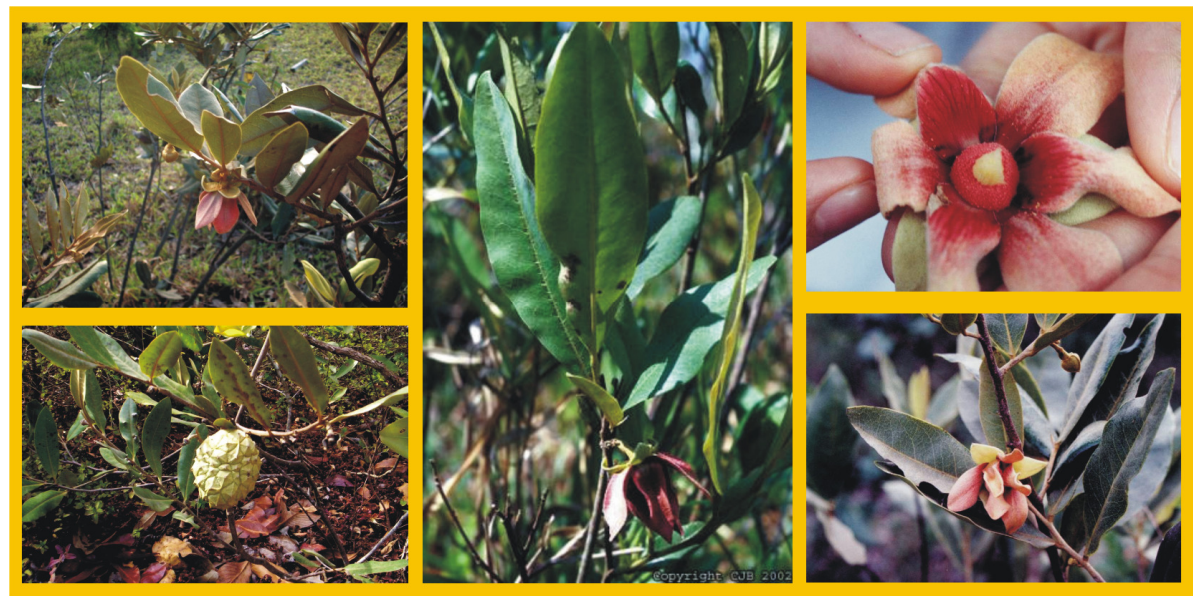

(Fonte: http://images.google.com.br/, termos pesquisados Duguetia furfuracea, 05/02/2010.)

Figura 59. Partes aéreas de Duguetia furfuracea St. Hil

Das folhas de Duguetia furfuracea foram identificados por UV/visível e CLAE/EMES quatro diferentes flavonóides glicosilados: 3-O-galactosil-galactosil-caempferol, 3-Ogalactosil-isorramnetina, 3-O-galactosil-ramnosil-isoramnetina, 3-O-ramnosil-glucosilisorramnetina $^{[178]}$.

O estudo químico das folhas de $D$. furfuracea conduziu ao isolamento de seis sesquiterpenos, um flavonóide, um esteróide e nove alcalóides [Figura 29] enquanto o estudo das cascas do caule aéreo levou à obtenção dos alcalóides oxaporfínicos: aterospermidina, liriodenina e lanuginosina ${ }^{[212]}$.

O extrato alcaloídico das folhas de D. furfuracea apresentou significante toxicidade contra Plasmodium falciparum sensíveis a cloroquina ${ }^{[223]}$. Essa atividade pode estar relacionada com a presença de alcalóides isoquinolínicos, uma vez que várias plantas que contêm esses alcalóides são tradicionalmente utilizadas contra malária, por exemplo, as espécies Annona muricata e Guatteria amplifolia, pertencentes à família Annonaceae ${ }^{[224]}$. 


\section{Alcalóide bisbenziltetraidro-}

Sesquiterpenos

isoquinolínico
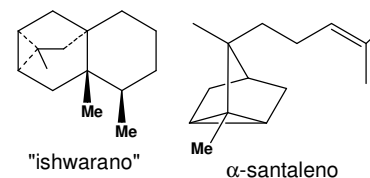

(1)

espatulenol

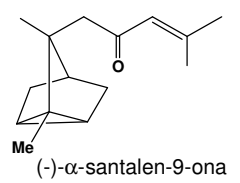

Me $(-)-\alpha$-santalen-9-ona<smiles>CC1=CCC2C(C=C(C)CCC1)C2(C)C</smiles>

biciclogermacrano

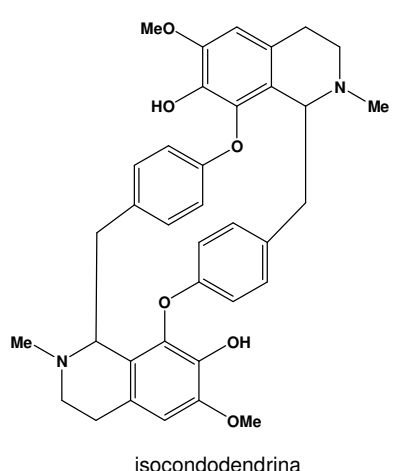

isocondodendrina
Alcalóide tetraidroprotoberberínico

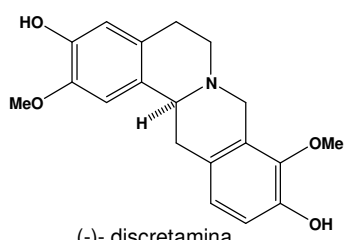

(-)- discretamina<smiles>COc1cc(-c2oc3cc(O)cc(O)c3c(=O)c2O)ccc1O</smiles>

$R=$ galactosil-ramnosila 3-O-galactosil-ramnosil-isorramnetina

$\mathrm{R}=$ ramnosil-glucosila $\quad 3-O$-ramnosil-glucosil-isorramnetina

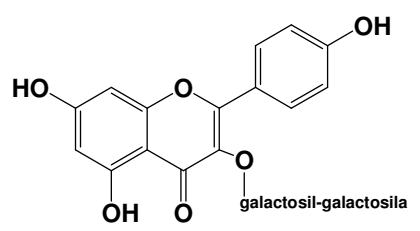

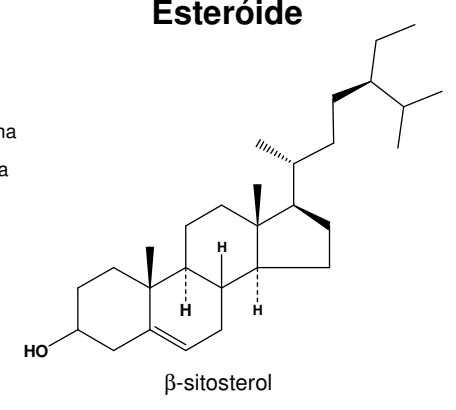

$\beta$-sitosterol

Esteróide
Alcalóides oxaporfínicos<smiles>O=C1c2cc(I)ccc2-c2c3c(c(O)c4ccnc1c24)OCO3</smiles>

$\mathrm{R}_{1}=\mathrm{OMe}, \mathrm{R}_{2}=\mathrm{H}$ aterospermidina

$R_{1}=R_{2}=H \quad$ liriodenina

$\mathrm{R}_{1}=\mathrm{H}, \mathrm{R}_{2}=\mathrm{OMe}$ lanuginosina

3-O-galactosil-galactosil-caempferol

Alcalóides aporfínicos

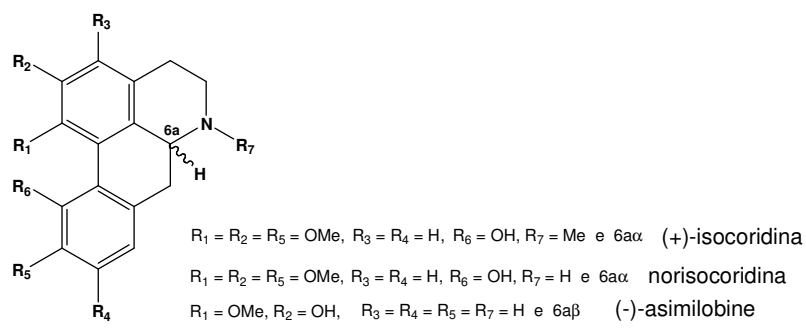

Alcalóide benziltetraidro-

$\mathrm{R}_{1}=\mathrm{OMe}, \mathrm{R}_{2}=\mathrm{OH}, \quad \mathrm{R}_{3}=\mathrm{R}_{4}=\mathrm{R}_{5}=\mathrm{R}_{7}=\mathrm{H}$ e $6 \mathrm{a} \beta \quad(-)$-asimilobine isoquinolínico
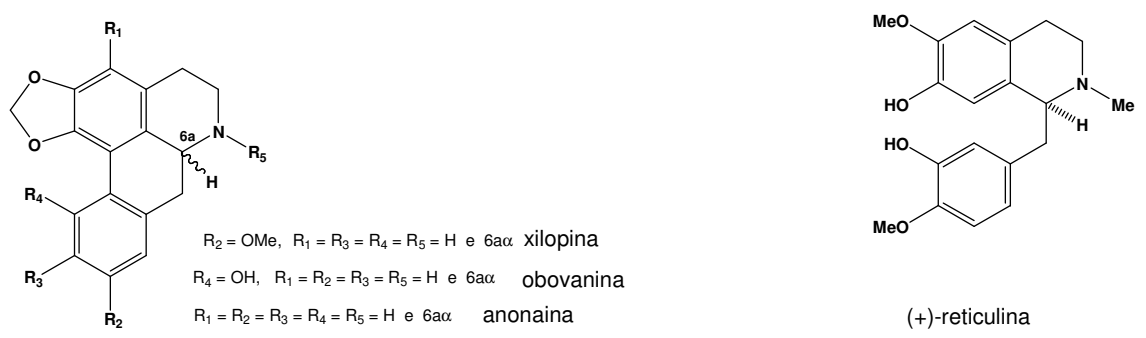

(+)-reticulina

Figura 60. Substâncias obtidas de espécimes da espécie Duguetia furfuracea (A. St.-Hil.) Benth. \& Hook f. [164,178,210,211,212,213,214,215,216,217,219,220,221,222] 


\section{Apêndice C: Obtenção da Fração DF de D. furfuracea}


As partes subterrâneas (casca do caule e madeira) de Duguetia furfuracea (A. St .Hil.) Benth. \& Hook f. foram coletadas em março de 2004, no campus da Universidade Federal de Mato Grosso do Sul (UFMS) em Campo Grande, MS e identificadas pelo Prof. R. Mello-Silva. Uma exsicata ( $n^{\circ}$. 023) foi depositada no Herbário CG/MS (UFMS, Campo Grande, MS). Como já mencionado, a coleta do material vegetal, obtenção do extrato e seu fracionamento foram realizados na maneira a seguir descrita, por Denise Brentan da Silva durante o seu curso de mestrado em Química na Universidade Federal de Mato Grosso do Sul.

Aproximadamente $1,32 \mathrm{~kg}$ de casca do caule subterrâneo de Duguetia furfuracea foi seco e pulverizado. Em seguida foi submetido à extração exaustiva com $\mathrm{CHCl}_{3}$ em meio básico $\left(\mathrm{NH}_{4} \mathrm{OH} 10 \%, \mathrm{PH}=9\right)$, obtendo-se, depois de eliminação do solvente, 68,81g do extrato bruto alcaloídico de casca de caule subterrâneo de D. furfuraceae.

Esse extrato bruto foi tratado em solução de $\mathrm{CHCl}_{3}$ com $10 \%$ de $\mathrm{HCl}$ para eliminar substâncias orgânicas não alcaloídicas. A fase aquosa ácida desta extração foi, então, neutralizada com $\mathrm{NH}_{4} \mathrm{OH} 10 \%(\mathrm{PH}=9)$ e submetida à uma partição com $\mathrm{CHCl}_{3}$ puro, obtendo-se 9,22g de extrato alcaloídico livre de graxa e aminoácidos.

Uma alíquota de 7,16g desse extrato alcaló́dico foi submetida ao fracionamento em coluna aberta de alumina (422g), seguindo o gradiente linear de polaridade $\mathrm{CHCl}_{3}$ $(100 \%) \rightarrow \mathrm{CHCl}_{3}: \mathrm{MeOH} \rightarrow \mathrm{MeOH}(100 \%)$ e $\mathrm{H}_{2} \mathrm{O}$, sendo coletadas 261 frações de $20 \mathrm{~mL}$ que foram agrupadas de acordo com semelhança dos perfis cromatográficos em cromatografia de camada delgada comparativa (CCDC), utilizando-se o revelador Dragendorff, específico para identificar alcalóides e variando-se a fase móvel de acordo com a necessidade: $\mathrm{CHCl}_{3}$ (100\%); $\mathrm{CHCl}_{3}: \mathrm{MeOH}-(6 \%) ; \quad \mathrm{CHCl}_{3}: \mathrm{MeOH}-(15 \%) \quad$ ou AcOEt:AcOH:HCOOH:H $\mathrm{H}_{2} \mathrm{O}$ (100:11:11:26), resultando na obtenção de 13 grupos (I a XIII) de frações semelhantes entre si. As frações de 80 a 102 eluídas com o gradiente $\mathrm{CHCl}_{3}: \mathrm{MeOH}$ entre 2 a $5 \%$ de $\mathrm{MeOH}$, foram reunidas no grupo VI. Este grupo foi denominado como Fração DF e submetido à análise por RMN-1D de ${ }^{1} \mathrm{H}$ e de ${ }^{13} \mathrm{C}\left({ }^{13} \mathrm{C}\left\{{ }^{1} \mathrm{H}\right\}\right.$ e DEPT $\left.135^{\circ}\right)$. A análise dos espectros obtidos e uma análise minuciosa por CCDC mostraram que a Fração DF é composta por dois compostos principais: um composto semelhante ao composto majoritário do Grupo V e outro semelhante ao do Grupo VII, respectivamente, dicentrinona (5) e (-)-duguetina- $\beta$-N-óxido (6). 